\title{
Role of Evidence in the Formulation of European Public Health Policies
}

Citation for published version (APA):

Passarani, I. (2019). Role of Evidence in the Formulation of European Public Health Policies: A Comparative Case Study Analysis. [Doctoral Thesis, Maastricht University]. ProefschriftMaken Maastricht. https://doi.org/10.26481/dis.20191008ip

Document status and date:

Published: 01/01/2019

DOI:

10.26481/dis.20191008ip

Document Version:

Publisher's PDF, also known as Version of record

\section{Please check the document version of this publication:}

- A submitted manuscript is the version of the article upon submission and before peer-review. There can be important differences between the submitted version and the official published version of record.

People interested in the research are advised to contact the author for the final version of the publication, or visit the DOI to the publisher's website.

- The final author version and the galley proof are versions of the publication after peer review.

- The final published version features the final layout of the paper including the volume, issue and page numbers.

Link to publication

\footnotetext{
General rights rights.

- You may freely distribute the URL identifying the publication in the public portal. please follow below link for the End User Agreement:

www.umlib.nl/taverne-license

Take down policy

If you believe that this document breaches copyright please contact us at:

repository@maastrichtuniversity.nl

providing details and we will investigate your claim.
}

Copyright and moral rights for the publications made accessible in the public portal are retained by the authors and/or other copyright owners and it is a condition of accessing publications that users recognise and abide by the legal requirements associated with these

- Users may download and print one copy of any publication from the public portal for the purpose of private study or research.

- You may not further distribute the material or use it for any profit-making activity or commercial gain

If the publication is distributed under the terms of Article $25 \mathrm{fa}$ of the Dutch Copyright Act, indicated by the "Taverne" license above, 


\section{Role of Evidence in the Formulation of European Public Health Policies \\ A Comparative Case Study Analysis}
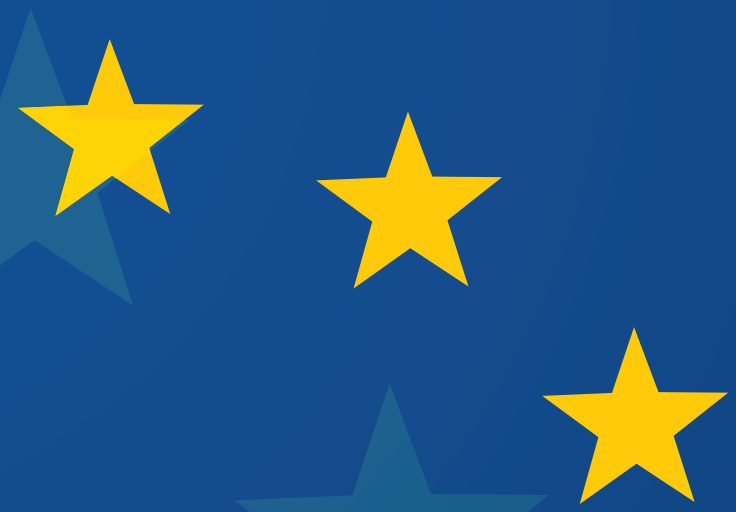

Ilaria Passarani 
Role of Evidence in the Formulation of European Public Health Policies

Ilaria Passarani 
(C) copyright Ilaria Passarani, Maastricht 2019

Printing: ProefschriftMaken || www.proefschriftmaken.nl

ISBN 978-94-6380-523-0

All rights reserved. No part of this publication may be reproduced, stored in a retrieval system or transmitted, in any form or by any means, electronic, mechanical, photocopying, recording or otherwise, without prior permission of the author or the copyright-owning journals for previous published chapters. 


\title{
Role of Evidence in the Formulation of European Public Health Policies
}

A Comparative Case Study Analysis

\author{
Dissertation \\ to obtain the degree of Doctor at the Maastricht University, \\ on the authority of the Rector Magnificus, \\ Prof.dr. Rianne M. Letschert \\ in accordance with the decision of the Board of Deans, \\ to be defended in public \\ on Tuesday 8 October 2019 , at 11.45 hours \\ by
}

Ilaria Passarani

Maastricht University

Care and Public Health Research Institute (CAPHRI) 


\section{Supervisor}

Prof. dr. Hans Maarse

\section{Co-supervisor}

Dr. Aggie Paulus

\section{Assessment Committee}

Prof. dr. Helmut Brand (Chair) - Maastricht University

Prof. dr. Esther Versluis - Maastricht University

Prof. dr. Scott Greer - University of Michigan, USA

Dr. Josep Figueras - European Observatory on Health Systems and Policies (WHO) 


\section{Table of Contents}

Abbreviations and Acronyms................................................................... 1

Chapter 1: General Introduction - Role of Evidence in the Formulation of EU Public Health Policies................................................................................ 3

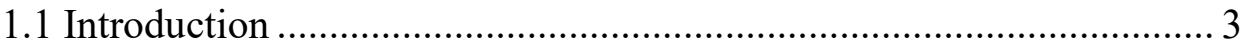

1.2 Evidence-Based Approach in European Public Health Policies .......... 3

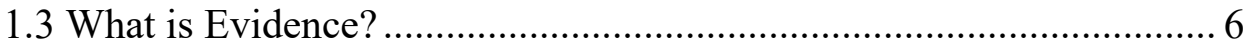

1.4 Evidence-Based Policymaking............................................................ 7

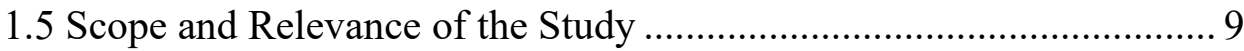

1.6 Research Aims and Questions ........................................................... 13

1.7 Structure of the Study ................................................................. 15

Chapter 2: Theoretical Framework ............................................................... 17

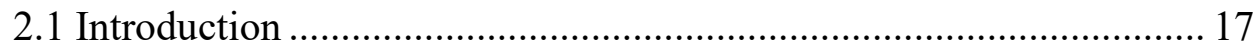

2.2 Evidence-Based Policymaking: The Knowledge Perspective............ 17

2.3 Use of Evidence in Policymaking: A Framework of Analysis ......... 22

2.4 Operationalising the Theoretical Framework .................................... 30

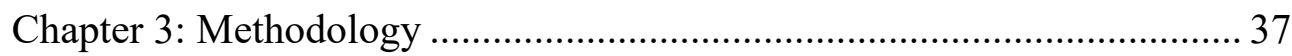

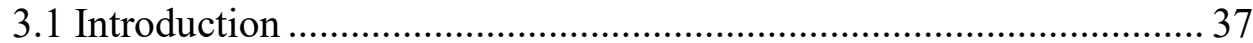

3.2 Comparative Case Study ................................................................ 37

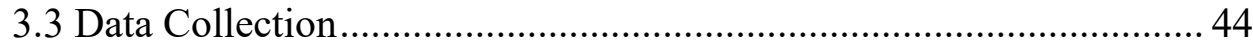

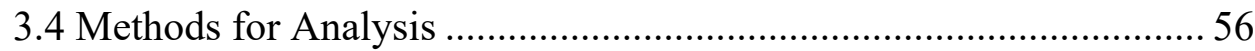

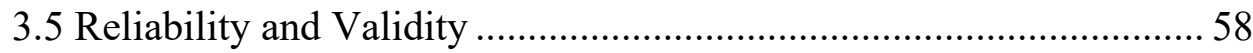

3.6 Reflexivity, Positionality and Bias ................................................. 59

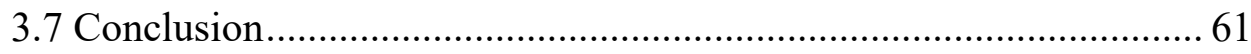

Chapter 4: Role of Evidence in the Formulation of the Directive on the Application of Patients' Rights in Cross-Border Health Care .................... 63

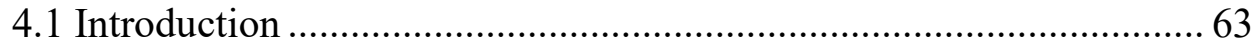

4.2 Context and Policy Idea: Cross-Border Health Care on the EU Agenda 63

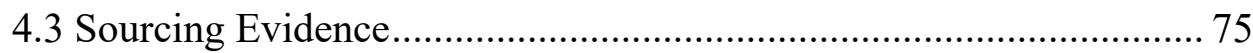


4.5 Capacity for Implementation: Hindering and Facilitating Factors for the Uptake of Research Evidence................................................................. 87

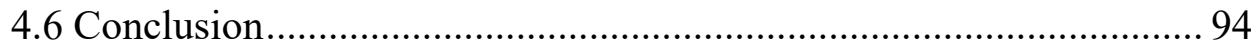

Chapter 5: Role of Evidence in the Formulation of the Directive on the Provision of Information to the General Public on Prescription Medicines 97

5.1 Introduction

5.2 Context and Policy Idea: Information to Patients on the EU Agenda 97

5.3 Sourcing Evidence

5.4 Using Evidence.

5.5 Capacity for Implementation: Hindering and Facilitating Factors for the Uptake of Research Evidence. 135

5.6 Conclusion.

Chapter 6: Role of Evidence in the Formulation of the Regulation on the Provision of Food Information to Consumers.......................................... 141

6.1 Introduction 141

6.2 Context and Policy Idea: Food Labelling on the EU Agenda 142

6.3 Sourcing Evidence. 151

6.4 Using Evidence: Impact Assessment 161

6.5 Capacity for Implementation: Hindering and Facilitating Factors in the Uptake of Research Evidence. 166

6.6 Conclusion. 172

Chapter 7: Comparison of Case Studies 175

7.1 Introduction 175

7.2 Legislative Pathways: Similarities and Differences 175

7.3 Sourcing Evidence 176

7.3 Using Evidence. 190

7.5 Capacity to Implement: Hindering and Facilitating Factors in the Uptake of Research Evidence.

7.6 Conclusions

Chapter 8: Conclusion, Discussion and Recommendations.

8.1 Introduction 201

8.2 Summary of Main Findings: Answering the Research Questions ... 201 


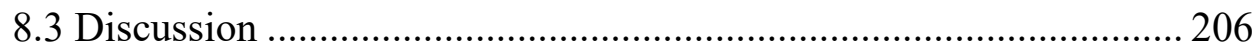

8.4 Policy and Research Recommendations........................................ 213

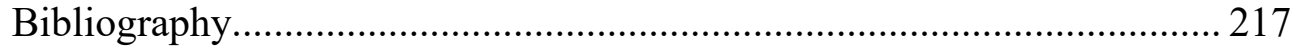

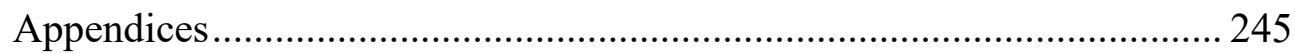

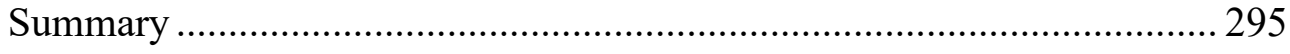

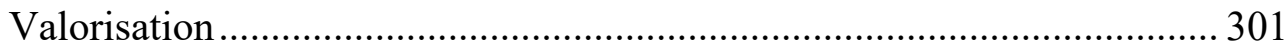

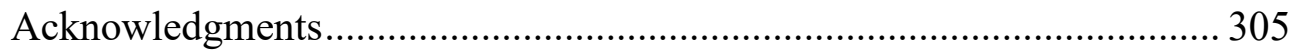

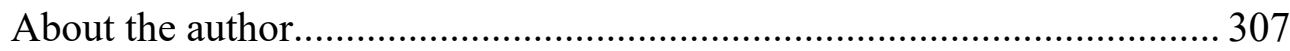





\section{Abbreviations and Acronyms}

ABPI - Association of British Pharmaceutical Industries

AIM - Association International de Mutualité

BEPA - Bureau of European Policy Advisers

BEUC - The European Consumer Organisation

CIAA - Confederation of Food and Drink Industries (now known as Food Drink Europe)

COREPER - Committee of Permanent Representatives

Council - Council of the European Union

DG ENTERPRISE - Directorate General for Enterprise and Industry

DG RESEARCH - Directorate General for Research and Innovation

DG SANCO - Directorate General for Health and Consumer Protection

DTCA - Direct to consumer advertising

DTCI - Direct to consumer information

EATG - European Aids Treatment Group

EC - European Commission

ECDC - European Centre for Disease Prevention and Control

ECJ - European Court of Justice

EESC - European Economic and Social Committee

EFPIA - European Federation of pharmaceutical industries associations

EFSA - European Food Safety Authority

EHN - European Heart Network

EHPF - The European Health Policy Forum

EMA - European Medicines Agency

ENVI - European Parliament Committee for Environment, Public Health and Food Safety 
EP - European Parliament

EPF - European Patient Forum

EPHA - European Public Health Alliance

EPP - European People's Party

EPSCO - Employment, Social Policy, Health and Consumer Affairs Council

EU - European Union

FDA - Food and Drug Administration

FDE - Food Drink Europe (former CIAA)

G10 - Group of 10

GDAs - Guideline Daily Amounts

HAI - Health Action International

HTA - Health Technology Assessment

IMCO - European Parliament's Committee on Internal Market and

Consumer Protection

IOM - Institute of Medicine

ITRE - European Parliament's Committee on Industry, Research and

Energy

MEP - Member of the European Parliament

NGO - Non-Governmental Organisation

PGEU - Pharmaceutical Group of the European

SPC - Summary of product characteristics

TABD - Transatlantic Business Dialogue

TFEU - Treaty on the Functioning of the European Union

UK - The United Kingdom

US - The United States of America

WHO - World Health Organisation 


\section{Chapter 1: General Introduction - Role of Evidence in the Formulation of EU Public Health Policies}

\subsection{Introduction}

This research study aims to investigate the role of evidence in the formulation of European public health policies. Three case studies and a comparative analysis are undertaken to investigate (a) the kind of evidence sourced and used in the European Union's (EU) public health policymaking, (b) the perceptions of the use of evidence of key participants in the process and (c) the uptake of a specific type of evidence, namely research evidence. This chapter outlines the key concepts underpinning the research and its scope and rationale. Lastly, it describes the structure of the research study.

\subsection{Evidence-Based Approach in European Public Health Policies}

Public health is "the science and art of preventing disease, prolonging life and promoting health through the organized efforts and informed choices of society, organizations, public and private, communities and individuals" (Winslow, 1920). One of the core functions of public health is the formulation of public policies designed to solve identified local and national health problems and priorities (IOM, 2003). According to the EU Treaty (Article 168 TFEU), a high level of human health protection shall be ensured in the definition and implementation of all EU policies and activities. The Treaty also gives the mandate to the EU to direct its action towards the improvement of public health, complementing national policies. Many EU laws have a significant impact on public health - from environmental to competition legislation - and EU public health policies affect the daily lives of 500 million citizens.

But how do EU policymakers inform their choices? Are European public health policies evidence based? What counts as evidence?

The evidence-based policy movement originated decades ago in the United Kingdom (UK) in the area of medicine but spread to other policies in areas such as criminal justice and education and beyond the UK to Australia, Canada and the United States of America (US). It reached the top of the political agenda under the Blair Government, which, in 1999, adopted the White Paper "Modernizing Government," calling for an enhanced use of evidence-based principles to improve policy and was accompanied by a substantial investment in policy-related research in the UK (Boswell, 2009). 
In the recent years, the concept of evidence-based policy has also become very popular at the EU level, and it is at the heart of the European Commission Better Regulation Agenda. The notion of Better Regulation was first introduced in the White Paper on European Governance adopted in 2001. The paper formulated five key principles to reform the regulatory practices of the Commission, namely openness, participation, accountability, effectiveness and coherence. Regarding the drafting phase of the legislation, the White Paper highlighted the need for the better involvement of stakeholders and a greater use of expert advice.

Following the commitment to publish guidelines on the collection and use of expert advice, made in the White Paper on European Governance (2001) and reiterated in the Science and Society Action Plan (2001), in 2002, the European Commission adopted a Communication on "Improving the Knowledge Base for Better Policies". The Communication aimed to outline and promote the good practices to be adopted by Commission officials, to build a solid knowledge base for the formulation of policies, by relying on the best available expertise. The second stated aim of the Communication was to demonstrate the credibility of the European Commission's process of collecting and using expert advice.

In the Communication "Improving the Knowledge Base for Better Policies", the European Commission openly acknowledged as follows:

No matter what seems to be the 'right' decision for those involved in the advisory process, it is essential that interested parties and the public at large are themselves convinced that decisions are sound. Increasingly, then, the interplay between policymakers, experts, interested parties and the public at large is a crucial part of policymaking, and attention has to be focused not just on policy outcome but also on the process followed. (European Commission, 2002, p.32)

The general Better Regulation approach signalled the importance of "input legitimacy" as opposed to "output legitimacy" as described by Scharpf (1997). The use of evidence on the one hand and the involvement of interest parties via public consultations or expert groups on the other hand are the key implementing these objectives.

On the occasion of the launch of the web-based communication platform called Scientific Information for Policy Support in Europe (SINAPSE) - a platform to enhance the exchange of information between the 
scientific community and policymakers at EU and national level - in March 2005, the European Commission further acknowledged as follows:

Scientific expertise is increasingly becoming a critical element in the design, implementation and assessment of public policies. This means that policymakers must be able to consult the scientific community. Scientists should have an opportunity to share their concerns and knowledge. This will ensure that decisions are objective and based on sound scientific evidence. However, the current wealth of scientific expertise, from an increasing variety of sources, coupled with the requirement for quick responses from many decision-makers, poses a considerable challenge. (European Commission, 2005, p.1)

The Communication "Improving the Knowledge Base for Better Policies" has been recently complemented by a so-called "Toolbox" on Evidence-Based Better Regulation, accompanying the European Commission's Better Regulation Guidelines adopted in May 2015. In the text, the European Commission confirms that "compiling a robust information or evidence base is an essential component of better policymaking". It also stresses the importance of ensuring the credibility and transparency of evidence that any EU policy must rely upon and making a clear distinction between "objective information from opinions which may be gathered through the stakeholder consultation" (European Commission, 2015, p. 17).

The core of Better Regulation is impact assessment, which provides evidence to inform and support the EU policymaking process. The Better Regulation guidelines contain guidance for the Commission on how to conduct impact assessments. Impact assessments are conducted both for undertaking legislative and non-legislative initiatives. The findings of an impact assessment process are summarised in an impact assessment report. The quality of each report is evaluated by an independent body, the Regulatory Scrutiny Board, which issues opinions. An impact assessment report must include a description of the environmental, social (including health) and economic impacts, details on who will be affected by the initiative and how, the consultation strategy and the results obtained from it. Impact assessment reports are published together with the proposals adopted by the Commission, and they are also sent to the European Parliament and the Council of the EU (European Commission).

This research study aims to investigate what EU policymakers consider as evidence in the formulation of European public health policies, how the evidence is gathered, how it is used in the impact assessment and 
how the key participants in the process perceive the use of the evidence by the European Commission.

\subsection{What is Evidence?}

Evidence is a difficult term to define and delimit. Beyond legal proceedings, the term generally refers to scientific outputs generated by objective research conducted by academics and gathered in systematic empirical studies.

Scientists and clinicians usually associate evidence with scientific research (research evidence). They classify research evidence according to the rigour of the scientific method applied, with randomised controlled trials and meta-analysis at the top of the pyramid and case reports at the bottom (Bagshaw \& Bellomo, 2008; Nutley, 2013; Nutley et al., 2007; Padian et al., 2010; Paxton et al, 2005; Petticrew \& Roberts, 2003). Emerging literature actually challenges the appropriateness of such hierarchy, especially when addressing complex social issues (Greenhalgh \& Russell, 2006; Worrall, 2010), but, in any case, for policymakers, the "hierarchy of evidence" has less relevance.

The current emphasis on evidence-based policy is based on the concept of evidence-based medicine. Medicine was one of the first domains in which evidence-based practice became institutionalised. Evidence-based medicine involves the integration of individual clinical expertise with the best available external evidence. It dates back to 1847 when Ignaz Semmelweis discovered the role of infections in puerperal fever, but the concept of evidence-based medicine was first introduced in the literature by Guyatt et al. (1992) as a more scientific and systematic approach in the practice of medicine. In the recent decades, the concept of evidence-based medicine has been expanded to include evidence-based public health policies (Anderson et al., 2006; Olsson, 2007; Meulen, \& Dickenson, 2002).

Sackett et al. (2000) define evidence-based medicine as "the integration of the best research evidence with clinical expertise and patients' values" and as an attempt to improve patient care (p. 1). Kohatsu et al. (2004) and Brownson et al. $(2009,2017)$ mirror this definition identifying evidencebased public health as the process of integrating science-based interventions with community preferences to improve the health of the population. On this basis, evidence-based public health policy can be defined as the integration of the best research evidence with policy expertise and people's preferences and values in the attempt to improve the life of citizens. 
According to Brownson et al. (2009), the key components of evidence-based public health are "making decisions on the basis of the best available evidence, and peer-reviewed evidence, using data and information systems systematically, engaging the community in decision making, conducting sound evaluation, and disseminating what is learned" (p. 177).

An alternative view is presented by Klein (2003) who describes the parallel between evidence-based medicine and evidence-based policy as "nonsense". He stresses that evidence-based medicine mostly relies on one type of evidence, namely scientific evidence, including systematic reviews and randomised controlled trials, while for policymaking, several types of evidence, such as organisational evidence and experience, are relevant. For example, in the case of health policy, experience in the health care system and feedback from the general public and the press are particularly useful to gain insights respectively on the "political acceptability" and the "feasibility of different policy options" (Klein, 2003, p. 429).

However, nowadays it is largely acknowledged that evidence-based medicine should also take into account other kinds of evidence when making decisions and the decision-making process should be transparent and include the views and experiences of patients (Hammersley, 2007; Pearce \& Raman, 2014) so the parallel may be more relevant than as suggested by Klein.

\subsection{Evidence-Based Policymaking}

In policymaking, research evidence often competes with other forms of evidence that may be timelier and more relevant for policymakers. Policymakers assume a much broader definition of evidence, to include data, analysis, views of stakeholders, information on the interests of constituencies and citizens and prior policies (Culyer \& Lomas, 2006; Glasby, Walshe \& Harvey, 2007; Lomas \& Brown, 2009; Petticrew et al., 2004). Thus, policymakers not only rely on scientific research evidence but also take into account many other types of evidence when formulating policies. As will be discussed in this research study, research evidence, based on "hard scientifically established facts", often only plays a secondary role in policymaking.

Notwithstanding policymakers' broad understanding of evidence, many authors still associate evidence-based policymaking with policymaking grounded upon scientific or research evidence. An example is Davies' (2003) definition of evidence-based policymaking as "the integration of experience, judgment and expertise with the best available external evidence from 
systematic research" (p.3). He also argues that evidence-based policy "helps people make well-informed decisions about policies, programs and projects by putting the best available evidence at the heart of policy development and implementation" (p. 3). Sutcliffe and Court (2005) define evidence-based policymaking as a discourse or set of methods that "advocates a more rational, rigorous and systematic approach" (p. 3) to the policy process. The concept relies on the idea that "policy decisions should be better informed by available evidence and should include rational analysis" (Sutcliffe \& Court, 2005, p. $3)$.

Klein (2003) defines evidence for policy as a "Delphic oracle, difficult to decipher and apt to be misinterpreted". Nevertheless, he does not attribute a negative connotation to evidence-based policy but only calls for a more nuanced approach that acknowledges the complexity of the policymaking process and the fact that different types of evidence are relevant. Klein (2003) also argues that policy itself constitutes a kind of evidence that functions as a trial and error process. He calls upon the scientific community to give up the "delusional vanity" of making policy recommendations on the basis of scientific research and rather to focus on providing "rigorous and fast evaluations" so that policymakers can learn from previous policies" (Klein 2003, p. 429). In a similar way, Perri (2002) argues that "better policy is more likely to come from frank acknowledgement that, in a democracy, we positively want a system which gives recognition to each kind of evidence and judgment, and not just to those who control the slide rule" (p. 8).

The Canadian Health Services Research Foundation provides a broader definition of evidence, recognising that research evidence is often unavailable or unreliable and policymakers nevertheless want to base their policies on evidence as much as possible:

Evidence is information that comes closest to the facts of a matter. The form it takes depends on the context. The findings of highquality, methodologically appropriate research are the most accurate evidence. Because research is often incomplete and sometimes contradictory or unavailable, other kinds of information are necessary supplements to or stand-ins for research. The evidence base for a decision is the multiple forms of evidence combined to balance rigor with experience - while privileging the former over the latter. (Canadian Health Services Research Foundation, 2005)

As anticipated above, this study adopts the policymakers' perspective and, therefore, their broad understanding of evidence in the public 
policymaking process as all elements that constitute the knowledge base of their decisions. It borrows Bowen and Zwi's (2005) definition of evidence that includes research evidence, knowledge and information, opinions and views of stakeholders and experts, and economic and political considerations (see Chapter 2). Such an all-encompassing conceptualisation of evidence helps to capture the complexity of the policymaking process as well as the various elements that influence policymaking.

Bowen and Zwi (2005) as well as Segone and Prons (2008) and Oxman et al. (2009) suggest that instead of "evidence-based policy", it would be more appropriate to consider an "opinion-based policy" or "evidenceinformed policy". Opinion-based policy relies on a "selective use of evidence and untested views of individuals or groups", often motivated by ideological beliefs and prejudices (Davies, 2004, p.3).

Evidence-informed policy is used to indicate that decisions are influenced by many external factors, with evidence just being one of them. It, therefore, recognises the political nature of the policymaking process and suggests that evidence is adapted to the context in which it is used. In this respect, this terminology will be more suitable in relation to the perspective of this research study. However, the term "evidence based" is still the most widely used in the literature, and it is also applied in this research study as the ideal scenario under the assumption that policies that are based on evidence are better than those that are not and as a useful starting point to better explain the reality of EU policymaking.

\subsection{Scope and Relevance of the Study}

Several studies exist on the use of evidence in health policy (Almeida \& Bascolo, 2006; Gold, 2009; Hanney \& Block, 2015; Lomas \& Brown, 2009; Petticrew, 2004; Cairney 2016), and many of them specifically address the gap between evidence and policy (Brownson et al., 2009; Dopson et al., 2003; Elliott \& Popay, 2000, Gorissen et al., 2005; Hughes, 2007; Lavis, 2009, 2015; Wehrens, 2001; Smith, 2013; Strehlenert et al., 2015; Cairney et al., 2016). Most of them are built on the assumptions of evidence-based medicine and consider evidence as research evidence only, often using the terms "research" and "evidence" as interchangeable. Most studies on the use of evidence and the barriers and facilitating factors for the uptake of evidence by policymakers mostly survey the views and perceptions of researchers (Hanney et al., 2003; Lemieux, Charles, \& Champagne, 2004; Mitton et al., 2007; Nutley, Walter, \& Davies, 2007; Innvaer, 2002; Oliver et al., 2014) with the exception of McDonough (2000) and Petticrew et al. (2004). 
Moreover, they are based on the local or national experiences in a few countries such as the UK, the US, Canada, Australia and New Zealand (Deelstra et al., 2003; Hyder et al., 2010; Strehlenert et al., 2015).

This study complements the above-mentioned body of literature in several aspects: (1) by endorsing a wider definition of evidence as to include not only research but also the other types of evidence, (2) by taking into account a wider perspective, investigating the views of policymakers, stakeholders and researchers on the use of research evidence, (3) by offering a more nuanced approach than that of surveys using a comparative case studies analysis (Innvaer et al., 2002; Shroff et al., 2015) and (4) by providing experiences from the EU dimension. This study focuses on the process of policymaking fully acknowledging its complexity and its inherent political nature. While offering an analysis of the hindering and facilitating factors for the uptake of research evidence and recommendations for scientists and policymakers to increase the effectiveness of their respective work, its main goal is not to provide solutions to bridge the evidence-policy gap. Rather, it aims to explain what constitutes as evidence for policymakers and how evidence fits in the policymaking process. It explores the role of stakeholders and policy networks (see Chapter 2) and the influence of institutional and organisational arrangements on the use of evidence.

Three relevant systematic reviews on evidence-based health policy are available: (1) Innvaer et al. (2002) covering 18 studies, interviews and surveys, (2) Orton et al. (2011) that analyses 24 studies on the use of research evidence by health policymakers and (3) Oliver et al. (2014), a more recently published study that includes in total 145 studies.

The three systematic reviews focus on the main barriers and facilitators in the use of research evidence by policymakers, and all concluded that policymakers have a different understanding of evidence from that of academics. Innvaer et al. (2002) and Oliver et al. (2014) point to the need to further investigate policymakers' attitudes towards evidence and gain more detailed knowledge about the policy process, namely who are the main actors, how decisions are made and how evidence fits in the policy process. Also, Liverani et al.'s (2013) systematic review that addresses the political and institutional influences on the use of evidence in public health policy revealed that "little empirical work has been done so far to analyse these issues" (p. 56). This research study aims to fill this knowledge gap by providing empirical evidence on the influence of the institutional factors, namely the European Commission's procedures and economic and political considerations in the 
formulation of public health policies. Despite the complexity of the policy process, this research study attempts to use and further develop the Bowen and Zwi (2005) framework for analysing the use of evidence in policymaking. It also ensures to characterise the policymaking process as a whole instead of focusing on single elements.

Orton et al. (2011) have found little reliable evidence to quantify the extent to which research evidence is used in public health decision-making, and only two qualitative studies have explored the types of research evidence used by public health decision makers, namely Whitehead et al. (2004) and Dobbins et al. (2009). Moreover, only two qualitative studies (Bickford, 2008; Ritter, 2009) have explored how research evidence was accessed by decision makers. This research addresses these issues, investigating the types of evidence used by EU policymakers and how they access information.

Extensive literature exists on the policymaking process (Lindblom, 1959; Sabatier, 1993) and, more specifically, the EU policymaking process (Broscheid \& Coen, 2007; Crombez, 2003; Peterson, 1995; Richardson, 1996), but this research study provides new insights on how the European Commission deals with evidence and an empirical description of the policy process useful for future research on lobbying theories, network analysis, advocacy coalitions and EU governance. Moreover, it contributes to the theories on knowledge utilisation (Boswell, 2008; Radaelli, 1995, 2011; Sabatier, 1993; Weiss, 1979) and the literature on evidence-based policymaking (Davies, Nutley \& Smith, 2000; Sutcliff \& Court, 2005) and evidence-based health policymaking (Brownson et al., 2009; Dobrow, 2004; Lomas \& Brown 2009).

In the recent years, several studies have been conducted on the influence of stakeholder groups on the EU policymaking process (Bouwen, 2004; Coen, 2007; Eising, 2007), analysing the impact of the transfer of regulatory function to the EU on the representation of interests as well as the complex and unique relationship between the EU institutions and lobbyists. Studies on the politics of the EU health policymaking have also been widely published (Boessen, 2008; Greer, 2009; Permanand, 2007); however, the tools used by EU policymakers in the formulation of EU public health policies and the evidence they gather to inform their decisions have not yet been investigated. Many studies on lobbying have focused on the creation of interest groups and their positioning in the EU arena (Broscheid \& Coen, 2003; Coen, 2007; Kohler-Koch \& Eising, 1999; Mazey \& Richardson, 1993), but only a few (Boswell, 2008; Kluver, 2013) have explored how the 
EU institutions use evidence and what kinds of evidence interest groups (hereafter stakeholders) provide to the policymaking process. The added value of this study is that it gives detailed accounts of how the evidence provided by stakeholders is sought and used.

To date, the literature on the use of evidence by the European Commission is relatively limited. Boswell (2007) has investigated the use of research in the area of immigration policy, while Rimkute et al. (2015) has looked into how the European Commission uses scientific expertise, by conducting a survey of Scientific Members of the Commission's Expert Committees. This study aims to fill this gap by shedding light on how the European Commission uses research evidence in the health sector. The focus of this research study is on the role of evidence in the policy formulation stage within the European Commission, which is also the focus of the Better Regulation Agenda. Its role in the other sub-processes of the policymaking process (agenda setting, policy implementation and policy evaluation) is not in the ambit of this study.

Moreover, how evidence may improve policymaking and the usefulness of evidence have not been thoroughly investigated. This is also linked to the fact that is not possible to measure in a rigorous manner the concrete weight of the evidence for the final policy decision (Smith, 2013) and disentangle it from other factors such as context, values and judgements.

This thesis explores the dominant model of knowledge utilisation by the European Commission in the formulation of public health policies, contributing to the research project, as outlined by Radaelli (1995), to analyse when and how knowledge matters in the policymaking process. Analysing the role of knowledge in the policymaking process helps to establish whether the EU policymaking procedures are designed in such a way that policies are evidence based, balanced and transparent. Ultimately, it seeks to understand what drives EU public health policies.

While describing the role of interest groups in the provision of evidence to policymakers, this study does not focus on the lobbying strategies used by interest groups to bring inputs and knowledge to the decision-making process. Rather, it analyses the channels and methods set by the European Commission itself to source information from stakeholders.

This study explores the dynamics of policy formulation in the EU policymaking process with a focus on the European Commission. The Commission is suitable for a good empirical test because it is less dynamic 
than the European Parliament and the Council and is characterised by more homogenous interests and common beliefs. In addition, the European Commission is relatively independent and has a more structured and focused internal decision-making process in terms of policy development.

Finally, being in charge of drafting EU legislation, the European Commission is the institution that most needs a robust and comprehensive understanding of the issue or area to be regulated (Chalmers, 2011; Coen, 2007; Gornitzka \& Sverdrup, 2011). In this respect, the Commission is different from the European Parliament, where there is more room for emotional arguments, and the Council of the EU, where only the positions of national governments really matter.

\subsection{Research Aims and Questions}

The aim of this study is to investigate the role of evidence in EU public health policymaking. It addresses three main topics:

The first topic is the sourcing of evidence by the European Commission in the formulation of EU public health policies. Two steps are involved in addressing this topic. The first step is to find out what constitutes as evidence for the European Commission, and the second step is to look at how the Commission collects evidence to build its knowledge base about the issues it wishes to address. As will be shown, the Commission's conception of evidence goes far beyond research evidence. It also uses various strategies to collect evidence.

Hence, the first research question is formulated as follows: What kind of evidence does the European Commission use in the formulation of EU public health policies, and how does it source it?

The second central research area is the use of evidence in the formulation of EU public health policies. The focus here is on how evidence is used in the impact assessments that EU policymakers use to support their policies. Furthermore, attention will be paid to how the key participants in the policymaking process perceive the use of evidence by the European Commission. These participants include senior officials of the Commission, researchers, stakeholders and members of the European Parliament.

The second research question is therefore as follows: How does the European Commission use evidence in the formulation of EU public health policies, and how do the participants in the process perceive the use of evidence by the Commission? 
It is widely admitted that robust research is lacking in evaluating and confirming that the use of research evidence improves the outcome of the policy process. However, especially in relation to health policies, the use of research findings to define more effective policies is considered an inspirational concept and an ethical and moral imperative. Therefore, this research study endorses the assumption that policies designed on the basis of research evidence perform better than policies that ignore research evidence. For this reason, the third central topic is the analysis of the hindering and facilitating factors in the uptake of research evidence in policymaking.

The research question for this part of the study is as follows: What are the hindering and facilitating factors in the uptake of research evidence in the formulation of EU public health policies?

To answer the research questions mentioned above, a comparative analysis of three case studies will be conducted to investigate the similarities and differences in how evidence is used and perceived in the formulation of legislation in the following areas:

- the application of patient rights in cross-border health care

- the provision of industry information to the general public on prescription medicines

- the provision of food information to consumers

According to the EU's classification of the topics it deals with, the three legislative areas form a part of the concept of "public health" that Versluis et al. (2011) define as "functional policies", which are policies "with a very specific and functional purpose" as opposed to other categories such as budget policies, sectoral policies, external policies, among others. The mission of the EU in public health is in fact to "protect and improve the health of all Europeans throughout their lives" (European Union, 2014). The main objectives of EU health policies are, therefore, to prevent disease, promote healthier lifestyles and well-being, improve access to health care, promote health information and education and improve patient safety (European Union, 2014). The three case studies meet these objectives. More specifically, they all aim at promoting patients' health information. The proposal on crossborder health care also aims to improve the access to health care. The proposal on information to patients is also intended to improve patient safety by providing patients with more information about their medicines, and the proposal on food information aims to promote healthier lifestyles and well- 
being by allowing consumers to make more informed and, hopefully, healthier food choices.

More details about the selection of the three case studies are provided in Chapter 3.

\subsection{Structure of the Study}

This research study is divided into eight chapters. Chapter 1 introduces the background and rationale of the research, explaining its aims and objectives. It also provides definitions of the keywords used throughout the research study.

The theoretical and operational framework underpinning the study is described in Chapter 2, while Chapter 3 explains the research methodology and includes some ethical considerations.

Chapters 4, 5 and 6 are dedicated to the analysis of the three case studies, and each chapter deals with a separate case.

Chapter 4 presents the case study on the Directive on the application of patient's rights in cross-border health care.

Chapter 5 discusses the Directive on the provision of information to patients, and Chapter 6 explores the Regulation on the provision of food information to consumers.

Chapters 4, 5 and 6 follow the same structure: The first part provides background information on the legislative proposal and addresses the first research question on how the European Commission uses evidence in the formulation of EU public health policies. The second part of each case study chapter presents an analysis of the proposal, applying the theoretical framework and concepts outlined in Chapter 2. The third part of each case study outlines the hindering and facilitating factors in the uptake of research evidence.

Chapter 7 presents a comparative analysis of the three case studies, focusing on the similarities and differences in the use of evidence in the policymaking process for the three legislative proposals investigated.

The study ends with a general discussion in Chapter 8. It includes the main findings of the research study and describes the relevance of the case studies for the research questions. Finally, it discusses the strengths and limitations of the study and provides policy recommendations for policymaking as well as future research. 



\section{Chapter 2: Theoretical Framework}

\subsection{Introduction}

This chapter outlines the theoretical framework by describing the key concepts of the study and explaining the relationships between them. Section 2.2 describes the theories that underpin the research and their relevance, section 2.3 depicts the framework adopted to analyse the use of evidence in policymaking and 2.4 presents how the framework of analysis has been applied to the three case studies. Section 2.5 summarises the main elements of the chapter.

\subsection{Evidence-Based Policymaking: The Knowledge Perspective}

This study draws upon what is known as the knowledge utilisation literature (Caplan1979; Weiss 1979; Lindblom 1990; Radaelli 1995; Boswell 2009). The knowledge utilisation perspective is particularly useful to analyse if, how and when knowledge (in this study evidence) matters in the policymaking process and offers a comprehensive framework for understanding the use of evidence. Much of this literature deals with research utilisation (Amara et al. 2004; Lavis et al. 2004; Lomas 2005) and the terms (knowledge and evidence) are often used interchangeably - including in this dissertation - yet knowledge utilisation theories provide a more comprehensive framework. Backer (1991) and Estabrooks (1999) argue that research utilisation is a specific type - or a subgroup - of knowledge utilisation. Thus, knowledge utilisation can be considered more inclusive than research utilisation.

To understand the role of evidence in policymaking, one has to look at both the supply and demand side of knowledge. Table 2.1 summarises the key features of the supply and demand aspect, namely the who, what and why of knowledge, in the policymaking process. Each of these features is further detailed in this paragraph. Table 2.2 illustrates how they have been applied throughout the research. 
Table 2.1.

Demand and Supply of Knowledge in the Policymaking Process

\begin{tabular}{|l|l|l|}
\hline & \multicolumn{1}{|c|}{ Demand } & \multicolumn{1}{c|}{ Supply } \\
\hline Who & Policymakers/institutions & $\begin{array}{l}\text { Experts (researchers, } \\
\text { stakeholders) }\end{array}$ \\
\hline What & $\begin{array}{l}\text { Data, research, information, } \\
\text { policy-oriented analysis, ideas } \\
\text { and arguments }\end{array}$ & $\begin{array}{l}\text { Data, research, information, } \\
\text { policy-oriented analysis, ideas } \\
\text { and arguments }\end{array}$ \\
\hline How & $\begin{array}{l}\text { Uncertainty, bounded } \\
\text { rationality, policy learning, } \\
\text { gaining legitimacy }\end{array}$ & $\begin{array}{l}\text { Influencing policies, changing } \\
\text { the belief systems, policy } \\
\text { learning }\end{array}$ \\
\hline $\begin{array}{l}\text { Working groups, research and } \\
\text { puther external studies, surveys, } \\
\text { conferences, bilateral meetings }\end{array}$ & Informational lobbying \\
\hline
\end{tabular}

\section{Who?}

Actors involved in policymaking within a policy subsystem (Freeman \& Stevens 1987; Howlett et al. 2009; Baumgartner 2009) usually form networks, alliances or coalitions to promote their interests. Policymaking involves a process of information exchange and bargaining within and between these networks. Scholars have developed various models to analyse network structures and their role in the search for and use of knowledge in policymaking. Heclo (1978) introduced the concept of "issue networks" to identify groups of actors who gather around problems or issues for public policy. Issue networks do not have very clear boundaries and its members do not necessarily share common values and interests. Epistemic communities (Haas, 1992), on the other hand, are formal and informal networks of actors with recognised expertise in a policy domain. The participants of epistemic communities share a common set of beliefs and value the same particular forms of knowledge. When actors are deeply integrated in the policymaking process and the relationships between government officials and representatives of interest groups are well established, actors form so-called "policy communities". Sabatier developed the Advocacy Coalition 
Framework that conceptualises policymaking as a competition between coalitions of actors (e.g. researchers, senior officials, politicians, a few journalists) each of whom shares a set of common beliefs or ideology while lobbying for specific policy decisions. The framework argues that actors perceive the world and process information according to a variety of cognitive biases which provide heuristic guidance in complex situations. In the case of public policies, such guidance is provided by the belief system regarding how a given public problem is structured and how it should be dealt with. The belief system consists of three categories: at the highest level the "deep core" which includes fundamental ontological and normative beliefs; second, the "policy core" beliefs which represent basic commitments and policy positions in a given policy domain and; the third and lowest level, the "secondary aspects" of a coalition's belief system which refers to instrumental decisions to support the policy core. When developing his framework, Sabatier was particularly interested in the role of knowledge and ideology throughout the policymaking process (Sabatier \& Jenkins-Smith 1993; 1999; Sabatier 1998).

Within the policy network (policy community, epistemic community or advocacy coalition), it is possible to distinguish between those who seek the evidence and those who provide it. Policymakers act at the demand side of knowledge utilisation. Policymaking is heavily influenced by institutions that can be described as "a collection of rules and practices endowed with action-enabling resources providing structures of meaning that explain, guide and justify behavior" (March \& Olsen 2006, p.691). Bouwen (2002; 2004) and Boswell (2009) offer useful insights regarding the method in which organisations seek evidence. Institutions influence what kind of knowledge is critical for an organisation. Furthermore, Radaelli (1995) emphasises the importance of institutions in the study of knowledge: they "give stability to shared casual beliefs, they set up structures of meaning, they create networks of actors, they constrain the perception of interests and of socio-economic change" (p.178). For the supply side, the main actors bringing the evidence in the policymaking process are experts in the given policy domain. The experts include researchers who belong to an academic institution and stakeholders who act in the interest of their organisation as advocates/ lobbyists.

\section{What?}

Data, research, information, policy-oriented analysis, ideas and arguments are sought on the demand as well as the supply side. These correspond to the knowledge defined in the literature (Kingdon 1984; 2011; Weiss 1986; 1991; Majone 1989; Radaelli 1995). Weiss (1991) refers to the 
same type of knowledge but she defines it as social science research. She develops three models on research utilisation in the policymaking process, each of them associated with specific assumptions about the nature of the policymaking process itself. The first one is "research as data" which assumes a technocratic view of research that is used only to solve a problem without any further goals. The second model considers "research as ideas". This means that the results of a study are "transmuted in a simple story" (Weiss 1991, p.2). According to Weiss, this type of research is used for complex problems with high uncertainty. The third model considers research as an advocacy tool and calls it "research as argumentation". This type of research is used when a decision has already been made (Weiss 1991, p.3).

\section{Why?}

Simon (1991) introduced the concept of "bounded rationality" in his famous study on administrative behaviour. In his view, pure rational decisionmaking based on complete information (knowledge) is an illusion. Decisionmakers cannot oversee all possible options and their potential consequences. Decision-making or policymaking inevitably deals with uncertainties. They can only strive for satisfying policy solutions. Analysing the problem of uncertainty, the former Secretary of Defense of the United States, Rumsfeld (2002), made a distinction between "known knowns", "known unknowns" and "unknown unknowns". The task and responsibility of the government is to source knowledge (evidence) to reduce the factor of uncertainty as much as possible. This is paramount in situations of crisis with high stakes.

Confronted with external pressure, uncertainty and bounded rationality (Botterill and Hindmoor 2012; Lewis 2013; Sabatier \& Weible 2014), policymakers source knowledge (evidence) to substantiate their decisions. This process on the demand side can be conceptualised as policy learning. Policy learning occurs when policy (sub)systems generate and use knowledge regarding the rationale, impact and formulation of policies and actors update their beliefs (Bennett \& Howlett 1992; Parsons 1995; Dolowitz \& Marsh 2000; Freeman 2006; Grin \& Loeber 2007; Dunlop \& Radaelli 2013). Hall (1993) speaks about social learning to indicate the exchange of information and ideas among officials, academics and experts and political interests to bring policy change.

The policymakers' need for knowledge at the demand side makes them dependent on the knowledge of experts and stakeholders. This resource dependency makes information an access good (Bouwen 2002) that offers experts and stakeholders at the supply side an opportunity to influence 
policymaking and gain access to power. Additionally, policy learning is important from the viewpoint of experts and stakeholders. Their involvement in the policymaking process enables them to learn how this process really works in practice (in this study, "How Brussels works") and how to deal with the information dependency of the policymakers in their contacts with them. Furthermore, gathering experience helps them to improve the effectiveness of their strategies to inform the policymakers. Needless to say, this effectiveness will be heavily dependent on its quality. Therefore, stakeholders must also invest in sourcing the evidence.

\section{How?}

On the demand, side there are several ways to source information: doing research, hiring experts, organising consultations or informal sessions with stakeholders, conducting surveys, organising working groups, conferences and bilateral meetings. Negotiations may also yield a lot of relevant information and reduce uncertainty.

The "how" dimension of the sourcing and use of knowledge is closely associated with the need for legitimacy. Transparent and efficient procedures in collecting information add to the legitimacy of the same. Hence, the institutional structure also includes rules of the game (procedures) for the collection of information. These rules give stakeholders the opportunity, or even the formal right, to be consulted before decisions are taken. In addition, they may require the policymakers to be transparent about all the evidence available.

On the supply side, stakeholders provide information to policymakers by means of informational lobbying. Lobbying as information exchange and as a strategic communication of specialised information is well documented in the literature (Potters \& Van Winden, 1992; Austen-Smith, 1993; Bouwen, 2002; Grossman \& Helpman, 2001; Crombez, 2002; Broscheid \& Coen, 2002; Baumgartner, 2009; Chalmers, 2011). Chalmers (2011) considers that information is "the currency of lobbying in the European Union" (p. 2). Broscheid and Coen (2002) argue that "the key to lobbying success is not political patronage or campaign contributions, but the provision of information" (p.170).

Basing their assumptions on game theory models, they argue that stakeholders have policy relevant information that policymakers require in order to take effective decisions. According to the literature, there are different types of informational lobbying depending on the intensity of the lobbying 
actions, the number of lobbyists, their positioning in the lobby community and the nature of the information that they can provide.

Feldman and March (1981) state that "using information, asking for information, and justifying decisions in terms of information have all come to be significant ways in which we symbolise that the process is legitimate, that we are good policy-makers, and that our organizations are well managed" (p.178). The legitimacy arises from increasing the use of evidence and allowing those who are affected by the policy to be consulted at an early stage, especially when options are being devised. Legitimacy is also obtained by transparent and efficient procedures to collect the information. In this respect, Majone (1998) distinguishes between two dimensions a procedural dimension and substantive dimension of legitimacy. Procedural legitimacy means that political institutions have been created by a democratically enacted legislation that defines their legal authority. Policymaking follows well-defined procedures that also give opportunities to the interest groups to be involved in the policymaking process. Furthermore, procedural legitimacy refers to the fact that each decision must be justified, monitored and open to judicial review. On the other hand, substantive legitimacy refers to the level of expertise of the regulators, their capacity to protect public interests, the ability to choose the right priorities, the capacity to ensure consistency between its stated objectives and activities.

\subsection{Use of Evidence in Policymaking: A Framework of Analysis}

The theories and concepts described above offer useful theoretical approaches to the study of the utilisation of evidence in the formulation of EU public health policies. However, they are not operational enough to analyse use of evidence in policymaking. Moreover, they do not take the context in adequate account. Neither do they sufficiently acknowledge that a broad information base is required to take policy decisions. To address these shortcomings, a more detailed and operational framework of analysis is adopted, namely the "evidence-informed policy and practice pathway" developed by Bowen and Zwi in 2005. Their framework constitutes a valuable and relevant tool to capture the different stages of evidence utilisation and is particularly suitable to answer the research questions. It claims to be the only existing framework on the use of evidence in policymaking that captures the policy context "and its influence on each stage of interaction between research, other forms of evidence, and the policy process" (Bowen \& Zwi 2005 , p.604). It offers a useful classification of the different types of evidence in policymaking, explains the role of research evidence in the same in relation 
with other types of evidence and provides an analytical tool to identify the barriers and facilitating elements for their uptake.

Figure 2.2 describes the key features of the Bowen and Zwi model. In the following sections, the building blocks of the model are explained. This is followed by the three stages into which Bowen and Zwi divide the "evidenceinformed pathway", namely sourcing the evidence, using the evidence and implementing the evidence. Paragraph 2.4 explains how the framework is applied to the formulation of EU public health policies. The limitations of the framework and proposals for improvement are elaborated in Chapter 8.

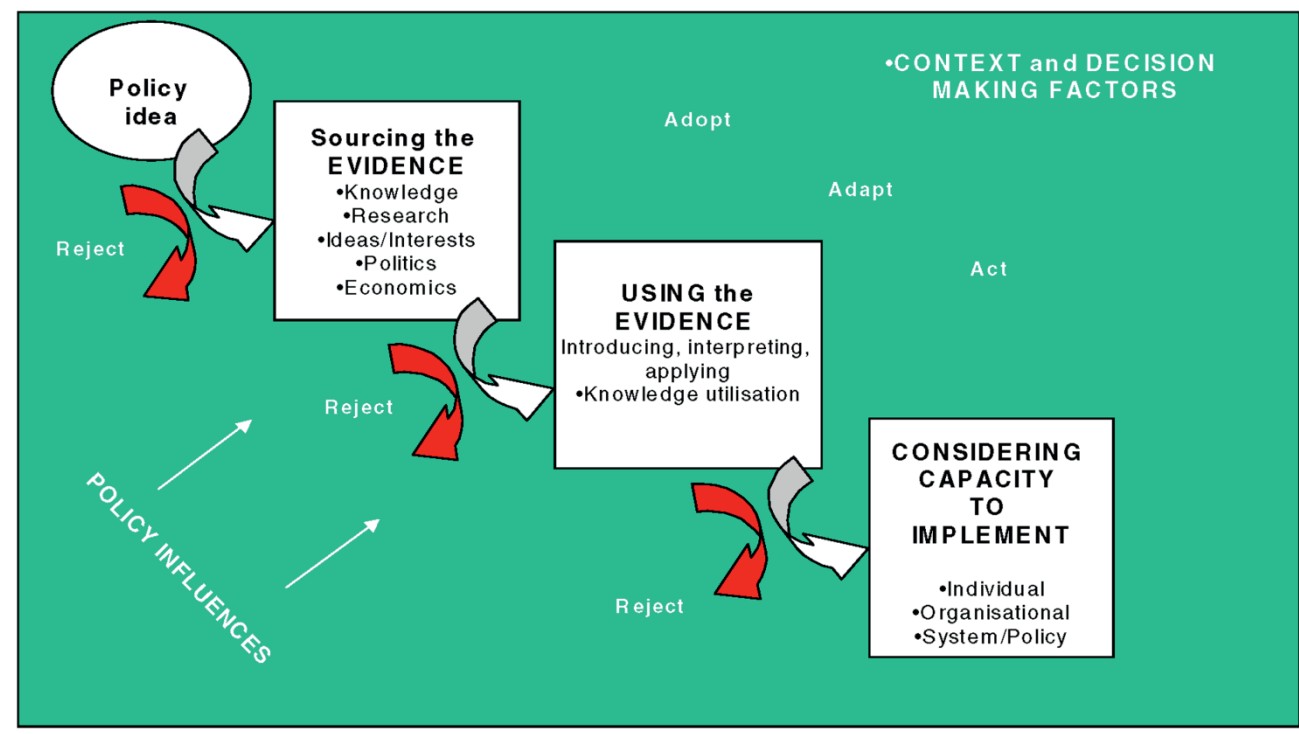

Figure 2.1. Evidence-Informed Policy and Practice Pathway (Bowen \& Zwi, 2005).

\subsubsection{Policy idea and context}

According to Bowen and Zwi, "understanding knowledge utilisation in policymaking requires an understanding of what drives policy" (2005, p.604). To understand what drives policy, an analysis of the context is essential. The context is the environment in which the policy idea, i.e., the new policy proposed, is conceived, developed and implemented. All the factors at play in the context determine how evidence is sought and used and which type of evidence prevails over the others. Bowen and Zwi argue that political and economic considerations as well as timing and the belief system of policymakers are the most critical factors influencing the ways in which 
evidence is used. Before being adopted, the evidence fully interacts with the context.

To analyse the policymaking context in which the evidence is used, Bowen and Zwi chose the policy network theory described above. Networks influence the way in which policy is formulated and how evidence is used (Bowen \& Zwi 2005; Davies et al., 2000). Within policy networks they look at both the role of individuals and the role of organisations in deciding which type of evidence is sought and used. Decisions regarding accepting or rejecting the evidence often lie with individuals who make their judgments based on their values, skills, knowledge, resources and so on. At the organisational level, the organisational structure influences which decisions are made and how they are made.

\subsubsection{Sourcing evidence}

According to Bowen and Zwi (2005) evidence is usually sought to show effectiveness ("it works"), show the need for policy action ("it solves a problem"), guide effective implementation ("it can be done"), and show cost effectiveness ("it is feasible and may even save money") ( p.601).

The starting point of this research is that the search for evidence goes beyond research evidence and includes other different forms of information gathered from different sources linked to the policy context. This includes political considerations, studies provided by stakeholders, experiences and so on. Bowen and Zwi offer a classification of the different types of evidence that policymakers' source, namely research, knowledge and information, ideas/interests, politics and economics (see below).

In the Bowen and Zwi classification, research includes empirical evidence from randomised controlled trials, analytic studies including cohort and case control studies, time series analyses, observations, experiences and case reports, qualitative studies and before and after studies. Knowledge and information refer to results of consultation processes with networks/groups, internet, published documents and reports such as policy evaluations and statistical analyses. Interest and ideas are opinions and views and include "experts' knowledge of individuals, groups and networks". With the term "politics", Bowen and Zwi refer to the information that is relevant to the agenda of the government, political risk assessment and saleability, opportunity and crises. Furthermore, "economics" includes finance and resources implications, economic evaluations (e.g. cost effectiveness) and 
opportunity costs. However, these two types of evidence tend to overlap and in the case studies they will be addressed together.

These are the types of evidence that, according to Bowen and Zwi, are sought to build the evidence base for policymaking.

\begin{tabular}{ll}
\hline Types of Evidence & Information and Influence on Decision-Making \\
\hline Research & Empirical evidence from randomized control trials and other trials \\
& Analytic studies such as cohort or case control studies \\
& Time series analyses \\
& Observations, experiences, and case reports \\
& Qualitative studies \\
& Before and after studies \\
Knowledge and information & Results of consultation processes with networks/groups \\
& Internet \\
& Published documents/reports (including policy evaluations and statistical \\
& analyses) \\
Ideas and interests & Opinion and view - "expert knowledge" of individuals, groups, networks \\
(shaped by past personal and professional experiences, beliefs, values, skills) & Information relevant to the agenda of government \\
Politics & Political risk assessment and saleability \\
& Opportunity \\
Crises & Finance and resource implications \\
Cost effectiveness or other forms of economic evaluation \\
Opportunity cost \\
\hline
\end{tabular}

DOt: 10.1371/journal.pmed 0020166.t001

Figure 2.2. Types of Evidence and How They Are Used in Policymaking (Bowen and Zwi, 2005).

\subsubsection{Using evidence}

According to Bowen and Zwi (2005), "evidence is usually sought to show effectiveness ("it works"), the need for policy action ("it solves a problem"), guide effective implementation ("it can be done"), and show cost effectiveness ("it is feasible and may even save money"). Building on the work of Dobrow et al. (2004), Bowen and Zwi identify three stages of research utilisation, namely introduction, interpretation and application. Introduction refers to the framing of the policy problem and the key questions to be addressed. Interpretation is the stage in which the research evidence is assessed, and application is the stage of the weighting and prioritisation of the different sources of evidence.

Similar to several other scholars in the area of evidence-based policymaking and knowledge utilisation (Hanney et al., 2003; Radaelli, 2005; 
Boswell, 2008), Bowen and Zwi refer to Weiss' $(1977 ; 1979 ; 1986)$ research utilisation models to describe if, how, when and where evidence is used in policymaking. These models are particularly relevant to capture the way in which research evidence is combined with other forms of evidence and help in understanding the meaning and use of evidence in policy development and practice. models.

Here follows a summary of the main features of each of Weiss' seven

The Knowledge-Driven model assumes that the mere existence of knowledge leads to its implementation. This model is mostly suitable for basic research in natural sciences, while it is less valid for social science research. Weiss (1986) argues that the findings of social science research are not "compelling or authoritative" enough to trigger an immediate implementation nor can they be "converted into replicable technologies" (p.32). Furthermore, she argues that policymakers are more likely to uptake social science research findings when an issue is highly debated and politicised, when there is consensus on the urgency of addressing a given social problem and when "the parameters of potential action" (Weiss, 1979, p. 446) have been agreed upon.

The Problem-Solving model corresponds to most people's perception of knowledge utilisation. It assumes the fact that research provides empirical evidence to solve a policy problem. It is used to fill a knowledge gap and reduce uncertainty to reach a decision on a pending issue. According to this model, social science research can enter policymaking via two routes. In the first route, policymakers seek research that is already available or commission certain research to meet their needs. Existing research can reach policymakers by chance, for instance when they fall on it in a conference, in a newsletter, in a magazine or by indication from colleagues, consultants or social science researchers themselves. However, Weiss identifies possible shortcomings in this method, namely that inside and outside experts and consultants may not be able to identify appropriate sources and that the information might be out dated and no longer relevant or usable. The second route can be used when policy goals and the feasible alternatives have been clearly identified. Here, research may facilitate the making of choices. In her description of the Problem-Solving model of knowledge utilisation, Weiss emphasises that for the uptake of social science research in policymaking, an "extraordinary" series of circumstances must occur. However, in her view, there are very limited cases where these circumstances apply. 
The Tactical model sees evidence as a tool to delay action or justify inaction in "bureaucratic politics". What is relevant in this context are not the research findings but simply the fact that research is being done.

In the Political model, policymakers are not receptive to research evidence because of their interests. They are receptive only if knowledge serves political gain by demonstrating "evidence" for a predetermined decision. In this context, research becomes "grist to the mill" and is used as "ammunition" when its findings support the views of one side of the debate, even if there is a bias in the selection and use of the findings. Weiss accepts the selective use of research findings and considers it illegitimate only in the case of the distortion and misinterpretation of findings.

The Enlightenment model suggests that cumulative research provides concepts and perspectives that permeate the policymaking process over time and influence people's thoughts regarding social issues. The model implies that policymakers are convinced that social science research has influenced their ideas and the way they approach certain issues, even if they cannot refer to any specific study that influenced them. Both good and bad quality knowledge can penetrate the policymaking process.

In the Interactive model, the search for knowledge goes beyond research to include a variety of sources such as politics and interests. First, policymakers seek information from various sources including social scientists, interests' groups, politicians, friends, administrators and so on. Second, research is considered just one part of a more complex process of gathering information. Other key parts are political considerations, experience, judgments, opinions and pressure. Third, the model suggests that certain political decisions cannot always wait for research to be completed.

Finally, in the Intellectual Enterprise model, social science research is considered as one of the many intellectual pursuits of society and researchers, and policymakers are influenced by trends in popular thinking.

Boswell (2008) argues that if knowledge is used as a source of legitimacy, the organisation is usually keen to make its use known to the actors operating in the policy environment. The impact assessment constitutes such a signal. This study seeks to understand how the signal is received and used by the target audience, namely the European Parliament and the Council as well as stakeholders, by gathering their views through semi-structured interviews (see Chapter 3). 


\subsubsection{Capacity for implementation}

To assess the third step, namely the capacity to implement the evidence, the hindering and facilitating factors are explored. This is followed by an assessment of the Bowen and Zwi classification that looks at individual, organisational and system levels. To answer the relevant research question, the focus of the study has been to examine the hindering and facilitating factors for the uptake of a specific type of evidence, namely research evidence. Interestingly, the Bowen and Zwi model also refers specifically to research and not to all types of evidence when outlining the framework to analyse the capacity to implement. Capturing the perceptions of policymakers and stakeholders on the use of evidence and by analysing the internal procedures of the European Commission, this research assesses whether the hindering and facilitating factors for the uptake of research evidence - as they emerged from systematic reviews of Caplan (1979), Innvaer (2002), Orton (2011) and Oliver (2014) - are valid for the EU policymaking process as well. Unfortunately, because of the limited number of interviewees and the relatively small sample available to the researchers on the issue of the case studies, the perception of the use of evidence described mainly refers to policymakers and stakeholders. Hence, it mostly reflects only one side of the story.

In the Bowen and Zwi model, individuals play a key role in deciding to accept or reject evidence. They argue that individual decisions "are influenced by a variety of personal qualities and capacities such as values and beliefs, leadership, knowledge and skills, resources, organisational support, partnership links, and networking. Additionally, individuals are influenced by the perceived benefit of change, and by the complexity of the innovation itself" (Bowen \& Zwi 2005, p.602).

The concept of "evidence informed pathway" refers in the terminology used by Bowen and Zwi on the capacity of policymakers to implement the evidence. They acknowledge the lack of extensive evidence on this aspect of policymaking and justify it by the complexity of defining and measuring the ability to act on the evidence gathered. They do not elaborate a lot on this part of their framework. However, they do suggest a couple of examples of what must be considered while assessing the capacity necessary to implement policies informed by evidence. On the basis of capacity-theory literature, they suggest a classification into three levels: individual level, organisational level and system level. At the individual level, they identify procedural knowledge, learning mechanisms, clear guidelines and personal 
qualities as key capacities. At the organisational level, they list, among others, processes and procedures such as planning and organisational culture as well as participation in internal and external groups and networks, technology to support the work, organisational support for innovation and research availability. At the system level, Bowen and Zwi see policy networks, advocacy and powerful lobbyists, funding, epistemic communities and decision-making processes as key elements that must be taken into account while assessing the system capacity to implement the evidence.

In 1977, Weiss already pointed to the gap between the knowledge needs of the policymakers and the research outputs of social scientists. She associated the limited attention paid to social research to the weakness of research itself, namely the fact that, in most cases, social science knowledge is flawed, inconclusive, ambiguous and contradicted by evidence from other studies. Study results can be outdated or limited in scope. Moreover, policymaking is mostly a political process aimed at finding consensus between conflicting parties and not at "implementing logic and truth" (Weiss 1977, p.533). Furthermore, Sabatier (1978) identified certain key variables affecting the influence of technical information provided by the staff of the agency or outsiders.

In his "two communities' theory", Caplan (1979) attributes the nonutilisation of scientific research in policymaking to fundamental differences between the community of policymakers and the community of social scientists. In his view, researchers and policymakers live in two different worlds. There are significant differences in their behaviour, values, judgments, and language. Caplan recognises the prevalence of instrumental utilisation of knowledge and mostly refers to social scientists, as opposed to natural or physical science researchers. He argues that social scientists are concerned with "pure science and esoteric issues" while policymakers are "action-oriented" (p. 459), more pragmatic and focused on short-term issues. The distance between the two worlds is partly due to the lack of trust and confidence. Caplan (1979) says: "The spectre of knowledge misuse by political power" tends to widen the gap.

Following Caplan, Innvaer (2002) made a systematic review of studies on the policy-research gap and the main facilitators and the main barriers for the uptake of research. He identifies the main facilitators to be personal contacts between researchers and policymakers and the timeliness and relevance of research. The main barriers are the absence of these in addition to the mutual mistrust between scientists and policymakers, power and budget 
struggles. The systematic reviews by Orton (2011) and Oliver and his colleagues (2014) drew similar conclusions. They identified the relationships between policymakers and researchers, training programs for researchers to learn how to disseminate clear, relevant and reader-friendly research as well as managerial support and change in policy culture as the main facilitators for the uptake of research. Unclear, irrelevant or low-quality evidence, lack of policymakers' research skills and practical constraints such as money, time and access to research are presented as the main barriers for uptake.

\subsection{Operationalising the Theoretical Framework}

The theories and concepts described above are applied to the formulation of European public health policies, particularly the three casestudies object of the research. Following the demand-supply scheme described earlier, those seeking the evidence are the policymakers in charge of formulating the policy, specifically the European Commission's legislative proposals. In the case of this dissertation, the key policymakers are the European Commission officials in charge of drafting the legislative proposal and, because of the focus of the research on policy formulation, only to a very limited extent, the representatives of the Member States of the Council of the EU and the members of the European Parliament. In assessing how the European Commission sources the evidence, the perspective of the European Commission is used instead of the perspective of those supplying the evidence. On the supply side, the focus is on the experts involved by the Commission in the policymaking process. The European Commission experts are mainly scientists, societal actors and government officials (Gornirzka \& Sverdrup 2015). Government officials are public officials from the EU Member States who participate in the European Commission working groups, whereas societal actors (or stakeholders) are mainly corporate and civil society organisations. The Commission officials, experts and elected politicians form the policy networks that influence the legislative proposals. Owing to the conflictual nature of the EU politics and existence of opposing fronts lobbying for different interests, in the EU policymaking process, policy networks often take the form of advocacy coalitions with different core beliefs. In the case of EU public health policies, public health vs. economic interests usually compete with business representatives on the one side and health NGOs on the other.

The European Commission facilitates the creation of policy networks and advocacy coalitions by creating ad hoc fora and choosing what Broscheid and Coen (2003) and Grant (2004) define as 'lobbying insiders.' Formally the 
European Commission is open to all interests' representatives, but for the effective and manageable involvement of stakeholders, it selects a core of few insiders organised in the forms of committees, conferences, working groups and other for a. This is what Coen and Richardson (2009) define as an "elite pluralist system in the form of forums to which access is generally restricted to a few policy players, for whom membership is competitive and strategically advisable" (p. 49). By choosing who can and who cannot sit around the table and allowing and denying access as an incentive for stakeholders to provide useful information, the European Commission inevitably influences stakeholders' strategies and shapes the policymaking process and behaviour of all those involved.

Regarding the data, ideas and arguments, Bouwen $(2002 ; 2004)$ and Coen (2007) argue that, as a technical bureaucracy, the European Commission seeks two types of evidence, namely grassroots and European-level information. Depending on the type of policy, the information can be of a very technical nature (e.g., standards) or more political (e.g., preferences of Member States or members of the European Parliament). This distinction clearly emerges in the three case studies. With regard to the quality and reliability of the information, Broscheid and Coen (2007) argue that the European Commission provides incentives to the stakeholders to bring useful information by offering access to its fora and privileged inside information on policy developments as well as grants and contracts and discourage the socalled "babbling," namely the provision of partial, self-serving or misleading information.

Within the remit of organisational theory, this research assumes with Bouwen (2002) that expertise constitutes a key asset for political organisations. It endorses Greenwood's (2017) view that the EU institutions have a "systemic dependence on organized civil society" (p. 7). Also, Coen (2007) speaks about "resource dependency" to identify the relationship between the EU officials and lobbyists based on regulatory needs, expertise, intelligence, information and reputation. According to Broscheid and Coen (2007), EU lobbyists tend to provide decision makers with biased information that reflects their positions unless they receive incentives to provide good and reliable information.

Gornitzka and Sverdrup (2008) define the European Commission's "one thousand expert committees that assist in initiating and formulating new legislation" as "the largest organised information system in the EU" (p. 733). Some argue that the strength and diversity of interest groups redeem the EU 
accountability and legitimacy (Bellamy \& Castiglione 2003; Smismans 2006). Smismans (2004) believes that the enormous amount of lobbying in Brussels provides a democratic legitimacy to the EU that it would otherwise lack, and many writers suggest that it is actually the Commission that chooses the most influential organisations and tailors their suggestions to its capacity and opportunism (Greer 2008; Broscheid \& Coen 2003; Greenwood 2017). Cram (2005) and Richardson (2006) define the Commission itself as a "purposeful opportunist," as, thanks to its organisational structure, it can easily add resources where needed in the most crucial moments using working groups to expand its expertise. Lobbyists become indispensable and are hired to complete the Commission's work and give it substance and legitimacy.

In their study, Broscheid and Coen (2007) illustrate this by showing how the interest groups' and Commission's preferences for forum and direct action are a function of the information needs of the given Directorate, number of interests and capacity to process interest groups' input balanced against the input and output legitimacy requirements of the policy domains. To manage the input/information overload, the Commission has established defined procedures and a system of privileged access to some preferred constituency to simplify their work. They try to establish the rules of the game and engage only with those who can respond to their needs. Those who do not stick to the rules, also in terms of the tone used to bring forward their instances, are out of the game. By establishing rules such as the EU lobby register, the Commission influences the lobbying community and the behaviour of the different interest groups. The Commission knows the bottom lines of all the actors involved, including the other institutions, and it is itself a lobbyist or, as Cram (2005) defines it a "policy entrepreneur." Cram (2005) also notes that in many policy sectors, the Commission usually tries to build confidence through the creation of supportive and consultative networks with stakeholders or by increasing (sometimes apparently) the level of transparency and legitimacy with public consultations.

Greer (2008) suggests that every Directorate General has interest in developing its network of information and support and find ways to finance it if needed, for example by giving support to umbrella NGOs, especially in the health field. This ultimately shapes interest groups, their strategy, their priorities, their way of working, including their budget structure, as they are obliged to invest more in research.

Lobbying and interest representation are inherently part of the work of the EU institutions. The European Commission has also established a register 
for interest groups called Transparency Register. Stakeholders, on their side, use all the venues they are offered to advocate for their interest and change the policy proposals according to their belief system.

To sum up, in the EU arena lobbying is a two-way mechanism where advocacy groups lobby the Commission and the Commission lobbies advocacy groups (sometimes offering financial support), shaping their strategy and using their resources.

Table 2.2 summarises how the features of the supply and demand side of knowledge apply to the EU policymaking process.

Table 2.2.

Demand and Supply of Evidence in the EU Policymaking Process

\begin{tabular}{|l|l|l|}
\hline Who & Demand & Supply \\
\hline What & $\begin{array}{l}\text { Grassroots and EU wide } \\
\text { reliable information } \\
\text { Technical information } \\
\text { Information about the } \\
\text { preferences of key actors } \\
\text { government officials }\end{array}$ & $\begin{array}{l}\text { Knowledge and information } \\
\text { as research, data, arguments }\end{array}$ \\
\hline Why & $\begin{array}{l}\text { Gaining legitimacy and } \\
\text { consensus, substantiating } \\
\text { policy decisions }\end{array}$ & Influencing EU policies \\
\hline How & $\begin{array}{l}\text { Creating working groups, } \\
\text { committees and other } \\
\text { consultation fora }\end{array}$ & $\begin{array}{l}\text { Participating in working } \\
\text { groups, committees and } \\
\text { other consultation }\end{array}$ \\
\hline
\end{tabular}

As for the use of evidence, the focus of this study is on the impact assessment accompanying the proposal. The impact assessment report constitutes the only tangible and publically accessible document showing the knowledge base of the Commission proposal. It is expected to reflect all the information gathered by the European Commission when drafting the proposal. It is also expected to be a useful tool for the policymakers in the European Commission and other European institutions to make informed decisions and have a complete overview of the likely impact of the legislative 
measures as well as the view of stakeholders. The impact assessment summarises the research evidence commissioned by the Commission (e.g., results of funded projects), data and information provided by the stakeholders (technical evidence), stakeholders' views (preference evidence) usually gathered via public consultation, economic evaluations (e.g., cost-benefit analysis, administrative burden) and political considerations (e.g., principle of subsidiarity). Therefore, it constitutes a unique tool to gain insights into the European Commission's use of knowledge.

Since 1997, with the Amsterdam treaty, every legislative proposal drafted by the European Commission must undergo a so-called "impact assessment" to assess the economic, social (including health) and environmental consequences. An impact assessment is conducted according to the specific guidelines by the European Commission. The first impact assessment guidelines were adopted in 2005 and later updated in 2006, 2009 and 2015. According to Smith et al. (2010), the guidelines that define the impact assessment methodology are biased themselves, as they place more emphasis on the economic impact rather than the impact of the policies on health.

According to Bowen and Zwi (2005), evidence is usually sought to show the need for policy action, feasibility and cost-effectiveness. The impact assessment covers all these elements. First, it describes the problem the legislative proposal aims at solving; then it details the need for the policy action, particularly that an EU action is needed to solve it and the EU is better placed than the Member States to address its so-called "subsidiarity principle." Finally, it quantifies the cost of the action.

According to Radaelli (2009), regulatory impact assessment (or impact assessment) is "an appropriate empirical reference for the analysis of learning over a long period of time" (p.1145). The impact assessment is a policy instrument for the systematic assessment of the impact of legislation on the environment, affected stakeholders and economy. The impact assessment is regularly used in the formulation of European legislative proposals by the European Commission.

\subsection{Conclusion}

This chapter showed the perspective used to answer the research questions. The key concepts underpinning this research are mostly borrowed from knowledge-utilisation theories. The complex dynamics of the evidence used in the EU policymaking are addressed looking at the demand-supply relationship between the policymakers seeking the evidence to inform their 
decision and gain legitimacy and consensus and policy networks of the affected stakeholders trying to shape the policy according to their beliefs. To better navigate the use of evidence in the formulation of policy, the Bowen and Zwi (2005) evidence-informed pathways are used as the main framework for the analysis. The Bowen and Zwi model is particularly suitable to analyse the EU policymaking process because it adequately considers the context in which policies are formulated and offers a useful classification of the different types of evidence that facilitate the understanding of how research relates to the other types of evidence used in policymaking. Bowen and Zwi, as well as other scholars of evidence-based policy, refer to Weiss' pivotal work on knowledge utilisation and the seven models she describes to explain how the evidence, particularly in social science research, is used by policymakers. The analysis of the hindering and facilitating factors for the uptake of evidence is based on Bowen and Zwi's implantation capacity elements and complemented with the findings of the systematic reviews on the gap between the policymakers and the researchers' communities. The last part of the chapter operationalised parts of the theoretical framework. The following chapter explains the methodology used to carry out the study. 



\section{Chapter 3: Methodology}

\subsection{Introduction}

This chapter describes the methodology and how the answers to the research questions have been sought. Section 3.2 explains the rationale behind the choice of case studies as a research strategy and details the reasons for the selection of the three case studies. Section 3.3 gives an overview of the type of information collected and sources of information used, while section 3.4 presents the methods applied to process and analyse the information. The chapter concludes with some reflections on the validity and reliability of the research (3.5) and on positionality and bias (3.6), followed by some conclusions (3.7).

\subsection{Comparative Case Study}

This study is a descriptive and exploratory qualitative research that applies a multiple comparative case-study design. Yin (2009) defines the case-study research method as an empirical inquiry that investigates a contemporary phenomenon within its context, when the boundaries between phenomenon and context are not evident and in which multiple sources of evidence are used (Yin, 2009). Moreover, a case-study design should be considered when it is not possible to manipulate the behaviour of those involved in the study and when contextual conditions need to be assessed because they are relevant to the phenomenon under study.

A multi-case-study design has been adopted because it allows an indepth and comparative analysis of the main issues and because conclusions drawn on the basis of multiple case-studies are considered more robust (Yin, 2009). According to Bowen and Petersen, with a comparison of a few and well understood cases and a focus on process and mechanisms, "much of the complexity of political life can be addressed while maintaining an ability to generalize" (Bowen \& Petersen, 1999, p. 4). All these conditions apply to the phenomenon investigated in this research, namely the sourcing and use of evidence in the formulation of European public health policies and the facilitating and hindering factors in the uptake of research evidence. Moreover, the research requires the use of several sources to be assessed and the researcher cannot influence the behaviour of the actors involved in the policy-making process. Lastly, restricting the analysis to three case studies allows for a thorough and in-depth analysis useful to gain insights about the EU's public health policymaking, and leaves room for the possibility of making some generalisations. 


\section{Case selection}

The main criterion for the case selection was obviously the case's relevance to the research objectives. To be selected, the case studies had to meet three specific requirements.

First, to assess what type of evidence is used in the formulation of European public health policies, the cases had to be policy initiatives at the EU level dealing with public health - i.e., decisions affecting health ${ }^{1}$ and health systems taken by European institutions.

Second, to investigate the three research themes, the cases had to present a significant number of similarities to narrow down the number of variables (timing, political orientations, legal basis, procedures, etc.), and facilitate comparison with and gain insights from key differences (see below).

Third, in order to allow the interviewees to speak more freely and with less bias associated with their involvement in the case, it was not advisable to select legislation which was still the object of political debate when the interviews were conducted.

A list of all EU public health policy initiatives was drawn on the basis of the European Commission work programmes from 2006 to 2009 and of the EU Legislative Observatory (Appendix I). The selection was then narrowed down to legislative proposals, considering they could offer more valuable insights than non-legislative initiatives on the topic investigated. For legislative initiatives, the European Commission is required to make an impact assessment and substantiate its work vis-a-vis the European Parliament and the Council. Moreover, legislative initiatives are likely to have more impact on public health; they also generate more political attention than non-legislative actions.

Among the five legislative initiatives listed, the following were selected for investigation in this research:

-The Directive on the application of patients' rights in cross-border health care (case 1)

-The Directive on information to the general public on prescription medicines (case 2)

\footnotetext{
${ }^{1}$ EU public health policies also cover animal health. For the purpose of this research, health is to be considered as human health only.
} 


\section{(case 3)}

-The Regulation on the provision of food information to consumers

The Directive on the application of patients' rights in cross-border health care was adopted by the European Commission in July 2008. The proposal aimed at clarifying the rules for receiving health care abroad and seeking reimbursement as well as the responsibilities for quality and safety in cross-border settings. It also aimed at strengthening cooperation between Members States in areas such as health technology assessment, e-health and centres of excellence for specialised care. The proposal constitutes an interesting case study for the use of evidence as it was based on many studies and research findings, including the results of different projects funded by the European Commission on patient mobility, an external report supporting the impact assessment and a Eurobarometer survey.

The Directive on information to the general public on prescription medicines was adopted by the European Commission in December 2008. The proposal aimed at extending the pharmaceutical industry's possibilities to disseminate information on prescription medicines directly to consumers on the internet and printed media, including via public campaigns on any issue in the interest of public health. The proposal constitutes an interesting case study because it was highly controversial and spurred a lively debate within the public health community in the EU - and partly at the national level - on the role of the pharmaceutical industry. The proposal has also generated interest among researchers in the past, as the topic has been on the EU agenda for almost 20 years.

The proposal on food information to consumers was adopted by the European Commission in January 2008. The proposal aimed at improving EU rules on food labels and helping consumers make informed choices. This proposal was also highly controversial and saw the creation of two opposing fronts: one on the side of public health and consumer groups and the other for the food industry. This element is particularly useful to see whether there is an impact on the use of evidence in the formulation of the policy proposal. The Regulation has been chosen as a case study because of its relevance for public health, in particular in the context of the fight against obesity and overweight. The World Health Organisation lists nutrition labelling as an important means of meeting consumers' requirements for "accurate, standardised and comprehensible information on the content of food items in order to make healthy choices" (WHO,2004), while the Organisation for Economic Cooperation and Development views nutrition labelling as "a main 
tool for preventing increasing rates of obesity and unhealthy diets" (OECD, 2012). This case is also interesting because of the polarised nature of the debate with two well-defined advocacy coalitions - the food industry on one side and health and consumer NGOs on the other - expressing divergent views on how and what type of information should be provided to consumers and supporting their arguments with data and studies with different conclusions.

The proposals on falsified medicines and on pharmacovigilance were excluded because they are highly technical and specific to the pharmaceutical sector. Moreover, the cases selected deal with a general societal issue and have in common the main focus on consumer information (see also below) as opposed to the more technical product-related issues addressed in the proposal on falsified medicines and pharmacovigilance. The three case studies present many similarities that facilitate the comparison, but also specific characteristics and differences that will enrich the reflection and contribute to the understanding of the research topic. Table 3.1 summarises the main general similarities and differences among the three case studies.

Table 3.1.

Main Similarities and Differences Among the Three Case Studies

\begin{tabular}{|l|l|l|l|}
\hline & $\begin{array}{l}\text { Case study 1 } \\
\text { Cross-border } \\
\text { health care }\end{array}$ & $\begin{array}{l}\text { Case study 2 } \\
\text { Information } \\
\text { to patients }\end{array}$ & $\begin{array}{l}\text { Case study 3 } \\
\text { Food } \\
\text { information } \\
\text { to consumers }\end{array}$ \\
\hline Proposal & Directive & $\begin{array}{l}\text { Directive }+ \\
\text { Regulation }\end{array}$ & Regulation \\
\hline $\begin{array}{l}\text { Legislative } \\
\text { procedure } \\
\text { Legal basis in } \\
\text { the } \\
\text { Commission } \\
\text { proposal }\end{array}$ & $\begin{array}{l}\text { Art.95 (now } \\
\text { Art.114) }\end{array}$ & $\begin{array}{l}\text { Amending } \\
\text { existing } \\
\text { legislation }\end{array}$ & $\begin{array}{l}\text { Amending } \\
\text { existing } \\
\text { legislation }\end{array}$ \\
\hline $\begin{array}{l}\text { Drafting DG } \\
\text { Art.114) }\end{array}$ & DG SANCO & $\begin{array}{l}\text { Art.95 (now } \\
\text { Art. 114) }\end{array}$ \\
\hline
\end{tabular}




\begin{tabular}{|c|c|c|c|}
\hline Policy field & Health care policy & $\begin{array}{l}\text { Public health/ } \\
\text { Pharmaceutical } \\
\text { policy }\end{array}$ & $\begin{array}{l}\text { Public health/ } \\
\text { Food policy }\end{array}$ \\
\hline $\begin{array}{l}\text { Year of } \\
\text { adoption }\end{array}$ & 2008 & 2008 & 2008 \\
\hline $\begin{array}{l}\text { Legal } \\
\text { instrument }\end{array}$ & $\begin{array}{l}\text { Directive } \\
\text { New legislation }\end{array}$ & $\begin{array}{l}\text { Directive + } \\
\text { Regulation } \\
\text { Amending } \\
\text { existing } \\
\text { legislation }\end{array}$ & $\begin{array}{l}\text { Regulation } \\
\text { Replacing } \\
\text { existing } \\
\text { legislation }\end{array}$ \\
\hline Policy field & Public health & Public health & Public health \\
\hline $\begin{array}{l}\text { Specific } \\
\text { policy field }\end{array}$ & Health care policy & $\begin{array}{l}\text { Pharmaceutical } \\
\text { policy }\end{array}$ & Food policy \\
\hline Legal basis ${ }^{2,3}$ & Internal market & Internal market & $\begin{array}{l}\text { Internal } \\
\text { market }\end{array}$ \\
\hline $\begin{array}{l}\text { Legislative } \\
\text { procedure }\end{array}$ & Co-decision & Co-decision & Co-decision \\
\hline $\begin{array}{l}\text { Responsible } \\
\text { DG }^{4}\end{array}$ & DG SANCO & $\begin{array}{l}\text { DG } \\
\text { ENTERPRISE }\end{array}$ & DG SANCO \\
\hline $\begin{array}{l}\text { Date of } \\
\text { adoption by } \\
\text { the EC }\end{array}$ & 2 July 2008 & $\begin{array}{l}10 \text { December } \\
2008\end{array}$ & $\begin{array}{l}30 \text { January } \\
2008\end{array}$ \\
\hline $\begin{array}{l}\text { Entry into } \\
\text { force }\end{array}$ & 24 April 2011 & $\begin{array}{l}\text { Withdrawn on } \\
21 \text { May } 2014\end{array}$ & $\begin{array}{l}22 \text { November } \\
2011\end{array}$ \\
\hline
\end{tabular}

\footnotetext{
${ }^{2}$ At the time of the adoption. For the proposal on information to patients, the information refers to the first draft proposal and not the amended versions.

3 Former Article 95 has been transformed into Article 114 with the entry into force of the Treaty Establishing the EU (TFEU) in 2010.

4 The proposal on information to patients was moved under the remit of DG SANCO with the transfer of the competence on pharmaceuticals from DG ENTERPRISE to DG SANCO under the Barroso II Commission 2009-2014. DG SANCO has been renamed DG SANTE and DG ENTERPRISE has been renamed DG industry and internal market under the Juncker Commission 2014-2019.
} 


\section{Similarities}

With regard to the similarities between the three cases, it can be noted that they are all binding legislative proposals adopted by the European Commission in 2008. The proposals were adopted with the Article of the Treaty regarding the internal market as a legal basis (then Article 95, now Article 114 of the Treaty ${ }^{5}$, following the entry into force of the TFEU in 2010).

The three proposals followed the so-called "co-decision" procedure now renamed ordinary legislative procedure" (Art. 289 and 294 of the TFEU) - which "consists in the joint adoption by the European Parliament and the Council of a Regulation, Directive or Decision on a proposal from the Commission". The three case studies are all based on the same policy instruments, namely binding legal acts as described in Articles 288-292 of the Treaty.

Each proposal was debated under the same legislative term (20042009). The political environment variable was the same, as they were debated by the same members of the European Parliament and the same national governments represented in the Council of the EU. The political constituency of the European Commission management was also the same, namely the same college of Commissioners appointed by the Member States on a political basis. These similarities neutralised possible differences in the use of evidence justified by the political orientations of the actors involved and helped disregard the political parties and political environment variable in the analysis.

All three proposals pertain to functional social policies in the field of public health and have in common the objective of improving public health. The fil rouge that links them is the provision of information to European citizens: key provisions of the Directive on cross-border health care aimed at ensuring patients have adequate information about their rights and obligations when seeking health care abroad as well as about the quality, safety and costs of the treatments they receive. The Directive on information to patients aimed at ensuring that patients have adequate information about the medicines they take. The Regulation on food information aimed at ensuring consumers have adequate information about the food they eat.

\footnotetext{
${ }^{5}$ Treaty on the functioning of the European Union (hereafter Treaty or TFEU), 2010.
} 


\section{Differences}

With regard to the differences, it should be noted that the policy instrument used for food information was a Regulation, a legal instrument that is directly applicable in all Member States and overrides national laws as soon as it enters into force, while the proposals on information to patients and crossborder health care have been adopted by the European Commission in the form of Directives. Directives need to be transposed into national legislation before they become applicable. A directive forces Member States to achieve certain objectives but leaves room for national governments to decide how the objectives should be met. This is also linked to the fact that the EU has almost full competences on food-related policies on the basis of the internal market principle of the free movement of goods while, as outlined in the Treaty (Article 168), competence on health-related issues lies mostly with the Member States.

The proposals on information to patients and food information to consumers were adopted as an amendment to the existing legislation, while the Directive on the application of patients' rights on cross-border health care was written from scratch and not aimed at amending existing legislation.

These case studies are also particularly interesting in comparing the process and procedures used by two different Directorates General of the European Commission and two different services within the same Directorate. In particular, both the Directive on cross-border health care and the Regulation on food information have been drafted by the Directorate General for health and consumer protection, whose mandate is to protect and improve the health and rights of European citizens. However, the proposals were drafted by two different services, namely the unit on health systems and on food information, respectively. The proposal on information to patients was drafted by the Directorate General for enterprise and industry, whose mandate is to promote the competitiveness of European industries (see also Chapter 5).

Lastly, it is worth noting that according to an analysis by Broscheid and Cohen (2007), DG ENTERPRISE and DG SANCO are the Directorates General of the European Commission with the highest number of active interest groups (221 and 149 respectively $)^{6}$. This makes legislative proposals stemming from them particularly useful case studies to analyse the role of stakeholders in providing evidence to policymakers.

\footnotetext{
${ }^{6}$ More updated figures on the number of interest groups per DG are not available.
} 
The similarities and differences among the selected case studies are particularly useful in analysing the dynamics of EU public health policymaking, use of evidence, use of impact assessment and public consultations as well as the role of stakeholders in the provision of evidence.

\subsection{Data Collection}

In this research, data from primary and secondary sources were collected. They were gathered from multiple sources, including existing literature, official documents of European institutions (texts of the legislation, impact assessment reports, minutes of meetings, speeches), positions of stakeholders (responses to public consultation, public statements) and grey literature (unpublished reports from the EU institutions and stakeholder groups). Documentary sources related to the general research topic were relatively abundant and easily accessible. Information gained from documentary sources has been complemented with primary data collected in semi-structured interviews and with direct participant observation (direct knowledge, participation to conferences and meetings). The type of data sought was the same for the three case studies.

Table 3.2 explains how the data collection instruments are linked to the research questions and justified. 
Table 3.2.

Research Questions, Data Collection Instruments and Justification

\begin{tabular}{|c|c|c|}
\hline $\begin{array}{l}\text { Research } \\
\text { questions }\end{array}$ & $\begin{array}{l}\text { Data collection } \\
\text { instruments }\end{array}$ & Justification \\
\hline $\begin{array}{l}\text { What kind of } \\
\text { evidence } \\
\text { does the } \\
\text { European } \\
\text { Commission } \\
\text { use in the } \\
\text { formulation } \\
\text { of EU public } \\
\text { health } \\
\text { policies } \\
\text { and how does } \\
\text { it source this } \\
\text { information? }\end{array}$ & $\begin{array}{l}\text { Literature study } \\
\text { Public records } \\
\text { Grey literature } \\
\text { Participant } \\
\text { observation } \\
\text { Interviews }\end{array}$ & $\begin{array}{l}\text { The literature study was necessary to } \\
\text { understand what was known about } \\
\text { the topics of the legislative proposals } \\
\text { chosen as case studies (cross-border } \\
\text { health care, information to patients } \\
\text { on medicines and food information to } \\
\text { consumers) } \\
\text { The analysis of the public records and } \\
\text { grey literature was necessary to } \\
\text { identify the typology of evidence } \\
\text { sought and used by the European } \\
\text { Commission in the formulation of EU } \\
\text { public health policies } \\
\text { Participant observation and } \\
\text { interviews aimed at understanding in } \\
\text { which venues and format the } \\
\text { European Commission sourced the } \\
\text { evidence }\end{array}$ \\
\hline $\begin{array}{l}\text { How does the } \\
\text { European } \\
\text { Commission } \\
\text { use evidence } \\
\text { in the } \\
\text { formulation } \\
\text { of its EU } \\
\text { public health } \\
\text { policies and } \\
\text { how do the } \\
\text { participants } \\
\text { in the process } \\
\text { assess the use } \\
\text { of evidence }\end{array}$ & $\begin{array}{l}\text { Public records } \\
\text { Grey literature } \\
\text { Semi-structured } \\
\text { interviews with } \\
\text { EU } \\
\text { policymakers } \\
\text { and } \\
\text { stakeholders } \\
\text { Literature study }\end{array}$ & $\begin{array}{l}\text { Public records and grey literature } \\
\text { were analysed to understand how the } \\
\text { European Commission uses evidence } \\
\text { in the formulation of EU public } \\
\text { health policies. The documents were } \\
\text { screened to count the references to } \\
\text { evidence they included. } \\
\text { Semi-structured interviews were used } \\
\text { to gain insights on how the } \\
\text { participants in the process assessed } \\
\text { the use of evidence by the } \\
\text { Commission }\end{array}$ \\
\hline
\end{tabular}




\begin{tabular}{|l|l|l|}
\hline $\begin{array}{l}\text { by the } \\
\text { Commission? }\end{array}$ & $\begin{array}{l}\text { The literature study on evidence in } \\
\text { policymaking was aimed at } \\
\text { understanding if there were studies } \\
\text { on researchers and policymakers' } \\
\text { perceptions of the uptake of research } \\
\text { evidence in policymaking and, in } \\
\text { particular, in the health sector }\end{array}$ \\
\hline $\begin{array}{l}\text { What are the } \\
\text { hindering and } \\
\text { facilitating } \\
\text { factors for the } \\
\text { uptake of } \\
\text { research } \\
\text { evidence in } \\
\text { the } \\
\text { formulation } \\
\text { of EU public } \\
\text { health } \\
\text { policies? }\end{array}$ & $\begin{array}{l}\text { Semi-structured } \\
\text { interviews with }\end{array}$ & $\begin{array}{l}\text { Semi-structured interviews provided } \\
\text { and account of those factors that EU } \\
\text { policymakers and stakeholders } \\
\text { stakeholders } \\
\text { for the uptake of evidence in the } \\
\text { formulation of European public } \\
\text { health policies } \\
\text { The literature study on evidence in } \\
\text { policymaking was aimed at assessing } \\
\text { if the hindering and facilitating } \\
\text { factors emerging from the research } \\
\text { were similar or different from those } \\
\text { identified by previous studies }\end{array}$ \\
\hline
\end{tabular}




\section{Literature study}

The literature study had four main objectives:

a) Defining the concept of evidence in public health policymaking (Chapter 1)

b) Understanding what was already known on the role of evidence in policy formulation (Chapter 1)

c) Defining a theoretical framework for the analysis of the role of evidence in the formulation of European public health policies (Chapter 2)

d) Understanding the topics of the legislative proposals chosen as case studies (Chapter 4-6)

With regard to the first objective, the literature search was based on three complementary search strategies. First, a systematic search of the published literature on evidence-based policymaking - with a focus on health and EU policy - was carried out in 2010 via the databases PubMed, Science Direct and Medline (accessed through the Maastricht University Library website) using the following key words: evidence-based policy, European policymaking, health policymaking, evidence-based health policymaking, health impact assessment, European lobbying.

Secondly, the search was extended to the search engines Google and Google Scholar. The selection relied mostly on Google's algorithm and only the first 40 pages of results for both search engines were screened for relevance. The search was conducted in English, French and Italian. The use of French and Italian in addition to the English language for the literature and the common internet search was not motivated by a content-driven argument; it was linked only to the fact that the researcher fluently speaks both languages. However, no relevant studies on the issue emerged in these two languages.

Thirdly, the bibliography of the first group of relevant studies selected via the databases and the Google search was screened to identify further relevant research articles and book chapters, using a snowballing approach which produced about twice as many references as first identified.

Through the search, 91 relevant studies were identified and used in the elaboration of the general introduction of the thesis to define the concept of evidence in health policymaking (Chapter 1). 
With regard to the second objective, in order to define a theoretical framework useful for the research, the search study was conducted with the same approach and three-fold search strategy. The main key words used were theories of the policy process, advocacy coalition framework, informational lobbying theory, theories of the EU policy process, grounded theories. Through the search, 67 relevant studies were identified and used to define a theoretical framework to analyse the role of evidence in the formulation of European public health policy (Chapter 2).

For the third objective as well, to understand the topics of the legislative proposals chosen as case studies, the search study was conducted with the same approach and three-fold search strategies; the key words used were: cross-border health care, information to patients on medicines and food information to consumers.

The literature study on the three case studies' policy areas showed that there were no specific studies on the three legislative proposals, with the exception of an analysis published in the British Medical Journal in 2011 on the proposal on cross-border health care (Legido-Quigley et al., 2011). However, it was useful to identify research evidence on the three topics (cross-border health care, information to patients on medicines and food information to consumers) and to see if and how research evidence was used in the formulation of the three legislative proposals, so to answer the research questions in relation to the case studies (see tables of research evidence for chapters 4,5 and 6 respectively).

In total, four literature studies were conducted between 2010 and 2016. The first and main literature study was conducted at the beginning of 2010 and focused on the concept of evidence in health policymaking, on the role of evidence and on the theories on the policy-making process applicable to the research. A second literature search was conducted in 2012, which focused on understanding the policy areas of the three case studies.

Two other literature studies, using the same approach (database search, web search and snowballing), were conducted between 2014 and 2016 to identify new useful publications on evidence in health policymaking and to see if, in the meantime, other studies had been conducted on cross-border health care, information to patients and food information to consumers. These literature studies produced additional new and useful references, especially with regard to the role of evidence in policymaking and on evidence in the EU policymaking process, such as Liverani (2013), Oliver (2014), Gornitzka \& Sverdrup (2015) and Malterud (2016). 


\section{Public records and grey literature}

Official public documents (e.g. draft legislative proposals), reports, meeting minutes and press releases from the Commission, the Council of Ministers and European Parliament covering the period 2002-2014 were accessed in English via the website of each institution. This type of document was a source of information for the case studies, not for the theoretical framework. Position papers released by various stakeholders (industry, NGOs, health care professionals' associations) during the period of the three selected legislative proposals were accessed via their websites. The institutions' and stakeholders' public documents were searched mostly in 2010 and 2013. Relevant web content (including press coverage and media releases) was identified prospectively through a Google search using the titles of the three legislative proposals as search words.

Press articles about the legislative proposals were used to reconstruct the policy-making process. Relevant press articles were mostly found in Brussels-based publications such as Euractiv and Europolitics, as national newspapers are usually not interested in the details of the EU policy-making process. Relevant press articles on the three case studies were searched between 2010 and 2011. Press articles on the use of evidence in the EU policy-making process were searched throughout the research process, namely between 2010 and 2015 .

In the course of the research, the so-called grey literature was also used, namely unpublished reports from the institutions, such as draft documents of the Council of the EU as well as unpublished internal reports of NGOs. According to O' Laughlin (1998) and Green and Thorogood (2009), grey literature is an important source of information for understanding the political process. Access to this information was useful to better understand the process and the power relations that exist between actors, which views were absent, which prevailed, which preliminary options were framed, and so on. The grey literature was collected mostly at the beginning of 2010, via the researcher's professional and personal contacts and thanks to the researcher's direct access to this type of document during her daily work at the European Consumer Organization (see below).

\section{Participant observation}

In 1958, Gold suggested a typology of observational methods, making a distinction between the possible roles of the researcher on the basis of how much they participate in the field of the study. On one side of the scale is the 
complete participant; on the other, the complete observer. In classic ethnographic studies, the researcher is somehow in between, while, in this specific study, the researcher can be considered a complete participant. Ethnography is defined as a "method of research in which the researcher participates, overtly or covertly, in people's daily lives for an extended period of time, watching what happens, listening to what is being said, asking questions" (Green \& Thorogood, 2009, p. 150).

There is a tradition of "sociological autobiography" where personal experiences are used for research purposes. In these cases, experiences become data only retrospectively and, at the time they are made, there is no intention to use them analytically for research purposes. What distinguishes ethnography from common sense is that it is not merely an insider description, but also an outsider analytical view. Anthropologists distinguish emic, the insider perspective - a person within the social group investigated - from etic, the perspective of the outsider analyst (the scientific observer) to indicate the two points of view of field research. Of course, the distinction is difficult to make in practice.

In the case of this research, the ethnographic method applied to the participation of working groups of the European Commission, sessions of the European Parliament and conferences and seminars relevant to the case studies. The researcher had a privileged direct observation of the EU policymaking process, working as senior policy officer for the European Consumer Organisation (BEUC), an NGO active in the EU lobbying environment. Consequently, the observation of the field investigated was, in principle, conducted on a daily basis, and it is difficult to quantify the number of relevant events observed. As an example, the most relevant public experiences could be identified as the following: 12 meetings of the EU health policy forum (two meetings a year from 2006 to 2011), 12 sessions of the European Parliament (Health and Environment Committee and plenary sessions) where cross-border health care and information to patients were on the agenda (from 2006 to 2011), 16 conferences/seminars on cross-border health care and 14 on information to patients between 2006 and 2011 (see also Appendix IV). In addition, the researcher had approximately more than 50 bilateral meetings with EU officials (e.g. with members of the cabinet of the EU Commissioners two weeks before the pharmaceutical package was adopted by the College of Commissioners) and stakeholders' representatives on cross-border health care and information to patients. All these meetings provided valuable insights on the main factors that influenced the formulation 
of the legislative proposals and on the typology of evidence used in the policy process.

The participant observation mainly applied to the case studies on information to patients and cross-border health care, while the case study on food information was analysed from a complete observer point of view. The participant observation can be divided into two parts: participant observation as a representative of BEUC till September 2010, and observation as both a representative of an NGO (BEUC) involved in the debate and a researcher on the topic discussed as of September 2010.

This implied that, for many of the observed events, there was no knowledge to be used as data in this research, so few written notes were available. Furthermore, due to professional secrecy, it was not possible to use some of the information gathered by the researcher in her role as complete participant. Despite these limitations, aware of the ethical considerations and also acknowledging that it is difficult to draw the line between research and non-research activities in this context, the insider perspective should be considered as an added value for the research.

\section{Interviews}

Primary data were collected via "elite" interviews with a selected group of people. Between September 2011 and May 2012, 30 semi-structured interviews were conducted on the basis of a questionnaire (see Appendix III). Appendix II provides a list of all the interviewees in an anonymised form, and the date when the interview was conducted. All the interviews were conducted during face-to-face meetings that took place in Brussels, with the exception of two interviews conducted via Skype and one conducted on the phone. Twenty-eight interviews were carried out in English, one in French and one in Italian. The interviews lasted, on average, 55 minutes.

Table 3.1 shows the number of interviews conducted for each case study classified on the basis of the type of actor. All interviewees provided insights on the use of evidence in the formulation of policies at the European level. Sixteen interviewees commented only on one case study, four commented on two case studies and 10 commented on the three case studies as they were involved in all of them. 
Table 3.3.

Number and Type of Interviewees for Each Case Study

Note. Some interviewees commented on more than one case study.

\begin{tabular}{|c|c|c|c|c|c|c|}
\hline & $\begin{array}{l}\text { 줄 } \\
\frac{0}{\vec{b}} \\
\frac{a}{2} \\
\frac{a}{a}\end{array}$ & 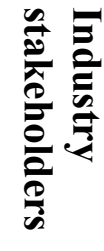 & 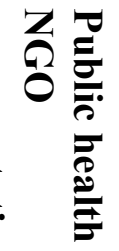 & 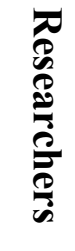 & 离 & $\overrightarrow{0}$ \\
\hline $\begin{array}{l}\text { Typology of } \\
\text { interviewees } \\
-\quad \text { total } \\
\text { number }\end{array}$ & 4 & 11 & 10 & 4 & 1 & 30 \\
\hline
\end{tabular}

Number of interviewees for each case study

\begin{tabular}{|l|c|c|c|c|c|c|}
\hline $\begin{array}{l}\text { Cross-border } \\
\text { health care }\end{array}$ & 8 & $/$ & 4 & 3 & 1 & $\mathbf{1 6}$ \\
\hline $\begin{array}{l}\text { Information } \\
\text { to patients }\end{array}$ & 7 & 1 & 5 & 2 & 1 & $\mathbf{1 6}$ \\
\hline $\begin{array}{l}\text { Food } \\
\text { information } \\
\text { to consumers }\end{array}$ & 9 & 3 & 4 & $/$ & 1 & $\mathbf{1 7}$ \\
\hline
\end{tabular}

Due to the researcher's previous knowledge of the EU health policy community, not applying a snowball technique to identify possible interviewees was initially considered. A first list was drafted on the basis of the following criteria:

a) the interviewees had to be senior representatives of an organisation

b) they had to be directly involved in the EU policy-making process (both from the EU institutions and from the stakeholders affected by the given policy decision) 
c) they had to have an in-depth knowledge of the topic

d) They had to have a sound understanding of the functioning of EU institutions

e) They had to have experience of at least five years in their policy domain

f) They had to be able to respond to the interview questions in English, French or Italian

The sample of interviewees was defined so as to ensure a balanced representation of views as much as possible. However, to reduce the risk of bias in the selection of interviewees, a "snowballing" referral technique was ultimately chosen for use and, at the end of each interview, the interviewee was asked to name two or three people who would be able to provide relevant information for the purpose of the research. None of the interviewees mentioned a name that was not already listed in the group of potential interviewees identified at the beginning.

A written meeting request was sent to the list of selected key informants, which included an explanation of the research aim, the importance of the interviewees' contribution to the research, how the information was going to be used and stored and an informed consent form.

Views of high-level officials in the Commission and those who were directly involved in the drafting of the policy proposals were sought. To gain the perspective of the Council of the EU, a request for interview was sent to 18 of the 27 Member States, ensuring a balanced geographical distribution as well as a balanced distribution between small and big countries. To ensure a balanced representation of political views, one MEP for each of the main political groups in the European Parliament was listed, also taking into account the geographical distribution. Interview requests were sent to the most relevant stakeholders identified on the basis of the interest they expressed in the policy debate, their position papers, the responses they provided to the open consultations and the number of public events they organised or attended linked to the policy proposal. Meetings were arranged with the most senior official (e.g. Secretary General or Director) of the stakeholders' organisations in order to benefit from their experience and knowledge of the policy-making process. To understand the influence of research in this process and vice versa, the researchers who were directly consulted by the European Commission for the chosen case studies were also selected. To grasp the perception of the public opinion with regard to the 
influence of lobbying and of evidence in the EU policy-making process, the views of a leading journalist in Brussels who very closely followed the developments of the selected legislative proposals were also sought. Interview requests were sent to 50 actors and 30 positive feedbacks were collected. The response rate was, therefore, $60 \%$. No one expressly refused the interview. The negative feedback reflects the lack of any answer after three requests. Unfortunately, among those not available for an interview were two Commission officials who drafted the Directive on information to patients and could have provided valuable insights. All of them had left the European Commission when the interviews took place and it was not possible to fix an interview with them. Because of data protection legislation, the European Commission felt unable to provide their new contact details and a Google search did not provide useful results. One was contacted via a LinkedIn message, but no answer was received.

Before conducting the interviews, the interviewees were provided with detailed information regarding the scope and content of the research, their role and the use of the data collected and the researcher's possible conflicts of interest. Full confidentiality was ensured. In order to guarantee anonymity, no detail that could make them identifiable was provided. For example, the indication "health attaché of the Permanent Representation of France" would make it possible to identify the person simply by looking at who was the health attaché of France at the time of the interview. Therefore, only the reference "health attaché" was retained for the public records. All interviewees' identities and research records were kept confidential. As seen from Appendix III, most of the questions covered elements of the theoretical framework. The interviewees were first asked about their organisation's involvement in the case studies to gain a general overview of their role and to get them focused on the main topic of the interview. They were asked which sources of information were used in the formulation of the proposal and what influenced the process. They were also asked if they considered the proposal evidence-based and their views on the impact assessment. To obtain the interviewees' views on the hindering and facilitating factors for the uptake of scientific evidence, they were asked if, on the basis of their experience and knowledge, EU policymakers have adequate resources to inform their choices. The interviews always ended with an open question allowing the interviewee to add any other element they wanted to raise in relation to the research, to ensure that the interview questions also reflected the concerns of the interviewees rather than pursuing only the researcher's perspective. All interviewees were asked the same questions to guarantee impartiality, 
comparability among case studies and systematic analysis. Some follow-up questions or comments aimed at validating the interviewees' statements or attempting to gain deeper insights varied among interviews depending on the interviewees' answers.

All the interviews were recorded and transcribed with the permission of the interviewee. Three interviewees refused permission to record the interview; the information they provided was collected via detailed written notes. The recordings of the interview and the transcripts were treated as confidential and securely stored. The transcripts of the interviews were not sent back to the interviewees to confirm the content because it was considered important to avoid the risk of receiving requests for changes or withdrawal of parts of the interviews linked exclusively to the fact that reading on paper certain own statements might have led some of the interviewees to consider them too strong or not politically correct. This would have had a negative impact on the spontaneity of many statements and relevant quotes which were particularly interesting to capture all the nuances of the phenomenon investigated. In addition, it was not considered appropriate to further disturb the interviewees who had already granted a part of their busy agendas to the interview with a further time-consuming activity, also considering the considerable length of many of the transcripts.

The quotes from the interviews reported in the research were selected based on their salience and when they were particularly useful to substantiate key findings. The selection has also considered the need to ensure a balanced representation of views (e.g. NGO and industry). There have been no cases where the interviewees disagreed on a specific issue. Therefore, there was no need to quote two interviewees to report divergent views on a specific aspect. Many interviewees were not native English speakers, and this influenced the linguistic accuracy of some of the quotes. This required the need to correct some grammar mistakes, such as plural nouns instead of singular or missing articles. Some interviewees did not have a clear memory about the impact assessment and, in most cases admitted they had not read it, so they had difficulty in answering the related question. In those cases where the interviewee did not recall a specific aspect of the legislative proposal, he/she was speaking about, the interviewer did not provide information to facilitate the answer to reduce the possibility of bias in the reply. Regarding unfinished sentences or missing words, the quotes reported have been adapted as little as possible and only to the extent of making them understandable by the reader. Additions of missing words or deletions of words (e.g. noises, intermissions 
etc.) have been made only in those cases where they could compromise the understanding of the sentence and they are clearly indicated.

\subsection{Methods for Analysis}

\section{Literature study}

Regarding the analysis of the literature on evidence in the policymaking process, a preliminary screening of the studies retrieved via the Maastricht University databases and the Google search was made on the basis of the titles and abstracts.

The full texts were obtained, and their relevance was assessed through an analysis of the main characteristics of the study - including the policy area (health), geographical focus, research methods and data sources - and of the findings against the research questions.

More specifically, with regard to the literature on evidence in the EU policy-making process, to decide on the relevance and inclusion, it was considered:

Whether the study offered definitions of the concept of evidence and of evidence-based policymaking

- Whether the study provided insights on the role of evidence in public health policies

- Whether the study included researchers' and policymakers' perceptions of the use of evidence in policymaking

- Whether the study analysed features of the European policymaking process, including lobbying and impact assessment journals.

Most of the studies were published in health and public policy

This method was applied consistently for the three literature studies focused on evidence in the policy-making process.

With regard to the literature on theories of the policy process, a similar methodological approach was followed. Studies were considered relevant if they offered concepts and a framework of analysis to assess the role of evidence in policymaking and to operationalise.

The methods for analysis were also the same with regard to the literature on the case studies. The studies considered relevant were classified into three categories, corresponding to each case study. 


\section{Participant observation}

With regard to the analysis of the data collected through participant observation, as indicated above, for many of the events observed there were few written notes available, because at the time the participant was not yet a researcher and was unaware that they were going to be used as data in this research. The analysis effort focused on the recollection of what occurred during the events and the main elements that emerged from the discussion in relation to the topic investigated. This enriched the accuracy of the description of the policy-making process and gave valuable insight into the debates surrounding each case study.

\section{Public records and grey literature}

Official documents of the EU institutions, grey literature such as unpublished reports and public records were analysed, classifying the information into two main themes: the first was all information necessary to trace the formulation of the legislative proposal, which was recorded in a timeline to map key developments. The second was references to the typology of evidence outlined in the theoretical framework.

\section{Interviews}

The data collected from the interviews were analysed using a so-called "framework analysis" (Ritchie \& Lewis, 2003; Smith \& Firth, 2011), relying on the theoretical framework outlined in chapter 2.

The framework analysis was developed by Ritchie and Spencer from the UK National Center for Social Research in the late 1980s, to be used in large-scale social policy research. It is increasingly used in health and medical research to generate policy-orientated findings and involves summarising and classifying data within a thematic framework, preserving the integrity of individual respondents' accounts (Gale et al., 2013). The framework analysis has been chosen because it is the most suitable tool to generate themes for comparative case studies and is mostly used to analyse semi-structured interview transcripts, one of the main sources of this research. It was also considered suitable because the data to be analysed covered very similar topics that made categorisation into common themes possible.

The first step in the analysis of the interviews was verbatim transcription of all the recorded interviews. The second step was familiarisation with the data, reading documentary material (minutes of 
meetings, responses to the public consultations, impact assessment, etc.), listening to the tapes and re-reading transcripts until familiar with them in their entirety. A coding scheme and indexing data was then developed, including not only the interviews transcripts but also the observational notes. For this purpose, the use of a program for qualitative research such as In Vivo or Atlas was considered but, after an assessment of the pros and cons associated with the use of such tools, a traditional manual coding was chosen. The codes were pre-selected with a deductive approach on the basis of the research questions and the classification of evidence offered by Bowen and Zwi (2005). The main codes used were therefore evidence, impact assessment, public consultations, stakeholders, research, information and knowledge, interests and ideas, politics and economics. The data were rearranged according to the thematic content by developing charts, which were used to compare across each code, look at the relationship between codes and understand where certain phenomena occurred or did not occur. The final step was mapping and interpreting the data.

\subsection{Reliability and Validity}

The concepts of reliability and validity are rooted in the positivist tradition. They have been challenged by many scholars, especially when applied to qualitative research. For example, reliability refers to the stability of findings (Altheide \& Johnson, 1994; Whittemore et al.2001) and indicates whether they are replicable. While some, like Stenbaka (2001), argue that reliability is irrelevant, and even misleading, for qualitative research, others like Seale (1999) and Flick (2006) interpret reliability as trustworthiness and consistency of results reached via different methods. Validity usually represents the truthfulness and accuracy of findings. A distinction should be made between internal validity, i.e., are the conclusions of the study justified and, external validity, i.e., are the results of the research suitable for generalisation.

Lincoln and Guba (1985) state that "Since there can be no validity without reliability, a demonstration of the former (validity) is sufficient to establish the latter (reliability)" (p. 316). They assess validity through credibility. According to Seale $(2004$, p. 77$)$, credibility is accessed via reflexivity and triangulation. To ensure reliability and validity and capture different dimensions of the same phenomenon, a variety of methods to collect data (triangulation) have been used. In particular, the information gathered through documents, interviews and observations has been triangulated to present a credible account on the role of knowledge in the formulation of 
European public health policies. A thorough and critical assessment of the key variables identified in the theoretical framework was also provided. Close attention was paid to the consistency of the information collected during the interviews and doubled with other written documents, for example, the response of the interviewee's organisation to the European Commission public consultation on the legislative proposal discussed during the interview. Interviews were conducted with the same approach, using the same questions. Overall, the amount of data collected, their thorough analysis and the clear explanation of all the processes guarantee the internal validity of the research.

Qualitative research is often criticised for the lack of capacity to be generalised and the subjective interpretation of the researcher (external validity), but qualitative inquiry is concerned with unreliable or unjustified findings as much as quantitative inquiry (Maxwell \& Delaney, 2004). In the opinion of George and Bennett (2004), "case studies allow a researcher to achieve high level of conceptual validity or to identify and measure the indicators that best represent the theoretical concepts the researcher intends to measure" (George \& Bennet, 2004, p. 19). Moreover, Yin (1994) describes the usefulness of case studies as a research method, but also points to the downsides, namely the "(...) lack of rigor" and the fact that they "provide little basis for generalization" (Yin, 1994, p. 9-10). These criticisms have been addressed by providing a detailed description of the methodology used to collect and analyse the research data, by reporting all the collected evidence and specifying that the findings were generalised to the theoretical concepts and not to all policy-making processes.

\subsection{Reflexivity, Positionality and Bias}

Reflexivity involves both critical thinking about the research experience and process and considerations on the role of the researcher in generating and analysing data. It means a self-scrutiny of the researcher and a conscious awareness of the relationship between the researcher and the observed phenomena (Pillow, 2003).

The position of the researcher influences all research, both qualitative and quantitative, including laboratory research. "A researcher's background and position will affect what they choose to investigate, the angle of investigation, the methods judged most adequate for this purpose, the findings considered most appropriate, and the framing and communication of conclusions" (Malterud, 2001, p. 483-484). In qualitative research, it is accepted that values are inevitably part of the research process and it is impossible for the researcher to stand outside those values and subjectivities. 
To overcome this, the principle of reflexivity was adopted throughout the research, meaning that the research itself was subject to the same critical analysis deployed when studying the research topic. This also meant reflecting on the research itself and on why certain questions were legitimate; the broader political and social context of the research was taken into account. Due attention was also paid to the fact that the researcher and her professional relationship with the interviewees could inevitably shape the kind of data generated and the dynamics between the interviewer and the interviewee. Most of the interviewees were very open and friendly while a few, especially representatives of the Member States' Permanent Representations in Brussels, were more rushed and less willing to speak. It was also considered that some interviewees could have made assumptions about the professional position of the researcher while doing the field work. Most researchers find it useful to approach the interviewee as neophyte in the field in order to get a more open and comprehensive feedback. This could not apply to this study because, as a professional working in a familiar setting, the interviewee related to the interviewer as an "expert". While it was considered that the answers to the interviews were conditioned by this factor, the special kind of relationship between researcher and interviewee allowed the interview to delve more in depth and generate a more specific and meaningful discussion on the issues relevant for the study.

When asked about this special kind of relationship, many interviewees said that they could not afford to make general statements because of the interviewer's expertise. All said the previous professional relationship with the interviewer did not influence the content of the answers they provided.

Roger Homan (1991) advocates that social research needs to develop what he calls a "professional morality around quality control and a commitment to truth and knowledge" (p. 183). This call was endorsed when conducting the research but, at the same time, it was considered that the role of the researcher is to improve society and that - while maintaining the highest standard of scientific rigor — people are partisan in their work, striving to redress inequalities and increasing social justice and public health protection through the research. Being partisan does not imply choosing one side but asking how we can contribute for the benefit of society, as suggested by David Silverman (1998).

According to Malterud (2001, p. 484) "preconceptions are not the same as bias, unless the researcher fails to mention them". The researcher admits her preconception towards the formulation of EU public health 
policies as being influenced by her position at the European Consumer Organisation (BEUC). In this sense, the results of the research are influenced by the research position. Conversely, the researcher was an insider in the formulation of the proposals of the three case studies and this provided her with a privileged observational perspective.

\subsection{Conclusion}

This chapter described the methodological approach at the basis of the research. The main sources of information and data have been a study of the literature on evidence-based policies, EU health policies, impact assessment, EU policy-making process and knowledge utilisation, official and unofficial written documents from the European institutions, media, stakeholders, interviews with key informants and direct observation courtesy of the researcher's privileged position of insider in the Brussels lobbying scene.

The chapter also outlined how the internal and external validity of the research results have been ensured as well as some reflections regarding positionality and bias in conducting the research. The next three chapters are dedicated to presenting the findings on the three case studies. Each chapter deals with a separate case. 



\section{Chapter 4: Role of Evidence in the Formulation of the Directive on the Application of Patients' Rights in Cross-Border Health Care}

\subsection{Introduction}

In July 2008, the European Commission adopted the proposal for a Directive (hereafter referred to as the Proposal or the Directive) on the application of patients' rights in cross-border health care. The Proposal sought to establish a clear legal framework with regard to the rights and the obligations of those seeking health care in another EU country and foster cooperation among Member States in areas such as eHealth and health technology assessment. The right to seek health care abroad was first established in 1971 with Regulation 1408/71, which was amended in 2004 (Reg.883/2004). Regulation 1408/71 covered only those temporarily staying abroad and those who sought prior authorisation for treatment in another EU Member State from their insurer. Over the years, the European Court of Justice (hereafter Court or the ECJ, now known as Court of Justice of the European Union) expanded these rights on the basis of Internal Market principles - Article 114 of the Treaty ${ }^{7}$ - but at the same time it led to the development of a few grey areas of legal uncertainty. The Directive aimed at bringing legal clarity and covering areas unaddressed by Regulation 1408/71. The Directive applies to all health care provisions that patients are entitled to at home, regardless of how they are organised, financed and delivered (Legido-Quigley et al., 2011).

This chapter is structured into four main sections. Section 1 describes the policy idea and the context in which the legislative Proposal was formulated (paragraph 4.2). Section 2 analyses the kind of evidence sought by the European Commission (paragraph 4.3), and section 3 presents how the evidence was used (paragraph 4.4). Section 4 explores the hindering and facilitating factors for the uptake of the evidence (paragraph 4.5). This chapter ends with a brief summary of the key findings of the analysis and the answers to the research questions (paragraph 4.6).

\subsection{Context and Policy Idea: Cross-Border Health Care on the EU Agenda}

This section covers what can be considered the difficult birth of the Directive, from the time cross-border health care started being discussed at the EU level to the adoption of the Proposal on the application of patients'

\footnotetext{
77 The word "Treaty" refers to the Lisbon Treaty (TFEU). All Articles of the Treaty referred to in the thesis are those of the Lisbon Treaty.
} 
rights in cross-border health care. Table 4.1 summarises the key developments, while the following paragraphs provide a detailed description of the policymaking process in chronological order.

Table 4.1

Timeline of Cross-Border Health Care on the EU Agenda

\begin{tabular}{|c|l|}
\hline Year & Key developments \\
\hline $\begin{array}{c}1971- \\
1972\end{array}$ & $\begin{array}{l}\text { Council regulations } 1408 / 71 \text { and 574/72 on the coordination } \\
\text { of social security systems }\end{array}$ \\
\hline $1978-$ & ECJ rulings on patient mobility \\
\hline 2010 & \\
\hline 2003 & $\begin{array}{l}\text { High-level process of reflection on patient mobility and } \\
\text { health care developments in the EU }\end{array}$ \\
\hline 2004 & High-level group on health services and medical care \\
\hline 2006 & $\begin{array}{l}\text { Removal of health services from the directive on services in } \\
\text { the internal market }\end{array}$ \\
\hline 2006 & $\begin{array}{l}\text { Council conclusions on common values and principles in } \\
\text { EU health systems }\end{array}$ \\
\hline $2006-$ & $\begin{array}{l}\text { Public consultation on the community action on health } \\
\text { services }\end{array}$ \\
\hline 2007 & $\begin{array}{l}\text { European Commission proposal for a directive on the } \\
\text { application of patients' rights in cross-border health care }\end{array}$ \\
\hline 2009 & European Parliament's first reading \\
\hline May & $\begin{array}{l}\text { Implementation of the revised social security coordination } \\
\text { framework (EC regulation 883/2004[12] and regulation }\end{array}$ \\
\hline 2010 & $987 / 2009)$ \\
\hline Jun 2010 & Council of EU ministers reaches a common position \\
\hline Nov & European Parliament's report, second reading \\
\hline Dec & Informal trialogue negotiations to reach a final joint text \\
\hline Jan 2010 & European Parliament plenary sitting, second reading \\
\hline 2011 & Entry into force \\
\hline Oct 2013 & Implementation in the Member States \\
\hline
\end{tabular}

\subsubsection{Triggering role of ECJ rulings}

From the documents of the EU institutions, the interviews (see Appendix II) and the literature review (Belcher, 2001; Palm \& Nickless, 2001; Sedgley, 
2001; Paulus et al., 2002; Bertinato et al., 2005;Rosenmöller et al., 2006; Obermaier, 2009; Wasserfallen, 2010), it emerged that the series of rulings of the ECJ on cross-border health care were the main trigger of the whole EU debate on patient mobility and the Directive.

After the initial "attempt of most Member States to try to ignore the Court rulings" (\#13, Researcher on Cross-Border Health Care), the Council of the EU recognised in its Conclusions on Common Values and Principles in European Union Health Systems "that recent judgments in the European Court of Justice have highlighted the need to clarify the interaction between the Treaty provisions, particularly on the free movement of services" (Council of the EU, 2006, p. 2). Also, in the Commission communication on a community action on health services, the impact assessment and the explanatory memorandum of the Directive, the rulings of the Court and the principles it established were acknowledged as the crucial elements to justify a community action in this area and identified as a starting point.

The European Parliament considered the understanding of the ECJ rulings as the first necessary step to start the debate on cross-border health care, and, in 2007, the Internal Market and Consumer Protection Committee (IMCO) commissioned a briefing note on the ECJ case law on cross-border aspects of health services to Prof. Hatzopoulos Vassilis from the University of Thrace (Greece) and the College of Europe.

Following the Kohll and Decker cases in 1998, a consistent body of case laws had accumulated over the years and changed the landscape of health policy at the European level. The various Court cases (see Appendix V) built a framework that constituted well-defined boundaries for the action of policymakers within the European institutions. The interviewees defined the ECJ as "the starter", "the engine", "the catalyst" (\#4, Senior Policy Officer, Public Health NGO), "the thing that lighted the fuse" of the whole debate. All highlighted that the Court had done "policymaking by default" and that policymakers "were always playing catching up" (\#6, Researcher on CrossBorder Health Care). Two of the interviewees, both health attachés (\#22; \#27), also argued that hadn't the Court touched upon this issue, there would never have been the Directive because the problem could have been easily solved by soft measures and bilateral contracts between Member States.

Hervey (2004), Steffen (2005), Greer (2006) and Brooks (2012) have highlighted the significant role of the Court in shaping EU health policies. Cross-border health care is considered as an illustrative example of the influence of the ECJ in health policymaking at the European level. Greer 
(2006) stated that patient mobility is a "dramatic case of neo-functional spill over dynamics" (p.142), driven by the Court and causing an interference in the EU in the health sector which was certainly not welcomed by the Member States. Wismar (2001) argued that the ECJ was in the driving seat, and Greer (2006) added that it acted in its traditional role of "supranational promoter of integration" (p.135). Despite the resistance from Member States, the Directive emerged to be the only tool to reduce the influence of the Court and avoid having a non-elected body deciding on such sensitive issues without any political guidance. In any case, the Court was given the time and the opportunity to define the core principles and guidelines on the topic and the framework within which the legislators had to draft the Directive. In the opinion of Mossialos et al. (2010) this "...means in essence that an unelected and unrepresentative body is in large part constraining the context in which decisions may be taken on social policy matters in relation to Member States health systems" (p. 16). Since the Pierik rulings in 1978 (see Appendix V), the Court has played an important role in clarifying the rights of patients to seek health care outside their own country. It clearly established that health services fall within the internal market rules (Articles 26 and 27 of the TFEU). In doing so, the Court rulings substantially limited the scope of Member States to refuse health coverage outside their territory, unless overriding reasons of general interests were present and it was proven that the limitations were proportionate, non-discriminatory and necessary. The Court indicated that the principles of free movement of goods and services also apply to health care, regardless of whether it is provided inside or outside a hospital setting. Moreover, according to the Court (e.g., Muller Fauré and Watts Cases), the right to reimbursement cannot be restricted on the basis of the nature of the reimbursement mechanism (e.g., benefits in kind, national health care system). All these principles have been faithfully reflected in the legislative text.

\subsubsection{Health care and patient mobility in the EU political agenda}

Beyond the ECJ rulings described above that pertain to the individual cases of European citizens receiving health care abroad, it is worth nothing that health care, as a general issue, has been trying to find its way in the EU agenda for almost three decades. According to Hervey and Vanhercke (2010), the first milestone in placing health care in the European Agenda was the Community Charter of Fundamental Social Rights of Workers of 1989 followed by the Council Recommendation on the convergence of social protection objectives and policies encouraging Member States to develop a high-quality health care system (1992). This early Council recommendation 
was followed by a series of Commission communications on social protection including health care. However, as mentioned above, the ECJ rulings were the engine of the debate on patient mobility, the role of the EU on health policy and the subsidiarity principle.

Confronted with the interference of the Court and concerned with its approach, the Member States tried to bring the debate back to the political level, but the Commission immediately took the lead and reacted with a variety of instruments (Greer, 2008). The Commission's first step was the creation of the European Commission Directorate-General for Health and Consumer (hereafter DG SANCO, now re-named DG SANTE) involving a high-level committee on health that received from the Nice Council of the EU the mandate to "examine, on the basis of studies undertaken by the Commission, the evolution of the situation with regard to cross-border access to quality health care and health products" (Presidency Conclusions, 2001). The Laken Council supported the continuation of the debate and asked for special attention "to be given to the impact of European Integration on Member States' health care systems" (Belgian Presidency Conclusions, 2001). In 2002, for the first time, the Health Council endorsed the "Conclusions on patient mobility and health care in the internal market" and invited the Commission to launch a high-level process of reflection on patient mobility and health care developments in the EU, which started working at the beginning of 2003. The high-level process involved representatives of all Member States. By the end of 2003, a series of 19 recommendations were adopted (HLPR/2003/16) on how to improve the quality of care, the sharing of information and cooperation and how to use resources more effectively. In particular, one of the recommendations to the Commission was to explore the ways to improve legal certainty following the ECJ jurisprudence. Another recommendation was to consider the "development of a permanent mechanism at EU level to support European cooperation in the field of health care and to monitor the impact of the EU on health systems". According to one of the interviewees (\# 13, Researcher on Cross-Border Health Care), "there was lot of good will, but with the reflection process Member States were simply trying to work their way around the real 'hot potato' by saying they would start to collaborate more". In 2004, the high-level group (HLG) on health services and medical care was established. In parallel, in July 2003, DG Market produced a report on the application of the internal market rules on health services pointing out that the internal market was not functioning well in the health care services sector. In 2004, in the draft Directive, it 
included health services in the services in the internal market (the so-called Bolkestein Directive).

The Directive generated outrage and overwhelming opposition among EU health groups, including NGOs, health care professional organisations, among others. It was rejected by the European Parliament and the Council that considered that it didn't adequately take into account the special nature of health services, their technical complexity and their political sensitivity (Greer \& Vanhercke, 2010). However, the demand for legal clarity and the need to avoid the Court making law remained. In April 2005, the European Parliament adopted a report on patient mobility and health care developments in the EU, followed, in June 2006, by the adoption of the Conclusions on common values and principles underpinning the EU health systems by the Council. In the Conclusions, the health ministers invited the Commission to ensure that the common values and principles contained in the statement were respected when drafting specific proposals concerning health services. Moreover, the Council asked for a broad framework encompassing patient mobility and looking at the issue from a broader perspective.

The above paragraph provided an idea about the political sensitivities concerning the discussion of health care related issues at the EU level. The following two paragraphs explain the further steps between the political discussion and the presentation of an actual piece of EU legislation regulating cross-border health care.

\subsubsection{A difficult birth}

After the failure of the Bolkestein Directive, DG SANCO was the last resort to address the issue of cross-border health care at the EU level. It succeeded precisely because it endorsed the need to adopt an approach broader than that indicated by the ECJ by not only including legal aspects but also considering the quality and the safety of health services. In view of drafting a legislative proposal, DG SANCO published a communication on the community action on health care, which was submitted for public consultation from September 2006 to January 2007. The consultation generated a considerable interest and gathered 280 responses from various stakeholders who confirmed the need for a broader approach. In the meantime, the Commission staff used all possible occasions to present the Commission's approach and gain consensus among stakeholders and Member States' representatives (Greer \& Vanhercke, 2010; participant observation). 
As for all legislative proposals, the first draft from DG SANCO was discussed in the so-called inter-service consultation - an internal procedure involving the different Commission departments to ensure that all the aspects of the matter in question were taken into account. At the beginning of 2007, DG SANCO started an interservice consultation with the representatives of many other Directorates-General, namely Competition, Employment, Enterprise, Justice, Market, Research, Regional policy, Trade, the Secretariat General of the Commission and the Bureau of European Policy Advisers (BEPA). The inter-service group met several times before the adoption of the proposal to identify the implications of the Directive on other EU policies and laws and also discussed the impact assessment and outcome of the public consultation. A Commission official involved in the inter-service consultation revealed that the discussion was very difficult and DG SANCO had to put forth a considerable number of arguments to defend its position. At the higher level as well, many Commissioners expressed reservations, and the adoption in the College took a very long time. In particular, Commissioner Walström, publicly said that "more thought and reflection need to be put into the proposal, in particular the reimbursement system, and its consequences" (Euractiv, 2008), despite the fact that her own country, Sweden, was one of the few Member States at that time to support the Commission's plans. Although the proposal was supposed to be presented in December 2007, owing to the political disagreement within the College of Commissioners, it was kept on hold. For some months, it was believed that it would never come out. Considering the complexity of the issue and the political sensitivity surrounding the EU that was concluding the negotiations for the ratification of the Lisbon Treaty, the Commission decided to delay the adoption and asked DG SANCO to re-draft the text. It was also considered to take out the most controversial aspects and present a simple Commission communication but at the end this option was not pursued (participant observation).

In the meantime, to put pressure on the Commission, in March 2007, the European Parliament adopted a resolution on community action on the provision of cross-border health care and in May 2007 a report on the impact and the consequences of the exclusion of health services from the Directive on the services in the internal market. Having a new Commissioner in charge, Ms. Androulla Vassiliou, and a change in the title of the proposal putting more emphasis on the aspect of "patients' rights" helped move things forwards. After repeated delays, the Proposal was finally adopted by the Commission on 2 July 2008 as part of the Renewed Social Agenda with the title "Directive on the Application of Patients' Rights in Cross-Border Health Care". The 
rephrasing of the title was rather superficial and considered by some as a marketing move, but it changed the destiny of the Directive (participant observation).

\subsubsection{Commission's proposal}

The stated objective of the Proposal was to establish a clear legal framework for cross-border health care within the EU. In particular, the Directive aimed at clarifying patients' rights to seek health care in another Member State and the terms of the reimbursement of the costs of cross-border care by their national health care systems. In addition, it aimed to ensure that European patients have access to safe and high-quality health care and enhance the cooperation among Member States.

According to the Proposal, EU citizens should have the right to seek non-hospital care such as medical consultations or dental care in another Member State without prior authorisation. For hospital and specialised care, i.e., treatments requiring at least one-night stay in the hospital or the use of expensive technologies, the Member States could put in place a system of prior authorisation to manage the outflow of patients and prevent the financial sustainability and planning of the system from being seriously undermined. In both cases, patients were entitled to be reimbursed only for treatments covered by their social security system and only up to the level of reimbursement they would have been entitled to if the care had been provided in their own country. In line with the Muller-Fauré, Watts and other ECJ rulings, the Directive would have applied to all types of health care, regardless of how they were financed, organised and delivered. The Directive also introduced the establishment of national contact points with the task of providing patients all the necessary information concerning the rights of and procedures for cross-border health care. Regarding the cooperation between Member States, the Directive introduced the principle of mutual recognition of prescriptions and established European reference networks of health providers. Finally, the text envisaged enhanced cooperation on e-health and on health technology assessment (HTA) (Legido-Quigley et al., 2011).

\subsubsection{Inter-institutional negotiations}

If the adoption of the Proposal by the European Commission was difficult, the path that the Directive followed afterwards before becoming an EU law was certainly not easier and free of obstacles. This paragraph details all the steps undertaken by the legislative proposal in the context of the so- 
called co-decision procedure (see also Chapter 3) looking both at the European Parliament and at the Council of the EU.

\section{First reading in the European Parliament}

The European Parliament committee responsible for the dossier was the Environment, Public Health and Food Safety Committee (hereafter ENVI). Other committees such as the one for internal market and consumer protection (IMCO) only delivered an opinion. John Bowis (EPP, UK) was the appointed rapporteur. The Committee voted on its 800 amendments in the first reading in March 2009. In a surprise turn at the final vote on the amended report, the shadow rapporteur, Member of European Parliament (MEP) Dagmar Roth-Behrendt (S\&D, Germany), called for a five-minute recess. After the recess, the Socialist group announced that it would have to abstain from the final vote. This decision was mainly due to the fact that the Committee didn't approve the amendment to add Article 152 (now 168) as a double legal basis. The same happened during the plenary vote, where once again the rejection of the amendments to change the legal basis was the reason for the Socialist group abstaining. The final report was adopted with 297 votes in favour, 120 against and 152 abstentions. In this regard, interviewee \#21 (EU Coordinator, Public Health NGO) said that in the European Parliament "decisions were being made amongst the big political groups (EPP and $S \& D)$ " and "the debate was around the right of the individual vs the public interest, so from completely different angles".

\section{The policy broker role of the Commission}

During the political debate about the Directive, the Commission never hid its dissatisfaction pertaining to the approach of the Council, not only with regard to the disputes on the legal basis and the principle of subsidiarity, but also for its attempt to remove any mention of quality and safety standards and restrict free movement by reinforcing the principle of prior authorisation (participant observation). The Commission engaged in bilateral discussions with the Member States, attempting to address the most controversial issues and overcome their resistance. In its attempts, it always stood by its original position and supported the Directive in its entirety. As foreseen by the Treaty, it issued a communication to the European Parliament concerning the Council's position at the first reading. To allow the legislative process to move forward, the Commission decided not to stand against the Council's position but stated that the Council's text contained elements that could create risks of legal uncertainty and reserved the right to support the Parliament amendments with regard to e-health and the scope of the prior authorisation. 


\section{Negotiations in the Council: Breaking the deadlock}

The Council started an in-depth analysis of the Proposal in autumn 2008 but made little progress, as health ministers raised fundamental issues such as the principle of subsidiarity. The Proposal was considered to interfere with the competencies of the Member States in organising and delivering health care as defined in Article 168 of the Treaty. Moreover, Member States were reluctant because of the possible consequences for health care budgets and waiting lists. In addition, the scope of the Proposal generated considerable discussions on long-term care and organ donation. The Council was also concerned about the extensive role given to comitology and the European Commission.

The French Presidency of the EU presented the first Council Progress Report and amended the text at the Health Council (EPSCO) meeting in December 2008. The amended working document removed much of the provisions on quality and safety standards and stated that all patients seeking health care abroad had to receive prior authorisation. The Czech and the Swedish EU Presidencies tried to reach an agreement during 2009, but this attempt did not yield results because the majority of the delegations were still strongly opposed to the Proposal. At the end of the Council meeting in December 2009, the former Health Commissioner, Androulla Vassiliou, declared that the Commission was going to consider the possibility of withdrawing the Proposal. The new Commissioner for health and consumers, John Dalli, during his hearing in front of the European Parliament on 14 January 2010, confirmed the Commission's intention to pursue the adoption of the Proposal and said he was going to personally engage in negotiations with the Spanish Government, which had just taken over the Presidency of the EU and was also one of the Member States with the most reservations on the text. After two years of negotiations, the health ministers reached a political agreement during the Council in June 2010 under the Spanish Presidency. The agreed text addressed issues regarding reimbursement and provided the Directive with a double legal base in Articles 168 and 114. In June 2010, the UK and Germany circulated an additional proposal to change the provisions concerning e-health.

The text was widely approved, with strong opposition only from Poland, which issued an alternative text for approval, and Portugal. Romania chose to abstain after the failure of the Polish text. Sweden, Slovakia, Ireland, Lithuania, France, Austria, Slovenia, Cyprus, Finland, Hungary, Malta, The Netherlands, Bulgaria and Denmark supported the text. Italy attacked the 
amendment tabled by the UK and Germany, claiming it served only to "water down" the proposal and weaken its impact. Luxembourg and Estonia expressed their concerns regarding the link between the Directive and social security systems. Latvia supported the compromise but noted that the provisions on prior authorisation could create a disproportionate administrative burden for Member States. Emphasising the "public" nature of health services, Greece highlighted the danger of turning health care into a consumer product ruled by market forces. Poland didn't support the text because, in their view, it didn't go far enough to guarantee equality of access to health care. According to the Portuguese government, its concerns regarding non-contractual private providers had not been met, so it didn't support the agreement and submitted a separate written declaration to the Council.

The Council's position, officially adopted in September 2010, didn't take into account most of the amendments proposed by the European Parliament and introduced significant changes. In particular, it excluded longterm care from the scope of the Directive, extended the scope for prior authorisation and reduced the Commission's power to implement measures. Furthermore, the Council added Article 168 on public health as a legal basis - originally the Proposal was based only on Article 114 on the internal market. In its position, the Council also agreed that in case of overriding reasons of general interest such as the risk of seriously undermining the financial balance of a social security system, a Member Stateof affiliation may limit the application of the rules on the reimbursement of the costs for cross-border health care. In addition, Member States were also allowed to manage the outgoing flow of patients by requiring prior authorisation for health care that requires overnight hospital accommodation, the use of highly specialised and cost-intensive medical infrastructure or raises concerns with regard to the quality or safety of the care or the application of the "gatekeeping principle". Finally, the sales of medicinal products and medical devices via the Internet and the access and allocation of organs for the purpose of transplantation were excluded from the scope of the Directive.

\section{Trialogue, second reading agreement and next steps}

After the Council had officially adopted its common position in September 2010, the Parliament started its second reading. MEP Françoise Grossetête (EPP, France) was nominated as the rapporteur. The European Parliament had another debate on the issue in October 2010, and the ENVI committee adopted its draft recommendation for the second reading 
amending the Council's position. Given that the Council didn't take into account the amendments proposed by the Parliament, the recommendations for the second reading aimed at re-introducing more patient friendly amendments. After the ENVI vote in the second reading in October 2010, the institutions started the so-called "trialogue" procedure to reach an agreement and conciliation. The most controversial issues were rare diseases, e-health, the definition of quality and safety standards and prior authorisation (LegidoQuigley et al., 2011). In her draft recommendation, the European Parliament rapporteur MEP Grossetête requested the exemption for rare diseases, considering that patients affected by rare diseases should be entitled to seek health care abroad (including medicines) without any form of prior authorisation and be reimbursed even if the treatment in question was not in the benefit basket of a Member State of affiliation. These demands were reconsidered during the vote in the Environment and Health Committee, but they still faced the opposition of the Council. On e-health, the Council diluted the provision regarding the measures to promote interoperability ${ }^{8}$, which was not well-received by the other two institutions. The Commission and the Parliament wanted to impose on the Member States the obligation to define clear quality and safety standards, while the Council opposed this and proposed as a compromise some provisions that might put pressure on the Member States to adopt such standards, including the possibility for a Member Stateto refuse prior authorisation in case of serious and concrete concerns about the quality standards of a health care provider in another member state. The Council also introduced a non-exhaustive list of criteria for refusing prior authorisation, which according to the European Parliament and the Commission created legal uncertainty. All involved parties were aware that if no consensus was reached in the trialogue, it could eventually result in a non-agreement, compromising the future of the entire Proposal. Even though the rapporteur considered the agreement insufficient, she was of the opinion that it should be considered as a first step and having something even if not perfect was better than nothing at all (participant observation). Owing to the flexibility of the rapporteur and the change in the position of the Spanish Government, which was in the blocking minority (\#6, Researcher on Cross-Border Health Care; \#9, Director General, Public Health NGO), in December, the three institutions finally reached an agreement. While the spirit and general structure of the Proposal were maintained, the Council didn't concede much especially on those provisions that were likely to have a major impact on the national health care budget and the Member States'

\footnotetext{
${ }^{8}$ The ability of a system or product to work with other systems or products
} 
responsibility to define the health care basket. The agreement was confirmed by COREPER - the Committee of the Permanent Representatives of the Member States to the EU - in December. The Parliament voted in plenary in January 2011. The Council adopted the final text on February 28, 2011. The Directive came into force in March 2011, but the Member States could transpose the new provisions in the national legislation until 25 October 2013. A dedicated committee composed of the representatives of the Member States and the Commission was set up to facilitate the implementation.

\subsection{Sourcing Evidence}

The previous section described the political context in which the Proposal was drafted, its rationale and its evolution during the policymaking process. This section examines what constituted the evidence base for the European Commission when drafting the proposal, how and which kind of evidence was actively sought by the European Commission and how and which kind of evidence was brought by the stakeholders into the policymaking process. Table 4.2 provides an introductory summary by also indicating when each type of evidence was sought during the process.

Table 4.2

Type of Evidence and the Period It Was Sought

\begin{tabular}{|l|l|}
\hline Period & Type of evidence \\
\hline 2004-2007 & $\begin{array}{l}\text { Six EU-funded projects: Europe4patients, MARQuIS, } \\
\text { Health Basket, SIMPATIE, Euregio, Health Access }\end{array}$ \\
\hline Sep 2006 & $\begin{array}{l}\text { Public consultation on a community action in the field of } \\
\text { health }\end{array}$ \\
\hline May 2007 & Eurobarometer survey on cross-border health care \\
\hline Jul 2007 & $\begin{array}{l}\text { European Observatory expert analysis on cross-border } \\
\text { health care in the EU supporting the impact assessment }\end{array}$ \\
\hline 2004-2008 & Conferences, workshops, seminars (see Appendix IV) \\
\hline
\end{tabular}

\subsubsection{Research}

According to the Bowen and Zwi model (2005), research includes trials, analytic studies, such as cohort studies, time series analysis, observations and case reports, qualitative and before and after studies. The type of research sourced by the European Commission in preparation of the legislative Proposal was very specific and included EU-funded projects and an external study to support the impact assessment. 


\section{EU-funded projects on cross-border health care}

According to Backlund (2009), the allocation of research funding is one of the ways to show that an issue represents a political priority and increase the knowledge on a certain topic. Following the ECJ rulings and in view of the preparation of an EU Action in the field of health, the Commission funded a series of research projects to collect evidence and generate knowledge around the topic of cross-border health care and health systems. Three of them were funded by DG Research under the 6th Framework Programme and in particular under the component Scientific Support to Policies (SSP), which was launched to serve the policymaking process "through targeted research which must respond to the specific needs identified by policy-makers" (European Commission, 2002). The stated aims of SSP were improving the quality of policy decisions, speeding up the decision-making process, providing a rapid response mechanism to urgent political needs and promoting the participation of researchers in the policy debate. The projects funded were Health BASKET, Europe for Patients and MARQuIS. The objective of Health BASKET was to describe how different countries define the services provided within their system by analysing the health-benefit baskets of nine European countries. The Europe for Patients project investigated the benefits and challenges of patient mobility using a case-study methodology. The MARQuIS project looked at the quality of care including that of hospitals contracting care for patients seeking health care abroad. An interviewee (\#2, Secretary General, Public Health NGO) involved in the project revealed that the original project was not intended to address cross-border issues and was adapted to fit with the Commission's agenda and get funding. The interviewee stated that the Commission "manipulated the results by bias of selection of the information to be used in the impact assessment and pushed researchers to give a political angle to the project" by requiring the inclusion of policy recommendations and "obliging researchers to cross the line and produce something that exceeded their competencies". Another interviewee pointed out the fact that "the Commission plays a game with research projects in order to meet its political needs and researchers accept in order to get funded other projects in the future" (\#5, Researcher on Cross-Border Health Care).

Three other projects that ran from 2004 to 2007 were funded by DG SANCO under the Public Health Work Programme. In particular, the SIMPATIE project aimed at establishing a common set of definitions and indicators for improving patient safety, while the EUREGIO and the Health Access projects analysed cross-border bilateral arrangements. Each project 
involved leading academic experts from reputable universities and key stakeholders (e.g., regional governments, hospital managers associations, among others). For example, the partners of the project Europe for Patients were the Spanish Business School IESE, which was the coordinator of the project, the London School of Hygiene and Tropical Medicine, the London School of Economics, the Belgian Observatoire Social Européen, the Faculty of Law Ghent University, the Irish Centre for Cross-border Studies, the Slovenian Institute of Public Health, the Estonian research Institute, the WHO European Observatory on Health Care Systems, the International Association of Mutual Insurances (AIM) and the Italian Region Veneto.

All the projects were based on the analysis of the existing literature and relevant policy documents. Three of them produced results that were published in peer-reviewed journals such as the European Journal of Health Economics and Health Policy. An interviewee who was involved in two of the projects noted that "the projects had the purpose of improving an existing policy proposal and in identifying potential gaps and barriers rather than generating a policy idea to be developed from scratch" (\#4, Senior Policy Officer, Public Health NGO). The results of the EU-funded projects were referred to seven times in the impact assessment (see also Appendix VI). However, one of the researchers involved in two of the projects questioned whether the Commission officials actually read the results and more generally the European Commission officials' efforts to gather evidence: "I hardly imagine anyone in the European Commission doing Google searches to see what evidence exists. I wonder to what extent they read the project, the studies that we produce" (\#5, Researcher on Cross-Border Health Care).

\section{European Observatory expert analysis on cross-border health care in the EU supporting the impact assessment}

DG SANCO commissioned the WHO European Observatory on Health Systems and Policies (hereafter Observatory) to undertake an independent expert analysis focusing on the specific aspects of cross-border health care such as patient rights, prior authorisation, quality and safety, cross-border collaboration, health care baskets, tariffs, among others. The Observatory produced a comprehensive and detailed 400-page study in which the editors highlighted that they have attempted to establish continuity with the previous research on cross-border health care and involve leading experts in the field. The study built on secondary research including literature reviews, case studies and the mapping exercises of the projects mentioned above. Moreover, many of those involved in the projects were invited to 
collaborate in the study. To complement this, the Observatory organised four expert panel meetings in April 2007 to gather additional information and test some of the policy options that the Commission had been investigating. Overall, about 80 international experts from various fields of cross-border health care were involved.

The experts were asked to elaborate on some key issues, including prior authorisation, patient rights, cross-border collaboration, liability, price, reimbursement, among others. For each issue identified, they explored the main barriers and the feasibility of various policy options. Moreover, they brainstormed on other aspects such as setting up a standardised patient information package and a clearing house for common clinical standards. The experts were also required to assess the potential impact of the various policy options, but this task revealed to be particularly complex due to the substantial differences among national health care systems and the lack of reliable data. They concluded that a community legislative initiative was necessary only for areas, such as reimbursement and liability, that the ECJ jurisprudence lacked clarity or where there was the perception that social values needed to be legally strengthened with respect to internal market principles. Moreover, the final report highlighted that because of the differences among national health care systems, a "bottom-up" approach was generally preferred over a "topdown" one, as building consensus at the national level while enabling benchmarking between Member States would be considered more feasible and effective (Wismar et al., 2011). In the MARQuIS project, the experts concluded that the problems in accessing health care within the Member States could not be solved by improving the access to cross-border care (European Observatory on Health Systems and Policies, 2007).

\subsubsection{Knowledge and information}

In the Bowen and Zwi model (2005), the evidence classified as knowledge and information includes results of consultation processes with network and groups as well as the results from the Internet, published documents and reports, including policy evaluations and statistical analyses. In preparation of the Proposal, DG SANCO ran a public consultation, testing the preliminary ideas on cross-border health care and used statistical data from Eurostat and Eurobarometer.

\section{Public consultation}

By engaging in the public consultation on a community action in the field of health launched in September 2006, DG SANCO extended the scope 
of its consensus and information seeking to the general public and encouraged all those interested, including individual citizens, to express their views on the issue. The Commission received 280 responses from national and regional governments, patients' and health care professionals' organisations, insurers, private companies, consultancies and individual citizens. Among the respondents, consensus existed on the need to improve legal certainty, the information available to patients and the cooperation among Member States. However, the questions were so generic that the four lobbyists and two member-state representatives interviewed by Greer in 2006 described it as a cosmetic exercise to achieve something that was already agreed upon (Greer, 2010). Indeed, also in the opinion of four of the people interviewed for this research (\#2; \#4; \#6; \#11), most of the key issues had already been decided upon when the public consultation was launched. They argued that public consultations are used like a checklist against an internal matrix to identify mismatches and understand the main arguments and battles during the policymaking process.

From the 280 responses, in the impact assessment, the Commission quoted the information provided by three stakeholders. One of these quotes was a table from the EU Administrative Commission included in the response from the Belgian Social Insurances. The second quote was from the Health Consumer Powerhouse, a private Swedish company, and the results of an EUwide survey conducted by the company was referred to. It suggested that $30 \%$ of Europeans were not aware of their rights to seek health care abroad. However, the sample and methodology used were not disclosed. The third quote was from the Portuguese Association of private hospitals and mentioned the increase in citizens' mobility, thanks to low-cost airlines and the Erasmus programme, both typologies of patients already covered by Regulation 1408/71 and not relevant for the Directive. One of the interviewees highlighted that "the Commission selection of quotes from the public consultation was biased as they cherry picked only information that matched with their goals" (\#2, Secretary General, Public Health NGO).

\section{Eurobarometer survey}

If the public consultation was mainly intended to gather the views of stakeholders, the Eurobarometer survey - an instrument used by the institutions to investigate EU citizens' opinions and behaviour - conducted in May 2007 aimed at securing the views of all those potentially affected by the legislation. In particular, the survey investigated the willingness of patients to seek health care abroad and the problems they could foresee encountering. 
The sample consisted of around 1000 interviewees per Member State. The results showed that $70 \%$ of the EU population believed that the costs of health care treatments received elsewhere in the EU would be reimbursed by their competent national authority and 53\% were willing to travel to another EU country to seek medical treatment. The main reason to do so would be the unavailability of the necessary treatment in the domestic health care system. Better quality treatment and quicker access to the necessary treatment were considered important motivations for patients. Despite the survey's good intention to seek and learn from the perceptions and problems of those directly affected by the Proposal, a member of the European Parliament considered it to be "one of the many tools used by the Commission to obtain legitimacy for its action” (\#23, Member of the European Parliament). Also, the results of the Eurobarometer survey were used in the impact assessment and referred to four times in the document.

\subsubsection{Interests and ideas: Expert knowledge and lobbying}

Bowen and Zwi (2005) classify as interest and ideas the expert knowledge of individuals, groups and networks "shaped by past personal and professional experiences, values and beliefs" (p. 601). One of the main sources of expert knowledge that the European Commission sought when formulating the Proposal was that of the Member States, not only because they were the ones mostly affected by the Directive but also because the Commission knew it was working at the borderline of its competencies. According to the Treaty, the management, financing and delivering of care is the responsibility of the Member States (Article 168, TFEU). The high-level reflection process and the HLG on health services and medical care (see paragraph 4.2.2) were established precisely to enable discussion among Member States, consider national positions, seek consensus on the issue and gather information and knowledge from the national governments and experts involved. The HLG included representatives from the Member States but also a number of technical experts, organised in working groups on specific issues including health professionals, centres of reference, eHealth, health technology assessment, patient safety, purchasing practices, health impact assessment. The two concrete outcomes of the HLG were the production of a set of non-binding guidelines for seeking treatment abroad and a toolkit for health systems' impact assessment. In addition, the working group on centres of reference commissioned an expert report on rare diseases. The report gave insights into the different approaches to rare diseases across the EU and implications of establishing a European network of centres of reference, which then became a part of the Proposal. 
The issue of cross-border health care was also extensively debated in the EU Health Policy Forum (hereafter referred to as the EHPF). The EHPF is a platform set up by DG SANCO 2001 as a part of its strategy to enhance the communication with the EU health community and increase the stakeholder involvement in the European health policymaking. The EHPF, which used to meet bi-annually, gathers 45 European associations including health care providers and health professionals, health insurance bodies, industry representatives, citizens and patient organisations and NGOs active in public health.

In 2005, the EHPF gave recommendations on the health services in the internal market in the context of the cross-border health care debate and in relation to the ECJ rulings and services Directive. With regard to the latter, it unanimously asked for the exclusion of health care from the Directive. Moreover, it asked the Commission to take into account the special nature of health services and sustainability of health care systems. It also emphasised the need to carefully assess the impact on health and health systems of any legislative initiative.

Many conferences, roundtable talks and workshops (see Appendix IV) were organised by different stakeholders to discuss specific aspects of the Proposal before and after its formal adoption by the European Commission in July 2008. There has always been general consensus about the definitions of the problems and key challenges to be addressed, and it has been difficult to clearly identify the opposing fronts and clear-cut divergences of opinion between the interested parties. This impediment was faced also due to the fact that given the relative marginal role of pure commercial interests, the Proposal didn't generate the traditional opposition between public and private interests. A small exception was linked to the provisions on health technology assessment where the pharmaceutical and medical device manufacturing industries have been vocal in asking for more stakeholder involvement in the HTA processes. According to Greer (2008), private health care groups that could benefit from the liberalisation maintained a low profile and never engaged in active lobbying with few exceptions.

In this regard, a Commission official stressed as follows:

The first and most important stakeholders for the European Commission were the Member States. As any other interest group, they lobby the European Commission to defend the national position... [Member States' lobbying was] the most aggressive, 
insistent and often misleading. (\#3, Head of Unit, European Commission)

This specific case was peculiar because the Commission didn't have a well-established relationship with the health ministers, as it was the first time they confronted each other on the differences on a legislative text on health services and, as two interviewees confirmed, the Member States still didn't consider health as an EU issue (\#7, Health Attaché, Council of the EU; \#14 Political Advisor, European Parliament).

An interviewee stressed that "the dialogue was mainly between the Commission and the Member States and health care professionals and other organisations didn't have any strong role in shaping the proposal and even less so after the Proposal was adopted by the Commission” (\#4, Senior Policy Officer, Public Health NGO). Other two interviewees expressed very similar views (\#14, Political Advisor, European Parliament; \#25, Director, Industry Association). A Commission official also indicated that the health insurances associations AIM and ESIP were the only interest groups who tried to gather evidence to back their position and who really engaged in the technical issues. Patient and health care professional organisations and public health NGOs didn't make any informative contribution (\#3, Head of Unit, European Commission).

Supporting informational lobbying theories (see Chapter 2), three of the interviewees $(\# 7 ; \# 10 ; \# 13)$ highlighted that the impact of stakeholders is closely linked to their reputation and the value of the information they convey to policymakers. They referred to the fact that most stakeholders lobbying on cross-border health care limited themselves by taking positions that were not built on evidence or based on a real problem but on a belief or an ideology. The interviewees highlighted that interest groups have different resources in terms of funding, capacity and expertise - and this may influence the likely impact they have on the policymaking process. Patient organisations tend to be structured around diseases, particularly, chronic diseases, and in this case, they didn't actively engage in the early stages of the policymaking process. However, they played a key role after the Directive was adopted by the Commission, particularly in the voting on rare diseases in the European Parliament. In general, the European Parliament emerged as the institution most open to integrating the views of the stakeholders. This is partly linked to the fact that MEPs have to deal with many technical dossiers at the same time and use information from interest groups to gain expertise on an issue that they do not have the time to investigate. Health care professionals' 
organisations had among themselves divergent views. For example, dentists' organisations favoured a more liberal approach and had different priorities than doctors and nurses' organisations.

\subsubsection{Economics and politics}

This paragraph analyses the evidence that Bowen and Zwi (2005) identify as economics and politics, namely the budgetary implications of the Proposal as well as its political sensitivities and risks. As explained in chapter 2, Bowen and Zwi (2005) consider economics and politics as separate categories, but for the purpose of this thesis, they are considered together. Political sensitivities are also analysed above in the description of the context and policy idea.

The debate on patients' mobility touched on politically sensitive issues, such as the sovereignty of welfare states, the territoriality principle of health systems, health benefit baskets, quality of care, patients' rights, liability, among others, that affect all national health care systems. Therefore, at the beginning, the debate was dominated by the fear of possible massive patient flow. This fear was not fully understood and taken seriously by the Commission, which focused its energies in pushing for an internal market for health care.

One of the interviewees recalled that when the Director of DG SANCO, Robert Madelin, first presented the Commission's ideas to the Member States, he received the political equivalent of "hits around the head" (\#3, Head of Unit, European Commission). Over the years, the Member States accepted the idea that an imperfect framework was better on balance than no framework at all. However, the level of ambition of the legislation, especially with regard to prior authorisation and standards, waned over time (\#18, Director, Pharmaceutical Industry Association). The Commission appeared as a democratic intermediary seeking what was politically sellable and acceptable and always trying to seek legitimacy and consensus. One of the interviewees argued that "the Commission was probably overreaching and pushing things further than they actually wanted in order to pull back to a more reasonable position during the negotiations" (\#17, Journalist Specialised in EU Public Health Policies). Another interviewee (\#10, Political Advisor, European Parliament) expressed a very similar view.

Economic arguments also played a role in the debate, especially for the Member States receiving considerable inflow of patients, such as Spain, which was one of the main opponents of the Directive because of the concerns of overflow of foreign patients jeopardising the sustainability of the Spanish 
health care system, or Belgium, which considered gaining a possible economic advantage from the inflow of foreign patients, thanks to the oversupply of Belgian hospitals.

\subsection{Using Evidence}

This section addresses the following questions: How did the European Commission use the evidence sourced in the impact assessment? How do the participants involved in the policy formulation process evaluate the way the Commission used the evidence it had sourced?

\subsubsection{Impact assessment}

All the evidence gathered by the European Commission via stakeholders' fora, commissioned studies, institutional meetings, among others is selected, assessed and summarised in an impact assessment report drafted on the basis of European Commission guidelines. Table 4.3 outlines the type of references used in the impact assessment accompanying the Proposal on cross-border health care and the number of relevant sources cited.

Table 4.3.

Typology of Evidence and Number of References Used in the Impact Assessment

\begin{tabular}{|c|c|}
\hline Type of evidence & $\begin{array}{c}\text { Number of sources } \\
\text { quoted }\end{array}$ \\
\hline Peer-reviewed and other scientific articles & 5 \\
\hline EU-funded projects & 3 \\
\hline $\begin{array}{c}\text { ECJ rulings } \\
\text { purostat, Eurobarometer surveys and other } \\
\text { polls }\end{array}$ & 4 \\
\hline $\begin{array}{c}\text { European-Commission-commissioned } \\
\text { studies and analyses }\end{array}$ & 2 \\
\hline $\begin{array}{c}\text { National government studies (including } \\
\text { regulatory agencies) }\end{array}$ & 1 \\
\hline \begin{tabular}{c} 
Stakeholders' surveys and studies \\
\hline
\end{tabular} & 3 \\
\hline Public consultation responses & 1 \\
\hline
\end{tabular}




\begin{tabular}{|c|c|}
\hline $\begin{array}{c}\text { Internal consultations with other commission } \\
\text { services, Member States and stakeholders via } \\
\text { advisory groups and ad-hoc working groups } \\
\text { and consultations }\end{array}$ & 4 \\
\hline $\begin{array}{c}\text { Documents from other institutions (e.g., } \\
\text { WHO, Council of the EU and European } \\
\text { Parliament) }\end{array}$ & 6 \\
\hline Other & 1 \\
\hline Total & 35 \\
\hline
\end{tabular}

Table 4.3 shows that part of the evidence gathered by the European Commission reflected in the impact assessment. Appendix V provides the detailed list. Many of the references concern the rulings of the ECJ and from Council documents. The report includes only three references from the adhoc projects funded by the European Commission on cross-border health care and only three references to the responses provided by the stakeholders in the context of the public consultation launched before the adoption of the Proposal. As mentioned above, from one of the interviews, it emerged that the European Commission was very selective in choosing the project results and responses to the public consultations that were in line with its agenda.

Two interviewees (\#2; \#4) expressed doubts about the reliability of the figures used in the impact assessment also because of the objective difficulty in estimating patient flow and costs. Four of the interviewees (\#4; $\# 5$; \#6; \#17) expressed reservations on the figure of $1 \%$ that referred to the public expenditure percentage on health care for patient mobility mentioned in the impact assessment. The Commission never explained how this estimation was made, but, once published, the figures were often used in the debate by all the actors involved, and nobody challenged it, as it was coming from an authoritative source. A Commission official involved in the drafting phase of the Proposal admitted that the figures used in the impact assessment were to be considered "heroic" and they had to "make assumptions over assumptions" ( \#3, Head of Unit, European Commission).

\subsubsection{Evaluating evidence}

From the above elaboration and analysis, it has emerged that various participants were critical on how the Commission dealt with the sourcing of evidence. One interviewee argued that the Commission had played a game with the research projects to meet its political needs, and another interviewee 
accused the Commission of even selectivity (cherry picking) in quoting from the public consultation.

The role of the impact assessment in the policymaking process was also met with scepticism. Referring to not only the impact assessment with regard to the Directive on cross-border care but also the assessment in the two other case studies, an interviewee said, "I wonder how many stakeholders genuinely read them (impact assessments) from start to finish because I think people recognise that in reality there's so much political shaping” (\#4, Senior Policy Officer, Public Health NGO). Another interviewee said, "I'm not familiar enough on the impact assessments that were used on those three (proposals). But in general, the impact assessment process, particularly health impact assessment, is not good enough" (\#11, Secretary General, Public Health NGO). A member of the European Parliament (\#23) admitted that he "didn't read the impact assessment of the Proposal".

The impact assessment is considered useful mainly for internal lobbying within the Commission, especially in the inter-service consultation, and as a backup for persuading the Member States even if they are not always interested in reading it:

Within the Commission you have to "sell" why you do certain things. An impact assessment is to have the green light to go further. If it is not successful, they have to change it, adapt it or wait until the right moment. It is good that the Commission has to convince and put on paper why it is important and be as scientific as possible, but the most important thing is to convince internally the Commission and not the public. (\#22, Health Attaché, Council of the EU)

Despite the impact assessment being based on a comprehensive study that involved leading experts and included results of Commission-funded projects, literature reviews and mapping exercises, the overall perception of those who wrote it and those who read it is that it was not reliable and was used only as a legitimising tool. In this regard, a Commission official admitted as follows:

The impact assessment is not science. It's pure journalism. You decide what you want to do. And this decision is taken politically. Then you go off and find the evidence to support this decision, the option that you have already decided to take. By the time you actually come to the impact assessment, you've decided what your options are and you're 
trying desperately to justify them. (\#3, Head of Unit, European Commission)

On top of this, it should be noted that the Commission invested a lot of time and resources to prepare the impact assessment, and even if fully taken into account by the Commission and reflected in the legislative Proposal, the Council and the European Parliament always bring substantial amendments that change the nature of many provisions, not necessarily in line with the results of the impact assessment. In other words, the impact assessment is made only in the first phase, and its value is somehow lost during the policymaking process. Only since 2012, with the establishment of an ad-hoc Impact Assessment Unit, the European Parliament started to invest more on impact assessment, and the Unit performs by itself some impact assessments for substantial amendments the Parliament wishes to introduce.

The way the impact assessment was conceived as well as the analysis on how the European Commission gathered the evidence show that the EU policymaking process presents the features of Weiss' interactive model (see paragraph 2.2.3, Chapter 2) because of the following reasons: (1) The search for knowledge goes beyond research to include a variety of sources such as Member States, scientists, health care professionals, among others. (2) The research conducted on cross-border health care was just one small part of a more complex process of gathering information. (3) As the interactive model suggests, a political decision was taken even with lack of evidence on the phenomenon.

\subsection{Capacity for Implementation: Hindering and Facilitating Factors for the Uptake of Research Evidence}

According to Bowen and Zwi (2005), “determining capacity to act on evidence is a neglected area of policy analysis and research efforts to date. This gap exists largely because capacity is a difficult concept to define and subsequently to assess or measure" (p.602). The concept refers to the capacity of policymakers to translate evidence into policy. and it ultimately reflects the influence that evidence has on policy formulation. As suggested by Bowen and Zwi (2005), also for this case study, it is very difficult to measure this aspect even if the evidence used and final text of the legislation are analysed in detail. Therefore, the considerations of this chapter are mostly based on the perceptions of policymakers, academics and the stakeholders concerning the influence of research evidence on the formulation of the Directive on crossborder health care. In particular, it seeks to establish the main challenges and 
facilitating elements that affected policymakers' decisions to use or not to use the research evidence.

"Capacity to implement" in the terminology of Bowen and Zwi (2005) refers to all the types of evidence they identified in their model. However, most observations of the interviewees were focused on the research evidence. Some of the comments of the interviewees refer in general to the way the European Commission operates in relation to the governance of evidence. Table 4.4 summarises those that are specific to the formulation of the Directive on cross-border health care. 
Table 4.4.

Hindering and Facilitating Factors for the Uptake of Research Evidence in the Formulation of the Directive on Cross-Border Health Care

\begin{tabular}{|l|l|}
\hline \multicolumn{1}{|c|}{ Facilitating factors } & \multicolumn{1}{c|}{ Hindering factors } \\
\hline Policymakers' information need & Lack of timely research evidence \\
\hline $\begin{array}{l}\text { Research evidence provided in a } \\
\text { solicy friendly format (including } \\
\text { summaries and policy } \\
\text { recommendations) }\end{array}$ & $\begin{array}{l}\text { Lack of reliable research evidence } \\
\text { (anecdotic and incomplete } \\
\text { evidence) }\end{array}$ \\
\hline $\begin{array}{l}\text { Direct relationship between } \\
\text { researchers and policymakers }\end{array}$ & $\begin{array}{l}\text { No EU-wide research evidence } \\
\text { available }\end{array}$ \\
\hline $\begin{array}{l}\text { Supportive organisational } \\
\text { procedures (e.g., impact } \\
\text { assessment) }\end{array}$ & Selection bias \\
\hline $\begin{array}{l}\text { Financial resources available for } \\
\text { research projects }\end{array}$ & $\begin{array}{l}\text { Ideological/political and } \\
\text { inconsistent use of research } \\
\text { evidence }\end{array}$ \\
\hline & $\begin{array}{l}\text { Policymakers' lack of expertise in } \\
\text { assessing research evidence }\end{array}$ \\
\hline & Lack of independent research \\
\hline
\end{tabular}

Provided that the findings of the research project commissioned by the European Commission under the SPP programme and the study commissioned to the Observatory could be considered a form of research evidence, it clearly emerged that there were significant factors facilitating the uptake of the evidence. First, the research evidence generated was asked for by the European Commission to respond to a specific information need. Second, the evidence generated was presented in the format required by the European Commission, including the summaries of the findings and specific policy recommendations. Moreover, the major facilitating factors, both at individual and organisational level, were that the European Commission is an official partner of the Observatory, the two organisations have a longstanding relationship and the personal knowledge between the Commission officials and the researchers of the Observatory. The SSP programme has been established by the European Commission to facilitate the use of evidence by funding research that meets the needs of policymakers and at the same time promoting researchers' involvement in policymaking. 
The biggest hindering factor for the uptake of the research evidence on cross-border health care was the lack of timely and reliable data. In the impact assessment, the European Commission admitted that "after repeated exercises over recent years, it is clear that there is as yet no comprehensive data about cross-border health care" (European Commission, 2008). The Observatory mentioned, among the limitations of the report, the lack of complete and reliable data. The experts pointed out the fact that the information used as the evidence base was "often unreliable or unrepresentative and in any case incomparable between projects and between countries" (Legido-Quigley et al., 2008). They also reported a selection bias concerning what was available in the literature in favour of the "mobility based on institutionalised cooperation between stakeholders, especially where public authorities have been involved" (Legido-Quigley et al., 2008, p.42). Moreover, there was a lack of information from the Mediterranean countries, as most of the information available came from northern European countries and, to some extent, Eastern European countries. Most of the information was about hospital management and other organisational issues rather than the actual needs of patients. The Observatory report attributed this lack of information on the views of patients to the phenomenon being relatively recent, the health services research being weak in most countries and the information about patient experiences and expectations having almost never been collected.

Four of the interviewees (\#2; \#3; \#4; \#11) and also the Observatory studies defined the available research evidence on cross-border health care as incomplete. The report and also the projects mentioned in point 3.6.2 list some examples, but in general, the information available on the phenomenon was rather scarce. For these reasons, the Observatory study recommended further research on not only patient flow, quality of health care, patients' information needs and expectations but also the future drivers of patient mobility, attitudes of health care professionals and the other stakeholders at local, regional, national and European levels and many other areas.

According to an interviewed Commission official (\#24, Administrator, European Commission), the timely availability of data and studies is a major factor that determines the capacity to uptake research evidence. The gap in the timely availability of data and studies exists because the policy process moves much faster than academic research. According to him, this has also been the case for the Directive on cross-border health care despite the five-year period between the first political discussion on cross- 
border health care at the high-level process of reflection on patient mobility and the adoption of the Proposal by the European Commission:

To be honest, even if I had wanted to use academic research, I couldn't have done it because there wasn't any at that point in time. A policy process moves much quicker than a scientific process which is logical. But that quite often means that you're actually responding to the problems and that you have to make decisions before, anyone has actually done any substantial analysis. (\#3, Head of Unit, European Commission)

Another interviewee attributed the lack of evidence to patient mobility not being an important issue:

In terms of the academic evidence, I didn't see much of that to be honest because I think one of the interesting things is actually (that) in many ways cross- border care isn't an issue. It's not an issue in number of volumes. (\#4, Senior Policy Officer, Public Health NGO)

Other hindering factors were ideological/political factors and the inconsistent use of evidence by the European Commission just to gain consensus and political support from the Member States as three of the interviewees pointed out. In this regard, one of them stated, "we had such massive opposition against this within the Commission because they hated the idea that we were doing anything on this at all. It had nothing to do with the evidence at all. It was an ideological position" (\#3, Head of Unit, European Commission).

To address this opposition, the Commission sought to downsize the impact of the Directive on the Member States. An interviewee said, "the Commission was using the 1\% figure to show Member States the whole Directive was not a huge deal and reduce their resistance" (\#4 Senior Policy Officer, Public Health NGO).

In this regard, another interviewee added as follows:

The Commission circulated among Member States confidential documents claiming at the same time that cross-border health care was important enough to be addressed via binding EU legislation and that the phenomenon was so negligible that Member States didn't have reasons to be worried about the potential implications for national health care systems. (\#7, Health Attaché, Council of the EU) 
Indeed, the research evidence confirms that cross-border health care is a very limited phenomenon and only a handful of patients actually seeks health care abroad. In this respect, Glinos (2012) argued that there are more doctors and nurses crossing borders than patients and defined the high interest around patient mobility "paradoxical and imprudent" (p. 256), especially considering the shortage of health care professionals and the current pressure on health care budgets.

Among the capacities that can hinder or facilitate the adoption of evidence, Bowen and Zwi (2005) list the personal knowledge and skills of the individuals analysing the information and their learning mechanisms of reflection and review to navigate the evidence.

A Commission official confirmed this point by stating as follows:

One of the skills that you have to acquire and that makes the difference between successful Commission officials and unsuccessful Commission officials is being able to work out who is saying what and why and which information you can use and which ways you can't. (\#3, Head of Unit, European Commission)

The same official also pointed out the fact that Commission officials do not have the necessary expertise to look at the evidence.

According to Bowen and Zwi (2005), an essential capacity required at the organisational level is a skilled and competent workforce that has an efficient system that makes evidence accessible and supports the evidence use. The European Commission provides various tools to facilitate the adoption of evidence, namely the resources to finance research, a supportive workplace and the procedures and leadership that promote evidence-informed policymaking. However, most of its staff consists of lawyers and economists who almost never read or engage with primary evidence collection. They are not expected to be experts in the domain of the policy they are formulating. This situation is slowly changing because of impact assessment, which imposes evidence searching even if time and resources are still mentioned as the main hindering factors. For this reason, the Commission relies on stakeholders acting as brokers of evidence:

The European Commission assumes that stakeholders get the evidence from the primary evidence if you like. But the commission itself almost never goes directly into primary evidence. Probably because it doesn't have the resources. Partly because it often doesn't have the time. (\#3, Head of Unit, European Commission) 
The European Commission put in place a model where a selected group of stakeholders brings it evidence in a filtered manner.

Even when research evidence reaches policymakers, an important hindering factor for its uptake is the lack of the trust of policymakers. From the interviews, it emerged that policymakers often consider that scientists have a political agenda. A researcher on cross-border health care admitted that independent research doesn't exist, and scientists are influenced by their personal beliefs and values:

Strictly speaking independence doesn't exist. For any institution or for any info, any research or academic, whatever we say we are coloured by our principles, values, beliefs, whether we want it or not. Maybe it is not strategic, but it happens with humans after all. (\#6, Researcher on Cross-Border Health Care)

Some interviewees also mentioned that the research evidence provided is significantly influenced by the perspectives of academics. For example, one of them said that a researcher from the London School of Economics has an obvious economic focus and look at cross-border health care from the paradigm of the free market, competition, among others, while a researcher with the medical background has a completely different take on the cross-border health care phenomenon. As evidence is often not consistent and clear-cut, policymakers exercise a high degree of judgment in terms of what evidence to look at, which should be discarded and how much weight to give to the different types of evidence. Moreover, both for researchers and projects, academics are influenced by the need to "please" the European Commission or other funders to be granted another funding in the future. Owing to this vested interest, researchers cross the line and become stakeholders themselves. A researcher admitted that "no researcher is neutral because if no one requests our work and no one requests evidence, we are unemployed in the worst-case scenario, and this is why we became sort of stakeholders in this process" (\#5, Researcher on Cross-Border Health Care).

Even when hard evidence exists (e.g., on purely scientific issues such as electromagnetic fields, diseases, among others), policymakers can decide not to follow it. This is even more applicable in those cases where the evidence is insufficient or contradictory or unreliable. Overall, research evidence, knowledge and information as well as interests and ideas do not play a major role in the policymaking process. Ultimately, the evidence that appears to count most is linked to politics: 
You can end up taking decisions, which are directly contradicted by hard science. They don't regard if you don't like the fact that it is contradicted by hard science, there's no veto, that doesn't seem to change the way the decision-making process is. The fact that 27 Member States will vote against it, that's a veto. Evidence in the policymaking process is considered just a tool that in most case leave all the room to political considerations. (\#3, Head of Unit, European Commission)

\subsection{Conclusion}

Triggered by many rulings of the ECJ, the Directive on cross-border health care was the first legislative proposal by DG SANTE in an area - health care - that the European Commission has only very limited competencies. To overcome the resistance from the Member States concerned about the possible massive patient flow and increase its legitimacy, the European Commission invested significant resources in gathering evidence to back up its Proposal.

Regarding the sourcing of evidence, it is possible to conclude that the Commission funded various ad-hoc research projects on cross-border health care under the Public Health Programme and the $6^{\text {th }}$ Framework Research Programme to meet specific policy needs. In addition, the Commission funded an independent expert analysis from the European Observatory on Health Systems and policies to support the impact assessment. The Observatory acted as evidence broker.

The views of the stakeholders and European citizens on the issue of cross-border health care were also sought through a public consultation and a Eurobarometer survey respectively. The European Commission also organised ad-hoc working groups with the Member States to seek the views of national governments and attended various conferences and roundtable talks on the issues raised by the stakeholders. There were no major opposing fronts among the stakeholders, and those who lobbied the European Commission the most were the Member States. Health care professionals, patients and the health care industry played a marginal role and focused their lobbying especially on the European Parliament.

As for the use of evidence, the role of the impact assessment was highlighted. However, some interviewees challenged the impact assessment because of the biased selection of the information gathered from the project results and the public consultation and the questionability of the reliability of 
the figures on patient flow. Researchers, stakeholders and policymakers revealed that the evidence gathered only had a legitimising role and was just a tool to justify a decision already taken at the political level. The impact assessment was considered a communication exercise, a lobbying tool with limited or no added value in providing a solid evidence base to the Commission's Proposal. Despite the efforts of the European Commission to seek and use the evidence, the interviewees representing the stakeholders and other EU institutions (MEPs and health attachés) considered the evidencegathering process just as a tool to obtain legitimacy for its action. With regard to research evidence, researchers themselves admitted that independent research doesn't exist. Academics are influenced by personal beliefs and values and can be biased due to financial interests, for example, in pleasing the European Commission to get other research projects funded, or political interests, for example in gaining influence on policymaking.

Concerning the hindering for the uptake of research evidence, it clearly emerged that the research evidence sourced was not useful because it didn't produce reliable data on the main issue, namely patient flow, and didn't have the EU-wide coverage needed by the European Commission. Regarding research evidence, the case study can be considered a good example of what Weingart (1982) as well as Everson and Vos (2009) define as the "politicisation of science". One of the interviewees revealed that the researchers involved in the project felt obliged to cross the line and produce something that exceeded their competencies. Four interviewees reported that most of the key issues were already decided by the European Commission before launching the public consultation, and one of them pointed to the cherry picking of the information gathered via the public consultation, which the European Commission selected in a biased manner to match its goals. Facilitating factors were policy makers information needs, the available research provided in a policy makers friendly format and the direct relationship between the European Observatory and the officials in charge of the dossier in the European Commission. 



\section{Chapter 5: Role of Evidence in the Formulation of the Directive on the Provision of Information to the General Public on Prescription Medicines}

\subsection{Introduction}

In December 2008, the European Commission adopted the proposal for a Directive on the provision of information to patients (hereafter referred to as the Proposal or the Directive). The Proposal sought to establish a clear legal framework for the provision of information on prescription-only medicines by pharmaceutical companies to the general public, while maintaining the ban on direct-to-consumer advertising in place in Europe. The issue of the provision of information to patients has been on the EU agenda for three decades and has always been highly controversial, especially in relation to the role of marketing authorisation holders in providing information about their products to the general public.

To contextualise the issue and understand the background, section 5.2 provides an overview of the key developments in the debate on Direct to Consumer Advertising (DTCA) and the provision of information on prescription medicines in Europe from 1997 to 2014. Analysing the political context and the forces at work in the policy environment is necessary to understand the challenges in integrating evidence into policy. The key steps of the policymaking process are presented in the chronological order on the basis of the procedures defined by the EU Treaty for ordinary legislative procedures (Article 289). Section 5.3 analyses the sourcing of the evidence by the Commission, and section 5.4 covers how the evidence has been used. Section 5.5 explores the hindering and facilitating factors for the uptake of research evidence. This chapter ends with a concluding section (5.6).

\subsection{Context and Policy Idea: Information to Patients on the EU Agenda}

Direct-to-consumer advertising on prescription medicines has been on the EU agenda since 1997 when DTCA was first introduced in the US. The topic was first discussed in the Bangemann roundtable talks on the single market in pharmaceuticals in 1997 that concluded in 1998 with a communication from the Commission indicating that the topic of direct-toconsumer advertising needed to be investigated in depth (European Commission, 1998). In 1998, the issue was also high on the agenda of the Transatlantic Business Dialogue (TABD), a regulatory cooperation forum between businesses in the EU and the US. According to the American and European pharmaceutical industry, US citizens were offered factual 
information about medicines, and European citizens also had "the right-toknow" (TABD, 1998). The issue was also raised in the so-called "pharmaceutical committee" (a committee composed by the representatives of all Member States and chaired by the Commission) in 1999. In particular, upon suggestion of the Directorate-General for Enterprise and Industry (hereafter DG ENTERPRISE ${ }^{9}$ ), the pharmaceutical committee established a working group with the task of starting a brainstorming process but without exploring the legislative aspects. The working group met only once in 2000 and decided to conduct a survey among the stakeholders via a questionnaire. The quality of the questionnaire was considered poor, and the outcome was never made public (Medawar \& Hardon, 2004). In 2000, as foreseen in Regulation 2309/93/EC, the Commission made an evaluation of the EU pharmaceutical framework, commissioning the study to McKenna \& Andersen consulting. The report indicated that no clear support existed for a revision of the legislation and suggested the elaboration of the guidelines to clarify the distinction between health education and promotion of prescription medicines to the general public. Even before the publication of the results of the evaluation, DG ENTERPRISE started a revision of the EU pharmaceutical legislation (Boessen, 2008).

Table 5.1 provides a summary of the key developments that are further detailed in the rest of the section.

Table 5.1

Overview of the 7-Year Discussion on DTCA in Europe

\begin{tabular}{|l|l|}
\hline Date & Main developments \\
\hline 1997 & DTCA allowed in the US \\
\hline Dec 1997/1998 & $\begin{array}{l}\text { Bangemann roundtable talks: Discussion on the } \\
\text { Internet and information }\end{array}$ \\
\hline May/Oct 1998 & $\begin{array}{l}\text { DTCI on the agenda of the Transatlantic Business } \\
\text { Dialogue }\end{array}$ \\
\hline Mar 2000 & First consultation on DTCA \\
\hline Oct 2000 & Cameron McKenna and Andersen report \\
\hline Jan 2001 & Workshop for stakeholders \\
\hline Mar 2001 & $\begin{array}{l}\text { Medicines High-Level Group on innovation and the } \\
\text { provision of medicinal products (G10) }\end{array}$ \\
\hline Jul 2001 & $\begin{array}{l}\text { Pharmaceutical review: Proposal for a pilot of DTCI on } \\
\text { asthma, AIDS and diabetes }\end{array}$ \\
\hline
\end{tabular}

${ }^{9}$ Known as DG GROWTH in the Juncker European Commission 2014-2019. 


\begin{tabular}{|l|l|}
\hline May 2002 & G10 recommendations \\
\hline $\begin{array}{l}\text { Oct 2002-Dec } \\
2003\end{array}$ & $\begin{array}{l}\text { European Parliament and Council reject the } \\
\text { Commission's Proposal on pilot studies }\end{array}$ \\
\hline Mar 2004 & $\begin{array}{l}\text { Adoption of Directive 2004/27/EC by the European } \\
\text { Parliament and the Council }\end{array}$ \\
\hline
\end{tabular}

In March 2001, DG ENTERPRISE established the G10 High-Level Group on the innovation and provision of medicines in Europe. The G10 High-Level Group composed of representatives of the European Commission, the Member States and the pharmaceutical industry. The Picker Institute was invited by the European Commission to represent patients' views as emerged from research (Boessen, 2008, p.113). The High-Level Group was criticised due to the imbalance in interest representation and the weightage given to the pharmaceutical industry at the expense of patients and other health NGOs such as Health Action International. The High-Level Group was established right before the beginning of the pharmaceutical review as a forum to build political consensus and maintain the controversial topics on the agenda independently from the outcome of the legislative process. The draft recommendations of the G10 High-Level Group were submitted for public consultation, and a workshop on the provision of information to patients was organised by the Commission in December 2001. In 2003, the G10 High-Level Group's recommendations were adopted in the form of a Commission communication. The G10 High-Level Group highlighted the need to find a workable distinction between information and advertising and the establishment of a private-public partnership. Meanwhile, in March 2001, the European Commission (DG ENTERPRISE) presented a legislative proposal to review the pharmaceutical legislation, including a fiveyear "pilot" for the advertising of medicines to treat asthma, AIDS and diabetes. The stakeholders were consulted only via a public consultation at the end of the process and after receiving several complaints on the lack of transparency of the pharmaceutical review. The Commission indicated that various patient associations asked for the legislative proposal, but they were unable to name any organisation (Boessen, 2008). Despite this, the topic remained on the agenda. The European Parliament introduced a requirement for the Commission to present a report within three years on the existing sources of information regarding prescription medicines and, in particular, the risks and benefits of the information on the Internet. In addition, the Commission conducted an informal mandate from the G10 High-Level Group to follow up on its recommendations, and in 2003 also, the EU Council of 
Ministers adopted a resolution inviting the Commission to explore the options for a European Information System.

\subsubsection{European Commission's Proposal on the provision of information to patients: Same path, same goal}

The previous section described how the issue of DTCA reached the policy debate first in the US and then the EU. This section explores the second part of the path followed by DTCA in Europe, from the adoption of the legislative Proposal to the review of the EU pharmaceutical legislation in 2004 till the adoption of a new legislative Proposal on the same issue but with a different focus, namely with a change of the word "advertising" with that of "information". The rationale of the change in wording and its implications are further described below. Table 5.2 summarises the main developments.

Table 5.2

Overview of the 8-Year Discussions on DTCI in Europe

\begin{tabular}{|c|c|}
\hline Date & Main developments \\
\hline $2005-2008$ & High-Level Pharmaceutical Forum \\
\hline Dec 2007 & $\begin{array}{l}\text { Commission communication on current practices with } \\
\text { regard to the provision of information to the patients in } \\
\text { the Member States }\end{array}$ \\
\hline Feb-Apr 2008 & $\begin{array}{l}\text { Public consultation on a legislative Proposal on the } \\
\text { provision of information to patients }\end{array}$ \\
\hline Jun 2008 & $\begin{array}{l}\text { Conclusions of the Council concerning the Commission } \\
\text { Communication on existing practices with regard to the } \\
\text { provision of information }\end{array}$ \\
\hline Dec 2008 & Commission's Proposal on information to patients \\
\hline Jun 2009 & $\begin{array}{l}\text { Council conclusions: The Commission's Proposal is not } \\
\text { a good basis for discussion }\end{array}$ \\
\hline Oct 2010 & European Parliament vote in the $1^{\text {st }}$ reading \\
\hline Feb 2011 & European Commission amended Proposal (version I) \\
\hline Feb 2012 & European Commission amended Proposal (version II) \\
\hline May 2012 & $\begin{array}{l}\text { The Council takes note of the fact that there is no } \\
\text { possibility to obtain a qualified majority in the Council } \\
\text { in favour of adopting Common Positions based on the } \\
\text { Commission's Proposal }\end{array}$ \\
\hline
\end{tabular}




\begin{tabular}{|l|l|}
\hline Jun 2012 & $\begin{array}{l}\text { European Commission's corrigendum to amend } \\
\text { Proposal version II }\end{array}$ \\
\hline May 2014 & European Commission's Proposal withdrawn \\
\hline
\end{tabular}

A few months after the review of the EU pharmaceutical legislation had been completed and Directive 2004/27/EC (amending Directive 2001/83/EC) had entered into force, as a follow-up of the G10 High-Level Group initiative, in June 2005, the European Commission set up the HighLevel Pharmaceutical Forum, a high-level ministerial platform for discussion between the Member States, EU institutions, pharmaceutical industry, health care professionals, patients and health insurers. According to the European Commission, the Forum was intended "to find relevant solutions to public health considerations regarding pharmaceuticals, while ensuring the competitiveness of the industry and the sustainability of the national health care systems" (European Commission, 2005). Like the G10 High-Level Group, the Forum was also publicly criticised for the imbalanced representation of interests in the composition of the group of stakeholders due to the excessive number of seats allocated to the pharmaceutical industry compared to the NGOs representing patients' and public health interests. Some consumers and health organisations challenged its legitimacy (BEUC, 2006; Friends of the Earth Europe, 2008). The Forum met once a year till 2008 and had three working groups, one of which was dedicated to the provision of information to patients. In the context of the Pharmaceutical Forum, in March 2007, the Commission (DG ENTERPRISE) launched a public consultation on the quality criteria for information on medicines and a model leaflet on diabetes that was supposed to test the public-private partnership principle recommended by the G10 High-Level Group. This was followed by an additional consultation in June 2007 on a draft report on the current practices on the provision of information to patients in the Member States prepared by the Commission as required by Article 88 of Directive 2001/83/EC. In July 2007, DG ENTERPRISE launched a third public consultation regarding the future of the pharmaceuticals in Europe, and a few months later, another consultation on the ideas for a legal Proposal on the provision of information to patients (see also section 5.7). Before the end of the consultation, DG ENTERPRISE commissioned an independent impact assessment study to Europe Economics, a private consultancy specialising in economic regulation and competition policy.

The legal Proposal was expected to be adopted on October 21, 2008 as a part of the so-called "pharma package" including the following: 
- a proposal on the information from pharmaceutical companies to the general public on prescription medicines,

- a proposal against counterfeit medicines,

- a proposal on pharmacovigilance,

- a communication on the future of the pharmaceutical sector.

The adoption was delayed because of the disagreement within the College of Commissioners in relation to the Proposal on the provision of information to patients, including a strong opposition from the Health Commissioner (Androulla Vassiliou) and the Commissioner for Communication (Margot Wallström) (Euractiv, 2008). Some of the opposition within the College was not directly linked to the Proposal on the provision of information to patients but the other proposals included in the so-called "pharma package", namely the proposal on counterfeit medicine in relation to the issue of parallel trade. The package was then announced for November 26, as, according to Vice President Verheugen, the texts needed some "technical adaptations". Finally, the pharma package, including the Proposal on the provision of information to patients, was officially adopted on December 10, 2008.

\section{First Proposal of the European Commission on the provision of information to patients}

As stated, the pharma package included a Proposal for a Directive amending, as regards information to the general public on medicinal products subject to medical prescription, Directive 2001/83/EC on the community code relating to medicinal products for human use. It also included a Regulation amending, as regards information to the general public on medicinal products for human use subject to medical prescription, Regulation (EC) No 726/2004 laying down Community procedures for the authorisation and supervision of medicinal products for human and veterinary use and establishing a European Medicines Agency (hereafter referred to as the EMA). The Regulation was just auxiliary to the Directive that introduced a few new tasks for the EMA, therefore requiring an adjustment of the Regulation regarding EMA responsibilities. For the purpose of this research, both proposals were considered, but given that they were fully interlinked and followed the same path and the secondary importance of the Regulation, for simplification, throughout the text the reference is to the Directive. 
According to the Commission's Proposal, marketing authorisation holders would be entitled to disseminate information to the general public regarding their prescription-only medicines. In particular, information would be allowed to be distributed only via health-related publications and the Internet through package leaflets and the summaries of product characteristics (SPC) as approved by the medicines' regulatory authority or in another rephrased/adapted representation. Moreover, they could provide information regarding changes in price, packaging and adverse effects as well as productrelated information on non-interventional studies. They could also present the product in the context of a disease or medical treatment. The information would have had to comply with certain quality criteria, namely be objective, unbiased, reliable, factually correct and not misleading, demonstrable, verifiable, recent, understandable to the general public and in line with the SPC and package leaflets. The Member States would have been required to put in place specific mechanisms (self or co-regulatory systems) to monitor the information before its publication or ensure an equivalent level of monitoring. The monitoring would have also applied to websites.

The amendments to the Regulation referred mainly to the amount of time the Agency would have had to monitor the information regarding centrally authorised products, which the Commission fixed at 60 days.

\subsubsection{Decisive role of the European Parliament}

In the European Parliament, the Environment, Health and Food Safety Committee (hereafter referred to as the ENVI) was responsible for the amendments. In 2008, the industry (ITRE) and internal market (IMCO) committees provided its opinion. Christopher Fjellner MEP (EPP, Sweden) was nominated as the rapporteur. Although, the ENVI exchanged views on the Proposal, the real debate was postponed due to the June 2009 parliamentary elections and re-started in the new legislative term in September 2009. Mr. Fjellner was the rapporteur confirmed by the new Parliament, and he drafted the report in March 2010. The vote in the ENVI took place in September 2010, and the European Parliament adopted its position in the first reading in November 2010. The European Parliament introduced significant amendments to the Proposal, and according to MEPs and various stakeholders, it changed the focus of the Proposal from the industry's right to disseminate information to the patients' right of accessing information on medicines. In this respect, a political advisor in the European Parliament reported that "the best the Parliament could do was damage control... The hard lobbying of the pharmaceutical industry and of the 
publishers made the MEPs understand the real interests behind the Proposal" (\#10). An EU health journalist $(\neq 17)$ also underscored the decisive role of the Parliament: "Clearly the Parliament had a huge role, as it shifted the direction around from pro industry to pro patient and obligations to provide rather than rights to provide information".

At that point of time, the European Parliament was also voting on the other two proposals of the pharmaceutical package, and the MEPs introduced an amendment related to the provision of information to patients in the pharmacovigilance Directive. The amendment, which was also supported by the Council, required the European Commission to present a report regarding the readability of the SPC and package leaflets and their value to health care professionals and the general public. The report was published on March 23, 2017.

\subsubsection{A changing political landscape}

Despite 11 years of discussions, the topic of changing the EU legislation on the advertising of prescription medicines (Article 88 of Directive 2001/83/EC) was still on the EU agenda. However, many elements in the scenario had changed: the terms of the debate, key actors involved, position of some stakeholders, procedures and context.

\section{From DTCA to DTCI}

Over the years, the word "advertising" had been replaced by the word "information", and the debate became about the "informed patient". The word advertising still appeared in some official documents in 2001, while after 2004, all Commission documents on this topic highlight that the EU ban on advertising of prescription medicines should remain. According to Brooks and Geyer (2012) the change in the semantics in the DTCA to "patient information" was "accompanied by a subtler and politically acceptable approach to circumventing the advertising ban by DTCA proponents" (p.1237). In this regard, one of the interviewees confirmed as follows:

The rationale (of the Proposal) definitely changed as it went through ...but I still wouldn't call it information. It was about giving more information about drugs to patients more than informing them in a manner that I would call meaningful. (\#8, Secretary General, Public Health NGO)

Nevertheless, the call for the provision of more information to patients had won consensus at all levels and started leading the debate. 
Several factors contributed to the shift in the focus of the debate from the industry's right to disseminate information about their products to the patients' right to information: (1) a genuine increased public demand for information, also linked to the availability of new channels of information such as the Internet and the patients' willingness to be more involved in health care decisions, (2) the lobbying arguments of the opponents of the Proposal who criticised the industry-oriented approach and stressed the need for more and better health information and (3) the lobbying arguments of those willing a change in the legislation and supporting the Proposal. In particular, the pharmaceutical industry's lobbying arguments concentrated on the patients' need of information and the privileged position of the industry in providing information about its own products. In addition, the Commission had a clear role in creating commitment to the information to patients.

The change of wording and focus deeply influenced the lobbying strategies and, more generally, the development of the Proposal, as all involved parties, including the industry (EFPIA 2008), stated they were against the advertising of prescription medicines, and no party, including the major opponents of the Proposal, namely the payers, could argue against the provision of information to patients. In this regard, a researcher stated as follows:

I think there was inherent conceptual misguided approach in which they said "No, this is about info to patients, so we are not going to talk about promotion, we are not going to talk about advertising". But you know if it was about info, why did they need to change law on advertising? They did not have to, they could have improved information without proposing to change the law. (\#21, Researcher on information to patients)

\section{Increased transparency}

Other important changes affected the policymaking process in relation to the Directive. The Lisbon Treaty, which came into force in 2010, stressed on the importance of openness and transparency in the decision-making process and the need to address the so-called "democratic deficit". This recommendation was also translated in the European Commission's "Better Regulation" (Barroso I) and "Smart Regulation" (Barroso II) agenda and changed "the rules of the game", requiring more transparency, more accountability, the need to be evidence-based and the increasing pressure of stakeholders to be more actively and "more officially" involved in the process. According to Boessen (2008), "there was hardly any debate on 
DTCA during the preparation of the pharmaceutical review" (p. 109). Public statements of health NGOs regarding the pharmaceutical review indicated that they were not consulted. EATG, the European AIDS Treatment Group, stated that "the legislative process itself needs to become more transparent and inviting, so that stakeholders can play a real role" (HAI, 2002, p.2). From the secrecy of the Bangemann round-table talks and the unpublished survey among the stakeholders conducted by the Pharmaceutical committee, the Commission moved towards a slightly more open G10 group and in 2005, to a certainly more open Pharmaceutical Forum even if many acknowledged an imbalanced representation of interests in both processes. The shift was characterised by the following changes: from almost no consultation with the stakeholders during the first pharmaceutical review to four consultations on the same topic in view of the review in 2008 and from unsubstantiated statements on unidentified patient groups asking for a legislative change in 2001 to 25 patient organisations asking for it in the public consultation and many other patients' groups vigorously advocating for it in various for after 2004. Among the patient organisations, one was the European Patient Forum (EPF) (also involved in the Pharmaceutical Forum). EPF had been created in 2004 as an EU umbrella organisation bringing together many disease-specific patient organisations. It was the first attempt to make sure that patients could speak to the EU institutions with a single voice. The position of EPF and other patient organisations changed over the years: from being in favour of pharmaceutical companies' providing information on prescription medicines on TV channels in 2007 (The Guardian, May 21, 2007) to firmly being against advertising while remaining in favour of more industry information about medicines in 2009. In addition, following some criticisms (HAI, 2006), patients organisations increased transparency in relation to their sources of funding, mostly pharmaceutical companies. They also gained legitimacy and a more active role in all EU debates regarding health care issues.

EU competence on pharmaceuticals: From an industrial perspective to a public health perspective

Since the EU was given competence on the regulation of pharmaceutical products (1965), the Directorate General in charge of the pharmaceutical dossiers has always been DG ENTERPRISE. In 2009, in view of the beginning of the new legislative term following the European election and the establishment of the Barroso II commission, EU public health NGOs launched a campaign for medicines to be tackled as part of health policies and no longer as a part of the EU policy to promote the competitiveness of the European industry (AIM, BEUC, EPHA, 2009). They requested and secured 
the competence on the dossiers regarding pharmaceuticals and medical devices to be moved from DG ENTERPRISE to DG SANCO. ${ }^{10}$

In his hearing in front of the European Parliament in January 2010, Health Commissioner John Dalli stated that "the inclusion of Pharma in the Health portfolio gives us the opportunity to reassess the proposal on the table and to inject a stronger patient perspective". His statements generated some misunderstanding as some understood that the Commission was going to withdraw the Proposal. The Commissioner had to clarify in a formal letter sent in April 2010 to the Chair of the ENVI Jo Leinen that he did not intend to withdraw or modify the Proposal, rather he was "committed to determine the Commission position strictly from a patient perspective". Finally, as mentioned above, after the European Parliament's first reading, the Commission modified the Proposal and presented an amended text in 2011. The Commission's decision to revise the Proposal as well as the public statements of its officials in public fora (see table Appendix IV) clearly indicated a change in perspective and had an impact on the policymaking. Brooks \& Geyer (2012) argue that the internal Commission struggle between DG ENTERPRISE and DG SANCO were "of central importance" to the outcome of the debate on DTCA and the provision of information to patients. In the meantime, with the Lisbon Treaty coming into force, the legislative framework had also changed. The new provision on public health (Article 168 ) includes a specific reference to the safety of medicines and medical devices. This means that the legal basis for the EU legislation on pharmaceuticals is no longer only the provision on internal market (Article 114) but also that on public health.

Many elements of the general context had also changed. Despite its limited competencies (Article 168), the EU had become more and more involved in health care and issues such as cross-border health care, health technology assessment and e-health, which also affected pharmaceutical policies. New information channels like social networks make the distinction between information and advertising even more difficult and challenge the definition of the EU legislative framework. The financial crisis and the ageing of the population also put more strain on already squeezed health care budgets. This is associated with citizens' increased expectations and quest for

\footnotetext{
${ }^{10}$ On September10, 2014, the President Elect of the European Commission, Jean Claude Juncker, announced that the competence on medicines and medical devices will be moved back to DG ENTERPRISE, which will be merged with the DG responsible for the internal market (DG GROWTH).
} 
information. Moreover, during the last seven years, the pharmaceutical industry has often been under the spotlight for a series of issues, owing to the following reasons: (1) the European Commission's competition inquiry in the pharmaceutical sector in 2008 that highlighted that the pharmaceutical industry put in place anti-competitive strategies to delay the access of generic and new medicines on the market, (2) scandals such as the case of Mediator, a diabetes medicine sold as a weight loss drug associated with the death of thousands of people and (3) the wave of clinical data transparency linked with the revision of the EU legislation on clinical trials in 2010.

\subsubsection{Second and third amended version of the European Commission's Proposal}

Owing to the reluctance of the Member States to start the discussion on the text and following the European Parliament's amendments, in October 2011, the European Commission adopted a modified Proposal on the provision of information to patients. Following the Mediator scandal, the European Commission conducted a "stress test" on the recently adopted Directive on pharmacovigilance that was part of the pharmaceutical package and finalised in December 2010. The newly adopted legislation failed the stress test, and the European Commission used the opportunity of the revision of the Proposal on the provision of information to patients to introduce elements on pharmacovigilance in the Proposal, especially in relation to the information to be provided to patients in case of safety problems. In the amended Proposal, many controversial issues such as the awareness campaigns of pharmaceutical companies and the possibility for the industry to publish revised package leaflet were removed. Considerable emphasis was placed on the right of patients to have access to high-quality information and not the industry's possibility of disseminating information to consumers about its products.

Following the Council exerting pressure on the European Commission, in February 2012, the European Commission adopted an amended version of the modified Proposal separating the parts on pharmacovigilance integrated in the previous text to another text to facilitate the discussion. In July 2012, the European Commission adopted a corrigendum to correct some minor mistakes in the Regulation on the provision of information to patients regarding the cross-references in Article 2. 


\subsubsection{Firm opposition of the Council: A closed road}

Since the adoption of the pharmaceutical package, the Council made it clear it was going to prioritise the discussion of the proposal on pharmacovigilance and counterfeit medicines over the one on information to patients. During the Health Council on December 1, 2008, Commissioner Günter Verheugen acknowledged that "it makes no sense to rush headlong into the wall" concerning patients' access to information on medicines. He stressed that the current situation allowing English-speaking patients to have access to information on the Internet, while other Europeans being "deprived of it, is not acceptable". However, he added that "the Commission is willing to take a step towards the Council to find a common basis". During the Health Council of June 2008, the Commission highlighted the need to have a common approach to the provision of information to patients in the EU. The Council never examined the text in detail and only exchanged view on the most critical issues, namely the distinction between information and advertising and self-regulation. The UK and the Swedish delegations were more positive towards the text, as they had in place already an advanced system for the provision of information to patients. Many of the other delegations expressed opposition to the text. The main concerns of Germany, France, Estonia and Finland were the difficulty in making a distinction between information and advertising, the difficulty of monitoring the information, the increased demands of pharmaceuticals and the associated danger to the sustainability of the national health care systems. Belgium adopted a more neutral approach and others such as Ireland, the Netherlands and Cyprus insisted on the key role that health care professionals should play in information provision. Some questioned the EU competence on the area and the added value of the Proposal. However, the lack of interest of the Member States in pursuing the legislation and their reservations remained, and no progress was made. At the Health Council in Luxembourg in June 2009, the EU health ministers concluded the following:

While agreeing that there is a need to improve the information to the general public on prescription-only medicinal products, many delegations feared that the suggested system will be overly burdensome for competent authorities without leading to significant improvements in the quality of the information provided to patients. In addition, many delegations hold that the distinction between information and advertising was not sufficiently clear and therefore feared that the proposals would not provide sufficient guarantees that the prohibition of advertising of prescription-only medicinal products 
to the general public would not be circumvented. (Council of the EU, 2009)

Following this, the Council decided to prioritise the other proposals concerning the pharmaceutical package, namely those on counterfeit medicines and pharmacovigilance, and not start discussing the Proposal on the provision of information to patients.

In June 2009, the European Economic and Social Committee (EESC) issued its opinion. The EESC expressed "reservations on individual aspects of the proposal" and general doubts on the text. In particular, it asked for an independent body to provide information to the public and health-related publications and post-authorisation safety studies to be taken out of the Proposal. It also highlighted the difficulty of making a distinction between information and advertising and the important role of health care professionals.

After three years of achieving no progress, the Health Council Conclusions of May 2012 reaffirmed that it was not possible to find consensus on the Commission's Proposal. In May 2014, the European Commission formally withdrew the Proposal.

Tracing the key developments of the debate on the Proposal has served to capture the gravity of the controversy surrounding the issue. This endeavour is useful to better understand if and to what extent the controversial nature of the policy impacted the sourcing and use of evidence, particularly during the policymaking process described in the next part of the chapter.

\subsection{Sourcing Evidence}

This section explores what constituted the knowledge base for the European Commission when drafting the Proposal. Additional studies, consultations or a new impact assessment were not undertaken by the European Commission when drafting the amended Proposal. Therefore, the analysis refers to the information the Commission considered when drafting the first version of the Proposal during the period between 2005 and December 2008. The types of evidence are analysed following the Bowen and Zwi (2005) classification. Table 5.3 summarises the main types of evidence considered and the period they were undertaken. 
Table 5.3

Type of Evidence and the Period It Was Sought

\begin{tabular}{|l|l|}
\hline Period & Type of evidence \\
\hline 2005-2008 & High-Level Pharmaceutical Forum \\
\hline $2006-2008$ & Conferences, workshops, seminars (see Appendix IV) \\
\hline $\begin{array}{l}\text { Mar 8- } \\
\text { May 2007 }\end{array}$ & $\begin{array}{l}\text { Public consultation by High-Level Pharmaceutical Forum" } \\
\text { on patient information: Quality criteria and information } \\
\text { package on diabetes }\end{array}$ \\
\hline $\begin{array}{l}\text { Apr-Jun } \\
2007\end{array}$ & $\begin{array}{l}\text { Public consultation on the European Commission's draft } \\
\text { report on current practices with regard to the provision of } \\
\text { information to patients on medicinal products }\end{array}$ \\
\hline $\begin{array}{l}\text { Jul-Oct } \\
\text { 2007 }\end{array}$ & $\begin{array}{l}\text { Public consultation on the future of pharmaceuticals for } \\
\text { human use in Europe }\end{array}$ \\
\hline Dec 2007 & $\begin{array}{l}\text { Report on current practices with regard to the provision of } \\
\text { information to patients on medicinal products }\end{array}$ \\
\hline $\begin{array}{l}\text { Jan-Mar } \\
2008\end{array}$ & $\begin{array}{l}\text { Europe Economics' independent impact assessment study } \\
\text { (including literature review, interviews with key } \\
\text { stakeholders, cost-benefit analysis) }\end{array}$ \\
\hline
\end{tabular}

\subsubsection{Research}

Europe Economics, the consultancy hired to conduct an independent impact assessment study to be used by the European Commission to prepare the official impact assessment of the European Commission, carried out a literature review. The stated aim of the literature review was to collect evidence to help assess the impact of the provision of information about medicines on patients, health care professionals, health systems and public health. The consultancy also attempted to categorise the impact on the basis of the likely effect of the information, namely compliance effect, preventative effect, awareness effect, prescription distortion effect and interaction effect. 
The research methodology was also described in Appendix 3 of the impact assessment. In particular, the consultancy followed a two-stages approach. The first stage consisted of listing several relevant articles using an Internet search and building on the references used in previous works in the area of provision of information to patients. The second stage involved using the abstracts to identify the articles most relevant and making a shortlist. In total, 22 publications were shortlisted and reviewed. No information was provided on the type and number of studies listed in the first stage. The selected items were then classified according to the thematic category. Among the studies considered, six concerned drug and health information, three the appraisal of medicine information, three the different models of regulation and the remaining ones pertained to consumer information, prescribing costs and the economic theory on advertising. Among the listed items, there were also six studies regarding the impact of DTCA in the US and New Zealand.

Although these studies were only indirectly relevant for the impact assessment, they were considered as "upper bound estimates of the effects of greater information provision" (European Commission, 2008, p. 47) with the assumption that any prescription distortion effect associated with more information was likely to be less relevant than that associated with advertising. A summary of the selected items was also included in the impact assessment. It also indicated that more detailed summaries were available in Appendix 11 of the impact assessment report, but the appendix was not public. It is worth noting that the literature review included not only scientific articles or publications in scientific journals but also reports from the stakeholders, including a report from the Royal Pharmaceutical Society of Great Britain and a report from the US National Institute for Healthcare Management.

Despite the European Commission explicitly stating that it considered similar experiences with DTCA, the two researchers on the provision of information to patients interviewed for this thesis did not find this effort to be sufficient. One of them insisted as follows:

There is actually quite a body of evidence out there that they could have referred to that wasn't referred to at all. And it's available under indexed computerised bibliographic databases that all academic researchers would be accessing... More research should have been conducted on the public health impacts, on how much the information source matters or not. Not a comprehensive review of what has happened in other jurisdictions where you have a more of ability for 
the industry to advertise its products to the public. I think Canada is actually quite a good example of a country where you still have a prohibition of direct-to-consumer advertising, but we've seen a very radical shift in the interpretation that has opened up many kinds of sort of partial and secondary type of direct-to-consumer advertising that might be seen to be quite similar to the Proposal. (\#28, Researcher on information to patients)

In this regard, another researcher stated as follows:

Ok, you could say there's no direct evidence in terms of what's exactly being proposed. But then you look at what is the closest, you know what are the closest kinds of activities that are out there and what do we know about the information quality, and the evidence of the facts. (\#21, Researcher on information to patients)

The perceptions of the interviewees concerning the use of evidence, as mentioned above, was probably due to the fact that the European Commission did not consider well-known comprehensive studies on DTCA (the bibliography in Appendix VIII includes several peer-reviewed scientific studies on the impact of DTCA that were used when conducting the literature review for this research). An example is the systematic review on the benefits and harm of DTCA by Gilbody et al. (2005) that concluded that the research evidence tends to support the negative impact feared by those who support a legislative ban. This study was not taken into account. Another neglected study was the review of Donohue et al. (2007) titled "A Decade of Direct-toConsumer Advertising of Prescription Drugs.

An editorial published in January 2007 in the Lancet also warned the EU legislators to carefully consider the US situation before proceeding with the relaxation of the ban on advertising. In particular, it pointed out the fact that it is very hard to regulate DTCA once it was "out of the genie bottle" and the difficulties US regulators face in overseeing the compliance of advertisements with the legislation. The Lancet editorial also bluntly stated that the purpose of DTCA was "clear: to sell lucrative, on-patent name branded drugs" and the "claims to the contrary just do not pass the straight face test" (The Lancet, 2007, p.1). The editorial recommended to "fund independent information sources, free of industry influence, to provide the public with unbiased evidence-based information". The Vice-President of the European Commission Verheugen and the Director of the European Federation of Pharmaceutical Industry Associations (EFPIA) responded stressing that the Commission was not considering lifting the ban and was 
just looking to improve the provision of information to patients about medicines.

During the public consultations and debate on the Proposal, many of the available studies on DTCA and evidence on the lack of effectiveness of self-regulation were brought up by those stakeholders mostly opposed to the Proposal to support their arguments and make them more convincing (see BEUC, AIM, HAI position papers on the provision of information to patients, 2008). In this regard, a researcher) stated as follows:

The Proposal should have looked at the international experience with similarly loosening the restrictions on the industry's ability to advertise prescription-only products to the public. Even to promote them in partial way... and there you have experience from the European Union from disease awareness campaigns. The first thing you will look at is, how accurate is that information, is it what do we know about the impact in terms of people understanding of their own health problems or lack of health problems, in terms of medicine use in a way that's more likely to create benefit than harm? All of those sides you could have looked at... so there is a total number of areas that seemed obvious to look at, and certainly came up if you looked at a lot of the responses that came from EPHA or from groups that where looking at this from a public health perspective. (\#28, Researcher on information to patients)

Europe Economics looked at not only the evidence on DTCA but also the studies on health information. Among the six literature items on drug and health information were the following: a policy paper with recommendations from the EU Health Policy Forum (a European Commission working group composed of EU umbrella health organisations, including NGOs and industry), a report of the British Pharmaceutical Company Association, a previous report of the consultancy Europe Economics itself and a document of the Finnish Medicines Agency. However, these studies were criticised by the two researchers on the provision of information to patients interviewed for this case study:

What was missing was an analysis of the public health literature. This wasn't a comprehensive analysis of what types of information initiatives are out there already... It is fair to say it was disregarded. I just think that the people who were doing that work had no idea that that evidence was available or what to do with it or that public health is a discipline more worthy than a report that comes from a 
consultancy or even from a university unless that is an internationally recognised public health centre. The literature tends to be a little bit selective and of course the literature that is selected tends to cluster around the original proposition, which in this case was that there was some form of deficiency in the current information regime in Europe. (\#28)

Both the researchers $(\# 21 ; \# 28)$ also criticised the Commission for its failure to consider the research on the provision of information to patients from a broader perspective and its focus only on the information from the pharmaceutical industry on prescription medicines:

If the starting point was to ensure that patients have information that helps them to make informed health care choices and improve health outcomes, the research evidence to be used would be completely different compared to the one mentioned by the European Commission in the explanatory memorandum of the Proposal and in the impact assessment. Research for that purpose would have rather covered aspects such as health literacy, patients' appraisals skills, information processing behaviour and health impact... If you look at the starting point of actually informing patients, you would be looking at a very different body of evidence than what they were looking at.

A similar opinion was shared by a representative of pharmacists who also considered that in its evidence search, the European Commission didn't sufficiently explore the impact of the Proposal on public health: "The Commission didn't fulfil its duty to look into what does the research evidence show in terms of public health impact" (\#11, Secretary General, EU Pharmacists' Association). However, it is worth noting that the evidence of the impact of DTCA is in general inconclusive regarding the impact on public health. Most studies report both positive and negative effects on the adherence to treatment, medicine consumptions and the impact on doctor-patient relationships, and in any case, most of them apply to non-EU countries. One of the interviewees mentioned a systematic review conducted in the UK that found only a very few studies matching the review criteria:

There is a systematic review that was carried out by the researchers in the UK looking at the influence of direct-to-consumer advertising, and they applied standards to the evidence. For instance, there had to be a control group, and they had to look at certain outcomes. They had fairly broad standards, but they still only found four studies that met their standards when they published it in 2005. And two of those studies were actually about non-branded information campaigns, one 
of them was in the Netherlands. So in a way, yes and no. Certainly, there is some evidence that could be used. (\#21, Researcher on information to patients)

Moreover, the available research evidence on the health benefits of the provision of non-promotional information to patients, e.g., package leaflets, in terms of enhancing patients' knowledge about treatments and ensuring the safe and effective use of medicines is inconclusive (Raynor et al., 2007).

Regarding the model of regulation, the literature review included three papers not specifically related to the pharmaceutical context, but it did not include specific available studies on the regulation in the pharmaceutical sector. For instance, concerning the monitoring system, the available studies on the US system (GAO 2002; Abel et al., 2008) showed that the US Food and Drug Administration (FDA) monitoring system of DTCA didn't work properly. In 2004, the Agency received 15.458 campaigns to be examined, but only a small portion of the material submitted was assessed.

The literature review also attempted exploring the effects of how the information is presented "drawing on behavioural economics research in framing effects" (European Commission, 2008, p. 35). To this end, a publication of the UK Better Regulation Executive and National Consumer Council was included among the items of the literature review. On the basis of the literature review, the consultant identified significant gaps in the available evidence and stressed that the literature highlighted the both benefits and risks associated with the provision of greater information on medicines and it was not helpful in making a distinction between information and advertising.

To sum up, despite the view expressed by one of the interviewees that "there was hardly any concrete piece of research evidence used during the whole debate" (\#10, European Parliament Political Advisor), the data collected shows that the European Commission at least attempted to use "research evidence", but the outcome presents a number of limitations.

First, given that the Proposal introduced the new concept of nonpromotional information about products from their manufacturers, no available evidence was available on the impact of such kind of information on patients. Second, some of the research evidence was looked at in a biased and selective manner. The studies on DTCA were used as an "upper bound reference" by the consultant who conducted the impact assessment, but the interviewed researchers on the provision of information to patients and editors 
of the Lancet article mentioned above stressed that the Commission failed to properly consider the impact of DTCA as it emerged from scientific studies. This was also due to the fact that the consultant took into account only a very limited and a specific sample of studies on DTCA, neglecting those highlighting the negative of DTCA on public health.

Another key element that characterises the search of research evidence in this case study is that most of the evidence on the negative impact of DTCA was brought to the attention of decision-makers by those opposing the Proposal. In this context, the stakeholders, particularly health and consumer NGOs, acted as brokers of research evidence and acted as a filter between academic research and policy. The experience of a researcher on information to patients (\#21) was that in the policymaking process, the "lobbyists acted as a filter and used the research evidence to win the lobbying from the industry" (\#21, Researcher on information to patients). The Secretary General of a public health NGO (\#8) said that "We acted as brokers of evidence".

\subsubsection{Knowledge and information}

The European Commission invested considerable time and resources in gathering the relevant knowledge and information. Particularly, in preparation of the adoption of the legislative Proposal, the European Commission established the EU High-Level Pharmaceutical Forum, a group of stakeholders and Member States that included a dedicated working group on the provision of information to patients and compiled information on the current practices with regard to the provision of information to patients.

\section{Pharmaceutical Forum}

As mentioned in section 5.2, in June 2005, the European Commission established the Pharmaceutical Forum, a high-level platform for discussing matter relating to pharmaceuticals among the European Commission, the Member States and the key stakeholders. The Forum was a follow-up to the G10 High-Level Group on Innovation and Provision of Medicines. The Forum ran for three years. The Steering Committee was restricted to seven Member States (selected from recent, current and upcoming Presidencies), a representative of the European Parliament and ten senior representatives from the key stakeholder organisations. The Committee was chaired jointly by Vice-President Verheugen in charge of Enterprise and Industry and the Commissioner for Health and Consumer Protection Kyprianou. The Committee oversaw the work of and provided operational guidance to three working groups. The role of the working groups was to provide expert advice 
on the provision of information to patients, pricing and relative effectiveness. The working groups were composed of the representatives of the Member States and stakeholders and chaired jointly by DG ENTERPRISE and Industry and DG Health and Consumer Protection. In September 2006, in his address to the members of the Forum, Commissioner Kyprianou stated as follows:

We need to go beyond theory and develop practical models and pilot them to ensure that they work in practice. I would like to suggest that in the three areas we develop these kinds of models based on evidence and experiences and that we pilot them. (European Commission, 2006)

The working group on the provision of information to patients was assigned the task to develop proposals for improving the quality of and access to information of European consumers on pharmaceuticals and other healthrelated issues. The group developed a factsheet on disease information using diabetes as an example and defined the criteria of high-quality information. In addition, it focused on how to improve the electronic and non-electronic dissemination of information and the availability of supporting information in the health care environments (such as pharmacies and hospitals). According to the European Commission (2006), the working group also "contributed with ideas for greater harmonisation of information activities at European level", which fed the report on the current practices of information provision in the Member States that constituted the basis of the legislative Proposal on the provision of information to patients. In spring 2007, the Commission organised a public consultation on the work of the Information to Patient Working Group, namely the factsheet on diabetes and the quality criteria to give all the relevant stakeholders the opportunity to provide their views and comments on the output of the working group. The consultation received much criticism:

Both inside and outside the working group, much criticism was expressed on the content and the process. Various stakeholders asked how the results of the consultation exercise would be used. The model information package in particular was criticised, among other things, for the fact that it did not meet the quality criteria proposed by the same group. Given the heterogeneous approaches pursued by the various Member States, it was questioned whether it was useful to organise information provision at the European level. (\#1, Senior Policy Officer, Health Insurers' Association) 


\section{patients \\ Report on the current practices on the provision of information to}

Article 88a of the pharmaceutical Directive 2001/83/EC, as amended by Directive 2004/27/EC, called on the European Commission to "present a report to the European Parliament and the Council in 2007 on the current practice with regard to information provision - particularly on the internet and its risks and benefits for patients". Article 88a also provided that "the Commission shall, if appropriate, put forward proposals setting out an information strategy to ensure good-quality, objective, reliable and nonpromotional information on medicinal products and other treatments and shall address the question of the information source's liability". The draft report was submitted for public consultation in April 2007. The Commission received 73 responses from various stakeholders. The responses were not published but reported in the form of a 5-page short summary that highlighted that most of the respondents supported the draft report, while others were critical. The report was adopted with few amendments in December 2007. The report constituted the knowledge base for the Commission concerning the situation on the provision of information to patients and included the following:

- $\quad$ a detailed analysis of the political and legal framework, - $\quad$ an overview of the current practices of information provision in 23 EU Member States and 3 other countries members of the EEA on the basis of the contributions provided by the national competent authorities,

- $\quad$ specific information on the availability of the information on medicines on the Internet and the existence of public-private partnership,

- $\quad$ an overview of the activities of the European Commission (e.g., EU Health Portal) and the EMA on the provision of information to patients (e.g., contributions of the patients and consumers' working party),

- A brief overview of what the European Commission considered as the evidence on patients' needs in terms of information and the role of health care professionals.

In particular, 18 items were listed as the reference of the evidence. Among the eighteen items, five were statistical reports from Eurostat, Eurobarometer and Internet World Stats; seven were articles published in peer-reviewed journals; one document was from the American 
Pharmaceutical Company Association, one from the British Consumers' Association, two from the UK research centre Picker Institute and one from the Brussels-based think tank Friends of Europe.

The Commission's efforts to gather evidence and consult the stakeholders were not considered sufficient by some stakeholders. In this regard, one of the interviewees stated as follows:

The majority of the respondents to the public consultation said that there is no need to change this legislation, and there was a general request first to analyse what are the real (information) needs of today, and this has not been done and is still not done. (\#1, Senior Policy Officer, Health Insurers' Association)

According to another interviewee, the European Commission took for granted that there was a need for action at the EU level:

The problem I think with the proposals was that the Commission accepted immediately the fact that there was a gap in info in Europe. They didn't even try to find out either qualitatively or quantitatively if there was a problem. (\#21, Researcher on information to patients)

\section{Three public consultations}

As mentioned above, the European Commission launched three different public consultations related to the provision of information to patients in the year that preceded the adoption of the Proposal.

The relatively high number of public consultations on the same topic could be attributed to the sensitivity of the issue, political and public interest in this area and need to increase transparency and consensus. However, according to one of the stakeholders involved, the questions of the consultations were biased:

I must say that we really started to be fed up with responding to all those consultations on information to patients. They were a lot, and it didn't change anything. We took part in the survey. There were no open questions but questions where they push you to get a certain kind of answer. Also, the public consultations had oriented questions, and all this was really misleading and certainly not done to make a good evidence-based analysis about the situation. (\#1, Senior Policy Officer, Health Insurers' Association)

The European Commission was criticised because of the following reasons: (1) The responses to the public consultation on the report on the current 
practices of the provision of information by the Member States and the responses of the consultation on the outcome of the Pharmaceutical Forum were not made public and (2) Some stakeholders (AIM, BEUC, HAI, ISDB, MIEF, 2007) considered that the results of the consultation were not presented in an accurate and neutral manner. In this respect, a researcher on information to patients stated as follows:

The representation of civil society participation in this decisionmaking process was very poor because from 2006 until they published the legislation, the European Commission had six public consultations, and from what I could see, every time there was a consultation, and even if a large majority of civil society groups would express their opinion, somehow in the analysis of the results, they never seemed to be taken it into account. (\#21, Researcher on information to patients)

\subsubsection{Interest and ideas: A case of informational lobbying}

From the interviews, direct observation and the position papers and answers to the public consultations of the key stakeholders, it has emerged that the Proposal on the provision of information to patients is a clear example of the "informational lobbying" theory described in Chapter 2. Potters and Van Winden (1991) define informational lobbying as the use of interest groups of expertise and information on the issue of interest to policymakers to convince them to implement a given policy. Rule 9(4) in the Rules of Procedure of the European Parliament formally acknowledges this by defining lobbyists as "persons who wish to enter Parliament's premises frequently with a view to supplying information to members within the framework of their parliamentary mandate in their own interests or those of third parties" (European Parliament,2010).

According to a political advisor who closely followed the dossier in the European Parliament, "the main sources of information were the lobbyists" (\#10, Political Advisor, European Parliament). Speaking to Nadia Carboni about the pharmaceutical package, a European Commission official (Policy Officer, DG ENTERPRISE) stated as follows:

We closely work with advocacy groups who produce evidence-based arguments. After a proposal is drafted, we usually have public consultation and impact assessment. We get many comments by advocacy groups. The best for us are the ones which produce knowledge... if we learn from that, it means they are good arguments. (Carboni, 2009, p.14) 
Carboni also gathered the views of two MEPs on this issue: "The advocacy groups do both promoting their interest and providing information. The last one is a very important function by which MEPs are educated on issues" (MEP, ENVI); "In writing the report we usually contact stakeholders for getting info, opinions, etc. At the same time, we receive a lot of opinions, ideas, critics by Member States national governments, patients' groups, industries, etc" (MEP, Committee on Industry, Research and Energy, Carboni, 2009, p.14).

Who were the lobbyists providing information to policymakers on the provision of information to patients, and what were their arguments? In consideration of the composition of the EU Pharmaceutical Forum, contributions to the public consultations related to the Proposal, organisers and participants of the most relevant working groups (e.g., Pharmaceutical Forum, Health Policy Forum, EMA, patients and consumers' working party) and conferences and seminars organised on the Commission's Proposal (see Appendix IV), the key stakeholders who influenced the debate can be identified. Applying Sabatier's (1999) definition of advocacy coalitions (see chapter 2), the most relevant stakeholders can be classified into two coalitions. Coalition I includes those organisations supporting the Proposal, namely the pharmaceutical industry, publishers and patients' groups. Coalition II consists of public health NGOs, consumers' organisations, health care professionals' associations and health payers who advocated against the Proposal and in support of public health. In Sabatier's advocacy coalition framework, stakeholders want to convert their beliefs into policy and then seek allies to form advocacy coalitions to pursue the identified policy objectives.

Table 5.4 gives a brief summary of the main arguments used by the two coalitions. The table is based on stakeholder position papers, the responses to the public consultations and from statements expressed in conferences, workshops and other EU fora that the researcher participated (see list in Appendix IV). 
Table 5.4.

Opposing Arguments: Views of Those in Favour and Against the Legislative Proposal on the Provision of Information to Patients

\begin{tabular}{|l|l|}
\hline \multicolumn{1}{|c|}{$\begin{array}{c}\text { Arguments of those supporting } \\
\text { Coalition I }\end{array}$} & $\begin{array}{l}\text { Arguments of those opposing the } \\
\text { Proposal: } \\
\text { Coalition II }\end{array}$ \\
\hline $\begin{array}{l}\text { Pharmaceutical companies can } \\
\text { provide non-promotional } \\
\text { information about their products } \\
\text { even beyond the statutory } \\
\text { information (package leaflets). }\end{array}$ & $\begin{array}{l}\text { It is not possible to draw the line } \\
\text { between information and } \\
\text { advertising. Even if possible, the } \\
\text { industry would provide } \\
\text { information only on the most } \\
\text { profitable products introducing a } \\
\text { bias. }\end{array}$ \\
\hline $\begin{array}{l}\text { Increased compliance and } \\
\text { adherence to treatments }\end{array}$ & $\begin{array}{l}\text { The Proposal does not allow the } \\
\text { comparison of information, and it } \\
\text { has no added value. }\end{array}$ \\
\hline $\begin{array}{l}\text { More information contributes to an } \\
\text { earlier diagnosis and in better } \\
\text { health outcomes }\end{array}$ & $\begin{array}{l}\text { The Proposal would lead to an } \\
\text { increase in medicine consumption } \\
\text { and higher health care costs. }\end{array}$ \\
\hline $\begin{array}{l}\text { A clear legal framework is needed } \\
\text { to avoid some circumventing the } \\
\text { ban on advertising. }\end{array}$ & $\begin{array}{l}\text { The Proposal would lead to } \\
\text { symptoms advertising }\end{array}$ \\
\hline $\begin{array}{l}\text { The Proposal improves patient } \\
\text { empowerment. }\end{array}$ & $\begin{array}{l}\text { An overload of information that } \\
\text { patients do not seek will not } \\
\text { empower them. On the contrary, it } \\
\text { can be disempowering. }\end{array}$ \\
\hline $\begin{array}{l}\text { The current provision of } \\
\text { is inadequate. }\end{array}$ & $\begin{array}{l}\text { Good sources of information } \\
\text { already exist. The Proposal will } \\
\text { not solve the problem of } \\
\text { information overload and } \\
\text { reliability of the information but } \\
\text { only fragment the information } \\
\text { further. }\end{array}$ \\
\hline
\end{tabular}




\begin{tabular}{|l|l|}
\hline $\begin{array}{l}\text { The pharmaceutical industry } \\
\text { knows best about its products. }\end{array}$ & $\begin{array}{l}\text { The Proposal only focuses on the } \\
\text { role of the pharmaceutical industry } \\
\text { without considering other sources. }\end{array}$ \\
\hline $\begin{array}{l}\text { The content is more relevant than } \\
\text { the source of the information. The } \\
\text { industry is a reliable source. }\end{array}$ & $\begin{array}{l}\text { 2.5 days for EMA to assess a } \\
\text { submission of information and } 60 \\
\text { days' time limit are not sufficient. } \\
\text { The system can be blocked by a } \\
\text { large number of industry requests } \\
\text { and result in no control over the } \\
\text { information. }\end{array}$ \\
\hline $\begin{array}{l}\text { The Proposal would reduce the } \\
\text { inequalities in the provision of } \\
\text { information. }\end{array}$ & $\begin{array}{l}\text { The information on specific } \\
\text { products would be combined with } \\
\text { already permitted symptom } \\
\text { advertising, resulting in } \\
\text { undesirable effects. }\end{array}$ \\
\hline $\begin{array}{l}\text { The Proposal would improve the } \\
\text { health literacy among EU citizens. }\end{array}$ & $\begin{array}{l}\text { The Proposal would increase the } \\
\text { inequalities, as the Member States } \\
\text { can have different interpretations } \\
\text { of what constitutes advertising and } \\
\text { what is information and also of } \\
\text { what can be considered as a } \\
\text { health-related publication. The } \\
\text { access to the Internet remains } \\
\text { unequal across the EU. The } \\
\text { Proposal would not solve the } \\
\text { problem. }\end{array}$ \\
\hline
\end{tabular}

During the debate, many examples of bad and good practices such as the Swedish medicines information system (the so-called FASS) have been brought to the attention of the policymakers and health community. The debate was also an opportunity to raise anecdotic evidence. In public 
statements, the representatives of the European Pharmaceutical Company Association (EFPIA) often referred to the case of a Japanese citizen who came to Belgium and was unable to find information about his medicine in English or his language. In this regard, an stated as follows: "I think the communication of the industry - like the Japanese guy's story - is perhaps far more effective than real evidence, and it gets to places" (\#21, Researcher on information to patients).

The debates that were heated at the beginning became slightly less confrontational over the years partly because it was clear that the Member States were far from reaching an agreement on the text. The few publishing companies involved at the beginning of the debate realised it was not politically possible to have a push mechanism concerning the information provided via the print media. The pharmaceutical industry insisted on the need to maintain the ban on advertising and since the beginning, showed interest only in the information provided via the Internet, as it considered it more appropriate to the EU landscape and pushed information was very expensive. Also, both public health and consumer organisations as well as health insurers toned down their criticisms because the European Parliament and the Commission removed the most controversial parts of the original Proposal and addressed many of their concerns and the terms of the debate had changed.

\section{Role of patients' organisations and the imbalance of resources}

Within the two coalitions, the role of patients' organisations deserves special attention because of their policy positions and role in the debate. Particularly, statements such as that of the Association of the British Pharmaceutical Industry (ABPI) as follows cast some shadows over the involvement of patients' organisations in the debate since DTCA became an issue in Europe:

The ABPI battle plan is to employ ground troops in the form of patient support groups, sympathetic medical opinion and health-care professionals - known as 'stakeholders' - which will lead the debate on the informed patient issue. This will have the effect of weakening political, ideological and professional defences (...) Then the ABPI will follow through with high-level precision strikes on specific regulatory enclaves in both Whitehall and Brussels. (Jeffries, 2000, quoted in Medawar \& Hardon, 2004, p.121) 
However, the problem of patients' groups being used by the pharmaceutical industry remained valid also in the context of the revision of the legislation in 2008. A political advisor of the European Parliament confirmed that the pharmaceutical industry uses patient organisations to bring forward their arguments to policymakers: "The pharmaceutical industry usually lobbies in indirect ways. They rarely propose amendments themselves. They rather host events, seminars. They work with patient organisations and they reach the level of creating their own NGOs" (\#10, Senior Political Advisor, European Parliament).

A study published by Health Action International in 2010 suggests as follows:

Corporate sponsorship may be associated with civil society perspectives on specific policy debates. The formation of pharmaceutical policy at the EU level relies on a multi stakeholder approach where each stakeholder group is given an opportunity to express their (its) unique perspective. These findings suggest that a financial relationship between commercial and civil society groups could jeopardise the uniqueness of the patient and consumer perspective and threaten the integrity of the multi-stakeholder format and the policy formulation process. (HAI, 2010, p.2)

Also, according to Carboni (2009), given that many patients' organisations receive funding from the industry, "they cannot be totally in opposition with it" (p.27).

On this basis, the reliability and independence of the views expressed by patients' organisations throughout the debate are questionable. It is also important to mention that in response to the criticisms from public health and consumers groups, over the years, patients' organisations have substantially increased the transparency concerning the sources of their funding and started publishing the donations and grants they receive from pharmaceutical companies.

More generally, regarding the financial resources used by the stakeholders to influence the policy debate, a key element that characterises the two advocacy coalitions is the imbalance of resources in terms of interest representation, especially between the pharmaceutical industry and health and consumers' groups. According to a report from the organisation Corporate Europe Observatory, the pharmaceutical industry spends 15 times more than civil society and consumers groups to lobby the EU policymaking process. In 
particular, on the basis of the information provided in the EU transparency register, they calculated that the industry spends 40 million euro every year and employs 176.5 lobbyists, while health NGOs spend 2.7 million and employ 48.4 lobbyists (CEO, 2015, p.9).

\subsubsection{The politics and economics of the provision of information to patients}

In the Bowen and Zwi model (2005), politics is defined as the evidence regarding the information relevant to the government agenda, political risk assessment, saleability, opportunity and crises, while economics includes evidence regarding finance and resource implications, cost effectiveness evaluation and opportunity costs. As explained in chapter 2 and 4, the Bowen and Zwi model (2005) has two different categories, but here they are addressed together.

Concerning economics, it is important to note that in all EU Member States, prescription-only medicines are mostly paid for by the national health care system and constitute a significant percentage of the health care budget spending. Following the expenses of inpatient and outpatient care, "pharmaceuticals represent the third largest expenditure item for health care spending, accounting for more than a sixth (16\%) of health expenditure on average across OECD countries in 2015, not taking into account spending on pharmaceuticals in hospitals" (OECD, 2017, p.187). The available evidence indicates that the promotion of pharmaceuticals has an impact on medicine consumption and therefore on pharmaceutical spending as well. The adverse effects of medicines cost the EU $€ 79$ billion every year and cause 197,000 deaths per year (European Commission, 2008). It is therefore not a surprise that politics and economics were crucial elements that influenced the policymaking process on pharmaceuticals and provision of information to patients. Although MEPs focused mostly on the principle of patients' right to information, politics and economics played a major role in the positioning of the Member States. From a selection of the Member States' responses to the public consultations on the key ideas for a legislative Proposal in 2007 ( $\mathrm{n}=$ 6 ) and official and unofficial documents of the Council $(n=5)$, it emerged that the members states were concerned about the impact of a change in the legislation on the consumption of medicines and therefore on their health care budgets.

For the impact assessment, the consultancy Europe Economics provided a detailed cost-benefit analysis. The analysis included the costs of information provisions, administrative costs and the costs for regulators presented with high and low estimates. Despite the Commission's attempts to 
quantify the costs of national governments on the basis of the various policy options (e.g., push and pull information), none of the interviewees representing the Member States $(n=3)$ mentioned the use of the economic figures of the impact assessment or the impact assessment in general as a basis for their government's position on the legislation.

Regarding politics, the European Commission knew the issue has always been an uncomfortable one and was difficult to "sell" to the Member States. The "saleability" element was instead more obvious for MEPs, when they placed emphasis on the right of patients to access information. Another political element that appeared decisive for the positioning of the Member States was the monitoring of information. For example, Sweden and Denmark stressed that according to their constitution, it was not possible to control information ex ante, as it would be considered censorship.

With regard to the evidence in the form of economic and political considerations, it emerged that it played a bigger role in the position of the Member States than that of the European Parliament and the Commission. In particular, regarding political saleability, the Commission knew the Proposal was going to generate considerable criticisms, but this was not considered as an obstacle for the adoption of the text. More generally, the interviewees confirmed the assumption of Bowen and Zwi (2005) that the political, ideological and economic factors "often gain strength at the expense of the research evidence" (Bowen \& Zwi, 2005, p.606). In addition, according to the interviewees, politics played a more important role for the Council than the European Parliament throughout the negotiations. In this respect, an interviewee stated as follows:

I got the sense that the Council was far more grounded in direct experiences in forms of evidence than the Commission. As for the Parliament, they're just nowhere. I mean serious consideration of the evidence barely comes into it. I hate to make this analogy but the difference between speaking to the Council and speaking to the Parliament is almost the difference between a technical journal and everyday newspaper. (\#11, Secretary General, EU Pharmacists' Association) 


\subsection{Using Evidence}

\subsubsection{Impact assessment}

Through the impact assessment, the European Commission communicates the evidence base for its Proposal. The impact assessment consolidated in a single document the problem, the legislative Proposal on the provision of information to patients and all the above-mentioned evidence to support the Proposal. It also included an appendix with the summary of the public consultations, appendices on methodology, calculations and the case studies provided by Europe Economics and an appendix with the literature review. Table 5.4 gives an overview of the sources of evidence used in the impact assessment, while Appendix VII provides a detailed list of the references used. 
Table 5.5

Sources of Information Used in the Impact Assessment

\begin{tabular}{|l|l|}
\hline Type of evidence & Number of references \\
\hline $\begin{array}{l}\text { Peer-reviewed and other scientific } \\
\text { articles }\end{array}$ & 26 \\
\hline EU-funded projects & 1 \\
\hline ECJ rulings & 2 \\
\hline $\begin{array}{l}\text { Eurostat, Eurobarometer surveys and } \\
\text { other polls }\end{array}$ & 0 \\
\hline $\begin{array}{l}\text { European-Commission-commissioned } \\
\text { studies and analyses }\end{array}$ & 1 \\
\hline $\begin{array}{l}\text { National government studies (including } \\
\text { regulatory agencies) }\end{array}$ & 4 \\
\hline Stakeholders' surveys and studies & 3 \\
\hline Public consultations & 2 \\
\hline $\begin{array}{l}\text { Internal consultations with other } \\
\text { commission services, Member States and } \\
\text { stakeholders via advisory groups and ad- } \\
\text { hoc working groups and consultations }\end{array}$ & 3 \\
\hline $\begin{array}{l}\text { Documents from other institutions (e.g., } \\
\text { WHO, the Council of the EU) and other } \\
\text { articles in non-scientific journals }\end{array}$ & 2 \\
\hline Total & 44 \\
\hline
\end{tabular}

The impact assessment accompanying the Proposal was based on an independent impact assessment study commissioned to the private consultancy Europe Economics. Before the adoption of the legislative text, it was assessed by the European Commission's Impact Assessment Board. In its initial opinion on the draft of assessment of the Proposal released in June 2007, the board concluded as follows:

The draft Impact Assessment is well explaining the consistency of the general objective of the initiative with other EU policies and horizontal objectives... and noted good effort to quantify overall costs and benefits using a broad set of data sources and assessment techniques. (European Commission, 2007) 
However, it made some suggestions for improvement. In particular, it asked to better explain how the stakeholders perceive the problem in relation to the current situation, to better integrate the results of the public consultation, demonstrate which patients' needs remain unmet because of the current legislation, clarify the channel of communication, present social and health impacts analysing them with examples from the literature, including diagrams clarifying the distinction between information and advertising, among others. On the basis of these recommendations, DG ENTERPRISE amended the draft and resubmitted it to the Board, which issued a new opinion in July 2007. The Board reiterated the positive aspects of the initial report and acknowledged that the re-submitted report followed most of the Board's recommendations. Nevertheless, it proposed some few additional improvements regarding the need of a better description of the negative consequences of imperfect information on the health of patients, the role of EMA and the subsidiarity aspects.

The final version of the impact assessment outlined the positive consequences (prevention, awareness, increased adherence, among others) and negative consequences (medicalisation of society, patient requesting specific products that are not the best treatment options, among others) of the provision of information and evaluated the costs of health care systems due to the increased use of medicinal products, the costs of the pharmaceutical industry to prepare the information, the costs of regulation and monitoring and the administrative costs for reporting and complaint procedures. The impact assessment also analysed a number of policy options:

1. Retaining the existing legislation

2. Harmonising the legislation, with manufacturers being allowed to provide information that is not covered by the definition of advertising by means of certain information channels and with the information having to meet certain quality criteria. For this option, the European Commission analysed various forms of supervision and enforcement, namely supervision by national medicines' regulatory authorities (Option 2a), self-regulation by the pharmaceutical industry with voluntary or compulsory membership (Options 2b and 2c) respectively or co-regulation (Option 2d).

3. Allowing some forms of DTCA in Europe (Option 3)

Options 1 and 2c were not investigated further. According to the European Commission, Option 2 was the best for patients, although no significant differences existed between the various monitoring mechanisms 
(European Commission, 2008). As for all impact assessments, the option of no legislation was formally considered, but in practice, an impact assessment implies the will of legislator to present a legislative proposal. This was also the case for the Proposal on the provision of information to patients.

The use of knowledge in this case study presents the features of the interactive model of research utilisation described by Weiss (1979). In the interactive model, policymakers search for information from not only research but also other sources and mostly from interest groups and politicians. The use of research, especially in the context of the Europe Economics report supporting the impact assessment, was only a negligible part of a "complex process that also 'uses experience, political insight, pressure, social technologies and judgement"” (Weiss 1979, p. 429).

\subsubsection{Evaluating evidence}

The quality of impact assessments and their genuine purpose of providing a sound, scientific and proper assessment of the available evidence and the views of stakeholders are often challenged. This also applies to the impact assessment on the provision of information to patients. An interviewee claimed that the procedure for the impact assessment failed and, in particular, the impact assessment was prepared at a very late stage:

Before they start their impact assessment study, they should already make contact with different actors to understand, and once they have a clear understanding on how it takes place, how it is organised, what are the problems, then they should start and make the impact assessment study et cetera, et cetera. But they always try to understand how things function only at the step when they are already preparing (the Proposal I.P) and the impact assessment study is at a very late stage. (\#1, Senior Officer, Health Insurers' Association)

The same interviewee also criticised the impact assessment because of the following reason:

The option not to change the legislation was certainly not seriously analysed. They are quoting from consultations, opinion surveys and then there's a bit of economic analysis about what they presume would be the effects but the basis for those assumptions it's completely non-transparent.

An interviewee (\#21) was critical about the lack of transparency concerning the methodology: 
I am very critical of these impact assessments and how they are conducted. Also quite obviously because the methodology is never revealed (....) The sources of the information from European Commission have been mainly the pharmaceutical industry or the groups acting on behalf of the pharmaceutical industry or even some regulatory agencies that have another close collaboration with the pharmaceutical industry that see themselves as service providers to the pharmaceutical industry and co-developers of medicines. (\#21, Researcher on information to patients)

Another researcher also criticised the methodology:

Where does the burden of proof lie? Do we need actually solid evidence of benefits compared to the status quo to make the change, or do we need solid evidence of harm in order not to make the change? The burden of proof is not very high, often on benefit these days. (\#29, Researcher on information to patients)

The Secretary General of the EU Pharmacists' Association (\#11) considered the impact assessment to be as follows:

A fairly unsatisfactory mixture of speculation and reliance on selected evidential sources. That is certainly my recollection of the information to patient's impact assessment which was partly utterly a priori in the sense that it simple assumed that there were inequalities of information as I recall without really putting firm evidence base on that.

Finally, an EU journalist summarised the whole procedure as follows: “The impact assessment was a 'fig leaf' for a decision already made" (\#17, EU journalist).

The European Commission's approach to the research on the provision of information to patients seems in line with Feldman and March's (1981) view on knowledge utilisation that states policymakers may ignore the information they have, ask for more information and then ignore this information when it is available. Health insurers represented by the European Social Insurance Platform (ESIP) and the International Association of Mutual Insurances (AIM) considered that even if formally involved in the Pharmaceutical Forum and the discussion accompanying the legislative process, their voice was not properly heard:

ESIP and AIM still have concerns about the lack of transparency of the processes, procedure and methodologies in the Forum, in 
particular the working group on information to patients. ESIP and AIM strongly regret that their constructive proposals made during this process, in particular the request for a survey for existing patient information practices and the use of an EU quality label to identify high quality information, have not been taken up for further discussion. (ESIP and AIM's Statement on the Pharmaceutical Forum, 2007)

In this regard, an interviewee stated as follows: "At the end, we are so frustrated, and you do not want to go on with it because you cannot influence. It is tiring to have to repeat for months and months always the same things" (\#1, Senior Officer, Health Insurers' Association).

The European Commission invested significant resources to gather evidence in preparation of the Proposal by commissioning a report, consulting the Member States and stakeholders in several fora and launching three consultations among the general public. However, the perception of the stakeholders and policymakers is that the actual use of the evidence collected was very limited. On the basis of the above, it can be concluded that evidence played a legitimising role to support a decision already made at the political level. Research evidence was collected and used selectively in favour of the greater dissemination of the information from the pharmaceutical industry with the goal of increasing the sales of medicines and profitability of the pharmaceutical industry. Also, the evidence from the stakeholders opposing the Proposal was not given due consideration, at least in the perception of the stakeholders themselves, even if ultimately their voices were heard because the Proposal was first amended to meet some of the concerns they had expressed and then withdrawn in 2014. 


\subsection{Capacity for Implementation: Hindering and Facilitating Factors for the Uptake of Research Evidence}

Table 5.6 summarises the main hindering and facilitating factors for the uptake of research evidence.

Table 5.6.

Hindering and Facilitating Factors for the Uptake of Research Evidence

\begin{tabular}{|c|c|}
\hline $\begin{array}{l}\text { Facilitating factors } \\
\end{array}$ & Hindering factors \\
\hline $\begin{array}{l}\text { The economic resources } \\
\text { available to commission an } \\
\text { independent impact assessment } \\
\text { study }\end{array}$ & $\begin{array}{l}\text { No specific evidence } \\
\text { available on direct-to-consumer } \\
\text { information }\end{array}$ \\
\hline need Policymakers' information & $\begin{array}{l}\text { The existing evidence was } \\
\text { not useful to make a distinction } \\
\text { between information and } \\
\text { advertising. }\end{array}$ \\
\hline \multirow{4}{*}{$\begin{array}{l}\text { Organisational procedures } \\
\text { (i.e., the need to make an impact } \\
\text { assessment) }\end{array}$} & $\begin{array}{l}\text { Selective use of the } \\
\text { available evidence }\end{array}$ \\
\hline & $\begin{array}{c}\text { Policymakers' lack of } \\
\text { knowledge about the policy area }\end{array}$ \\
\hline & $\begin{array}{l}\text { Policymakers' perspectives } \\
\text { linked to the organisational } \\
\text { arrangements (DG ENTERPRISE } \\
\text { industry perspective) }\end{array}$ \\
\hline & $\begin{array}{l}\text { Policymaker's personal } \\
\text { beliefs }\end{array}$ \\
\hline
\end{tabular}

The Proposal introduced the new concept of an industry communicating about its products to consumers for information purposes only. The available research evidence was on direct-to-consumer advertising where the acknowledged purpose of the communication was to increase sales. Therefore, it was necessary to make upper-bound estimates to assess the likely impact of direct-to-consumer information on public health. Despite its attempt to make use of the evidence on DTCA, European Economics concluded that the available studies did not help to make a clear distinction between information and advertising.

Another element that hindered the uptake of evidence was raised mainly by the researchers interviewed, namely the selective use of scientific 
evidence and the limited scope of the literature review. The selection resulted in a bias towards scientific evidence that was in line with predetermined policy decisions. In this regard, an interviewee stated as follows:

I just think that the people who were doing that work had no idea that that evidence was available or what to do with it or that public health is a discipline more worthy than a report that come from a consultancy or even from a university unless that is an internationally recognised public health centre. The literature tends to be a little bit selective and of course the literature that's selected tends to cluster around the original proposition which in this case was that there was some form of deficiency in the current information regime in Europe. (\#28, Researcher on information to patients)

Another interviewee also raised the academic backgrounds and organisational positions of the policymakers as a factor that influenced the type and extent of the evidence used:

They were so limited in their approach to the issue, of course this is also very related to the fact that it was done by DG ENTERPRISE, so their perspective was mainly a legislative procedure that had people involved that were lawyers that have no notion about the real life, no notion about needs of patients, no notion about the implications for health care professionals and not only they did not have the notion, they were not interested in listening the people that could explain. (\#21, Researcher on information to patients)

The need to gather data and undertake data analysis to prepare the impact assessment as well as the obligation to conduct public consultations can be considered as the factors that facilitate the search of evidence, but the use of the evidence remains linked to subjective issues, namely the policymakers' will to make proper use of the information collected.

From the interviews and the European Commission's statements, it appears that in this case study, an individual played a more prominent role than others - the Vice President of the European Commission, Gunther Verheugen:

From our perspective, it was a clear vision of a commissioner, maybe not of the commission as a whole but only of the commissioner in charge of the topic. I think that even the commission staff see this as a topic which has been put on the table because it was some deal to 
the commissioner and not to respond to the needs of citizens. (\#1, Senior Officer, Health Insurers' Association)

\subsection{Conclusion}

This chapter started with a description of the political background that shaped the Commission's Proposal, which helped understand the changing role of evidence during the never-ending debate on the provision of information to the patients in Europe.

The analyses of the documents, interviews and participant observations highlight that the main driver of the Commission's Proposal was to allow the European pharmaceutical industry to communicate more freely to the general public about their products, even if for years, emphasis had been placed on patients' right to information. Three of the interviewees (\#1; \#11; \#29) indicated that the European Commission, namely DG ENTERPRISE, and the industry, maintained overlapping positions throughout the process and the main rationale of the Proposal was to improve the profitability of the EU pharmaceutical industry.

As for the sourcing of evidence, the analysis shows a common pattern in the way the European Commission approached the evidence generation in the adoption of the pharmaceutical review in 2001 and 2008, namely with the creation of parallel stakeholder fora used to generate consensus and ideas about the issue but formally detached from the legislative policymaking process.

The types of evidence used by the European Commission to formulate the Proposal also included a limited literature review conducted by a consultancy that prepared an independent study report to support the impact assessment, ad-hoc working groups with the Member States and stakeholders, in addition to horizontal EU fora such as the EU Health Policy Forum, public consultations and the economic and political arguments gathered from the stakeholders and Member States. Over the years, the Commission demonstrated at least a commitment to improve the use of scientific evidence and involvement of the stakeholders in the formulation of policy, but the actual impact on the legislation proposed remains unclear. Rather, the selective choice of research evidence and the way the stakeholders were consulted (the number of public consultations, wording of the questions, presentation of the consultation results, imbalance in the composition of working groups such as the High-Level Pharmaceutical Forum) confirm that the use evidence by the European Commission was a sort of cosmetic exercise 
to increase legitimacy and consensus around a Proposal already decided at the political level.

As for the use of evidence, Maynard and Bloor's (2003) reflections on the regulation of pharmaceuticals seem still valid and particularly relevant to the case study. Their analysis of the pharmaceutical market showed that "there is little new, and much unconsciously replicated, with scant recourse to the evidence base" and the reluctance to scientifically evaluate policy innovations allow those supporting the given policies the opportunity to "reinvent them" (Maynard \& Bloor, 2003, p. 39). Concerning evidence-based or opinion-based pharmaceutical policy, Lyes (2004) argued that "if pharmaceutical economics and health policy research are to have value for society, then the translation of research into policy must become both more credible and more routine" (p. 89). He also noted that "in politics, the public's perception can raise and frame more issues than any research result" (Lyes, 2004, p.89).

Overall, the perception of the interviewees is that in the EU policymaking process, evidence doesn't play a strong role. One of the interviewees defined it as "an evidence free policymaking decision" (\# 28, Researcher on information to patients), at least in relation to the use of scientific evidence, and the selection of the evidence, including the interests and ideas expressed by stakeholders, is biased.

Despite the several attempts to build consensus, the Proposal never saw light. The unsuccessful destiny of the Commission's Proposal, which for the first time in the EU history was amended both in terms of content and technical details thrice, has been explained differently by the interviewees. An interviewee stated that "they shot themselves in foot because of acting that way, that they had such a bad text in the beginning" (\#29, Researcher on information to patients), while another interviewee stated as follows:

So you could say that the impact on information to patients is something that could have been disastrous for public health and we've stopped. But that's not the same as improving public health, that's stopping it from getting worse (....) There was a sense from me that it was a storm in a teacup like (the Proposal on) cross-border health care). (\#8, Secretary General, Public Health NGO)

The lack of clear-cut research evidence on the possibility to make a clear distinction between information and advertising, the selective use of the available literature on DTCA used as upper-bound evidence and the lack of interest, training and skills to assess the research evidence on the public health 
of the policymakers who drafted the Proposal emerged as the key hindering factors for the uptake of evidence, but the decisive factors that influenced both the use of evidence and the overall Proposal was the personal will of Commissioner Verheugen. One of the interviewees powerfully expressed this by stating as follows:

One of the paradoxes of democracy is that the will of the people trumps the evidence, I mean that's the way it works. Democratically elected people want to adopt a particular point of view, then that's their right to do it because they have legitimacy. (\#11, Secretary General, EU Pharmacists' Association)

The main facilitating factor for the uptake of research was the organisational procedure of the European Commission requiring an impact assessment to accompany a legislative proposal. Financial resources were allocated for an external consultancy to provide a report that included a limited overview of the existing research evidence on the topic via a literature review. The main hindering factors of the uptake of research evidence were that there was no specific evidence available on direct-to-consumer information and the available research was not useful to make a distinction between information and advertising. Moreover, the existing evidence on direct-to-consumer advertising was used selectively to align with the political stand already taken by the European Commission. The personal beliefs of the Commissioner in charge of defining the first draft of the Proposal had a significant impact on the uptake of research evidence, especially that pertaining to the negative impacts of DTCA on the consumption of medicines. Those beliefs were influence by the professional experience of Commissioner Verheugen, who was previously a journalist and also by the fact that he was the Commissioner responsible for increasing the competitiveness of the European pharmaceutical industries and not the Commissioner in charge of health policies. 



\section{Chapter 6: Role of Evidence in the Formulation of the Regulation on the Provision of Food Information to Consumers}

\subsection{Introduction}

In December 2008, the European Commission adopted the proposal for a Regulation on the provision of food information to consumers (hereafter referred to as the Proposal or the Regulation). The aim of the Proposal was to clarify and update the existing food labelling legislation and provide clear and comprehensible information to consumers on food packaging. In particular, the Proposal sought to consolidate and replace two European Directives, namely Directive 2000/13/EC on the labelling, presentation and advertising of foodstuffs, and Directive 90/496/EC on the nutrition labelling of foodstuffs, which had been amended several times over the years to adapt to the changing consumer expectations and food supply chain.

The goal of this chapter is to understand what constituted the evidence base of the Commission's Proposal and the role this evidence played in the policymaking process. As explained in chapter 2, the focus of this research is the formulation of legislation within the European Commission, but to set the context and for completeness, the interinstitutional debate that led to the adoption of the final text has also been reported. The key steps of the policymaking process are presented in the chronological order on the basis of the procedures defined by the EU Treaty for ordinary legislative procedures (Article 289).

This chapter follows a similar structure as that of the previous two chapters. It consists of four sections: The first section gives an overview of the key developments in the European food labelling legislation (Section 6.2). The second section includes an analysis of the kind of evidence sought by the Commission and explores the role of the stakeholders with a focus on the information they provided for the decision-making process (Section 6.3). The following two sections investigate the use of evidence (Section 6.4) and the facilitating and hindering factors for the uptake of the research evidence respectively (Section 6.5). This chapter ends with the discussion of the main conclusions (Section 6.6). 


\subsection{Context and Policy Idea: Food Labelling on the EU Agenda}

The issues of overweight and obesity are constantly increasing in Europe, especially among children. According to the most recent estimates ${ }^{11}$ from Eurostat, in 2014, more than half of the population (51.8\%) in Europe was overweight or obese, while, according to WHO, one in three elevenyear-old children in the EU Region were obese or overweight (WHO, 2014). The problem has been increasing at a rapid pace over the last years. Obesity and overweight, especially among children, are associated with a higher risk of chronic diseases such as type 2 diabetes and cardiovascular diseases and increased health care costs. In 2012, it was estimated that the direct and indirect obesity costs in Europe were around $€ 81$ billion per year (Health and Environment Alliance, 2014).

Food labelling, which is the practice of providing the nutritional value information of food products on its packaging, is considered a crucial aspect in the fight against obesity, as it has a significant influence on consumers' purchasing decisions and therefore on their diets (Liaukonyte, 2013; Mueller \& Szolnok, 2010; Ollberding et al., 2010; Schuldt, 2013). Clear, legible and accurate nutritional information is therefore a core element of a comprehensive public health strategy to help people improve their diets and ultimately reduce the risk of diet-related diseases.

The current EU policy on food labelling developed over a long period of time, starting in the mid-to-late 1970s. The first European law on food labelling was Directive 79/112/EC, the main goal of which was to harmonise labelling requirements to facilitate the free movement of goods between the Member States. In other words, the main objective was to support the internal market and not to protect consumers or improve public health. However, over time, consumers' interests became a more specific objective of the EU with the introduction of a specific reference to consumer protection in the Treaty (Article 100a and 129a in the Single European Act). Over the years, the Directive was amended several times, and new requirements were introduced. A consolidated text was adopted in 2000 with the so-called General Food Labelling Directive (Directive 2000/13/EC). This horizontal ${ }^{12}$ piece of legislation defined a mandatory set of information such as the list of ingredients, the quantity of certain ingredients and the date

\footnotetext{
${ }^{11}$ According to Eurostat, the figures were the same in 2008 when the Proposal was adopted. The next European health interview survey (the source of these data) is expected in 2019.

${ }^{12}$ Horizontal legislation refers to general rules addressing common aspects for a broad range of foodstuffs. Vertical legislation refers to specific food products (Meulen, 2013).
} 
of minimum durability for all foodstuffs to be sold to consumers, restaurants and caterers. The general labelling requirements have been complemented by a number of vertical Directives applicable to specific groups of products such as the Directive on foods containing caffeine or quinine (Directive 2002/76/EC). It is estimated that all together there are about $100 \mathrm{EU}$ legislations on the labelling of food products.

Following the adoption of a White Paper on Food Safety in 2000, the Commission initiated a reform of the food labelling rules. In 2003, the Directorate for Health and Consumers (hereafter referred to as DGSANCO ${ }^{13}$ ) launched an evaluation of the whole European legislation on food labelling to assess its effectiveness and capability of meeting the needs of consumers and industry. The evaluation was made by a consortium of four consultancies called European Advisory Services and was submitted for comments to the Member States. The final report, published in 2004, identified the key elements to be addressed to improve consumer information and provided a list of recommendations to strengthen the legal framework. Following the evaluation of the existing rules, a public consultation, some internal consultations and a series of additional studies commissioned by DGSANCO (see section 6.5), the revision of EU food labelling legislation was announced in 2007 in the White Paper on "Strategy for Europe on Nutrition, Overweight and Obesity-related Health".

\subsubsection{Commission's Proposal}

In January 2008, the Commission finally adopted the Proposal for a Regulation on the provision of food information to consumers. The main aim of the Proposal was to ensure "high levels of consumer protection in relation to food information, taking into account the differences in the perception of consumers and their information needs whilst ensuring the smooth functioning of the internal market" (Article 1). In particular, the Proposal introduced mandatory front-of-pack labelling for a range of nutrients (energy, total fat, saturated fats, carbohydrates and salt) selected on the basis of scientific advice about the key nutrients associated with the risk of obesity and other non-communicable diseases. The Proposal suggested that this information should have been provided as amounts per $100 \mathrm{ml} / \mathrm{g}$ or per portion size in relation to "reference intakes" such as guideline daily amount (GDA). The Commission also proposed a clear contrast between print and the background and minimum font size of $3 \mathrm{~mm}$ to improve readability. The

13 Renamed DG SANTE by the Juncker Commission 2014-2019. 
labelling requirements applied to processed food and beverages. Nonprocessed food such as meat and vegetables were excluded. The Proposal also included an exemption for alcoholic beverages such as wine, beer and spirits from the labelling requirements and an obligation for the European Commission to produce a report on the reasons justifying the possible exemptions within 5 years of the Regulation coming into force. Moreover, the Proposal extended the requirements on the information about allergenic ingredients such as nuts and milk and non-prepacked food. Lastly, labelling the country of origin of products was considered voluntary, except if the failure to give such information could mislead consumers.

\subsubsection{Lengthy negotiations}

The dossier was highly controversial because the main stakeholders - the food industry on one side and the consumer and health NGOs on the other side - strongly disagreed on the type of information that should be provided on food products. The industry was also concerned about the economic burden of new labelling requirements, while the consumer and health NGOs pushed for more and better information to help consumers make better informed and healthier choices. From the original idea of changing the legislative framework on food information, it took nine years to enable the final implementation of the new rules, and some provisions (e.g., the rules concerning legibility and allergen labelling) are not fully applied yet ${ }^{14}$. Table 6.1 summarises the key steps of this long process.

Table 6.1

Food Labelling on the EU Agenda

\begin{tabular}{|l|l|}
\hline Date & Main developments \\
\hline May 2007 & Commission's White Paper on obesity \\
\hline Jan 2008 & $\begin{array}{l}\text { Commission adopts the Proposal for a Regulation on food } \\
\text { information for consumers }\end{array}$ \\
\hline Nov 2008 & $\begin{array}{l}\text { First draft report of the European Parliament's ENVI - } \\
\text { legislative term 2004-2009 }\end{array}$ \\
\hline Nov 2009 & $\begin{array}{l}\text { New first draft report of the ENVI- legislative term 2009- } \\
2014\end{array}$ \\
\hline Jun 2010 & First reading vote in the European Parliament \\
\hline Dec 2010 & $\begin{array}{l}\text { Political agreement of the Council of the EU (Member } \\
\text { States) }\end{array}$ \\
\hline
\end{tabular}

${ }^{14}$ At the time of writing in 2018. 


\begin{tabular}{|l|l|}
\hline Jul 2011 & Second reading vote in the European Parliament \\
\hline Nov 2011 & $\begin{array}{l}\text { Regulation 1169/2011 on the provision of food } \\
\text { information to consumers published in the EU official } \\
\text { journal }\end{array}$ \\
\hline Dec 2014 & $\begin{array}{l}\text { Key provisions on the list of ingredients (e.g., allergens, } \\
\text { nano labelling) become applicable. Country of origin } \\
\text { labelling for meat in place as of April 2015 }\end{array}$ \\
\hline Dec 2016 & Nutritional labelling provisions become applicable \\
\hline
\end{tabular}

The European Parliament rapporteur Dr Renate Sommer (EPP, Germany) presented an initial report in November 2008, but because of the large number of amendments $(1,332)$ and the imminence of the European elections, the legislative process was postponed to the following legislative term. Member of European Parliament (MEP) Sommer, confirmed as rapporteur again in the new legislative term, presented a new report in November 2009. The report was voted by the Environment, Public Health and Food Safety Committee (ENVI) on March 16, 2010. The key changes proposed in the ENVI report mostly concerned the legibility of the labels, including the contrast between the letters and the background, the spacing of lines, among others. The report was voted on by the whole European Parliament in its plenary session on June 16, 2010, with 559 votes in favour, 54 against and 32 abstentions. MEPs voted to make the nutrition labelling of pre-packed foods mandatory but rejected the calls from public health NGOs and consumer groups for a colour-coded labelling scheme like the traffic light system - red, amber and green - used by some retailers in the UK. The Commission's original Proposal suggested that national governments should be allowed to decide on visual support systems for nutrition labelling. However, MEPs excluded the option of national schemes. The European Parliament also asked the producers of processed foods, such as biscuits or prepared meals, to indicate on the front of the packaging the content of energy, salt, sugar, fat and saturated fat. These should have been accompanied by GDAs and expressed with values per $100 \mathrm{~g}$ or per $100 \mathrm{ml}$ instead of 'per portion'. The Commission's initial Proposal did not refer to nanomaterials, but the Parliament voted for the mandatory labelling of foods that contain nanoparticles and requested the mandatory labelling of appetite-enhancing substances in products like sweeteners. Furthermore, the Parliament asked for the mandatory origin labelling to be extended to fish, poultry and dairy products, even when used as an ingredient in processed food as well as other single-ingredient products. 
The Council adopted its common position in December 2010. One of the key elements agreed on by the Council was the mandatory nature of nutrition declaration (fat, saturates, carbohydrates, protein, sugars and salt). Regarding labelling schemes (e.g., the traffic-light system), the Member States agreed that in addition to the requirements set in the legislation, additional forms of expression and presentation would still be allowed, provided that "they are not misleading and are supported by evidence that consumers actually understand them" (Council of the EU, 2010). They also required the European Commission to present a report on the use of these additional forms of presentation, their effect on the internal market and on the advisability of further harmonisation of such ways of displaying information within five years of the new rules coming into force ${ }^{15}$. In addition, the Council voted against the European Parliament and Commission's proposals of making the front-of-pack labelling of some nutrients mandatory. The Council agreed that the labelling of the country of origin should be compulsory only if a failure to do so would mislead consumers, but it introduced mandatory labelling of the country of origin for several types of meat and asked the Commission to submit within three years of the new regulation coming into force a report examining the possible extension of the compulsory labelling of the country of origin to further products such as milk (Council of the EU, 2010).

After three years of negotiations between the Commission, the Council and the European Parliament, the so-called "trialogues" (see also Chapter 4) between the three EU institutions were organised in spring 2011 over a period of 10 weeks to reach an agreement at the second reading. An agreement on a compromise text was achieved between the Council and the Parliament on June14, 2011. The final vote in the European Parliament took place in July 2011. The compromise text was approved with 606 votes in favour, 46 against and 26 abstentions. The Regulation became an EU law in November 2011. Companies were given three years to adapt to the new rules, while smaller business with employees fewer than 100 and an annual turnover of under $€ 5$ million were given five years to comply.

\subsubsection{A polarised debate: David vs Goliath}

Looking at the debate that accompanied the draft Regulation on food information through the lenses of Sabatier's advocacy coalition framework (Sabatier, 1958 and 1991) and taking into account the interest groups that the

\footnotetext{
15 To date the report has not been published.
} 
European Commission formally involved in the EU policymaking process via working groups, advisory groups and consultations, it is possible to clearly identify two "advocacy coalitions". Coalition I composed of industry stakeholders mostly represented by Food Drink Europe (then called CIAA), the pan EU Trade Association representing national food industry federations and large food companies. Coalition II consisted of consumer and health organisations along with the European Consumer Organisation (BEUC), the European Heart Network (EHN) and the European Public health Alliance (EPHA) as the most vocal organisations. The industry coalition considered that there were too many labelling requirements, which involved the industry having to implement detailed technical rules, while the consumer and health coalition advocated more and "better" information on food labels to allow consumers make informed and possibly healthy food choices.

The food industry and consumer groups agreed in principle that some forms of mandatory labelling were required to help the public make informed choices. However, differing views existed concerning the kind of information to be provided. While consumers demanded front-of-pack the provision of data regarding salt, sugar, total fat and saturated fat content, manufacturers preferred to display only energy information - calorie content - leaving companies to decide on any additional information that could be provided. The industry also argued that the room left for voluntary national schemes to co-exist would substantially weaken the single market and lead to consumer confusion rather than consumer information. In addition, the food industry believed that the Commission's Proposal completely ignored the need of consumers for simple information and lacked any flexibility for smaller labels and smaller packaging. The retail association EuroCommerce criticised the requirement for a minimum font size of $3 \mathrm{~mm}$ for all mandatory labelling provisions, as the requirement would incur considerable costs on food businesses without providing any benefits to consumers. The industry also regretted that the voluntary commitments on labelling made by food retail companies to the EU Nutrition Platform had "not been given more time to work before the EU legislates" (EuroCommerce, 2008, p.2) and urged the legislator to focus more on education to contribute to the efforts made by the commercial sector.

BEUC welcomed the Commission's intention to impose binding rules on nutrition labelling for the food industry to tackle the severe problem of obesity. However, the organisation took issue that the Commission didn't introduce an EU-wide multiple colour-coding scheme that would help consumers judge at a glance the nutritional value of a particular food product. 
EHN publicly acknowledged that the Commission's Proposal had gone a long way to meet health organisations' demands for a simplified front-of-pack nutrition labelling scheme but differed on the issue that the Commission had stopped short of prescribing a harmonised format that would add an interpretive element such as traffic-light colour coding.

Table 6.2 outlines the views of the two advocacy coalitions on the key provisions of the Proposal.

Table 6.2

Opposing Arguments of the Two Advocacy Coalitions on the Key Provisions of the Proposal

\begin{tabular}{|l|l|}
\hline \multicolumn{1}{|c|}{$\begin{array}{c}\text { Advocacy coalition I } \\
\text { Food industry }\end{array}$} & \multicolumn{1}{c|}{$\begin{array}{c}\text { Advocacy coalition II } \\
\text { Public health and consumer } \\
\text { groups }\end{array}$} \\
\hline $\begin{array}{l}\text { Only energy per portion and per } \\
100 \mathrm{~g} / \mathrm{ml} \text { should appear at the } \\
\text { front of the pack, accompanied by } \\
\text { GDAs. }\end{array}$ & $\begin{array}{l}\text { Energy, salt, sugar and saturated } \\
\text { fat content per } 100 \mathrm{~g} / \mathrm{ml} \text { should } \\
\text { appear at the front of the pack } \\
\text { together with the traffic-light } \\
\text { scheme. }\end{array}$ \\
\hline $\begin{array}{l}\text { The traffic-light labelling scheme } \\
\text { is too simplistic and demonises } \\
\text { food. There are no unhealthy } \\
\text { products but unhealthy diets. } \\
\begin{array}{l}\text { Consuming products with green } \\
\text { lights only would not be healthy. }\end{array}\end{array}$ & $\begin{array}{l}\text { A simplified traffic-light labelling } \\
\text { scheme at the front of the pack } \\
\text { could give consumers information } \\
\text { at a glance and allow them to } \\
\text { easily compare products and make } \\
\text { healthy choices. }\end{array}$ \\
\hline $\begin{array}{l}\text { Portion sizes are useful and well } \\
\text { understood by consumers. }\end{array}$ & $\begin{array}{l}\text { Portion sizes can be unrealistic and } \\
\text { mislead consumers. }\end{array}$ \\
\hline $\begin{array}{l}\text { Energy, sugar, salt, fat, saturated } \\
\text { fat, fibre, protein and } \\
\text { carbohydrate content should } \\
\text { appear at the back of the pack. }\end{array}$ & $\begin{array}{l}\text { Energy, salt, sugar, total fat, } \\
\text { saturated fat, added sugar and } \\
\text { fibre, transfatty acid and protein } \\
\text { content should appear at the back } \\
\text { of the pack. }\end{array}$ \\
\hline $\begin{array}{l}\text { Providing information with the } \\
\text { minimum font size of 3 mm } \\
\text { would be very costly for business } \\
\text { without providing benefits for } \\
\text { consumers. }\end{array}$ & $\begin{array}{l}\text { Providing information with the } \\
\text { minimum font size of 3 mm } \\
\text { improves legibility of the } \\
\text { information. }\end{array}$ \\
\hline
\end{tabular}




\begin{tabular}{|c|c|}
\hline $\begin{array}{l}\text { National labelling schemes would } \\
\text { create obstacles to the internal } \\
\text { market. }\end{array}$ & $\begin{array}{l}\text { National governments should be } \\
\text { able to introduce national labelling } \\
\text { schemes to help consumers make } \\
\text { informed choices. }\end{array}$ \\
\hline $\begin{array}{l}\text { Country-of-origin labelling } \\
\text { should be voluntary. Mandatory } \\
\text { country-of-origin labelling creates } \\
\text { a big burden and extra costs for } \\
\text { companies. Producers often } \\
\text { change suppliers and use multiple } \\
\text { suppliers for the same ingredient. } \\
\text { It would be impossible to list all } \\
\text { origins. }\end{array}$ & $\begin{array}{l}\text { The vast majority of consumers } \\
\text { want to know where their food } \\
\text { comes from. Country-of-origin } \\
\text { labelling should be mandatory and } \\
\text { extended to various food categories } \\
\text { (before it was mandatory for fruit } \\
\text { and vegetables, beef, olive oil and } \\
\text { honey only). }\end{array}$ \\
\hline $\begin{array}{l}\text { Alcoholic beverages should be } \\
\text { excluded from the labelling } \\
\text { requirements. }\end{array}$ & $\begin{array}{l}\text { Alcoholic beverages should be } \\
\text { included in the scope of the } \\
\text { Regulation. }\end{array}$ \\
\hline
\end{tabular}

The responses to the consultation in 2006 confirmed the polarisation of views on a number of issues and demonstrated that the labelling legislation and label itself were not used to their full potential. More specifically, criticisms focused on the fact that despite the many detailed rules, the existing legislation was not working effectively, that consumers found it difficult to read and understand the many labels on products, that some key information was missing and that origin labelling was a problematic area. When presenting the Proposal in January 2008, the Health Commissioner Markos Kyprianou anticipated the stakeholders' reactions and referred to the two sides of the debate and defined well the nature of the Proposal as a compromise that didn't make anyone happy. In this regard, he said, "I'm sure there will be some criticism from both sides: from those who want us to do more and from those who want us to do less. But the fact is it is a balanced proposal" (Euractiv, 2010).

The lobbying campaigns on both sides came under the spotlight during the legislative process. Corporate Europe Observatory (CEO), a Brussels-based watchdog, claimed that the food and drink industry had invested more than $€ 1$ billion in a lobby campaign to block the EU-wide traffic-light labelling scheme. In a CEO report, published in 2010, it was argued that the public affairs consultancy Fleishman-Hillard had been paid up to $€ 671,000$ to promote the GDAs by the food industry association Food Drink Europe (CIAA back then). Food Drink Europe admitted that members 
had spent $€ 1$ billion in implementing the voluntary GDA schemes on their products across Europe but didn't disclose how much they had spent on lobbying. In a statement to the press in response to the CEO report, Food Drink Europe stressed that the $€ 1$ billion figure was "quite simply unfounded and untrue" and their members didn't engage in any "improper lobbying activity" (Euractiv, 2010).

The imbalance in resources was also reflected in the possibility of stakeholders lobbying policymakers and providing evidence. An MEP quoted in the CEO report estimated that the food industry lobbyists were successful in "drown(ing) out the message from public health campaigners on a scale of 100 to 1 " ahead of the key votes and confirmed that MEPs were flooded with thousands of e-mails, letters, phone calls, reports, lectures and conferences (CEO, 2010).

Continuous polarisation was also present in the European Parliament with divergent views on most of the key elements of the legislation between the left and the right wing. The European People Party (EPP), the Conservatives (ECR) and most of the liberal (ALDE) MEPs shared the views of the industry, while the Socialists (S\&D), the Greens and the United Left (GUE) expressed views in line with the position of consumer and health organisations.

The Member States obviously wished to balance the needs of consumers and the industry with respect to the general food labelling legislation, taking into account, where necessary, any consumer or industry issues specific to their own country. However, their capacity to act and the effectiveness of the implementation of the labelling legislation depended on the design of the labelling legislation. Therefore, in terms of governance, for the Member States, a trade-off was involved between the desire for flexible solutions to labelling on the one hand and the requirements of the single market as well as the desire of the industry for a unified regulatory framework on the other hand.

\subsubsection{In the name of consensus}

The final deal struck between the EU institutions on the Proposal was broadly welcomed by the various interest groups, but, as discussed before, no party was entirely happy. The EU Health Commissioner Kyprianos, health NGOs and consumers groups were not in favour of the deletion of front-ofpack nutritional declarations from the initial European Commission Proposal. The industry was pleased, as they were given the opportunity to continue the 
voluntary scheme based on GDAs, but they said the new rules might impact the competitiveness of the sector. Small and medium enterprises were overall pleased but highlighted the problems of small food operators regarding the compulsory country-of-origin labelling as they would have to frequently change the list of ingredients. The rapporteur noted that the new labelling rules would probably result in higher food prices because of the increased costs of businesses, especially small companies. After the final vote in the European Parliament, the spokesperson of the Green Party described well the outcome of the negotiation stating that for them the glass was "only half full". interviewee:

The practice of consensus building was explicitly recognised by an

The information comes easily to EU decision-makers. They have to be aware of the bias and be sure they speak with everybody, also in bilateral meetings. At the end, policymakers are humans. No man is an island. You need check and balances. EU legislation is more about consensus rather than what is good for the people. (\#15, Director, EU Affairs, Food Industry)

\subsection{Sourcing Evidence}

This section analyses the knowledge base utilised by the European Commission when formulating the draft Proposal, including evaluations commissioned to consultancies, researchers and studies funded by public authorities, views from industry and non-industry stakeholders and economic and political arguments.

The data for the analysis was gathered mostly from the testimony of the Commission officials and stakeholders closely involved in the preparation of the draft Proposal as well as the quotes and references in the draft Regulation and the impact assessment reports - both the impact assessment report on general food labelling issues and the impact assessment report on the nutritional labelling issues - accompanying the Proposal. Table 6.3 provides the types of evidence sought by the European Commission in preparation of the Proposal. 
Table 6.3

Type of Evidence and the Period It was Sourced

\begin{tabular}{|l|l|}
\hline Period & Type of evidence \\
\hline Jan 2003 & $\begin{array}{l}\text { Member States and stakeholders consultation on the } \\
\text { implementation of Directive 90/496/EEC }\end{array}$ \\
\hline 2003 & $\begin{array}{l}\text { Evaluation of the food labelling legislation } \\
\text { Consultation on the results of the study among the Member } \\
\text { States and stakeholders }\end{array}$ \\
\hline 2004 & $\begin{array}{l}\text { EAS study on mandatory nutrition labelling for pre-packed } \\
\text { food products }\end{array}$ \\
\hline 2005 & $\begin{array}{l}\text { OPTEM study on consumers' attitudes and expectations } \\
\text { towards labelling }\end{array}$ \\
\hline 2006 & $\begin{array}{l}\text { RAND study on the policy options that emerged during the } \\
\text { public consultation in 2006 }\end{array}$ \\
\hline Mar 2006 & Public consultation on food labelling \\
\hline $2006-$ & Conferences, seminars, workshops \\
2008 & \\
\hline
\end{tabular}

\subsubsection{Research}

As indicated in Chapter 1, the word "research" mainly refers to scientific studies conducted by universities or independent research bodies and published in scientific journals. On this basis, the references to qualitative and quantitative studies published in scientific journals in the impact assessment reports were analysed. Among the 80 information sources referred to in the impact assessment report (see table 6.4), in the report on general food labelling issues, 8 scientific research articles published in peer-reviewed journals such as the Journal of Consumer Policy were quoted, while 14 scientific articles were quoted as a source of information in the impact assessment report on nutrition issues. They were published in various journals with different impact factors, focus and reputation, ranging from the Journal of Public Health to the Journal of Marketing Research.

Scientific articles were found mostly in the context of the desk research conducted by the consultancy RAND, which had been assigned by the European Commission the task to produce a report to support the impact assessment. In the technical report, RAND (2008) indicated that it conducted a document and literature review of four key areas: background/context information, country or region of focus, area of labelling discussed and types of costs and benefits. The RAND report reference list included 84 elements. 
Among those, 12 were scientific articles, while the others were mostly the reports from national authorities, stakeholder studies and poll results (e.g., Eurostat). Unfortunately, the RAND study did not explain in detail the methodology used to conduct the literature review and the criteria for the selection of the relevant studies. The report only mentioned that the available evidence was scanned. It also stated that limited literature existed from the EU on the impacts of labelling and that most of the literature originated in New Zealand, the US and Australia. Due to the stated limitations of the available literature, RAND filled the identified data gaps with surveys and interviews with stakeholders. The report also explained that while extensive literature existed on the labelling of pre-packed food, little literature was available on the costs of labelling food that is sold loose (e.g., food served in canteens, takeaways, unpackaged bread) as well as the issue of small packaging. It should be noted that the RAND report and the impact assessment report also referred to other literature reviews, namely a review of the extensive marketing literature on country-of-origin labelling in the field of food labelling (Lusk et al., 2006) as well as the UK Food Standards Agency's literature review titled "Food Labelling Consumer Research: What Consumers Want. A Literature Review" (FSA, 2007).

Scientific articles were also brought to the attention of the European Commission via the stakeholders' responses to the various public consultations conducted in preparation of the draft Proposal.

The analysis of the different types of evidence used by the European Commission in the formulation of the draft Regulation on food information clearly reveals the Commission's commitment to gather relevant information on the topic with a specific focus on the likely impact of a change in the law on the food industry. Despite the fact that the RAND report and the impact assessment pointed out that the scientific evidence on food labelling and nutrition was limited and there were many information gaps in the available literature, scientific studies were widely referred to as an information source in the impact assessment reports.

\subsubsection{Knowledge and information}

Following Bowen and Zwi's (2005) definitions of knowledge and information, this section analyses the statistical data, the policy analyses and published reports used by the policymakers to draft the Proposal. The preparatory work started in 2003 when DG SANCO, in cooperation with the representatives of the Member States, consumers, industry and trade, launched an evaluation of the legislation on food labelling. Following this, to 
feed the impact assessment, the European Commission used various information sources, including Eurobarometer surveys, Eurostat data, external consultancies as well as several working groups along with the Member States and stakeholders in the area of food.

\section{External policy analysis and surveys}

In 2003, following the adoption of a White Paper on Food Safety in 2000, DG SANCO launched an evaluation of the legislation on food labelling. The evaluation was made by a consortium of four consultancies and was submitted for comments to the Member States and stakeholders. The aim of the review was to enable the Commission to re-assess the effectiveness of its labelling policy and its legal basis and identify the needs and expectations of consumers as well as the possible obstacles for the implementation by food producers. The final report, which was published in 2004, identified the key elements to be addressed to improve consumer information and provided a list of recommendations to strengthen the legal framework.

In November 2004, the Commission published an impact assessment report on the introduction of mandatory nutrition labelling for pre-packaged food products across the EU. This study was commissioned to the group of four consultancies mentioned above, and the group joined forces under the heading European Advisory Services (EAS). It focused on the potential impact of the introduction of mandatory nutrition labelling on consumers, the food industry and the public authorities in charge of enforcing the legislation.

In 2005, DG SANCO commissioned to the external contractor OPTEM a qualitative study on labelling to evaluate the consumer attitudes and expectations towards food labelling. In 2006, to further build the knowledge base of the Commission and feed the impact assessment, DG SANCO sought the expertise of the external consultancy RAND Corporation (hereafter referred to as RAND), a research organisation financed under the so-called "European Commission Framework Contract Agreement". RAND's mission is "to help policymakers make decisions that are based on the best available information" (RAND website). The aim of the RAND study was to assess the potential costs and benefits of the policy options identified by the European Commission as they emerged from the public consultation conducted in 2006. In the framework of the contract, RAND conducted a document and literature review, semi-structured interviews with the key stakeholders, a cost-consequences analysis and an online consultation with the food industry to collect information and data on the possible impacts of the main issues under consideration for the revision of the legislation. More 
than two hundred responses were submitted to the online consultation. RAND produced a thorough 170-page report to respond to the European Commission's specific information needs. However, for an interviewee representing a member state, the accuracy of the study did not guarantee its reliability: "Lately all impact assessments follow a certain cliché. For example, the RAND study was very in depth, but it was not objective" (\#7, Health Attaché, Council of the EU).

Between October 26 and December 8, 2006, DG ENTERPRISE organised a Small and Medium Enterprises (SMEs) Panel on Food Labelling to gather the opinions and data on food labelling from SMEs. The survey was conducted in 19 Member States.

The European Commission also used the data on the food sector from the Eurostat database, the EU statistical system and a consumer survey conducted by the consultancy Nielsen in 2005 on the consumer preferences of food labelling in different countries.

\section{Public consultations}

In January 2003, the Commission launched a consultation on the implementation of Directive 90/496/EEC on the Nutrition Labelling of Foodstuffs among the Member States and stakeholders only; i.e., the consultation was not open to the general public. In total, the consultation gathered 50 responses, namely 14 from governmental organisations, 2 from consumer groups, 4 from public health NGOs and 30 from the food industry.

In March 2006, DG SANCO launched a broader public consultation on food labelling. The consultation document included specific questions related to the strategic goal of labelling, the structure and scope of the legislation, the legibility of labels, origin labelling and the labelling of alcoholic beverages. In addition to the consultation process, discussions were also conducted within several advisory groups (see section 6.2 ). The public consultation ran till June 2006. The European Commission gathered 247 contributions from public health NGOs, the food industry, consumer organisations, governmental organisations as well as individuals. 73 responses were identical; therefore, they were counted as one response. The individual responses as well as a summary were published on the European Commission's website.

The information gathered from the Member States was also the result of the government consultations with the stakeholders at the national level. 
One of the Commission officials in charge of the Proposal admitted that the tendency to consider the views matching the political direction the Commission already had in mind existed, while acknowledging that more and more active stakeholders could offer useful policy alternatives during the consultation process: "I think that you will certainly have a tendency to take into account the views that support a little bit what the Commission would already have in mind. This is a normal and easy to understand" (\#28, Administrator, European Commission). The same official also acknowledged that the Commission mostly relied on the stakeholders, as the Commission considered labelling not a scientific but a societal issue: "Sometimes you can see that with all this evidence we are not referring to scientific evidence because labelling is not scientific, it is very social. So, what we needed was more consultation with the stakeholders" (\#28, Administrator, European Commission).

\subsubsection{Interests and ideas}

Bowen and Zwi (2005) distinguish between knowledge and information, i.e., statistical and policy analysis, results of consultation processes and the information available on the Internet and interests and ideas, namely opinions, views and experts' knowledge of the individuals, groups and networks involved in the policy formulation. As outlined in the previous chapters, this distinction appears blurred in the EU policymaking process, but it is maintained for practical reasons.

\section{European Commission's consultative groups}

According to the impact assessment reports as a part of the consultation process on labelling launched by DGSANCO in 2006, the European Commission held discussions with the Advisory Group on the Food Chain and Animal and Plant Health, the Consumer Policy Network of senior consumer officials, the European Consumer Consultative Group and the Health Policy Forum. Moreover, regarding nutrition labelling, presentations and discussions were undertaken within the EU Platform for Action on Diet, Physical Activity and Health and the Round Table on Obesity. The Advisory Group on the Food Chain and Animal and Plant Health comprises 45 stakeholder organisations representing the food industry, retailers, farmers and consumer organisations. It meets twice a year in a plenary session and also has ad-hoc working groups functioning during the year. It provides the European Commission with recommendations on food safety, nutrition, animal and plant health and "ensures that the Commission's policies on food and feed safety take account of the opinions and needs of consumers, farmers, 
the food industry and retailers". The Consumer Policy Network of senior consumer officials is an informal network of Member States' officials working on consumer protection issues. The European Consumer Consultative Group is a platform used by the European Commission to discuss with national consumer organisations the issues that affect consumers. It meets three times a year. The Health Policy Forum is a group of $52 \mathrm{EU}$ organisations active in the health sector. Its aim is to ensure that "the EU's health strategy is open, transparent and responds to public concerns". In 2004, DG SANCO organised three meetings of an ad-hoc working group called Obesity Round Table with the aim of providing a forum for open and informal discussions on the approaches to tackle the obesity epidemic. The EU Platform for Action on Diet, Physical Activity and Health was created in 2005 with the aim of encouraging the stakeholders to commit to concrete activities to tackle obesity and overweight, including self-regulatory commitments from the industry on voluntary initiatives regarding adverting, reformulation or labelling. It is composed of 33 organisations, including those from the food industry, advertisers, consumer organisations and public health NGOs.

\section{Informational lobbying: Stakeholders as the brokers of evidence}

As described in chapter 2, in line with the predominant theoretical approaches, in this dissertation, lobbying is considered as "the strategic communication of specialised information" (Broscheid \& Coen, 2007, p. 347). This approach is particularly relevant for the study of the European policymaking process (Crombez 2003; Grossman \& Helpman, 2001). The analysis of the documents and interviews related to this case study confirms Coen's (2007) assumptions on "resource dependency" between the European Commission and interest groups and match the definition of "informational lobbying", according to which interest groups have expert information that policymakers need to make effective policy decisions (Potters \& Van Winden 1992; Broscheid \& Coen, 2007). The European Commission required information about the issue of food labelling both from the industry especially with regard to the potential costs and practical implications - as well as consumer organisations, to know the consumer needs and expectations concerning food labelling:

If key decision-makers are not informed properly, it means that they are missing a part of the puzzle and that it will influence their ability to make a balanced decision. In that sense, I think it is not so much about lobbying, but it is about informing the policymaker about 
certain views or certain arguments. (\#25, Director, EU Association of Food Companies)

Another interviewee stressed that the flow of and interest in receiving information were a two-way street: On the one side, the stakeholders were interested in having access to relevant information about the legislative and other policy developments within the European Commission that could affect their constituency, and on the other side, a clear need and interest of policymakers existed in receiving high-quality and useful input from the stakeholders: "It's not always just lobbying... We want information from them, or they want information from us" (\#16, Director, Public Health NGO).

A lobbyist from the food industry described how the European Commission successfully managed to punish what, in the formal models of communication (Gilligan \& Krehbiel, 1989), is called "babbling", i.e., the provision of biased information that only reflects the position of the interest group. The Commission has put in place a system of privileged access to the policymaking process (ad-hoc consultations, consultative groups) for some selected lobbying insiders (Broscheid \& Coen, 2003) that creates incentives for them to provide credible expert information and reduce information bias:

If you are a lobbyist and you don't get anything of what you want, or you are really a bad lobbyist, or you cheated in the information you provided. Here in Brussels, it is never black and white. It is always grey. On food information, there was consensus on the fact that labelling was needed. The discussion was rather on the approach to be followed. (\#15, Director, EU Affairs, Food Industry)

The European Parliament rapporteur interviewed for this research also raised the negative connotation of the word "lobbying" for the general public and stressed its usefulness for policymakers. She explained that when drafting the Regulation, she had listened to all parties, contacted scientists and the national governments or ministries responsible and read scientific newspapers. In this regard, she admitted as follows:

Lobbying is a very important source of knowledge. And that is one reason why we really need it. Lobbying has a very bad image in public. But of course, all of these lobbyists' interest groups have the right to inform us about their special so called 'needs' let's say. In the end, it is the decision of the MEP what is accepted and what is not. I always compare it with a mosaic: I collected information as a rapporteur. I talked to everybody who wanted to talk to me. And of 
course, I received hundreds and hundreds of letters, emails over all these years, and I studied everything. I listened to everybody who wanted to talk to me, and in the end, I decided what is relevant and what are, as we say in Germany, "crocodile tears". (\#20, Member of the European Parliament)

Having scientific evidence to support certain lobbying arguments is considered as an important asset, but substantial disparity exists between forprofit and not-for-profit interest groups concerning the amount of resources available to conduct research. In particular, non-industry stakeholders have at their disposal less financial resources to fund studies and produce evidence to be used for lobbying: "The issue for us is that we don't have the resources to provide as much evidence as the industry side can provide, that we don't have enough money to do our own research" (\#12, Head of Department, BEUC).

The stakeholders acknowledged that the European Commission was keen on securing the evidence to support the Proposal and considerable consumer data was taken into account:

The Commission started to be very keen to get evidence-based (information). So, they initiated the discussion on whether to make nutrition labelling mandatory in 2003-2004 with the discussion paper, and it was one of the very few (moments) when they tried to get consumer data. So, they launched the study back then, and since then, there were a number of studies that were being brought in, both on the consumer understanding and on the market reality, and I think those played a significant role. (\#19, Director, Global and Public Affairs, Food Industry)

Therefore, stakeholders as well provided evidence very early. The representative of a public health NGO said, "We started very early to see what evidence was out there, to see what consumers do and what they do not" (\#16, Director, Public Health NGO). However, in the impact assessment reports, no trace of evidence provided by this organisation was found.

Also, an industry representative referred to a "puzzle" of various inputs that fed the process and confirmed the Commission's role in balancing the various views and making a judgment on the views to take into account.

All the stakeholders interviewed acknowledged that they played a significant and legitimate role in feeding information to the policymakers and acted as brokers of the evidence of research findings. However, they admitted that the provision of scientific evidence didn't have a major impact on the 
beliefs and behaviour of policymakers. In this regard, an interviewee said, "Decision-makers don't read peer-reviewed journals. Someone needs to bring them the evidence... It will probably be brought to the decision-makers by those groups that want the decision-maker to be aware of the research" (\#16, Director, Public Health NGO).

The stakeholders, both representing the industry and consumers, consider evidence as a legitimising tool, and many of those interviewed in the context of this research stressed the importance of having sound evidence to support their lobbying activities: "We are a health charity, so anything to do with cardiovascular heart disease, we need to know what the research is. We can't go out and do things without having the research, it wouldn't be credible" (\#16, Director, Public Health NGO). Similarly, another stakeholder argued as follows: "We need to have the evidence to support what we are calling for. We don't lobby for something if we don't have the independent evidence (of it). I think there is a difference between evidence and independent evidence" (\#12, Head of Department, BEUC).

The Member States also carried out studies on the topic to substantiate their position on the Commission's Proposal. For example, in December 2009, the Food Safety Authority of Ireland published a research study on consumers' attitudes to food labelling. The Food Standards Agency of the UK published a research study on consumers' priorities of labelling and how consumers form priorities. The study showed important regional differences in how consumers interpret food information.

Both the industry and consumer groups contributed to the policymaking process with the specific studies they commissioned to external research bodies. Some of them were also taken into account in the impact assessment. On the one hand, BEUC's research showed that the traffic-light labelling system is more effective than the so-called "GDAs" in encouraging consumers stay off unhealthy products. On the other hand, the industryfunded European Food Information Council (EUFIC), an industry-funded non-profit organisation that provides science-based information on nutrition and health, food safety and quality, conducted a study on the consumer understanding of the traffic-light labelling system and GDAs and concluded that no significant differences existed between the two. Two similar studies reached different conclusions. Unfortunately, although the methodology used was reported in both studies, it was not possible to determine why two studies on the same topic generated different conclusions. 
One of the interviewees said that those MEPs who look for evidence do so in a selective manner depending on their political orientation, alluding to the fact that a right-wing MEP might be more inclined to listen to evidence from the industry, while a left-wing MEP might be disposed to listen to the arguments of NGOs:

It is important to decide the source of the information: for example, GUE will choose NGOs while the EPP will choose information from the industry. Officials are humans but embedded in a system of checks and balances to reduce biases. Most decisions are a balancing out of opposing views. Most studies are made with the input from stakeholders. At a certain moment you have to draw the line and take a decision. Listening to the patient is not enough, you have to take the temperature, make the test. In democracy you have 10 doctors and you have good chances that the doctors will not have the same diagnosis and most of all not necessarily good for the patient. In democracy you don't always have a democratic decision. You have to decide which part of society you have to regulate with a democratic process and which not. It depends a lot on the problem you need to solve. You have to choose for an input or for output legitimacy. (\#15, Director, EU Affairs, Food Industry)

A political advisor in the European Parliament (\#14) expressed the same view.

\subsubsection{Economics and politics}

As explained in chapter 2 and implemented in the previous two case studies, in this case study also, the categories economics and politics are addressed together. In particular, the political positions of the Member States and some MEPs were largely influenced by the considerations of the economic impact of the new labelling requirements on the food industry. As indicated in section 6.3.2, the consultancy RAND conducted a costconsequence analysis focused on the financial burden on the food industry, and, as pointed in section 6.4, the focus of the impact assessment was on the economic impact of the proposed changes to the labelling rules on food companies.

\subsection{Using Evidence: Impact Assessment}

The results of the public consultation, the stakeholder consultations via advisory groups (e.g., Advisory Group of the Food Chain), the ad-hoc working groups (e.g., DG ENTERPRISE workshop with SMEs), the 
European Commission advisory groups together with the RAND report were used as the basis for the impact assessment. The impact assessment was conducted according to the European Commission Impact Assessment Guidelines of 2005.

For the impact assessment, two issues were on the table: general food law and nutritional labelling. The European Commission didn't know if they had to consider them together or separately, but at the end, two separate impact assessments were presented, as the presentation of one impact assessment was considered to prejudice the outcome of the impact assessment process. Specific areas of overlap between the two impact assessments were the considerations of the regulatory approaches including the alternative flexible approach of the exchange of information and development of best practices, the estimation of the fundamental costs associated with food labelling and the legibility of the information on the label. To resolve the problems encountered by the piecemeal legislation, the need for the simplification of the existing legislative framework was obvious. Making the legislation more accessible by reducing the number of legislative texts had the potential of reducing the information costs for food businesses. However, the available evidence suggested that the costs of gathering information constituted a small part, although not negligible, of the overall costs of the administrative burdens related to food labelling. Information costs were estimated to contribute up to 5 percent to the labelling costs in Denmark and up to 13 percent of all the food legislation in the UK. However, other potential direct impacts existed for stakeholders if the issues that had been identified in the various consultations over the years were addressed in the revision. Concerning some issues, such as the use of country-of-origin labelling, the rules on ingredient listing, legibility and the lack of information on allergenic ingredients, the impact on the different stakeholders could have been significant, and these were the focus of the impact assessment.

Table 6.4 includes the main sources listed as references in the impact assessment reports classified according to their typology. Some sources were quoted in both reports, so they were merged into one table. Appendix X provides more details about the types of evidence reported in the impact assessment reports, including the title, authors and type of publication. 
Table 6.4.

Sources of Information in the Impact Assessment Reports

\begin{tabular}{|l|c|}
\hline \multicolumn{1}{|c|}{ Type of evidence } & Number of references \\
\hline Peer-reviewed scientific articles & 22 \\
\hline EU-funded projects & $/ /$ \\
\hline ECJ rulings & 4 \\
\hline $\begin{array}{l}\text { Eurostat, Eurobarometer surveys and } \\
\text { non-commissioned polls }\end{array}$ & 4 \\
\hline $\begin{array}{l}\text { European-Commission-commissioned } \\
\text { studies and analyses }\end{array}$ & 25 \\
\hline $\begin{array}{l}\text { National government studies (including } \\
\text { regulatory agencies) }\end{array}$ & 4 \\
\hline Stakeholders' surveys and studies & 1 \\
\hline Public consultations & 9 \\
\hline $\begin{array}{l}\text { Internal consultations with other } \\
\text { commission services, Member States and } \\
\text { stakeholders via advisory groups and ad- } \\
\text { hoc working groups and consultations }\end{array}$ & \\
\hline $\begin{array}{l}\text { Documents from other institutions (e.g., } \\
\text { WHO, Council of the EU) and articles in } \\
\text { non-peer reviewed journals }\end{array}$ & 80 \\
\hline Total & \\
\hline
\end{tabular}

The Commission official in charge of the dossier admitted that when they commissioned the impact assessment, they had already filtered out considerable information on the basis of the extensive stakeholder consultations and they already knew the issues they wanted to cover in the legislation:

To do the impact assessment we had asked a contractor to make a study, asked him to evaluate the impact of certain options. But then I say it was advanced because we had already filtered in a way all the information we had received, and we had some views that where a little bit more mature. It means we had already in mind what would be the issues that we would want in the legislation to cover. (\#28, Administrator, European Commission) 
Two of the interviewees confirmed that the impact assessment was focused on economic elements:

It (the impact assessment) focused on the economic impacts. (It) was very much focused on what would the impact be on the industry and of course you have to think the SMEs. With a lot of economic argument saying this would cost a lot and so on and so forth. (\#16, Director, Public Health NGO).

The aspect mentioned above was confirmed by the Commission official in charge of the Proposal who said that "economics actually plays an important role in terms what's coming forward and what people accept and push for. The cost of things was important for our impact assessment” (\#28, Administrator, European Commission).

Moreover, in the impact assessment document itself, the European Commission had admitted that some of the assumptions of costs made by the industry were largely overestimated. However, while it is relatively easy to measure the costs associated with administrative burden, it is more difficult to estimate the benefits of the legislation for European citizens and industries. Moreover, the short-term impacts are easier to quantify than the long-term ones, and this is one of the reasons used to justify such a long transition period for the implementation of the Regulation.

It's difficult to quantify at the end the consumer benefit. It easier maybe to quantify costs and burdens for the companies, but more difficult to quantify health benefits and outcomes. It's the difficulty of trying to make an assessment of the potential long-term benefits against the short-term impacts. And it was also one of the reasons we gave quite a long transition period of three-year period in which labelling could be adapted to the new rules. But that's more about the costs rather than the evidence behind the legislation. (\#28, Administrator, European Commission)

The above statements highlight that the standard option of not legislating was not seriously taken into consideration. To the knowledge of the researcher - based on participant observation - over the last 10 years, none of the impact assessments produced by the European Commission has recommended a "no-legislation" option.

An interviewee stressed the importance of impact assessments and particularly added that the option of not legislating should always be on the table. Unfortunately, this often seems to be forgotten: 
It is important that impact assessments include the results of a broad consultation with stakeholders. There is little objective information in Brussels. A lot is grey, and that's why it is difficult to legislate. There is also a lot of misinformation. Impact assessment forces civil servants to justify their proposals, outlining all the options, including the option not to legislate, which is often forgotten. It is vital to have an independent scrutiny check of impact assessment. The Commission has to put on paper the mental process they made in their heads. The Impact Assessment Board has an impact. There should be more focus on impact assessment all along the process. But it is difficult resources wise. It is a political decision to have an impact assessment on a piece of legislation. It is very important if they assess the impact afterwards. If you make a proposal to solve a problem and then the problem remains unsolved, the legislation should be withdrawn. (\#15 Director, EU Affairs, Food Industry)

Concerning the other two case studies of this research, from the interviews, it emerged that in the case of the Regulation on food information as well, the impact assessment was made on the provisions that are far from those included in the final text of the legislation. For example, one of the interviewees acknowledged that impact assessment is useful to inform the debate and evaluate whether something is feasible or not. However, he also highlighted the significant differences between the original Proposal by the European Commission and the final text of the legislation. Similar to the other interviewees for this case study and the other two case studies, he suggested an impact assessment to be done at least on the most substantial amendments introduced by the European Parliament and the Council:

If you look at the impact assessment that has been done for the Proposal on food information to consumers and if you compare it with the final text, there is quite a big difference because the Council has made changes to the Commission's Proposal and EP made changes to the Commission's Proposal. I wonder whether an impact assessment on some of those amendments or on all those may be done at the final stage of the Proposal. (\#25, Director, EU Food Industry Association)

The search for knowledge went far beyond research evidence and included the interests and views of public health and consumer groups. In this respect, the Weiss (1979) model of research utilisation that best applies to this case study is the interactive model. As for the other two case studies, search 
for knowledge was only a very small part of a wider and more complex process that mostly relied on political considerations, lobbying pressure and personal judgment.

\subsection{Capacity for Implementation: Hindering and Facilitating Factors in the Uptake of Research Evidence}

As mentioned in the previous chapters, measuring policymakers' capacity to use and act upon evidence is a very difficult task, owing to the impossibility of disentangling the different elements that ultimately played a decisive role in choosing a policy element over another. How evidence is integrated in the policymaking process and the concrete influence it has on the final decision remain blurred. One of the interviewees attributed this aspect to the lack of transparency of the policymakers in dealing with the evidence:

And you know there's a lack of transparency, so you always have these impact assessments, but you don't know how the final proposal was developed. What I think is missing is the link (between the proposal) and the feedback (from stakeholders) or information on why certain evidence was given preference over other evidence and to try to justify their arguments... Sometimes there could be a good justification behind what they have done, but when you are not aware, when you have no idea from what angle they are coming... So I think there is just a lack of transparency. (\#12, Head of Department, BEUC)

Table 6.4 gives a quantification of how often research and other types of evidence were mentioned in the impact assessment. However, overall it is not feasible to determine from a quantitative and qualitative point of view which evidence was used and which was not used. More specifically, the analysis of the case study demonstrated the difficulty of both decision-makers and stakeholders in making a clear distinction between the different types of evidence used in the policymaking process. In this regard, a Commission official admitted as follows:

There is also a small difference that is difficult sometimes to make, the distinction between evidence which is one thing and the positions of the stakeholders. Because for me, evidence is something that is objective. Then you have all these positions which are sometimes supported by evidence sometimes they are not. So there is the evidence and then there is the game of power. Which is the political risk you take. (\#28, Administrator, European Commission) 
The capacity to implement has therefore been investigated considering the main hindering and facilitating factors of the uptake of a specific type of evidence, namely research evidence. They are summarised in table 6.5.

Table 6.5

Facilitating and Hindering Factors for the Uptake of Evidence on Food Labelling

\begin{tabular}{|l|l|}
\hline \multicolumn{1}{|c|}{ Facilitating factors } & \multicolumn{1}{c|}{ Hindering factors } \\
\hline Policymakers' information need & $\begin{array}{l}\text { Lack of relevant and timely } \\
\text { research }\end{array}$ \\
\hline $\begin{array}{l}\text { Organisational procedure (i.e., the } \\
\text { need to make an impact } \\
\text { assessment) }\end{array}$ & No-EU wide research available \\
\hline $\begin{array}{l}\text { Economic resources available to } \\
\text { commission an independent } \\
\text { impact assessment study }\end{array}$ & $\begin{array}{l}\text { Lack of policymakers' skills to } \\
\text { search and assess the evidence }\end{array}$ \\
\hline & Policymakers' personal beliefs \\
\hline
\end{tabular}

The main facilitating factors that emerged from the analysis of the documents and interviews were the need of the European Commission to gather information, especially from the stakeholders, and the need to search for evidence to prepare the impact assessment (organisational factor).

\subsubsection{Lack of available, timely and reliable evidence that meets policy needs}

Despite the limited use of research evidence in the formulation of the draft Proposal, during the interviews, the policymakers and stakeholders voiced several reservations on the use of research in the policymaking process, particularly, in relation to its validity, independence and neutrality. Moreover, some explained that evidence searching can be an endless process and research evidence can be non-conclusive. They also argued that information other than academic evidence, such as industry data, can be useful to correct inaccurate information.

Most of the literature on consumer preferences and the impact of labelling were not usable in the context of the Regulation. When the Proposal was drafted, dome peer-reviewed articles were available, but they were highly specific or covered only a specific sector, such as the origin labelling of meat, or a limited geographical area. In addition to availability, timeliness is also a 
key factor in the EU policymaking process. The representatives of both the European Commission and the European Parliament (\#20; \#28) indicated that it takes too long to plan a scientific study, or a survey and the results cannot be produced on time to be used before a proposal is adopted. The geographical coverage of the evidence - both scientific research evidence and other types of evidence - is also very relevant. Concerning the provision of food information to consumers, the evidence of a color-coded labelling scheme based only on the UK experience was used, and therefore, it was less relevant for an EU legislative Proposal.

The distance between the academic and the policy community was also raised as a key hindering factor. A representative of the food industry (\#19) indicated that academics want to their keep distance from policymaking to preserve their credibility. However, at the same time, three interviewees explicitly mentioned the problem of bias in conducting research by academics and surveys or interviews by consultancies (e.g., RAND report) or stakeholders. A representative from the European Commission noted that the way questions are framed influences the final results and policymakers do not usually look at the methodology used and only focus on the study conclusions:

When you take research or studies, you see the result. So you see the report, but if you don't know the methodology that was used to collect this information, for example, whether the question was prompting a reply... Now we are discussing about some behavioural studies, or when we do the questionnaires, which are part of the impact assessment, we know what we ask and how we ask, and I think one of the elements especially which consumer attitude, which are very important is the nature of the question. Is it an open question? Is it a closed question? Is it a question with multiple choices? Does it prompt? Does it not prompt? (\#28, Administrator, European Commission)

Some interviewees also pointed out the fact that academic studies, including those published in peer-reviewed journals, can be biased as well and it is important to disclose who funds a study. A representative of the European Parliament also commented on the independence of universities and the option of delinking funding from an industry to a university by creating a sort of common bucket:

Many universities are dependent on financing from a lot of industries. In Germany, the State finances universities. But Member States have 
less and less money as you probably have heard. As long as they just finance it and don't try to influence science, then it's absolutely ok. Yes, they should do, and I think they have a kind of responsibility, but for me the question is always: should they finance directly one university, or wouldn't it be better for those who are willing to finance science to pay it on one account altogether and then it is spread to different universities. (\#20, Member of the European Parliament)

In January 2015, the European Ombudsman published a report on the decision about the inquiry into a complaint against the European Food Safety Authority filed in 2013 by a UK NGO that monitors the developments in the field of genetic technologies. The complaint was about the allegation that EFSA had failed to address conflict-of-interest issues in relation to certain members of a working group dealing with the issue of genetically modified insects. In the decision, the Ombudsman noted that it is increasingly common for universities and other third-level bodies to work closely with companies to carry out research and commercialise the results of research. According to the Ombudsman, "the traditional understanding that academia is necessarily and automatically 'independent' must evolve to reflect these developing deeper relationships between academia and business. The view that academia, academic institutions and individual academics are independent of business must be based not on preconceived assumptions, but rather on an examination of the specific relevant facts" (European Ombudsman, 2015).

A representative of a public health interest group alluded to the fact that the industry undermines some evidence claiming that the available evidence is not enough (e.g., negative health consequences of high salt consumption) and more research is needed. On the other hand, a food industry representative stated as follows:

You are never going to have a complete picture. You are never going to have enough to be satisfied, but at some point, you have to say 'ok, fine, I'll base my policy decision on the evidence I have today'. Probably what we need is not to wait until we are totally satisfied, but to have a process that is flexible enough to allow us to adapt moving forward, assuming that new evidence or new elements come into, rather than such a complex process of adapting the legislation. (\#19, Director, Global and Public Affairs, Food Industry)

Regarding the research evidence provided by the stakeholders, for example, in this case study, the stakeholders' research on consumers' understanding of labelling, a representative of one of the Member States 
indicated that it was not very influential and was not used to make decisions because it was considered subjective. He stressed the need to have reliable information that cannot be challenged and can actually be used. At the same time, he also admitted that research from reputable scientific institutions is not always taken into account, depending on the political will:

We need solid information that cannot be easily challenged and that we can actually use. Our main sources of data are trusted and reputable international scientific bodies such as EFSA, ECDC and WHO... Stakeholder studies are not very influential... Stakeholders studies are not taken into account because they are a subjective source of information. In some cases, stakeholder information is just a source of inspiration. Of course, if the information doesn't come from stakeholders but from an organisation that represents the general public, you don't have so much contradiction. For example, we had a study on candies from a university and all the institutions used it because they considered it relevant for the precautionary principle... For novel food, despite many positive scientific opinions, prudence prevailed. (\#22, Health Attaché, Permanent Representation to the EU)

\subsubsection{Lack of staff resources to search and use research evidence}

One of the main elements identified as a barrier for the uptake of research evidence in the formulation of the Proposal on food information is the lack of staff resources within the European Commission dedicated to the dossier. For the dossier on food information, only two desk officers and a head of unit were in charge, and they also lacked the scientific background on the issue to be able to search, process and apply research and other types of relevant evidence. As for the previous case study, two interviewees mentioned that MEPs as well are overloaded and lack the competence and resources to search and use evidence.

\section{evidence \\ 6.5.3 Personal beliefs and emotions prevailing over research}

Two of the interviewees, both from public health NGOs (\#8; \#12), said that the research evidence was repeatedly and completely ignored, but they mostly referred to the evidence on the traffic-light labelling system collected in the UK, which was in line with their policy demands. In what appears an evidence-informed policymaking, it is clear that ultimately policy 
decisions are mostly the result of personal judgments of key decision-makers and a political choice is often made in the name of consensus:

The aim is to be as much facts based as possible, but the reality is that from a political point of view, consensus needs to be made, and it means that compromises need to be found between the different institutions. (\#25, Director, EU Food Industries' Association)

One specific hindering factor that appears to have been a decisive factor in the formulation of the Proposal on food information are personal beliefs and emotions. Consumer groups accused the Commission official in charge of the dossier of following personal conviction and beliefs, especially with regard to the traffic lights system:

Maybe what may have influenced their (European Commission) position was also that the many commission officials who dealt with this dossier are from southern Europe and you could see that there was a resistance from Member States of these countries because of olive oil etc. and you say red light on olive oil that our national product, we don't want that. (\#12, Head of Department, BEUC)

Another interviewee (\#16, Director, Public health NGO) referred to the higher level of administration indicating that the final decision depended on the Commissioner himself/herself.

In his analysis of decision-making, Simon (1983) argued that "in order to have anything like a complete theory of human rationality, we have to understand what role emotion plays in it" (p. 29). The word "emotion" emerged several times during the interviews concerning the important influence of the views of individuals in the policymaking process:

I think a lot of emotions came into it. As I said already, I think the Commission's Proposal was a compromise. And once it came into the Parliament, it became a fight, and it was very emotional. And I think that certainly many of the MEPs do not seem to be very evidence based in their decision-making. It's very much about what I think and what I do and my grandmother or daughter or in my family, this is what you hear when you go down there and listen to the debate. It's very emotional, very personal. The MEPs in their debate in the Parliament can be very emotional and very personal. (\#16, Director, Public health NGO) 
In this regard, another interviewee stated that "the political discussion was an emotional one. So no one was interested in the evidence, and everybody was interested in the emotional attachment towards food" (\#8, Secretary General, Public Health NGO). The same interviewee also attributed the failure of consumer groups and health NGOs in achieving their goals to them focusing on the technicalities rather than emotions and them losing the human element.

In particular, the European Parliament seemed more "emotional" than the Council and also more subject to the influence of stakeholders:

I'm always very astonished by the input that the Council (provides) and how technical they are, how they can get really good evidence of reality, so MEPs were influenced much more by the stakeholders. It was a very emotional debate in this particular case, driven by one or two MEPs that often have their own personal agenda that is not grounded in any reality and come up with the weirdest ideas that you as an industry have to apply, which is not always possible. It's never grounded in reality, the position of the Parliament is very emotional and very much driven by the stakeholder one particular MEP listens to so, whoever is close, whichever constituency is closer to a particular given MEP. (\#22, Director, Global and Public affairs, Food Industry)

Interestingly, similar to the case study on the provision of information to patients, in the case of the Proposal on food information, EU officials were accused of being too detached from real life:

In the European Commission, there are of course civil servants that have very long experience in drafting proposals and they are specialised too, but the problem is from my point of view that, especially those civil servants who are there since decades lost the lot of contact to real life, they really don't know what's going on in the heads of the normal citizens. In the Commission, people are not competent in, let's say real life. (\#20, MEP)

\subsection{Conclusion}

Food labelling is a key public health policy tool in the fight against obesity and overweight, as it allows consumers to better understand the nutritional value of their food and make healthy choices. Food labelling is also a basic consumer right, as people have the right to know what they are eating. The harmonisation of rules on food labelling was considered 
necessary by all the stakeholders due to the fragmented application of industry guidelines. However, in the debate on the definition of EU common rules, the benefits of public health and consumer protection arguments had to be weighed against the costs the food industry had to bear because of the new labelling requirements.

In preparation of the draft legislation, the European Commission actively sought different sources of evidence on the costs and benefits of bringing a change in the legislation. The two impact assessment reports that accompanied the Proposal were the results of the three studies commissioned to external consultancies and various forms of consultations with the stakeholders.

While measuring the administrative costs of the industry was relatively easy - even if the Commission admitted that the industry figures were overestimated - deciding on what kind of information consumers were entitled to and in which format the information should be provided were considered to be the more "societal issues" that had to be discussed with the stakeholders.

The research findings of studies by academics and reports from national authorities were among the main sources of information referred to in the impact assessment. However, from the analysis, it emerged that the Commission largely relied on the inputs from the stakeholders. The Stakeholders, who are increasingly active in the formulation of EU policies, provide Commission officials with expert information and data as well as act as the brokers of evidence from research.

The key stakeholders in relation to the draft legislation were, on the one side, the food and drinks industry and, on the other side, health NGOs and consumer associations. The stakeholders were consulted in different ways, including closed consultations addressed to some constituencies only, public consultations, surveys and interviews conducted as part of the external studies commissioned to consultancies, via consultation made by the Member States at the national level as well as via the various European Commission stakeholder fora (e.g., Diet platform on nutrition and health).

EU policymakers listen to all stakeholders but favour information that is reliable, has a European dimension and is in line with their way of thinking. Ultimately, decisions are influenced by the beliefs, values and judgments of individuals and result in a political choice made in the name of consensus. 
"Good enough evidence" on food labelling was not fully available when the Commission was preparing the draft legislation, and information gaps existed that the Commission and the consultancies that worked on the topic tried to fill in consulting the stakeholders. Both the stakeholders and the Commission made significant efforts to gather the necessary evidence, but despite all efforts, the policymakers and stakeholders' perceptions of both research and other types of evidence were rather negative. They consider that evidence was not taken up in the policymaking process not only because of practical hindering factors such as the lack of time and expertise of decisionmakers but also because it is often considered non-conclusive, irrelevant and biased. Despite the EU policymaking process being highly regulated and the formal requirements in place to gather the evidence to build the impact assessment accompanying the legislative Proposal, personal beliefs, value and emotions seem to have prevailed over the evidence. 


\section{Chapter 7: Comparison of Case Studies}

\subsection{Introduction}

This chapter compares the three case studies presented in the previous chapters and aims to identify the similarities and differences between the sources and use of evidence in the EU policymaking process for the three legislative proposals and the factors that facilitate and hinder the uptake of research evidence. This attempts to generalise the findings from each case study to the formulation of European health policies and to answer the general questions guiding the research (as described in Chapter 1).

The chapter is constructed as follows: Section 7.2 outlines the similarities and the differences in the legislative pathways followed by the proposals and section 7.3 analyses the similarities and the differences in the sourcing of evidence in the formulation of the proposals according to the Bowen and Zwi classification as presented in Chapter 2. Section 7.4 compares the use of evidence and impact assessments accompanying the proposals while section 7.5 elaborates on the hindering and facilitating factors for the uptake of evidence in the three case studies. Section 7.6 draws the main conclusions of the comparative analysis.

\subsection{Legislative Pathways: Similarities and Differences}

The three case studies have more similarities than differences in terms of the legislative pathway they have followed. As indicated in Chapter 2, the three proposals have in common the objective of improving public health and information to European citizens and the internal market principle as the legal basis (Article 114 of the TFEU) They are all binding legal acts adopted under the so called 'ordinary legislative procedure', and each proposal was adopted by the European Commission in 2008. The proposals on food information and cross-border health care were both drafted by the Directorate General for Health and Consumers (DGSANCO, now DG SANTE), which is in charge of protecting public health, while the proposal on information to patients was originally drafted by the Directorate General for Industry (DG ENTERPRISE, now DG GROWTH), which is in charge of promoting the interests of the European industries. The move of the competence on pharmaceuticals and medical devices from DG ENTERPRISE to DG SANCO in the Barroso II Commission and the moving the file on information to patients to DG SANCO contributed to change the focus of the proposal, from the interests of the pharmaceutical industry to the interests of patients. 


\subsection{Sourcing Evidence}

The first research question focuses on the way the European Commission sourced the evidence for is legislative proposals. Table 7.1 summarises the main similarities and differences in the sourcing of evidence among the three case studies. The table includes specific figures about collection of evidence by the European Commission including, for example, the number of months spent on public consultations, the number of responses to the public consultations accompanying the proposals or the number of studies quoted. A more detailed analysis of the similarities and differences is offered below.

Table 7.1.

Comparison of Case Studies: Similarities and Differences in the Sourcing of Evidence

\begin{tabular}{|l|l|l|l|}
\hline \multicolumn{1}{|c|}{$\begin{array}{c}\text { Cross } \\
\text { border } \\
\text { health care }\end{array}$} & $\begin{array}{l}\text { Information to } \\
\text { patients }\end{array}$ & Food labelling \\
\hline $\begin{array}{l}\text { EC consultative } \\
\text { groups (in } \\
\text { addition to the } \\
\text { inter service } \\
\text { consultation) }\end{array}$ & 3 & 2 & 5 \\
\hline $\begin{array}{l}\text { Number of } \\
\text { public } \\
\text { consultations on } \\
\text { the key } \\
\text { legislative } \\
\text { proposals and } \\
\text { related issues }\end{array}$ & 1 & 3 & 1 \\
\hline $\begin{array}{l}\text { Duration of the } \\
\text { key consultation } \\
\text { on the legislative } \\
\text { proposal }\end{array}$ & 4 months & 2 months & 3 months \\
\hline $\begin{array}{l}\text { Number of } \\
\text { responses to the } \\
\text { main public } \\
\text { consultation per } \\
\text { stakeholder } \\
\text { group }\end{array}$ & $\begin{array}{l}\text { National } \\
\text { organisations: } \\
108\end{array}$ & $\begin{array}{l}\text { Health care } \\
\text { professionals } \\
\text { and } \\
\text { organisations: } \\
59\end{array}$ & $\begin{array}{l}\text { On general } \\
\text { food labelling: } \\
\text { governmental } \\
\text { organisations, } \\
10 \text { consumer }\end{array}$ \\
\hline
\end{tabular}




\begin{tabular}{|c|c|c|c|}
\hline & $\begin{array}{l}\text { International } \\
\text { organisations: } \\
77 \\
\text { Member } \\
\text { States: } 26 \\
\text { Commercial } \\
\text { Organisations } \\
\text { and } \\
\text { companies: } \\
20 \\
\text { Regional } \\
\text { authorities: } \\
19 \\
\text { Universities:9 } \\
\text { Citizens:5 } \\
\text { Other:5 } \\
\text { National } \\
\text { Parliaments: } \\
2\end{array}$ & $\begin{array}{l}\text { Patient } \\
\text { organisations: } \\
40 \\
\text { Regulators:28 } \\
\text { Pharmaceutical } \\
\text { industry } \\
\text { organisations } \\
\text { and } \\
\text { companies:26 } \\
\text { Research and } \\
\text { others: } 10 \\
\text { Consumer } \\
\text { organisations : } \\
9 \\
\text { Media and } \\
\text { patient } \\
\text { information } \\
\text { organisations :7 } \\
\text { Social } \\
\text { insurance } \\
\text { organisations: } 6\end{array}$ & $\begin{array}{l}\text { groups, } 5 \\
\text { public health } \\
\text { NGOs, } 55 \\
\text { food } \\
\text { industry } \\
\text { organisations } \\
\text { or companies, } \\
4 \text { from } \\
\text { individuals. } \\
\text { On nutrition } \\
\text { labelling: } \\
22 \\
\text { governmental } \\
\text { organisations, } \\
10 \text { consumer } \\
\text { groups, } 7 \\
\text { public health } \\
\text { NGOs, } 51 \\
\text { food industry } \\
\text { organisations } \\
\text { or companies } \\
\text { and } 4 \text { from } \\
\text { individuals. }\end{array}$ \\
\hline $\begin{array}{l}\text { Total number of } \\
\text { responses to the } \\
\text { key public } \\
\text { consultation on } \\
\text { the legislative } \\
\text { proposal }\end{array}$ & 276 & $\begin{array}{l}185 \text { responses } \\
\text { and } 7 \\
\text { comments }\end{array}$ & $\begin{array}{l}247 \text { responses } \\
\text { were } \\
\text { registered, of } \\
\text { which } 73 \text { were } \\
\text { essentially the } \\
\text { same. These } \\
\text { were counted } \\
\text { as one } \\
\text { response, so it } \\
\text { was } \\
\text { considered } \\
\text { that } 175 \\
\text { contributions } \\
\text { were received. } \\
101 \text { of the } \\
\text { respondents }\end{array}$ \\
\hline
\end{tabular}




\begin{tabular}{|c|c|c|c|}
\hline & & & $\begin{array}{l}\text { provided } \\
\text { views on the } \\
\text { general food } \\
\text { labelling } \\
\text { aspects of the } \\
\text { consultation. } \\
95 \text { on nutrition } \\
\text { labelling. }\end{array}$ \\
\hline $\begin{array}{l}\text { Number of } \\
\text { scientific studies } \\
\text { mentioned as } \\
\text { supporting } \\
\text { evidence in the } \\
\text { impact } \\
\text { assessment and } \\
\text { supporting } \\
\text { studies }\end{array}$ & $\begin{array}{l}2 \text { in the } \\
\text { impact } \\
\text { assessment } \\
\text { report } \\
78 \text { in the } \\
\text { OBS study } \\
\text { used to } \\
\text { support the } \\
\text { formulation } \\
\text { of the } \\
\text { Directive by } \\
\text { the EC }\end{array}$ & 26 & 22 \\
\hline Eurobarometer & Yes & No & No \\
\hline $\begin{array}{l}\text { Number of } \\
\text { external studies } \\
\text { and surveys } \\
\text { Commissioned } \\
\text { by the EC }\end{array}$ & $\begin{array}{l}1 \text { study } \\
4 \text { EU funded } \\
\text { projects }\end{array}$ & 3 & 4 \\
\hline $\begin{array}{l}\text { Number of } \\
\text { stakeholder } \\
\text { (including } \\
\text { national } \\
\text { authorities) } \\
\text { studies/report } \\
\text { used as } \\
\text { supportive } \\
\text { evidence in the } \\
\text { impact } \\
\text { assessment }\end{array}$ & 10 & 7 & $\begin{array}{l}4+25 \text { from } \\
\text { national } \\
\text { authorities = } \\
29\end{array}$ \\
\hline $\begin{array}{l}\text { Economic } \\
\text { Impact }\end{array}$ & $\begin{array}{l}\text { Health care } \\
\text { systems }\end{array}$ & $\begin{array}{l}\text { Pharmaceutical } \\
\text { industry }\end{array}$ & Food industry \\
\hline
\end{tabular}




\begin{tabular}{|l|l|l|l|}
\hline & $\begin{array}{l}\text { Media industry } \\
\text { Health care } \\
\text { systems }\end{array}$ & $\begin{array}{l}\text { Health care } \\
\text { systems } \\
\text { (indirectly) }\end{array}$ \\
\hline
\end{tabular}




\subsubsection{Research}

\section{Similarities}

The main similarity among the three case studies with regard to the sourcing of research is that they went beyond academic research and included studies and reports from non-academic institutions (e.g. Finnish National Agencies for medicines, UK Department of Health, European Commission) and research commissioned by stakeholders (e.g. UK Consumer Association study on colour coded labelling schemes).

Officials in the European Commission, who are in charge of drafting the legislative proposals, have at their disposal a library to conduct research, and some make a general and preliminary desk research. However, for the three case studies, a limited analysis of the existing literature was delegated to an external body in charge of writing an independent report to feed the impact assessment. Organisations supporting the European Commission to draft the impact assessments - namely the European Observatory on health care system and policies (hereafter Observatory) for the proposal on crossborder health care, the RAND Corporation for the proposal on food information and Europe Economics for the proposal on information to patients - were chosen as a so-called framework contract agreement, an agreement between the European Commission and shortlisted external operators defining the terms of the contracts between the two entities over a given period of time to avoid an open call for each contract. Despite the different nature of the bodies involved - the two private consultancies (RAND and Europe Economics) and the WHO European Observatory - they all share the same type of core business, namely, to support evidence-based policymaking through comprehensive analysis. It could be argued that none of the reports were fully independent for the following four main reasons: first, because they were all funded by the European Commission; second, because they were developed to serve specific policy needs; third, because the European Commission contributed to frame the study and lastly, they didn't follow rigorous scientific/academic standards, for example, when conducting the literature search. With regard to the literature study, another key similarity between the three case studies is the lack of academic research on the specific issue that each of the legislative proposals aimed at regulating, mostly because research was strictly related to the specific topic to be regulated was limited or non-existing.

With regard to food information, the RAND report highlighted that there was limited literature on the impacts of labelling in the EU and that most of the literature was from New Zealand, Australia and the US. It also indicated 
that there was extensive literature on a specific issue, namely labelling of prepacked food, but not on the other aspects they had to look at, such as small packaging and food sold loose. To fill the knowledge gap, RAND chose to interview relevant stakeholders in the field.

A similar problem was found in the case study on information to patients. Taking into account that the key concept of the Commission proposal - namely the provision of non-promotional information from drug manufacturers to patients about their products - was new, there was no available evidence on its impact on health outcomes, health care costs and so on. Therefore, the consultancy sourced evidence on Direct to Consumer Advertising (DTCA) as an upper bound estimate of the likely impact.

On cross-border health care, the European Commission funded research on the phenomenon via EU projects, but it was futile as the research didn't produce reliable data on the main issue, namely patient flows, and didn't have the EU-wide coverage needed by the European Commission.

\section{Differences}

For the proposal on cross-border health care, the literature research on the topic to be regulated was extensive and done with academic standards in the context of the Observatory report and work with experts (see section 4.7). On the other hand, for the report on food information and information to patients, the literature review was based on fewer references. In particular, to draft the report on information to patients, Europe Economics reviewed 26 items of literature while the RAND report on food information had 88 references. The report on cross-border health care from the Observatory was published in the form of a book and involved 18 academics and experts on the topic. The 396-page report lists more than 300 references (it is actually 337 , but some are repeated in more than one chapter). As mentioned above, the three literature reviews include both scientific articles published in peer reviews and other scientific publications and studies from non-academic institutions. Moreover, while academics were involved as experts in the case of cross-border health care and information to patients and were invited to participate in the meetings of the high-level group on health care and of the high-level pharmaceutical forum, they were not formally involved by the European Commission for the formulation of the proposal on food information. 
An element that characterises the proposal on cross-border health care and not the others is that the European Commission decided to actively finance projects to produce useful evidence on patient mobility.

The case studies on information to patients and food information demonstrated that stakeholders acted as brokers of research evidence to policymakers. In particular, for the proposal on information to patients, public health NGOs and consumer groups used existing evidence on the negative consequences of DTCA to oppose the Commission's proposal, while for the proposal on food information, both advocacy coalitions (the industry on one side and the consumers/health NGO on the other) promoted the research evidence they produced and/or selected academic research that was in line with their arguments. An official of the European Commission indicated: 'There was specific information from the literature that we had from the stakeholder reports' (\#28, Administrator, European Commission). This aspect didn't emerge from the case study on cross-border health care and this is also linked to the absence of defined advocacy coalitions.

From the above, it is possible to draw three main conclusions. First, the typology of evidence and the methods to collect it are the same for the three case studies as they depend on the informational needs and on the formal procedures of the European Commission, in particular, in relation to the obligation to conduct an impact assessment of the legislative proposal. Second, research is actively sought after, especially to seek legitimacy and consensus around the legislative action of the European Commission. The Commission is interested in gaining legitimacy and consensus mostly from internal services of the European Commission - a proposal is made by one Directorate-General (DG) but is adopted by the entire college of Commissioners and goes through the inter-service consultation, so other DGs also have to agree with and support it - and from the European Parliament and the Member States who need to approve the proposal in order for it to become an EU law. Third, the existence of opposing coalitions leads stakeholders to become 'evidence brokers' and bring to policymakers research evidence that support their arguments.

\subsubsection{Knowledge and information}

In the Bowen and Zwi model, evidence classified as 'knowledge and information' are published reports (including policy analysis and statistics) on the internet and results of consultations with groups and networks. The channels and methods used by the European Commission to gather this type of evidence are linked to the European Commission's procedures, including 
calls for tenders (and in the specific case, framework contract agreements) for the selection of the providers, as well as the type of analysis and information sought by the European Commission, which inevitably shapes the results of the sourcing process and the way they are presented. Also, with regard to surveys and public consultations, the many similarities among the three case studies are linked to the existence of specific European Commission public consultation guidelines as well as the specific rules for the establishment and working methods of the European Commission's expert groups (selection procedures, transparency, publication of minutes and so on). The guidelines and the institutional procedures provide general rules and ensure a high degree of harmonisation. However, an in-depth analysis of the case studies revealed some differences, which provide useful insights on the use of evidence. The main similarities and differences are outlined below.

\section{Similarities}

For all the three case studies, the European Commission sourced data from Eurostat, the Statistical Office of the EU. Eurostat gathers and analyses figures from different European statistics offices in order to provide comparable and harmonised data in different sectors of the economy, including health. Eurostat data were sought especially with regard to figures of health care expenditure in relation to the proposal on cross-border health care and for figures regarding the food industry in the proposal on food information.

The European Commission consults the Member States and stakeholders for each case study via ad-hoc working groups and standard consultations groups. The main stakeholders consulted were of the same typology, namely EU umbrella organisations representing both the for-profit and the non-for-profit sector. Some of them were the same for each proposal - for example, the European Public Health Alliance - while the others differed only because of the sector involved (e.g. the pharmaceutical industry for the proposal on information to patients and the food industry for the proposal on food information to consumers).

The Advisory Group on the Food Chain, the European Consumer Consultative Group, the EU Health Policy Forum and the EU Platform on diet, physical activity and health discussed the proposal on food information to consumers and provided expert advice to the European Commission. 
The proposal on information to patients was discussed by the European Consumer Consultative Group, which also submitted a written position to the European Commission.

The European Consumer Consultative group and the EU Health Policy Forum discussed the proposal on cross-border health care, but this was not mentioned in the impact assessment.

For the three proposals, the European Commission created ad-hoc working groups discussion topics related to the proposals even if formally not associated to them. They were the Pharmaceutical Forum for the proposal on information to patients, the Platform on Obesity for the proposal on food information and the high-level reflection process and the high-level group on health services and medical care for the proposal on cross-border health care. The high-level reflection process was composed of Member States only and external experts were invited to some of the meetings on an ad-hoc basis, while the pharmaceutical forum included representatives of all Member States and stakeholders. Also, the Obesity Roundtable hosted mostly stakeholders, but it met only three times.

Finally, for the three legislatives proposals, the DG in charge of the dossiers consulted other DGs concerned via the 'inter-service consultation'. This consultation aims at ensuring that all aspects of the matter in question (e.g. impact on the environment, impact on trade and so on) are taken into account and poses another opportunity for the officials drafting the legislation to gather information and knowledge.

\section{Differences}

For the proposal on food information, in addition to the RAND report, DG SANCO commissioned other two reports to two consultancies - one on the introduction on mandatory labelling and one on consumer attitudes towards labelling.

A source of information for the European Commission were surveys to gather perceptions of Europeans, especially the Eurobarometer. This tool was used only for the proposal on cross-border health care. For the proposal on cross-border health care, in addition to the Eurobarometer survey, the Commission also quoted a pan-European survey conducted by the liberal think-tank Health Consumer Powerhouse. The report on current practices on information to patients in the Member States referred to a Eurobarometer survey conducted in 2003 on the sources of health information used by EU citizens, but it was not conducted specifically in preparation of the legislative 
proposal, which was the case for cross-border health care. For the proposal on food information, the Commission relied on a private statistical body (Nielsen, 2005) survey on consumer perceptions on food labelling, but the survey was not EU specific nor was it conducted in preparation of the legislative proposal. Instead of a direct poll among Europeans, DG SANCO commissioned a qualitative study on consumers' perceptions to the consultancy OPTEM.

Ad-hoc surveys among stakeholders were used in the preparation of the reports that supported the impact assessments of the proposals on food information and on information to patients; a survey among stakeholders in addition to a specific survey among small and medium enterprises for the proposal on food information and a survey among three types of stakeholders (health care payers, health care providers and national medicines agency) were conducted in the context of the Europe Economics study in preparation of the proposal on information to patients in addition to standard interviews with stakeholders. For the proposal on cross-border health care, there was no ad-hoc survey, but stakeholders were extensively consulted via other channels as mentioned above and in Chapter 4.

Differences can be highlighted also with regard to the public consultations. For the proposal on cross-border health care, DG SANCO launched a public consultation with broad questions and obtained 280 responses. The consultation was open for four months.

In preparation of the proposal on food information, DG SANCO launched a public consultation on labelling for three months and received 175 valid responses. It is worth noting that, in preparation of the legislative proposal on information to patients, DG Enterprise launched three different public consultations - one on the draft report on current practices on information in the Member States, which run for three months and gathered 73 responses; the second public consultation, conducted between February and April 2008, specifically addressed the key ideas of the forthcoming legal proposal on information to patients and collected 185 responses and the third consultation was on the quality criteria and the information package on diabetes produced by the high-level pharmaceutical forum. This consultation was not mentioned in the impact assessment accompanying the legislative proposal because, officially, the forum was not linked to the legislative initiative even if the quality criteria developed by the forum became an integral part of the proposal (Article 100d). The high number of public consultations has been associated by two interviewees (\#1, \#2), both 
representing public health NGOs, as an attempt of the European Commission to seek legitimacy around a highly controversial issue.

Among the objects of these three proposals, the proposal on crossborder health care was the one that received the highest number of responses. For the proposals on food information and information to patients, the number of contributions received by the European Commission were very similar. The European Commission didn't provide the average number of responses they usually received in the context of public consultations in the same period of the three proposals investigated. Since this information is not available in the literature on EU studies, it is not possible to use other terms of comparison to assess the participation in the stakeholder consultations in relation to other legislative proposals.

However, as one of the interviewees noted, the number of respondents is not as important as taking into account who responded and how those responses are interpreted. 'With stakeholder consultation is very difficult because it is not reliable. For example, during the consultation on tobacco they (the European Commission) received thousands of responses by people paid by the industry. The most important thing is to see who responded.200 responses doesn't say much. The number of respondents doesn't say much about the evidence. You have to interpret the responses' (\#7, Health Attaché).

It can therefore be concluded that, apart from differences pertaining to the different sectors involved (food, pharmaceutical and health services), the typology of actors involved as well as the procedures followed to gather the evidence were identical and can be considered as 'independent' variables when looking at the sourcing of evidence in the formulation of European public health policies.

\subsubsection{Interests and ideas}

\section{Similarities}

Versluis et al. (2011) noted that in functional social policies, the policymaking process is particularly exposed to lobby groups (such as consumer and environmental NGOs) and that they are especially involved in the first stages of the policy process. On the basis of the analysis of documents (responses to the public consultations, impact assessment reports, conferences proceedings) and from the interviews, it is evident that this was the case for all case studies and that they are all examples of the so-called 'informational lobbying' (see paragraph 2.2 in Chapter 2). Stakeholders provided policymakers with useful information and knowledge about the 
issues addressed in the draft legislation. One of the interviewees defined the evidence of stakeholders as 'subjective evidence that is only used as a source of inspiration rather than as a source of information' (\#22, Health attaché, Council of the EU). However, evidence from stakeholders is mentioned in each impact assessment to support specific statements.

\section{Differences}

The most remarkable difference among the three case studies, with regard to the category interests and ideas, is that while the case study on information to patients and the case study on food information can clearly identify two opposing advocacy coalitions (Sabatier \& Weible 2007), the case study on cross-border health care, did not aggregate the representation of interests around supporting or opposing arguments. On food information, there was a clear opposition between the commercial interests of the food industry and the public interests represented by consumers and health NGOs. For the proposal on information to patients, there were the commercial interests of the pharmaceutical industry on the one hand and the public health interests on the other. However, the opposition was less clear-cut because of the blurred distinction between information and advertising and the position of patient organisations, which was the same as that of the industry. Moreover, regarding food information, the industry had a sort of defensive agenda which was willing to maintain the status quo and the opposing coalition asking for more information; however, in the case of pharmaceuticals, the industry pushed to change the status quo, while health NGOs adopted a defensive lobbying strategy opposing any change to the legislation.

On food information, the Member States also acted as lobbyists, and some, like the UK, commissioned their own studies on the topic. In the proposal on information to patients, their position as stakeholders was more visible, taking into account that they are also payers for pharmaceuticals. In the cross-border health care case study, Member States were the most important interest group as they are capable of managing and delivering health care and are directly or indirectly, via taxes and social insurances, the payers of health care services.

Because of the commercial interests at stake, the case studies on food information and information to patients clearly highlighted an imbalance in the representation of interests in terms of resources at the disposal of the two main opposing advocacy coalitions (industry vs NGOs). 
The analysis also shows that stakeholders such as health care professionals and others didn't have a strong impact in shaping the legislation and even less so after the Proposal was adopted by the European Commission. However, also for the proposal on cross-border health care, interviewees highlighted that interest groups have different resources in terms of funding and expertise and that this has influenced the likely impact they have on the policymaking process. The lobbying on the proposal on information to patients from the pharmaceutical industry was more 'discreet' than the lobbying of the food industry on food labelling.

Overall, the main element that emerges from the analysis of the similarities and differences on the impact of interests and ideas as a form of evidence in the policymaking process is that the stakeholders' views do play a crucial role in informing the policy process and that stakeholders act as 'brokers of evidence' to policymakers.

\subsubsection{Politics and economics}

Politics and economics played a significant role in the three case studies but with different connotations and weight and also depended on the phase of the policymaking process. As explained in Chapter 2, the two often overlap, and it is impossible to make a clear-cut distinction between economic and political considerations.

\section{Similarities}

In particular, with regard to the drafting phase of the legislation by the European Commission, political arguments were associated to the saleability of the proposal to Member States in the first place - and then to the other stakeholders - and to gain legitimacy and consensus. 'The commission is mostly political. Is this sort of democratic intermediary, if you like'. (\#3, Head of Unit, European Commission)

The three case studies demonstrate that the European Commission considers Member States as 'privileged stakeholders' engaging in preliminary discussions and consultations with them in order to increase their acceptance of the legislative proposal. Moreover, the impact assessment appears to be used as a lobbying tool of the European Commission to justify a proposal to the Member States, the European Parliament and other Commission services.

Economic arguments in the case study on cross-border health care were linked to the impact of the Directive on the sustainability of national health care systems because of the potential number of patients seeking health 
care abroad. The costs for the national health care systems were also the key economic argument that characterised the debate on information to patients. In particular, one of the key reasons for which Member States opposed the proposal was the costs associated with the administrative burden for the control of the information provided by pharmaceutical companies and with the potential increase in pharmaceuticals consumption and, consequently, public spending.

With regard to food information to consumers, a representative of a public health NGO (\#16) and the European Commission official in charge of the legislative proposal (\#28) stressed that the focus of the impact assessment was on the economic impact and on the costs of the new labelling requirements for the food industry.

Another common feature of the three case studies in relation to the role played by politics is the focus on finding consensus. Finding legitimacy and consensus appears to be the ultimate goal of the European Commission when sourcing and using evidence to formulate legislative proposals. The case studies confirm that the policymaking process is a 'political game' aimed at winning consensus where no party is entirely happy.

The results of this appear limited if compared with the time and resources invested in the policymaking process. With regard to food information, no one was satisfied with the final text adopted, nor the industry nor consumers and health NGOs. The proposal on cross-border health care was adopted after four years of very difficult negotiations but will only benefit a handful of patients willing to seek health care abroad, while the proposal on information to patients was withdrawn after six years of unsuccessful negotiations.

\section{Differences}

Political dynamics played a strong role in the preparation of the draft directive on cross-border health care as the European Commission was conscious that it was entering into a sensitive area of competence of the Member States and they used formal and informal meetings with the Member States to identify the most sensitive issues and the likely reaction of the Member States. Also, after the adoption by the European Commission, politics and, in particular, the division of competences on health care between the European Commission and the Member States largely characterised the negotiations on the proposal. 
With regard to the proposal on food information, economics played a greater role than politics. Economic considerations were focused on the costs of more information for food producers and on the competitiveness of the industry. These considerations emerged both in the formulation of the proposal by the European Commission and during the negotiations in the Council and in the European Parliament.

The main difference among the three case studies is the political parties' position in the European Parliament during the negotiations because they adopted contradictory approaches: on food information, the left-wing parties were calling for more information to consumers, while the right-wing parties were more sensitive to the burden on the industry. For the proposal on information to patients, the right-wing parties were more supportive of the provision of more information to patients from pharmaceutical companies, while the left-wing parties wanted to limit the information manufacturers could provide on their products to patients. A member of the European Parliament noted that 'that's probably why they are more left/righter divide because they are more about your view of empowering people in a modern society and how they are empowered to take decisions and know about things, (Member of the European Parliament, \#23). However, this doesn't explain why there was a different approach between the food and the health sector especially because both concerned the provision of more information to citizens. It is only possible to argue that, in both cases, the right-wing parties supported the position of the industry while left-wing parties supported the views of consumers and public health NGOs.

On cross-border health care, the positions of the political parties were more aligned, and the opposition was rather between the Member States who wanted to limit options for treatment abroad because of costs considerations and the European Parliament who were keener in allowing patients to seek health care abroad.

\subsection{Using Evidence}

The analysis of the use of evidence focused on two elements. The first element was the impact assessment in which the Commission brought all evidence together to substantiate and legitimise its legislative proposals and the second element was the way in which the participants in the policymaking process judged the use of evidence by the Commission. 


\section{Similarities}

To prepare the impact assessment of the proposals of the three case studies, the European Commission commissioned an external study (see section 7.3). The interviews revealed that the impact assessment was done after the European Commission already had a clear idea about the legislative proposal it wanted to adopt. Moreover, the commission officials interviewed admitted that at the time of commissioning the impact assessment, a lot of the information had already been filtered on the basis of consultations with stakeholders and on the basis of the ideas the commission already had on what the legislation should cover. The officials in charge of the information to patients were not available for an interview, but two of the interviewees confirmed, regarding the impact assessment on information to patients, that it was utterly a priority and that they were seeking evidence when they had already started drafting the legislative text. The interviews showed that the impact assessments were conducted at a late stage of the policy debate and that the option of no legislation was not seriously considered in any of the three impact assessments. The perception of the interviewees is also that the impact assessments of the three proposals were built on assumptions not based on scientific and rigorous research evidence and were an unsatisfactory mix of speculation and not fully reliable.

The impact assessment aims at making a cost-benefit analysis of the impact of the legislation. The impact assessments of the three proposals investigated have in common also the fact that though measuring costs for companies or national authorities associated with the administrative burden is relatively easy (e.g. costs of ex ante evaluation of the information on pharmaceuticals, costs for food producers of changing information on food labels), measuring the benefits is particularly challenging mostly because certain aspects (e.g. benefits for public health, consumers benefits from better food labelling) are more difficult to quantify.

For the legislation on information to patients, despite the attempt to describe the positive impact of more information from pharmaceutical companies, the impact assessment failed to convince all stakeholders, in particular, those opposing a change of the legislation, regarding the benefits for patients and public health.

For the proposal on cross-border health care, the difficulty in proving the benefits of the legislation were linked to the very small percentage of citizens who could actually seek health care abroad owing to the legislation. The impact assessment didn't measure the likely impact of the provisions of 
the legislation regarding health technology assessment, information about quality and safety of health care, eHealth and so on.

For the proposal on food information, the Commission official in charge of the dossier confirmed that the impact assessment focused on the economic aspects and that it was difficult to quantify the benefits for consumers of the legislation. The impact assessment text itself acknowledged that the estimations of costs for the industry associated with labelling requirements were exaggerated.

Another common aspect that emerged in relation to the case studies is that the impact assessment was conducted on provisions close to those that the European Commission included in its legislative proposals, while the amendments introduced by the European Parliament and by the Council throughout the legislative process were not subject to an assessment, even when they introduced significant changes. Most of the interviewees wished for a minimum requirement of impact assessment for amendments that were likely to have a significant impact which was not assessed in the European Commission impact assessment. To this end, in 2012, the European Parliament created an impact assessment unit, but it was established after the legislative proposals' objects of this study were adopted by the European Parliament.

For each case study, the evidence gathered in the impact assessment was almost exclusively based on input from stakeholders and from the information of the reports commissioned by the European Commission to external bodies in preparation of the impact assessment. Overall, the three impact assessments present the same structure and layout. In this respect, there are no major differences in the use of evidence among them.

Looking at the use of evidence in the formulation of the three proposals through the lenses of Weiss (see Chapter 2), each case study has the features of the interactive model in which the search for knowledge goes beyond research to include other sources such as economics, stakeholders' interests and politics, and in which research and other types of evidence are used to legitimise decisions already taken. Commissioning research is just a small part of a more complex process of gathering information and policies are mainly based on other types of evidence.

With regard to the use of evidence, the most interesting aspect emerging from the case studies is that, taking into account that the research evidence is often not available or non-conclusive and that the many input 
from stakeholders are often diverging, Commission officials can exercise a high degree of judgment as one of them confirmed: 'When the evidence is available, almost never in my experience has there been clear, consistent, obvious evidence coming down on one side of an argument. So you got to the exercise judgment, but it does mean that the commission officials are exercising in high degree judgment about amongst all of this, which evidence they take and which evidence they weight more heavily and less heavily and how they assess the interests of the people who are coming and talk to them' (\#3, Head of Unit, European Commission).

Another common element emerging from the case studies is the importance of personal values and beliefs of policymakers involved in the process: The Health Commissioner John Dalli played a key role in advancing the debate on cross-border health care, which was stuck in the Council and about to be withdrawn. The personal interest of Commissioner Verheugen was mentioned several times during the interviews as a key push behind the proposal on information to patients. Values and emotions were also mentioned in several occasions in the interviews on food information. In particular, emotions were referred to against scientific research evidence on so called 'societal issues' like consumer information where it was not possible to rely on hard facts, at least in the view of the European Commission officials.

\section{Differences}

As stated above, the structure of the impact assessment is the same for the three case studies and there are more similarities than differences in how the evidence sought has been used by the European Commission.

Some differences can be reported mostly with regard to the perceptions about the use of evidence by stakeholders and policymakers. It is the same for the proposal on food information and information to patients and less so for the proposal on cross-border health care, mostly because the first two had two well-defined advocacy coalitions with different core beliefs. For the proposal on food information, public health NGOs claimed that the evidence was not taken into account, but they were referring to the evidence supporting their arguments, mostly a color-coded labelling scheme. For information to patients, four of the interviewees stated that the European Commission didn't take into account the available evidence or that it selected the evidence in a biased way. 
For the case studies on food information and information to patient, stakeholders claimed to have acted as brokers of research evidence, but they referred mostly to academic research and partially to research they commissioned themselves that supported their arguments.

For the three case studies, two interviewees highlighted that the European Parliament is more transparent in how it interacts with stakeholders and uses the evidence. At the same time, MEPs usually follow emotions and what is politically saleable, while the Council of the EU is less transparent both in the way it interacts with stakeholders and in how it takes into account the available evidence. However, there was consensus on the fact that representatives of the Member States take decisions on their national experience and can count on more expertise from experts from the capitals working in the ministries.

\subsection{Capacity to Implement: Hindering and Facilitating Factors in the Uptake of Research Evidence}

The third research question was about the uptake of research evidence in the policymaking process, namely which factors facilitated the uptake and which factors hindered it. This section analyses the similarities and differences on the basis of the three case studies. Table 7.2 provides a general overview.

Table 7.2.

Hindering and Facilitating Factors in the Uptake of Research Evidence

\begin{tabular}{|l|c|c|c|}
\hline & $\begin{array}{c}\text { Cross- } \\
\text { border } \\
\text { health } \\
\text { care }\end{array}$ & $\begin{array}{c}\text { Information } \\
\text { to patients }\end{array}$ & $\begin{array}{c}\text { Food } \\
\text { labelling }\end{array}$ \\
\hline \multicolumn{2}{|c|}{ Facilitating Factors } \\
\hline $\begin{array}{l}\text { Policymakers' information } \\
\text { need }\end{array}$ & $\mathrm{X}$ & $\mathrm{X}$ & $\mathrm{X}$ \\
\hline $\begin{array}{l}\text { Supportive organisational } \\
\text { procedures (e.g. impact } \\
\text { assessment) }\end{array}$ & $\mathrm{X}$ & $\mathrm{X}$ & $\mathrm{X}$ \\
\hline $\begin{array}{l}\text { Financial resources available } \\
\text { for research projects and to } \\
\text { commission an independent }\end{array}$ & $\mathrm{X}$ & $\mathrm{X}$ & $\mathrm{X}$ \\
\hline
\end{tabular}




\begin{tabular}{|l|l|l|l|}
\hline $\begin{array}{l}\text { study to support the impact } \\
\text { assessment }\end{array}$ & & \\
\hline $\begin{array}{l}\text { Research evidence provided } \\
\text { in a policy friendly format } \\
\text { (including summaries and } \\
\text { policy recommendations) }\end{array}$ & $\mathrm{X}$ & & \\
\hline $\begin{array}{l}\text { Direct relationship between } \\
\text { researchers and } \\
\text { policymakers }\end{array}$ & $\mathrm{X}$ & & \\
\hline \multicolumn{1}{|c|}{ Hindering factors } & $\mathrm{x}$ \\
\hline $\begin{array}{l}\text { Lack of relevant, complete } \\
\text { and timely research } \\
\text { evidence }\end{array}$ & $\mathrm{x}$ & $\mathrm{x}$ & $\mathrm{x}$ \\
\hline $\begin{array}{l}\text { No EU-wide research } \\
\text { evidence available }\end{array}$ & $\mathrm{x}$ & $\mathrm{x}$ & $\mathrm{x}$ \\
\hline $\begin{array}{l}\text { Selective use of the } \\
\text { available research evidence }\end{array}$ & $\mathrm{x}$ & $\mathrm{x}$ & $\mathrm{x}$ \\
\hline $\begin{array}{l}\text { Personal beliefs of } \\
\text { policymakers }\end{array}$ & $\mathrm{x}$ & \\
\hline $\begin{array}{l}\text { Policymakers perspective } \\
\text { linked to the organisational } \\
\text { arrangements }\end{array}$ & $\begin{array}{l}\text { Policymakers lack of } \\
\text { knowledge about the policy } \\
\text { area }\end{array}$ & & \\
\hline
\end{tabular}

7.5.1 Similarities and differences among the three case studies

\section{Similarities}

For the three case studies, the main factors that favoured the uptake of research evidence - as opposed to other types of evidence - were policymakers' information need, the availability of funding for external bodies to conduct a literature review as part of a wider study to support the impact assessment. Research evidence was therefore sought to feed the external studies. This implies that the organisational procedures requiring an impact assessment to accompany the legislative proposal are a key element that at least attempts to favour the uptake of research evidence for policymakers. 
Beyond the formal organisational procedures, research evidence was sought together with other types of evidence mostly to gather legitimacy and consensus on the legislative proposal.

With regard to the hindering factors, the three case studies have in common the fact that the available research evidence on the issue to be regulated was not available in a timely manner, incomplete and irrelevant. Moreover, none of the case studies had information that was representative of the EU situation and/or was specific only to some Member States.

Some of the research was not taken up because of a bias in the selection of the research studies. The bias was due to the personal beliefs of policymakers or more generally to the fact that the evidence used was the one that best matched with the policy the European Commission had already decided to take.

Another main common hindering factor for the uptake of research evidence was policymakers' lack of expertise in assessing it.

However, the most relevant aspect that emerged from the three case studies is that research evidence is often not available or not reliable. If available, it is not fully relevant for the legislative process, not available in a timely manner or immediately applicable. Evidence produced by stakeholders has been defined as subjective and not reliable because of lack of information regarding the methodology, which is allegedly biased - even if most didn't read the evidence from stakeholders nor the methodology used or the full text of the impact assessment accompanying the proposal. In this respect, one attaché noted: 'Some evidence is not reliable. There is also evidence funded by the industry, but we know who sponsors it' (\# 22, health attaché).

\section{Differences}

One difference among the three case studies is that for the proposal on cross-border health care, the European Commission invested additional resources to finance specific research projects on the issue to be regulated. This favoured the production of research evidence. However, its use was limited because the data produced were not as comprehensive and, in any case, the European Commission didn't make significant references to the findings of the projects in the impact assessment.

For the proposal on information to patients, the European Commission became aware of research evidence only through the impact assessment, with a short summary of the existing studies. For the proposal on food information, 
the research evidence was included as an integral part of the RAND report and not in an ad-hoc section. For the proposal on cross border health care, the research made within the EU funded projects was presented in a policy friendly format including policy recommendations; however, as stated above, this didn't facilitate its uptake. Contrary to the other two case studies, for cross-border health care, the European Commission could count on a direct relationship with the researchers because of the long-standing formal partnership between the European Commission and the European Observatory.

\subsection{Conclusions}

The analysis shows that there are more similarities than differences among the three case studies. This helps in generalising the research findings and in considering them more widely applicable to the formulation of public health policies in Europe.

The legislative proposals analysed are similar with regard to the policy instruments used and the policy goals that the European Commission wanted to achieve, and they followed very similar legislative pathways within the well-defined procedures set out in the Treaty. The European Commission's internal procedures influenced the way decision makers seek, analyse and uptake both the research evidence and the evidence provided by stakeholders via the European Commission expert groups and public consultations.

Because of the differences in terms of policy styles and organisational cultures and the different approaches in 'framing' issues (Surel, 2000) between the different DGs, the European Commission is described as a multiorganisation (Cram,1994). While confirming the differences of approaches between DGs, from the analysis it emerged that there are no substantial differences in the way the different DGs and different units within the same DG source use evidence. This is linked to the organisational procedures and the defined institutional mechanisms for the generation of evidence, including specific procedures to seek the views of stakeholders, namely the guidelines for the conduct of impact assessments and public consultations.

More specifically, it is possible to conclude that the European Commission placed equal efforts in gathering research evidence for the three proposals. Even if the proposal on cross-border health care quotes a higher number of references to articles in peer reviews journals (78), the interviews, the analysis of documents and the direct observation indicate that the overall impact of research evidence was the same for the three proposals and that it 
was extremely limited. Interviewees perceived that often the available research evidence is inconclusive or biased or not relevant and that several factors (e.g. lack of time, lack of training and so on) hinder its proper uptake in the formulation of EU policies.

For the three proposals, the European Commission gathered knowledge and information via polls but conducted further surveys for the proposal on food information. The stakeholders' views had more weight for the proposal on information to patients and food information as they were organised around two opposing advocacy coalitions while they were more dispersed and voiced less strongly for the proposal on cross-border health care. Evidence about costs played a more important role in the proposal on information to patients and food information than for the proposal on crossborder health care while politics was more relevant for the proposal on crossborder health care due to disputes over the limited EU competence on health care. Overall politics, including the political saleability of a legislative proposal as well as the need to adopt a balanced legislation with the consensus of all interested parties, is the element that seems to influence most of the policymaking process.

Moreover, one of the interviewees noted that all the three legislative proposals were the result of an explicit choice by the European Commission who could have also chosen not to act in any of the three policy fields. Nonaction would not have caused any immediate harmful consequences for public health. 'They are all things where there is a political choice to act in these three areas, we could have said we are not acting in any of them. Now if food isn't labelled properly that doesn't have an immediate impact on public health. It has an auxiliary impact. If people know that a pizza is high in salt, fat and sugar we hope that they make judgments, but it is not the same kind of thing. It's not like stopping the acid rain, these are political choices' (Member of the European Parliament, \#23). Another interviewee said in this respect: 'We can also ask opinions to independent or government research centers but the ministry takes choices on what to believe. It is making choices, and this is politics. If we only use evidence, we don't need politicians' (Health attaché, \#30).

To conclude, the uptake of research evidence is facilitated by the specific organisational procedures within the European Commission requiring for an impact assessment to accompany legislative proposal and the corresponding financial resources to externalise an analysis including a research of the existing literature. However, the lack of timely, complete and 
relevant research on the topic to be regulated hindered the final uptake in the formulation of the proposals. 



\section{Chapter 8: Conclusion, Discussion and Recommendations}

\subsection{Introduction}

The concept of evidence-based policy is very popular among EU policymakers. But what counts as evidence in the EU health policymaking process? Chapter 1 explained why the European Commission looks for evidence and how evidence-based health policymaking is addressed in the literature. In Chapter 2, a theoretical framework was developed to capture the use of evidence in the complex EU policymaking process. Chapter 3 presented the methodology used for data collection and analysis. Chapter 4, 5 and 6 described in detail the sourcing and use of evidence in the formulation of three specific policy proposals. Chapter 7 provided a comparative analysis of the main similarities and differences among the three case studies. This chapter draws the main conclusions of the research study. Section 8.2 summarises the research findings by answering the research questions. Section 8.3 outlines the strengths and limitations of the research study with regard to the theoretical framework and methodology and discusses the research outcomes. Section 8.4 presents some recommendations for policymakers and researchers.

\subsection{Summary of Main Findings: Answering the Research Questions}

The main goal of this research study was to investigate the role of evidence in the formulation of European public health policies. It analysed the kind of evidence used, how it is sourced and used in the EU policymaking process, the perceptions about the use of evidence of key participants in the process and the hindering and the facilitating factors in the uptake of a specific typology of evidence, namely research evidence. The Bowen-Zwi "evidenceinformed policy and practice pathway" model (2005) has been used as the operational framework for the analysis.

\footnotetext{
What type of evidence does the European Commission source in the formulation of $\mathrm{EU}$ public health policies, and how does it source it?

Table 8.1 summarises the types of evidence sourced by the European Commission and the information channels used to collect them. The classification is adapted from the Bowen and Zwi model (2005) and it is specific to the EU policymaking process.
} 
Table 8.1.

Types of Evidence Sourced by the European Commission and its Information Channels

\begin{tabular}{|c|c|c|}
\hline $\begin{array}{ll}\text { Type } & \text { of } \\
\text { Evidence } & \end{array}$ & Source & Channel \\
\hline Research & $\begin{array}{l}\text { Consultancies } \\
\text { Stakeholders } \\
\text { EU-funded } \\
\text { projects } \\
\text { Think tanks } \\
\text { National } \\
\text { governments }\end{array}$ & $\begin{array}{l}\text { Consultancies' studies } \\
\text { Bilateral meetings with } \\
\text { stakeholders } \\
\text { Conferences } \\
\text { European Commission experts' } \\
\text { groups (working groups, } \\
\text { stakeholders' platforms, among } \\
\text { others) } \\
\text { Stakeholder reports } \\
\text { Responses to public consultations }\end{array}$ \\
\hline $\begin{array}{l}\text { Statistics and } \\
\text { other data }\end{array}$ & $\begin{array}{l}\text { European } \\
\text { Commission's } \\
\text { internal bodies } \\
\text { National } \\
\text { governments }\end{array}$ & $\begin{array}{l}\text { Eurostat data } \\
\text { Eurobarometer surveys }\end{array}$ \\
\hline $\begin{array}{l}\text { Stakeholder } \\
\text { interests and } \\
\text { ideas }\end{array}$ & Stakeholders & $\begin{array}{l}\text { Consultancies' studies (via } \\
\text { stakeholder interviews and/or } \\
\text { questionnaires) } \\
\text { Bilateral meetings with } \\
\text { stakeholders } \\
\text { Conferences } \\
\text { European Commission experts' } \\
\text { groups (working groups, } \\
\text { stakeholders' platforms, among } \\
\text { others) } \\
\text { Stakeholders' reports } \\
\text { Responses to public consultations }\end{array}$ \\
\hline $\begin{array}{l}\text { Economic and } \\
\text { political } \\
\text { interests }\end{array}$ & $\begin{array}{l}\text { Member States } \\
\text { Stakeholders }\end{array}$ & $\begin{array}{l}\text { European Commission's expert } \\
\text { groups with the Member States } \\
\text { Member States and stakeholders } \\
\text { responses to public consultations }\end{array}$ \\
\hline
\end{tabular}




\begin{tabular}{|l|l|l|}
\hline & $\begin{array}{l}\text { Bilateral meetings with the } \\
\text { Member States and the } \\
\text { stakeholders }\end{array}$ \\
\hline
\end{tabular}

From the three case studies and comparative analysis, it emerged that for the European Commission, evidence goes beyond what is commonly understood as evidence in relation to evidence-based policies and it includes:

- Research evidence usually gathered indirectly through the filter of stakeholders (via bilateral meetings, responses to public consultations, stakeholders' reports) or consultancies conducting external studies to support the European Commission impact assessments. Consultancies act as brokers of research evidence because their studies usually include a literature search on the topic to be regulated. Also stakeholders act as "brokers of evidence" or "knowledge brokers", because they bring to the attention of policymakers the studies that they commissioned themselves and/or research studies conducted by others and are in line with their policy demands. It is considered research evidence not only the research produced by academic institutions and published in peer-reviewed journals but also the research by think tanks, consultancies and governmental bodies.

- Eurobarometer surveys, statistics and other data collected by the European Commission's statistics office Eurostat, by other Directorate Generals and by the Member States.

- Stakeholders' views collected via public consultations, ad hoc surveys, conferences and workshops, stakeholders' reports, bilateral meetings and stakeholders' platforms such as the EU platform on Diet, Nutrition and Health and the EU Health Policy Forum.

- Economic and political interests of the Member States gathered via the European Commission experts' groups or ad-hoc high-level groups (e.g., Pharmaceutical Forum), Member States and stakeholders' responses to public consultations and bilateral meetings with the Member States and the stakeholders.

From the participant observations and interviews, it emerged that when sourcing and using evidence, EU policymakers also draw on emotions and personal beliefs.

The type of evidence sourced, and the information channels used to gather it, were very similar among the three case studies. This is explained by 
the fact that the way evidence is sourced largely depends on the organisational procedures put in place by the European Commission itself and that EU officials have a limited margin of manoeuvre. These procedures favour some types of evidence such as views of stakeholders, political and economic arguments especially from the Member States over others such as peerreviewed studies and some sources such as the European Commission's stakeholder platforms over others such as academics.

How does the European Commission use evidence in the formulation of EU public health policies, and how do the participants in the process assess the use of evidence by the Commission?

The European Commission uses the evidence gathered to draft the impact assessments accompanying its proposals and, more broadly, to inform the policy formulation process. However, the methodology used to select the information that is ultimately reported in the impact assessments among all the inputs collected - for example, the selection of certain views expressed by stakeholders during the public consultations over others - remains unclear. The participants in the process believe that the European Commission selects evidence by choosing data and information in line with its political agenda and decisions already taken. They perceive that research evidence has a marginal role and other types of evidence, namely those collected via public consultations or interests of stakeholders, are not sufficiently taken into account. They consider that the collection of evidence is just a cosmetic exercise to gain legitimacy and consensus. The Commission officials interviewed for this research study revealed that they use impact assessments as a lobbying tool to justify a given proposal vis a vis other Commission services, the Member States and the European Parliament and that they shape them politically.

This emerged consistently from the three case studies which didn't reveal any substantial difference with regard to the use of evidence by the European Commission and to the perceptions of the key participants.

\section{What are the hindering and facilitating factors in the uptake of research evidence in the formulation of $E \mathrm{U}$ public health policies?}

From the three case studies and comparative analysis, it is possible to identify the elements that facilitate or hinder the use of research evidence in the formulation of European public health policies.

The main facilitating factors in the uptake of research evidence, including academic and non-academic research, are policymakers' 
information needs linked to the necessity to gain legitimacy and consensus around legislative proposals, specific organisational procedures within the European Commission for the gathering of evidence, including the availability of funding for external bodies to conduct an independent study, and the need to gain information and data to feed the European Commission's own impact assessments.

The main hindering factor in the uptake of research evidence that emerged from the three case studies is the lack of timely, complete and relevant research. The European Commission considers as relevant the research which is specific to the issue to be regulated, it's reliable, and has an EU-wide coverage (i.e. it is not focused on one or few EU countries).

For EU policymakers the hierarchy of evidence is less relevant than for scientists; however, they pay attention to the source and potential biases linked to who funded the research.

Overall, on the basis of the results of the research in relation to the three main research questions, it is possible to conclude that the formulation of EU public health policies can be defined as evidence-based only if evidence is defined in a very broad sense so as to include not only research evidence but also other types of evidence such as information, interests and ideas of stakeholders, politics and economics.

If evidence is intended only as the information, data and knowledge produced by academic or other scientific studies, then the formulation of EU public health policies is far from being evidence based, as the case studies proved that the uptake of research evidence by the European Commission is very low.

On the other hand, if one applies the Sacket et al.'s (2000) definition of evidence-based medicine - "the integration of the best research evidence with clinical expertise and patients' values" (p. 1) - and Kohatsu et al. (2004) or Brownson et al.'s $(2009,2017)$ definitions of evidence-based public health - the process of integrating science-based interventions with community preferences to improve the health of the population - it is possible to conclude that EU health policies are partly evidence based or, more appropriately, "evidence-informed" because even if research evidence plays a marginal role, the European Commission integrates in the formulation of policies people preferences and values via stakeholders' and public consultations.

As indicated in Chapter 1, the term "evidence based" has been endorsed in this research study as an inspirational concept and a starting 
testing point; however, the term "evidence informed" is more accurate, as it focuses on the process rather than the outcomes and better describes the reality and political nature of the EU policymaking process where there are competing interests and, therefore, competing sources of evidence that policymakers take into account. It also signals that evidence plays just a role in the process, but it is not the decisive element.

\subsection{Discussion}

This section outlines the strengths and the limitations of the research study with regard to the theoretical framework and methodology for data collection and analysis. It also provides explanations of the results by comparing them with the results of other studies in the same domain.

\subsubsection{Discussion of the theoretical framework}

The theoretical framework used in this research study has been operationalised via the "evidence-informed policy and practice pathway" model developed by Bowen and Zwi in 2005.

At the time of its choosing, the Bowen and Zwi model (2005) was indeed the one that presented most of the features required to capture all the types of evidence used in the EU policymaking process. It also offered a good basis for the analysis of the policymakers' capacity to implement evidence and to identify the hindering and facilitating factors in the uptake of research evidence. Other theoretical frameworks such as the Sabatier's Advocacy Coalition Framework were also considered, but they were not equally comprehensive and detailed with regard to the different factors that influence policymaking, such as the context as well as the values and beliefs of policymakers.

Bowen and Zwi's (2005) categorisation of the types of evidence revealed to be very useful for the analysis of the case studies; however, it also presented some weaknesses. First, the broad definition of evidence adopted by them is so encompassing that it risks making evidence an empty concept. To address this, the hindering and the facilitating factors for one type of evidence, namely research evidence, was chosen to be investigated in depth. Second, some categories overlap in the EU policymaking process. For example, according to the Bowen and Zwi (2005) model, the results of public consultations are considered as information, but they mostly represent the opinions, views and expert knowledge of individuals and networks. 
Therefore, they can also be considered as the interests and ideas of stakeholders. This makes it difficult to draw the line between the two categories. Also, economics and politics are so interlinked and closely related that they often overlap. Political positions are mostly based on the economic considerations on the impact of legislation for the Member States and stakeholders. Moreover, both politics and economics are not the only types of evidence but also integral parts of the system in which policies are developed, so they should be considered both as the context in which a policy is formulated and as the inputs.

The broader knowledge utilisation framework (Boswell, 2009; Caplan, 1979; Lindblom, 1990; Radaelli, 1995; Weiss, 1979) has been useful to understand the role of evidence; however, most of the existing literature uses the terms "evidence" and "research" interchangeably, while sometimes the term "evidence" is used to identify evidence other than research. This practice resulted in confusion, making it difficult to apply the concepts to this research study.

Maintaining a clear distinction between research and other types of evidence revealed to be the main challenge throughout this study, especially when analysing the interviews because the participants themselves confused research evidence with other types of evidence and they referred to research also to indicate stakeholders' studies and other non-academic publications such as reports from governmental bodies.

\subsubsection{Discussion of methods}

With regard to the methods used for data collection, the main strength of the study also represents a limitation: The direct involvement of the researcher in the EU debates on public health policies offered a privileged observational perspective, valuable insider knowledge as well as easy access to official and confidential documents. It also allowed the researcher to undertake in-depth and open conversations with the interviewees. At the same time, such a position of the researcher increased the risk of bias and possible influences on the answers given by the interviewees. Specific safeguards have been applied to reduce this problem, namely the triangulation of the findings from the interviews with other sources such as the literature study, including quotes from the interviewees given to other researchers on a similar issue (e.g., Carboni, 2009), documents and statements in the press. An additional limitation of participant observation as a source of data is that it is not possible to report and phrase all that has been observed and the lack of proof concerning what is reported. 
The second main limitation of the data collection methodology is the limited sample of the interviewees. This issue arose due to the limited number of people actually involved in the formulation of policies within the European Commission, the limited response rate $(60 \%)$, the limited number of researchers on the issues covered by the case studies and the difficulty of interviewing MEPs and the representatives of the Member States. To increase the response rate, three attempts were made to persuade the selected interviewees to participate. With regard to the Commission officials, it was decided to interview senior officials and those in charge of the legislative proposal investigated. It was possible to reach only those responsible for the proposal on cross-border health care and food information because both the person in charge of the proposal on the provision of information to patients as well as his deputy had left the European Commission. Owing to privacy reasons, the researcher was not provided with their new contact details. With regard to the researchers, the analysis revealed that not many academics are working/have worked on the issues addressed by the legislative proposals (cross-border health care, provision of information to patients and food information) and only very few among them are involved in the EU policymaking process. With regard to food information, also looking at the programs of the various conferences organised on the topic during the adoption of the proposal as well as the references to the literature listed in the documents accompanying the proposal, it was not possible to interview an academic specifically dealing with the issue. The fact that the interviewed researchers on cross-border health care and information to patients were close to the EU policymaking process represented both a strength and limitation. It proved a strength because of their understanding of the EU policymaking procedures and EU policymakers' approaches to evidence. The limitation arose because their views do not necessarily represent the views of all researchers, including those who have no knowledge of the policymaking process and its constraints.

More generally, it should be noted that the total number of researchers interviewed was rather small compared to the number of interviewees representing stakeholder organizations and those representing the EU institutions therefore, the results, especially in relation to the perception of the use of evidence, reflect one side of the story, that of policy makers and stakeholders.

The third main limitation of data collection is linked to the fact that in general the information secured from interviews is influenced by poor recall and linguistic problems. However, the people interviewed for this research 
study had a good recollection of the events. The poor recall was mostly in relation to the content of the impact assessment and this was addressed by taking into account only the information which the interviewees had a clear recollection of. When the interviewees were unable to recall certain details, the interviewer refrained from providing background information to help the interviewee in order to reduce the possibility of bias in the answer. As for linguistic problems, the quotes reported have been adapted as little as possible and only to the extent of making them comprehensible by the reader. Additions of missing words and deletions of words have been made only in those cases where comprehensibility has been compromised, and they are clearly indicated.

With regard to data analysis, as for the data collection, participant observations can be considered both the main strength and weakness. It is a strength because the researcher's in-depth knowledge of the EU policymaking process and familiarity with the EU jargon facilitated the analysis of the legislative documents, the understanding of the context in which the case studies were developed, the relationships between concepts and the background of the statements of the interviewees. It proved a limitation because a priori knowledge can result in interpretation biases. The possible interpretation bias has been addressed by complementing participant observation with other information sources, including the literature review, the interviews and the analysis of documents.

The second most important limitation of the data analysis is that even if in-depth case studies are suitable to trace processes of knowledge utilisation, they cannot show whether their findings are confined to the cases or hold valid more generally, as the use of knowledge depends on the politicisation of the issue, the level of contestation as well as the level of technicality of the issue. The inherent complexity of the EU policymaking process makes it difficult to disentangle the influence of the various actors involved and, therefore, the actual impact of the evidence provided by the different sources (academics, stakeholders, Member States, internal sources). The process is so long and cumbersome that it is not possible to identify the link between the evidence gathered and the actual provisions in the legislation, both in the Commission's proposal and even less so in the final piece of legislation adopted by the European Parliament and the Council of the EU. 


\subsubsection{Discussion of results}

\section{Sourcing of evidence}

With regard to the sourcing of evidence, compared to the other studies on the role of evidence in the EU policymaking process such as Boswell (2008) and Radaelli (2015), this research study sheds lights on the key role played by consultancies. Consultancies are selected under the so-called "framework contract agreements" to conduct policy analysis and gather evidence to support the European Commission in preparing the impact assessments. The evidence they provide usually matches the European Commission's information/policy needs, as the evidence gathering process is framed by the European Commission itself in the terms of reference of the contract. Consultancies have little room for manoeuvring with regard to the content and the methodology of the research process. This challenges the independence of the work of the consultancies as well as the outcome of the evidence-gathering process. In an interview from May 2014, the former European Commission Chief Scientist ${ }^{16}$, Dr. Anne Glover, said that consultancies have no incentives to produce evidence not in line with the Commission's political agenda: "If they (consultancies) want repeat business, they are not going to go out and find the evidence to show that this is a crazy idea" (Euractiv, May 2014).

The quotes from many interviewees, including the admission by an interviewee that the objectives of an EU-funded project were changed to meet the European Commission's agenda and receive funding, confirm this assertion.

It can also be argued that the funding of research projects, the commissioning of external studies and the performing of impact assessments clearly indicate a scientification of the policy process (Everson \& Vos, 2009) or, at least, an attempt to prove that the policy formulation at the EU level is not based on gut emotions but on a robust and comprehensive knowledge base.

Dr. Anne Glover admitted that the European Commission's efforts to gather evidence to inform policy is closely related to, what she defines as, the

\footnotetext{
${ }^{16}$ With the Juncker Commission, the role of the Chief Scientist has been scrapped and replaced, on November 2015, with a high-level group of scientific advisors as part of a new Scientific Advise Mechanism.
} 
European Commission's "political imperative", namely driving legislative proposals. In this regard, she stated as follows:

Let's imagine a Commissioner over the weekend thinks, "Let's ban the use of credit cards in the EU because credit cards lead to personal debt". So that Commissioner will come in on Monday morning and say to his or her Director General, "Find me the evidence that demonstrates that this is the case". The Commissioner's staff might resist the idea but, in the end, they will do exactly what they're asked and "find the evidence" to show that credit card use leads to personal debt, even though this may not be the case in reality... So you can see where this is going... You're building up an evidence base which is not really the best.

Dr. Glover also said that the European Commission is not the only institution "trying to distort facts" and the European Parliament and the EU Council of Ministers adopt the same tactic. She admitted that sourcing research evidence is used as a delaying technique when there is no support for something that is proposed (Euractiv, May 2014).

\section{Use of evidence}

With regard to the use of evidence, the findings of this research study confirm Weiss's (1979) opinion that the evidence produced is even more important than its actual use. In the case of the European Commission, research evidence is used as a tool to address the external pressure from stakeholders and, most of all, the European Parliament and the Council in highly political negotiations. The research findings indicate that evidence is always only an input to political judgment and never a substitute for it. It can reduce the uncertainty but not solve the uncertainty problem. In some cases, it also increases uncertainty. As Majone (1989) indicates, evidence is never conclusive enough to guarantee certainty and remove ambiguity, so arguments and persuasion prevail (p. 21). The use of evidence is a political process itself, an exercise of power to justify decisions. Scientists compete with a wide range of actors who provide evidence to processes and claim to be often more knowledgeable about the policy process.

In this context, undertaking impact assessments is sort of a fake exercise according to the interviewed participants. Despite the significant resources invested in producing impact assessments, their added value appears rather limited. Only few interest groups are interested in reading impact assessment reports to gather information and data to support or oppose 
legislative proposals according to their agenda. The interviewees confirmed that the impact assessments were conducted at a late stage of the policy debate and the option of no legislation was seriously not considered in any of the three impact assessments.

The interviewees noted that all the three impact assessments were built on assumptions not based on research evidence and were an unsatisfactory mix of speculation and not fully reliable data. Even if the legislative proposals and the accompanying impact assessments were fully based on the best available evidence, the Commission proposals are, in most cases, significantly amended before they become an EU law, and the amendments introduced by the Council and the European Parliament are not necessarily evidence based.

The analysis of documents, participant observations and interviewees' views confirm that because of the political nature of the European Commission and, more generally, the EU policymaking process, knowledge is used as a legitimising tool; moreover, owing to the highly political and contested nature of the issues addressed in the analysed legislative proposals, evidence is also used to substantiate policy decisions already taken at the political level.

This can be explained by the fact that the European Commission's outcomes, namely legislative proposals, need to be politically acceptable as well as technically sound. The former Commission President, Jose Manuel Barroso, described the situation as follows: "We need both the gin and the tonic. We need the blend of political judgment and technocratic expertise" (The Economist, April 14, 2012).

The sourcing and use of knowledge by the EU institutions present all the key features of Weiss' (1979) interactive model: (1) Policymakers seek information from various sources, including social scientists, interest groups, politicians, friends, administrators, among others. (2) Scientific research is considered just a part of the more complex process of gathering information. Other key parts of the process are political considerations, experience, judgments, opinions and pressure. (3) When formulating policies, the European Commission and the other institutions cannot wait for research to be completed and must take political decisions without evidence. (4) The formulation of EU policies are characterised by different information providers, different decision makers and different interests at stake constantly interacting among each other.

\section{Facilitating and hindering factors}


With regard to the facilitating and hindering factors in the uptake of research evidence, the results obtained are in line with what emerged from the three main systematic reviews on the topic, namely Innvaer (2002), Orton (2011) and Oliver et al. (2014) (see section 8.2 above and Table 7.2 in Chapter 7) in particular with regard to the availability of timely, relevant and reliable research, with regard to the policy makers lack of skills to assess the evidence and with regard of the importance of a personal contact between researchers and policy makers. However, the added value of the research is to offer insights on the uptake of research evidence in a specific unexplored area, namely that of the formulation of EU public health policies. In this respect the comparative analysis of the case studies demonstrated that main the facilitating factors for the sourcing of research evidence in the EU policy making process are policymakers' information need, the availability of funding for external bodies to conduct a literature review as part of a wider study to support the impact assessment, and the need to gain legitimacy and consensus on a legislative proposal. However, the three case studies also showed that the sourcing of research evidence doesn't necessarily translate into a full uptake of research findings.

From the analysis, it also emerged that presenting research outcomes in a reader friendly format, translating scientific findings into simple stories with an emotional appeal, engaging in policy makers-researchers workshops could certainly be useful but it not decisive to increase research evidence uptake in the policy making.

\subsection{Policy and Research Recommendations}

\subsubsection{Recommendations for policymakers}

On the basis of the results of the comparative analysis of the case studies it is possible to draw some key recommendations for policy makers.

First of all, the thesis has demonstrated that what policymakers mean with evidence is different from what is commonly understood by citizens and researchers. Therefore, the main recommendation for EU policy makers is to be clearer with themselves and, most of all, with citizens and stakeholders about what they consider as evidence. This could be achieved by updating the European Commission Better Regulation Toolbox and making a better distinction between scientific evidence, expertise provided for example by the European Commission decentralised Agencies such as EMA, EFSA and ECDC and the evidence provided by stakeholders. 
The thesis also showed that the way the evidence is collected and used is influenced by political goals and personal beliefs. Therefore, the second recommendation for EU policymakers is to update and further clarify the European Commission guidelines for the commissioning of external studies and for the drafting of the impact assessments and to reduce as much as possible any potential bias.

A third recommendation is to ensure that EU officials have the necessary training, time and resources not only to collect the evidence but also to assess it critically and to use it appropriately.

Lastly it would be useful to be more transparent about the limitations of both research and other types of evidence collected and used in the policy making process and openly acknowledge that evidence cannot replace political decisions. This would help adjusting researchers, stakeholders and citizens expectations with regard to the impact of the evidence collected for example via EU funded research projects, public consultations or Eurobarometer surveys.

Implementing the above-mentioned recommendations would contribute to increase the transparency and the legitimacy of the EU policy making process.

\subsubsection{Recommendations for researchers}

Based on the limitations of the theoretical framework identified in this research study, the first recommendation for future researchers willing to investigate the role of evidence in policymaking is to clearly identify what they mean by the term "evidence" and use a consistent definition through their study. The evidence-based policy literature offers a wide range of definitions of evidence. Some are very concise and generally refer to information or facts and they might be too generic to be useful. Others like the one of the Canadian Health Services Research Foundation (see Chapter 1) are very elaborated but they indicate an already predefined view about the role of evidence in policy making. With regard to the theoretical framework, as mentioned above, the Bowen and Zwi model proved to be useful to capture the complexity of the EU policy making process but also presented a number of limitations. Therefore, it might be useful to choose another operational framework such as the "good governance of evidence" framework developed by Hawkins and Parkhurst (2016) or to adapt the general knowledge utilisation concepts elaborated by Radaelli (1995), Boswell (2009) and Cairney (2016) to the specific context investigated. 
The second recommendation is to analyse the wider policy process, including the context, the lobbying environment, the creation of coalitions, to ensure that all the elements that influence the uptake of evidence are taken into account, as done in this research study.

Building on the limitations of the methodological framework adopted in this research study beyond the standard measures to address the shortcomings of interviews as a source of data collection, the third recommendation concerns researchers using participant observation as a method for data collection. To improve the recollection of events, reduce the margin of bias and facilitate the analysis of data, it can be useful to note down all observations immediately after they have been made using a pre-defined structure.

Lastly, this research study shows that it would be useful for those who wish their work to be used in the EU policymaking process to know more how the process works - for example via specific courses on EU politics or policy making in the course of studies in public health - and to tailor their research to policymakers needs, both in terms of content and in terms of how their findings are presented (lengths, technical language). It is also vital to understand the complexity of the policy environment and accept it as it is, including that for policy makers evidence has a different meaning and that research evidence is just a very small factor in policy making. It would also be helpful to accept that policy makers need for information might be unpredictable and within a very short time frame that doesn't allow proper scientific research rigor, so that researchers do not feel frustrated if their research is ignored by policy makers. Moreover, it is important for researchers to be aware that their research can be used selectively and used as an ammunition by policy makers or stakeholders to serve their needs. Researchers also need to decide whether they want to play an active role and make sure their work is used for policy purposes at the risk of being biased or if they prefer to maintain full academic independence, decide on the research agenda, find alternative funding and just publish their studies.

With regard to future research, although this research study focused on the formulation of policies by the European Commission, it would be useful to investigate the in-depth use of evidence throughout the entire policymaking process till the adoption of the proposals by the three institutions to include the European Parliament and the Council of the EU. Further research is also needed to investigate the nature of the research evidence selected by the 
European Commission and conveyed by stakeholders. An additional element to be explored in further research is also the cost-effectiveness of the evidence-gathering process, namely the number of staff and amount of financial resources to commission external studies, conduct public consultations, perform Eurobarometer surveys, among others, and the actual use of the results in the formulation of policies. 


\section{Bibliography}

Abel, G.A., Neufeld E.J., Sorel M. \& Weeks J.C. (2008). Direct-to-consumer advertising for

bleeding disorders: a content analysis and expert evaluation of advertising claims.

Journal of Thrombosis \& Haemostasis 6 (10), 1680-1684.

Almeida C., \& Bascolo E. (2006). Use of research results in policy decisionmaking, formulation, and implementation: A review of the literature. Cadernos de Saúde Pública, 22, S7-S33.

Altheide, D. L., \& Johnson, J. M. (1994). Criteria for assessing interpretive validity in qualitative research. In N. K. Denzin \& Y. S. Lincoln (Eds.), Handbook of qualitative research (485-499). Thousand Oaks, CA: Sage; Mahwah, NJ: Lawrence Erlbaum.

Amara, N., Ouimet, M., \& Landry, Ré. (2004). New Evidence on Instrumental, Conceptual, and Symbolic Utilization of University Research in Government Agencies. Science Communication, 26(1), 75-106. https://doi.org/10.1177/1075547004267491

Anderson, J. E. (2006). Public policymaking. Boston, MA: Houghton Mifflin Company.

Austen-Smith, D. (1993). Information and influence: Lobbying for agendas and votes. American Journal of Political Science, 37(3), 799-833.

Backer, T. E. (1991). Knowledge utilization: The third wave. Knowledge Creation Diffusion Utilization, 12(3), 225-240.

Backer, T. E. (1991). Knowledge Utilization: The Third Wave. Knowledge, 12(3), 225-240. https://doi.org/10.1177/107554709101200303

Bäcklund, A. (2009). Impact assessment in the European Commission - A system with multiple objectives. Environmental Science \& Policy, 12, 1077-1087. 10.1016/j.envsci.2009.04.003.

Bagshaw, S., \& Bellomo, R. (2008). The need to reform our assessment of evidence from clinical trials: A commentary. Philosophy, Ethics, and Humanities in Medicine, 3(23). https://doi.org/10.1186/1747-53413-23.

Baumgartner, F. R., Berry, J. M., Hojnacki, M., Kimball, D. C., \& Leech, B. L. (2009). Lobbying and policy change: Who wins, who loses, and why. Chicago. University of Chicago Press 
Belcher, P. J. (2001). Health in Other EU Policies or an EU Health Policy? Eurohealth, 7(4), 1.

Bellamy, R., \& Castiglione, D. (2003). Legitimizing the Euro-'polity' and its 'Regime': The Normative Turn in EU Studies. European Journal of Political Theory, 2(1), 7-34. https://doi.org/10.1177/1474885103002001277

Bennett, C., \& Howlett, M. (1992). The lessons of learning: Reconciling theories of policy learning and policy change. Policy Sciences, 25, 275-294. https://doi.org/10.1007/BF0013878

Bertinato, L., Busse, R., Fahy, N. Legido-Quigley, H., Mckee, M., Passarani, I.,(...), Ronfini, F. (2005). Policy brief: Cross-border health care in Europe. World Health Organization on behalf of the European Observatory on Health Systems and Policies, 28.

BEUC, EHN, \& EPHA. (2008). Common position on nutrition labelling. Retrieved from http://www.beuc.eu

Beyers, J., Eising, R. and Maloney, W. (2008) 'Much we study, little we know? The study of interest group politics in Europe and elsewhere', West European Politics, 31(6), 1103-28.

Bickford, J. J., \& Kothari, A. R. (2008). Research and knowledge in Ontario tobacco control networks. Canadian Journal of Public Health, 99(4), 297-300.

Black, N., \& Donald, A. (2014). Evidence-based policy: Proceed with care BMC Health Services Research, 14, 2.

Boessen, S. (2008). The politics of the European Union health policy making. An actor-centred institutional analysis. Maastricht: Maastricht University Press.

Boseley, S. (2007, May 21). Drug firms and patient groups join in fight to overturn advertising ban. The Guardian. Retrieved from https://www.theguardian.com

Boswell, C. (2007). The European Commission's use of research in immigration policy: Expert knowledge as a source of legitimation? Retrieved from http://aei.pitt.edu/7709

Boswell, C. (2008) The political functions of expert knowledge: Knowledge and legitimation in European Union immigration policy, Journal of European Public Policy, 15(4), 471-488. https://doi.org/ 10.1080/13501760801996634 
Boswell, C. (2008) The political functions of expert knowledge: Knowledge and legitimation in European Union immigration policy. Journal of European Public Policy, 15(4), 471-88. https://doi.org/ $10.1080 / 13501760801996634$.

Boswell, C. (2009). The political uses of expert knowledge: Immigration policy and social research. Cambridge: Cambridge University Press

Botterill, L. \& Hindmoor, A. (2012). Turtles all the way down: Bounded rationality in an evidence-based age. Policy Studies, 33(5), 367-79.

Bouwen, P. (2002). Corporate lobbying in the European Union: The logic of access. Journal of European Public Policy, 9(3), 365-90.

Bouwen, P. (2004). Exchanging access goods for access: A comparative study of business lobbying in the European Union institutions. European Journal of Political Research, 43(3), 337-69.

Bowen, J. R., \& Petersen, R. (1999). Critical comparisons in politics and culture. Cambridge, UK: Cambridge University Press.

Bowen, S., \& Zwi, A. B. (2005). Pathways to "evidence-informed" policy and practice: A Framework for Action. PLoS Medicine 2(7): el66. https://doi.org/10.1371/journal.pmed.0020166

Brooks, E. (2012). Crossing borders: A critical review of the role of the European Court of Justice in EU health policy. Health Policy, 105(1), 33-37.

Brooks, E., \& Geyer, R. (2012). From DTCA-PD to patient information to health information: The complex politics and semantics of EU health policy. Journal of Evaluation in Clinical Practice, 18(6), 12351240 .

Broscheid, A. \& Coen, D. (2003b). Insider and outsider lobbying of the European Commission: An informational model of forum politics. European Union Politics, 4(2), 165-89.

Broscheid, A. \& Coen, D. (2007). Lobbying activity and fora creation in the EU. Journal of European Public Policy, 14(3), 346-65.

Broscheid, A., \& Coen, D. (2007). Lobbying activity and fora creation in the EU. Journal of European Public Policy, 14(3), 346-365.

Brownson, R. C., Baker, E. A., Deshpande, A. D., \& Gillespie, K. N. (2018). Evidence-based public health (3rd ed.). New York: Oxford University Press. 
Brownson, R., Fielding, J. E., \& Green, L.W. (2017). Building capacity for evidence-based public health: Reconciling the pulls of practice and the push of research. Annual Review of Public Health, 39, 27-53, retrived from

https://www.annualreviews.org/doi/pdf/10.1146/annurev-publhealth040617-014746

Brownson, R., Fielding, J. E., \& Maylahn, C. M. (2009) Evidence-based public health: A fundamental concept for public health practice. Annual Review of Public Health, 30. Retrieved from 175.10.1146/annurev.publhealth.031308.100134

Cairney, P. (2016). The politics of evidence-based policy making. Basingstoke: Palgrave McMillan.

Cairney, P., Oliver, K., \& Wellstead, A. (2016). To bridge the divide between evidence and policy: Reduce ambiguity as much as uncertainty. Public Administration Review, 76(3), 399-402.

Canadian Health Services Research Foundation. (2005). Annual report 2005. Ottawa.

Caplan, N. (1979). The two-communities theory and knowledge utilization. American Behavioral Scientist, 22(3), 459-70.

Carboni, N. (2009). Advocacy groups in the multilevel system of the European Union: A case study in health policy-making. Retrieved from

http://www.ose.be/files/publication/OSEPaperSeries/Carboni_2009_ OSEResearchPaper1_1109.pdf

Chalmers, A. W. (2011). Interests, influence and information: Comparing the influence of interest groups in the European Union. Journal of European Integration, 33(4), 471-486. https://doi.org/ $10.1080 / 07036337.2011 .579751$

Chalmers, A. W. (2011). Interests, influence and information: Comparing the influence of interest groups in the European Union. Journal of European Integration, 33(4), 471-86. https://doi.org/ $10.1080 / 07036337.2011 .579751$.

Coen, D. (2007). Empirical and theoretical studies in EU Lobbying. Journal of European Public Policy, 14(3), 333-45. 
Coen, D. (2009). Business lobbying in the European Union. In D. Coen \& J. Richardson (Eds.), Lobbying the European Union: Institutions, Actors and Issues. (19-38). Oxford: Oxford University Press.

Coen. D \& Richardson J. (2009.), Lobbying the European Union: Institutions, Actors and Issues. Oxford: Oxford University Press

Corporate Europe Observatory (2010). A red light for consumer information. Brussels: Corporate Europe Observatory. Retrieved from https://www.corporateurope.org

Corporate Europe Observatory (2015). Policy prescriptions: the firepower of the EU pharmaceutical lobby and implications for public health. Retrived from http://corporateeurope.org/sites/default/files/20150904_bigpharma web.pdf

Council of the European Union. (2001). Council Directive 2001/83/EC of 6 November 2001 on the Community code relating to medicinal products for human use. (2001). Official Journal of the European Union, L311, 67-128.

Council of the European Union. (2004). Council Directive 2004/27/EC of 31 March 2004 amending Directive 2001/83/EC on the Community code relating to medicinal products for human use. (2004). Official Journal of the European Union, L136, 34-57.

Council of the European Union. (2006). Council conclusions on common values and principles in European Union Health Systems. Official Journal of the European Union C 146/1 22.6.2006.

Council of the European Union. (2010). Council adopts its position on patient's rights in cross-border healthcare. 13535/10, PRESSE 239 2010. 2010.

Council of the European Union. (2010). Proposal for a directive of the European Parliament and of the council on the application of patients' rights in cross-border healthcare (first reading) $(L A+S)$ Adoption of (a) the Council's position; (b) the statement of the Council's reasons..

Council of the European Union. (2011). Position of the Council at first reading with a view to the adoption of a Regulation of the European Parliament and of the Council on the provision of food information to consumers. 
Council of the European Union. (December 2001). Presidency conclusions. Doc. SN 300/1/01 REV 1,14-15.

Council of the European Union. (June 26, 2002). 2440 ${ }^{\text {th }}$ Council meeting on health, doc. 100090/02 (Press 182), Luxembourg.

Cram, L. (1994) The European Commission as a multi-organization: Social policy and IT policy in the EU. Journal of European Public Policy, 1(2), 195-217. https://doi.org/ 10.1080/13501769408406955

Cram, L. (2005) Policy-Making in the European Union. Conceptual lenses and the integration process. London: Routledge.

Crombez, C. (2002). Information, lobbying and the legislative process in the European Union. European Union Politics, 3(1), 7-32.

Crombez, C. (2003). The democratic deficit in the European Union: Much ado about nothing? European Union Politics, 4(1), 101-120.

Culyer, A.J., \& Lomas, J.. (2006). Deliberative processes and evidenceinformed decision-making in health care: Do they work and how might we know? Evidence and Policy, 2(3), 357-371.

Davies, H. T. O., Nutley, S. M., \& Smith, P. (2000). What works? Evidencebased policy and practice in public services. Bristol: The Policy Press.

Davies, H. T. O., Nutley, S. M., \& Smith, P. C. (Eds.). (2000). What Works?: Evidence Based Policy and Practice in Public Services. Bristol: The Policy Press.

Deelstra, Y., Nooteboom, S.G, Kohlmann, H.R., van den Berg, J., and Innanen, S. (2003) Using knowledge for decision making purposes in the context of large projects in The Netherlands, Environmental Impact Assessment Review,23, 517-41.

Dobbins, M., et al. (2009). A description of a knowledge broker role implemented as part of a randomized controlled trial evaluating three knowledge translation strategies. Implementation Science, 4(23), 116.

Dobrow M.J., Goel, V., Upshur, R.E. (2004). Evidence-based health policy: context and utilisation. Social Science Medicine. 2 58(1):207-17. https://doi.org/ 10.1016/S0277-9536(03)00166-7

Dolowitz, D.P. and Marsh, D. (2000) Learning from Abroad The Role of Policy Transfer in Contemporary Policy-Making. Governance, 13, $5-24$. 
Donohue, J. M., Cevasco, M., \& Rosenthal, M. B. (2007). A decade of direct-to-consumer advertising of prescription drugs. New England Journal of Medicine, 357, 673-681.

Dopson, S., Locock, L., Gabbay, J., Ferlie, E., \& Fitzgerald, L. (2003). Evidence-Based Medicine and the Implementation Gap. Health, 7(3), 311-330. https://doi.org/10.1177/1363459303007003004

Dunlop, C., \& Radaelli, C. (2013). Systematising policy learning: From monolith to dimensions. Political Studies, 61, 599-619. https://doi.org/10.1111/j.1467-9248.2012. 00982

Eising, R. (2007) The access of business interests to EU institutions: Towards élite pluralism? Journal of European Public Policy, 14(3), 384-403. https://doi.org/10.1080/13501760701243772

Elliott, H., \& Popay, J. (2000). How are policy makers using evidence? Models of research utilisation and local NHS policy making. Journal of epidemiology and community health, 54(6), 461-8.

Estabrooks, C. A. (1999). The conceptual structure of research utilization. Research in Nursing \& Health, 22, 203-16.

Euractiv. (2008, January 20). Confusion surrounds EU's health services directive. Euractiv. Retrieved from https://www.euractiv.com

Euractiv. ( 2014, May 27). EU twisting facts to fit political agenda, chief scientist says.

Retrived from https://www. euractiv.com

Euractiv. (2010, June 17). Food industry wins battle on 'traffic light' labels. Euractiv. Retrieved from https://www.euractiv.com

Euractiv. (2011, July 4). Parliament to rubber-stamp new food labelling rules. Euractiv. Retrieved from https://www.euractiv.com

Euractiv. ( 2010,November 25). Lawmakers tighten rules on drug information to patients. Euractiv. Retrieved from https://www.euractiv.com

Euractiv. ( 2008, September 21). Who drives demand for more information to patients? Euractiv. Retrieved from https://www.euractiv.com

Eurocommerce. (2008, January 30). Commission's proposal on "Food Labelling": A missed opportunity for simplification? Brussels: Eurocommerce. Retrieved from https://www.eurocommerce.eu 
European Commission (2003). High level process of reflection on patient mobility and health care developments in the European Union. Outcome of the reflection process. HLPR/2003/16

European Commission (2001) G10 High Level Group medicines consultation paper. Brussels.

European Commission. (1998). The single market in pharmaceuticals [Communication from the Commission]. COM (98)588 final. Brussels.

European Commission. (2001). European Commission Communication. European Governance. A White Paper. COM (2001) 428 final

European Commission. (2001). Science and Society Action Plan. Retrieved from

https://ec.europa.eu/research/swafs/pdf/pub_gender_equality/ss_ap_ en.pdf

European Commission. (2002). Communication from the Commission on the collection and use of expertise by the commission: principles and guidelines.

European Commission. (2002). Improving the knowledge base for better policies. COM (2002) 713 final.

European Commission. (2003). Commission staff working paper. Report on the application of internal market rules to health services by the European Commission. SEC(2003) 900.

European Commission. (2003). High level process of reflection on patient mobility and healthcare developments in the European Union. Health and Consumer Protection Directorate-General.

European Commission. (2004). High level group on health services and medical care. HLG/2004/21 FINAL.

European Commission. (2005). EU Health Policy Forum Recommendations on health services in the internal market.

European Commission. (2005). Pharmaceutical Forum: Delivering better information, better access and better prices [Press release] (IP/06/1282).

European Commission. (2005). Strengthening evidence-based policy making through scientific advice reviewing existing practice and setting up a European science advice mechanism. 
European Commission. (2006). Communication from the Commission.

Consultation regarding Community action on health services. SEC (2006) 1195/4.

European Commission. (2007). Flash Eurobarometer. Cross-border health services in the EU: analytical report. The Gallup Organization.

European Commission. (2008). Commissions Staff Working Document acindustrying the Proposal for a Regulation of the European Parliament and the Council on the provision of food information to consumers. Impact Assessment Report on General Food Labelling Issues. COM (2008) 40 final, SEC (2008) 92.

European Commission. (2008). Commissions Staff Working Document acindustrying the Proposal for a Regulation of the European Parliament and the Council on the provision of food information to consumers. Impact Assessment Report on Nutrition Labelling Issues. COM (2008) 40 final, SEC (2008) 92.

European Commission. (2008). Communication from the Commission to the European Parliament pursuant article 294(6) of the Treaty on the functioning of the European Union concerning the position of the Council at first reading on the adoption of a Directive of the European Parliament and of the Council on the application of patients' rights on cross border health care. 2008/0142 (COD).

European Commission. (2008). Proposal for a directive of the European Parliament and the council on the application of patients' rights in cross-border healthcare. COM 414 final.

European Commission. (2008). Proposal for a Directive of the European Parliament and of the Council amending, as regard information to the general public on medicinal products subject to medical prescription. Directive 2001/83/EC on the Community code relating to medicinal products for human use, COM (2008) 662.

European Commission. (2008). Proposal for a Directive of the European Parliament and of the Council amending, as regard information to the general public on medicinal products subject to medical prescription. Directive 2001/83/EC on the Community code relating to medicinal products for human use - Impact assessment, SEC (2008) 2667. 
European Commission. (2008). Proposal for a regulation of the European Parliament and of the Council on the provision of food information to consumers. COM (2008) 40 final.

European Commission. (April 19, 2007). Draft report on current practice with regard to provision of patient information on medicinal products. Brussels. Retrieved from http://ec.europa.eu/enterprise/pharmaceuticals/pharmacos/docs/doc2 007/2007_04/draft_infopatients2007_04.pdf [2009, 19 February].

European Commission. (February 2006). Labelling: Competitiveness, consumer information and better regulation for the EU. ADG SANCO consultative document.

European Consumers' Organisation (BEUC). (September 29, 2006). Patients need real information...not more brand awareness. Retrived from www.beuc.eu

European Ombudsman. (2015). Decision of the European Ombudsman closing the inquiry into complaint 346/2013/SID against the European Food Safety Authority ('EFSA').

European Parliament and Council of the European Union ( 1971). Regulation (EEC) 1408/71 of 14 June 1971 on the application of social security schemes to employed persons and their families moving within the community: Official Journal L 149, 05.07.1971. 1971.

European Parliament and Council of the European Union ( 2004). Regulation (EC) no 883/2004 of the European Parliament and of the council of 29 April 2004 on the coordination of social security systems: Official Journal of the European Union L 166, Official Journal L 149, 30.4.2004. 2004.

European Parliament and Council of the European Union.(2009). Regulation EC 987/2009 of 16 September 2009 laying down the procedure for implementing regulation (EC) no 883/2004 on the coordination of social security systems, OJ L 284 of 30 October 2009: Official Journal of the European Union. 2009.

European Parliament. (2009). European Parliament legislative resolution of 23 April 2009 on the proposal for a directive of the European Parliament and of the Council on the application of patients' rights 
in cross-border healthcare. (COM(2008)0414 - C6-0257/2008 2008/0142(COD))(Codecision procedure: first reading).

European Parliament. (2009). First Draft Report on the proposal for a regulation of the European Parliament and of the Council on the provision of food information to consumers COM (2008)0040 - C6 0052/2008 - 2008/0028(COD)

European Parliament. (2010). Amendments by the European Parliament to the council position at first reading with a view to the adoption of a directive of the European Parliament and of the council on the application of patients' rights in cross-border healthcare.

(11038/2/2010 - C7-0266/2010 - 2008/0142(COD)).

European Parliament. (2010). News: cross-border health care-Françoise Grossetête MEP explains ahead of vote Public health.

European Parliament. (2010). Position of the European Parliament adopted at first reading on 16 June 2010 with a view to the adoption of Regulation (EU) No 1169/2010 of the European Parliament and of the Council on the provision of food information to consumers, amending Regulations (EC) No 1924/2006 and (EC) No 1925/2006 and repealing Commission Directive 87/250/EEC, Council Directive 90/496/EEC, Commission Directives 94/54/EC and 1999/10/EC, Directive 2000/13/EC, Commission Directives 2002/67/EC and 2004/77/EC and Commission Regulation (EC) No 608/2004 (EPPE_TC1-COD(2008)0028).

European Parliament. (2010). Recommendations for second reading on the council position at first reading with a view to the adoption of a directive of the European Parliament and of the council on the application of patients' rights in cross-border healthcare. $11038 / 2010$ - C7 0266/2010 - 2008/0142(COD).

European Parliament. (2010). Report on the proposal for a regulation of the European Parliament and of the Council on the provision of food information to consumers (COM (2008)0040 - C6-0052/2008 2008/0028(COD)).

European Parliament. (2010) Rules of procedures. $7^{\text {th }}$ Parliamentary Term. Retrived from http://www.europarl.europa.eu/

European Patients Forum. (2010). Report of the high-level roundtable on the draft directive on patients' rights in cross-border healthcare: 
moving forward on health inequalities, patients rights, quality, and safety. Brussels: European Patients Forum. Retrieved from https://www.eu-patient.eu

European Union. (2002). Decision No 1513/2002/EC of the European Parliament and of the Council of 27 June 2002 concerning the sixth framework programme of the European Community for research, technological development and demonstration activities, contributing to the creation of the European Research Area and to innovation (2002 to 2006). Official Journal of the European Union, $L$ 232, 29.8.2002, p. 1-33.

European Union. (2007). Consolidated Version of the Treaty on the Functioning of the European Union. Official Journal of the European Union 2008/C 115/01.

European Union. (2014). European Union explained: Health policy.

Retreived from

http://europa.eu/pol/pdf/flipbook/en/public_health_en.pdf

European Union. (2014). Regulation (EU) No 282/2014 of the European

Parliament and of the Council of 11 March 2014 on the establishment of a third Programme for the Union's action in the field of health (2014-2020) and repealing Decision No 1350/2007/EC.

European Voice. (2010, June 8). Ministers strike cross-border healthcare deal. European Voice. Retrieved from https://www.europeanvoice.com

Everson, M., \& Vos, E. (2009). The scientification of politics and the politicisation of science. In M Everson, \& E Vos (Eds.), Uncertain risks regulated (pp. 1-17). London: Routledge/Cavendish Publishing.

Feldman, M., \& March, J. (1981). Information in organizations as signal and symbol. Administrative Science Quarterly, 26(2), 171-86

Flick, U. (2006). An introduction to qualitative research (3rd ed.). London: Sage.

Food Standard Agency. (2007). Food labelling consumer research: What consumers want. A literature review. London: Food Standard Agency. Retrieved from https://www.food.gov.uk 
Freeman, J. L., \& Stevens, J. P. (1987). A theoretical and conceptual reexamination of subsystem politics. Public Policy and Administration, 2, 9-24.

Freeman, R. (2006). Learning in public policy. In M. Moran, M. Rein, \& R. E. Goodin (Eds.), The Oxford handbook of public policy (pp. 36788). New York, NY: Oxford University Press.

Friends of the Earth Europe. (2008). Whose views count? Business influence and the European Commission's high-level groups. Retrieved from http://www.foeeurope.org/corporates/pdf/whose_views_, count.pdf

Gale, N. K., Heath, G., Cameron, E., Rashid, S., \& Redwood, S. (2013). Using the framework method for the analysis of qualitative data in multi-disciplinary health research. Retrieved from http://www.ncbi.nlm.nih.gov/pmc/articles/ PMC3848812 /\#B1

George, A. L., \& Bennett, A. (2005). Case studies and theory development in the social science. Cambridge: MIT Press.

Gilbody, S., Wilson, P., \& Watt, I. (2005). Benefits and harms of direct to consumer advertising: A systematic review. Quality \& Safety in Health Care, 246-50.

Gilligan, T. W., \& Krehbiel, K. (1989). Asymmetric information and legislative rules with a heterogeneous committee. American Journal of Political Science, 33(2), 459-490.

Glasby, J., Walshe, K., \& Harvey, G. (2007). What counts as 'evidence' in 'evidence-based practice'? Evidence and Policy, 3(3), 325-327.

Glinos, I. A., \& Baeten, R. (2006). A literature review of cross-border patient mobility in the European Union. Observatoire Social Europeen, 114.

Gold M. (2009). Pathways to the use of health services research in policy. Health services research, 44(4), 1111-36.

Gorissen, W.H.M., Schulpen, T.W.J., Kerkhoff, A.H.M., Heffen, O. (2005). Bridging the gap between doctors and policymakers: The use of scientific knowledge in local school health care policy in The Netherlands, European Journal of Public Health, 15 (2), 133-139.

Gornitzka, A. \& Holst, C. (2015) The role of expert knowledge in EU executive. Institutions, Politics and Governance, 3(1). 
Gornitzka, A. \& Sverdrup, U. (2015). Societal inclusion in expert venues: Participation of interest groups and business in the European Commission expert groups. Politics and Governance. https://doi.org/10.17645/pag.v3i1.130

Gornitzka, Å. and Sverdrup, U. (2008) 'Who Consults? The Configuration of Expert Groups in the European Union', West European Politics, $31,725-750$.

Gornitzka, Å. and Sverdrup, U. (2011) 'Access of Experts: Information and EU Decision-making', West European Politics, 34, 48-70.

Government Accountability Office (2006). Prescription drugs: improvements needed in FDA's oversight of direct-to-consumer advertising. Washington, DC.

Grant W. ( 2004), Pressure Politics: The Changing World of Pressure Groups, Parliamentary Affairs, 57,(2 ) 408-419 https://doi.org/10.1093/pa/gsh033

Green, J., \& Thorogood, N. (2009). Qualitative methods for health research. London: Sage.

Greenhalgh, T., \& Russell, J. (2006). Reframing Evidence Synthesis As Rhetorical Action in the Policy Making Drama. Healthcare Policy, $1,34-42$.

Greenwood, J. (2017). Interest representation in the European Union. Basingstoke: Palgrave McMillan.

Greer, S. L. (2006). Uninvited Europeanization: Neofunctionalism and the EU in health policy. Journal of European Public Policy, 13(1), 134152.

Greer, S. L. (2008). Choosing paths in European Union health services policy: A political analysis of a critical juncture. Journal of European Social Policy, 18(3).

Greer, S. L. (2008). Power struggle: The politics and policy consequences of patient mobility in Europe. Observatoire Social Europeen, 2.

Greer, S. (2009). The politics of European Union health policies. London: Open University Press.

Greer, S. L., \& Vanhercke, B. (2010). The hard politics of soft law: The case of health. In E Mossialos et al. (Eds.), Health systems governance in Europe: The role of European Union Law and policy, 
European Observatory on health systems and policies. Cambridge: Cambridge University Press.

Grin, J., \& Loeber, A. (2007). Theories of policy learning: Agency, structure, and change. In F. Fischer, G. Miller, \& M. S. Sidney (Eds.), Handbook of public policy analysis: Theory, politics, and methods (pp. 201-19). London: CRC Press.

Grossman, G. M., \& Helpman, E. (2001). Special interest politics. Cambridge, MA: The MIT Press.

Guyatt G., Cairns J., Churchill D. (1992). Evidence-based medicine: a new approach to teaching the practice of medicine. JAMA 268, 24202425.

Haas, P. M. (1992). Introduction: Epistemic communities and international policy coordination. International Organization, 46(1), 1-36

HAI. (2002). Providing prescription medicine information to consumer: Is there a role for direct-to-consumer promotion? - Symposium report. Amsterdam: HAI.

Hall, P.A. (1993). Policy paradigms, social learning, and the State: The case of economic policymaking in Britain. Comparative Politics, 25(3), 275-96.

Hammersley, M. (2007). The issue of quality in qualitative research. International Journal of Research \& Method in Education, 30(3), 287-305.

Hanney, S. R., Gonzalez-Block, Buxton M. A, M.J., Kogan, M. (2003), The utilisation of health research in policy-making: Concepts, examples and methods of assessment. Health Research Policy and Systems https://doi.org/10.1186/1478-4505-1-2

Hanney, S.R. \& Block, M.G. (2015). Health research improves healthcare: Now we have the evidence and the chance to help the WHO spread such benefits globally. Health Research Policy and Systems, 13(12).

Hatzopoulos, V. (2007). The ECJ case law on cross-border aspects of health services, Briefing note for the European Parliament's committee on internal market and consumer protection. DG Internal Policies of the Union Briefieng Note, IP/A/IMCO/FWC/2006- 167/C3/SC1.

Retrieved from https:// www.europarl.europa.eu/comparl/imco/ studies/0701_healthserv_ecj_en.pdf 
Hawkins, B., Parkhurst, J. (2016) The 'good governance' of evidence in health policy, Evidence \& Policy, vol 12 no 4, 575-92, https://doi.org/:10.1332/174426415X14430058455412

Health Action International (2011). The patient \& consumer voice and pharmaceutical industry sponsorship. Retrived from www.who.int.

Health and Environment Alliance ( 2014). Health Costs in the European Union - How much is related to ECDS? Retrived from www.envhealth.org

Heclo, H. (1978). Issue networks and the executive establishment. In A. King (Ed.), The new American political system (pp. 87-124). Washington, DC: American Enterprise Institute for Public Policy Research

Herbst, S. (2003). Political authority in a mediated age. Theory and Society, 32, 481-503.

Hervey, T., \& McHale, J. (2004). Health law and the European Union. Cambridge: Cambridge University Press.

Hervey, T., \& Vanhercke, B. (2010). Health care and the EU: Law and policy patchwork. In Mossialos, E., Baeten, R. \& Hervey, T. (Eds.), Health systems governance in Europe (84-133). Cambridge: Cambridge University Press.

Homan, R. (1991). The ethics of social research. Logman: London.

Howlett, M., Ramesh, M., \& Perl, A. (2009). Studying public policy: Policy cycles and policy subsystems (3rd ed.). Toronto: Oxford University Press

Hughues, C. E. (2007). Evidence-based policy or policy-based evidence? The role of evidence in the development and implementation of the Illicit Drug Diversion Initiative. Drug and Alcohol Review, 26(4),363-8. HTTPS://DOI.ORG/ 10.1080/09595230701373859.o

Hyder, A. A., Corluka, A., Winch, P. J., El-Shinnawy, A., Ghassany, H., Malekafzali, H., Lim, M. K., Mfutso-Bengo, J., Segura, E., ... Ghaffar, A. (2010). National policy-makers speak out: are researchers giving them what they need?. Health policy and planning, 26(1), 73-82.

Hyder, A.A., Corluka, A., Winch, P. J., El-Shinnawy, A., Ghassany, H., Malekafzali, H., (...) Ghaffar, A. (2003). National policymakers 
speak out: Are researchers giving them what they need?

Environmental Impact Assessment Review, 23, 517-541.

Innvaer, I., Vist, G., Trommald, M., \& Oxman, A. D. (2002). Health policymakers' perceptions of their use of evidence: A systematic review. Journal of Health Services Research and Policy, 17(4), 239-44. Institute of Medicine. (2003). The future of the public's health in the 21st century. Washington, DC: National Academies Press.

Joint Declaration by AIM, BEUC, HAI Europe, ISDB, and MiEF. (October $3,2006)$. Relevant health information for empowered citizens, 3 October 2006.

Joint Open Letter on Information to Patients from 18 Organizations. (2008). Joint open letter on information to patients from 18 organizations. Retrieved from http:/www.healthyskepticism.org/global/library/item/13770

Kingdon, J. W. (1984). Agendas, Alternatives and Public Policies. Boston: Little, Brown and Company.

Kingdon, J. W. (2011). Agendas, alternatives, and public policies. Boston: Longman.

Klein, R. (2003). Evidence and policy: Interpreting the Delphic oracle. Journal of the Royal Society of Medicine, 96(9), 429-31.

Kluver. (2013). Lobbying in the European Union. Oxford University Press.

Kohatsu, N.D, Robinson, J.G. \& Torner, J.C. (2004). Evidence-based public health: An evolving concept. American Journal of Preventive Medicine, 27(5), 417-21.

Kohler-Koch, B., \& Eising, R. (1999). The Transformation of governance in the European Union. London: Routledge

Lavis et al. (2015). Developing and refining the methods for a 'one-stop shop' for research evidence about health systems. Health Research Policy and Systems, 13, 10.

Lavis, J. N., Oxman, A. D., Lewin, S., \& Fretheim, A. (2009). Support tools for evidence-informed health policymaking (STP) 3: Setting priorities for supporting evidence-informed policymaking. Health Research Policy and Systems, 16(7). HTTPS://DOI.ORG/ 10.1186/1478-4505-7-S1-S3.

Lavis, J.N., Posada, F.B., Haines, A., Osei, E. (2004). Use of research to inform public policymaking. Lancet. 364(9445),1615-21 
Lee, N., \& Kirkpatrick, C. (2006). Evidence-based policy-making in Europe: An evaluation of European Commission integrated impact assessments. Impact Assessment and Project Appraisal, 24(1), 2333. HTTPS://DOI.ORG/ 10.3152/147154606781765327

Legido-Quigley, H., Glinos, I., Baeten, R., \& McKee, M. (2007). Patient mobility in the European Union. British Medical Journal, 334, 8890 .

Legido-Quigley, H., Passarani, I., Knai, C., Busse, R., Palm, W., Wismar, M., \& McKee, M. (2011). Cross-border healthcare in the European Union: Clarifying patients' rights. British Medical Journal, 342:d296. https://doi.org/ 10.1136/bmj.d296.

Lemieux-Charles, L., \& Champagne, F. (2004). Using knowledge and evidence in health care: Multidisciplinary perspectives. Toronto: University of Toronto Press.

Lewig, K., Scott, D., Holzer, P., Arney, F., Humphreys, C., \& Bromfield, L. (2010). The role of research in child protection policy reform: A case study of South Australia. Evidence \& Policy, 6(4), 461-82.

Lewis, P. (2013). Policy thinking, fast and slow: A social intuitionist perspective on public policy processes. American Political Science Association Annual Meeting. Available at SSRN:

$\mathrm{http}: / /$ ssrn.com/abstract=2300479.

Liaukonyte, J., Streletskaya, N.A., Kaiser, H.M., \& Rickard, B. J. (2013). Consumers response to "contains" and "free of" labeling: Evidence from lab experiments. Applied Economic and Perspectives and Policy, 35(3), 476-507.

Lincoln, Y. S., \& Guba, E. G. (1985). Naturalistic inquiry. Newbury Park, CA: Sage Publications.

Lindblom, C. E. (1959). The science of "muddling through". Public Administration Review, 19, 79.

Lindblom. (1990). Lobbying and policy change: Who wins, who loses, and why. Chicago and London: University of Chicago Press.

Liverani, M., Hawkins, B., \& Parkhurst, J. O. (2013). Political and institutional influences on the use of evidence in public health policy. A systematic review. PLoSONE 8(10): e77404. HTTPS://DOI.ORG/ 10.1371/journal.pone.0077404 
Lomas, J. (2005). Using research to inform healthcare managers' and policy makers' questions: From summative to interpretive synthesis. Healthcare Policy, 1(1), 55-71.

Lomas, J., \& Brown, A. (2009). Research and advice giving: a functional view of evidence-informed policy advice in a Canadian ministry of health, Milbank Quarterly, 87, 4, 903-926.

Lyles, A. (2004). Evidence- or opinion-based pharmaceutical policy? Retrieved from http://www.clinicaltherapeutics.com/article/01492918(04)80355-2/pdf

Macintyre, S.C.I., Horton, R., \& Smith, R. (2001). Using evidence to inform health policy: Case study. BMJ, 322, 222-5.

Mackenbach, J. (2003). Tackling inequalities in health: the need for building a systematic evidence base. Journal of Epidemiology and Community Health, 57, 162.

Majone, G. (1989) Evidence, argument and persuasion in the policy process. New Haven, CT: Yale University Press.

Majone, G. (1998) Europe's 'Democratic Deficit': The Question of Standards. European Law Journal 4 (5), 28.

Malterud, K. (2001). Qualitative research: Standards, challenges, and guidelines. Lancet (London, England), 358(9280), 483-8. Retrieved from http://www.ncbi.nlm. nih.gov/pubmed/11513933

Malterud, K., Bjelland, A.K.\& Elvbakken, K.T. (2016). Evidence-based medicine - An appropriate tool for evidence-based health policy? A case study from Norway. Health Research Policy and Systems, 14, 15. https://doi.org/10.1186/s12961-016-0088-1

March, J. G., \& Olsen, J.P. (2006). Elaborating the "New Institutionalism". In R.A.W. Rhodes, S. Binder \& B. Rockman (eds.), The Oxford Handbook of Political Institutions (pp.3-20). Oxford: Oxford University Press.

Maynard, A., \& Bloor, K. (2003). Dilemmas in regulation of the market for pharmaceuticals. health affairs. Retrieved from https://www.healthaffairs.org/doi/pdf/10.1377/hlthaff.22.3.31

Maxwell, S. E., \& Delaney, H. D. (2004). Designing experiments and analyzing data: A model comparison perspective (2nd ed.). Mahwah, NJ, US: Lawrence Erlbaum Associates Publishers. 
Mazey, S., \& Richardson, J. (1993). Introduction: Transference of power, decision rules, and rules of the game. In S. Mazey, \& J. Richardson (Eds.), Lobbying in the European Community (pp. 3-26). Oxford: Oxford University Press.

McDonough, J. E. (2000). Experiencing politics: A legislator's stories of government

and health care. Berkeley: University of California Press/New York: Milbank Memorial Fund.

Medawar, C., \& Hardon, A. (2004). Medicines out of control?:

Antidepressants and the conspiracy of goodwill. Amsterdam: Aksant Academic Publishers.

Meulen, R.T., \& Dickenson, D. (2002). Into the hidden world behind evidence-based medicine. Health Care Analysis, 10(3), 231-241.

Mitton, C., Adair, C. E., McKenzie, E., Patten, S.B., \& Waye Perry, B. (2007). Knowledge transfer and exchange: Review and synthesis of the literature. The Milbank Quarterly, 85(4), 729-68.

Mossialos, E., Permanand, G., Baeten, R., \& Hervey T. (2010). Health systems governance in Europe: The role of European Union law and policy. Cambridge University Press.

Mueller, S. \& Szolnoki, G. (2010). The relative influence of packaging, labelling, branding and sensory attributes on liking and purchase intent: Consumers differ in their responsiveness. Food Quality and Preference, 21(7), 774-783.

Nutbeam, D. (2001). Evidence-based public policy for health: Matching research to policy need. IUHPE Promotion Education, 2, 15-27.

Nutley, S. M., Powell, A.E. \& Davies, H.T.O. (2013). What counts as good evidence. Alliance for Useful Evidence, London.

Nutley, S. M., Walter, I., \& Davies, H. T. O. (2007). Using evidence: How research can inform public services. Bristol: The Policy Press.

O’ Laughlin, B. (1998). Interpreting institutional discourses. In Thomas, A., Chataway, J., \& M. Wuyts (Eds.), Finding out fast: Investigative skills for policy and development (pp. 107-126). London: Sage.

Obermaier, A. J. (2009). The end of territoriality: The impact of ECJ rulings on the British, German and French social policy. Aldershot: Ashgate.

OECD. (2012). Health at a Glance Europe 2012. 
OECD. (2017). Health at a Glance 2017: OECD indicators. OECD Publishing: Paris. Retrieved from https://doi.org/10.1787/health_glance-2017-en.

Oliver, K., Innvaer, S., Lorenc, T., Woodman, J., \& Thomas, J. (2014). A systematic review of barriers to and facilitators of the use of evidence by policymakers. BMC Health Services Research, 14(1), 2. http://www.biomedcentral.com/1472-6963/14/2.

Oliver, K., Lorenc, T., Innvaer, S. (2014). New directions in evidence-based policy research: A critical analysis of the literature. Health Research Policy and Systems, 12, 34.

Oliver, T. R. (2006), The Politics of Public Health Policy. Annual Review of Public Health ;27:195-233, retrived from https://www.annualreviews.org/doi/pdf/10.1146/annurev.publhealth. 25.101802 .123126

Ollberding, N.J., Wolf, L.R., \& Contento, I. (2010). Food labels use and its relation to dietary intake among US adults. Journal of the American Dietetic Association, 110(8), 1233-1237

Olsson, T.M. (2007). Reconstructing evidence-based practice: An investigation of three conceptualisations of EBP evidence \& policy. A Journal of Research, Debate and Practice, 3(2), 271-285.

Orton, L. (2011), The use of research evidence in public health decision making processes: Systematic review. PLoS One, 6, e2170. HTTPS://DOI.ORG/ 10.1371/journal.pone.0021704.

Oxman, A. D., Lavis, J. N., Fretheim, A., \& Lewin, S. (2009). SUPPORT Tools for evidence-informed health Policymaking (STP) 17: Dealing with insufficient research evidence. Health research policy and systems, 7 Suppl 1(Suppl 1), S17. https://doi.org/10.1186/14784505-7-S1-S17.

Padian, N. S., Mccoy, S. I., Balkus, J. E., Wasserheit, J. N. (2010). Weighing the gold in the gold standard: Challenges in HIV prevention research. AIDS, 24, 621-35.

Palm, W., \& Nickless, J. (2001). Access to healthcare in the European Union-The consequences of the Kohll and Decker judgements. Eurohealth, 7, 13-5.

Parkhurst, J. (2017). The politics of evidence: From evidence-based policy to the good governance of evidence. Abingdon: Routledge 
Parsons, D. W. (1995). Public policy: An introduction to the theory and practice of policy analysis. Aldershot, UK: Edward Elgar.

Paulus, A., Evers, S., Fecher, F., Van Der Made, J. \& Boonen, A. (2002). Cross border health care: An analysis of recent ECJ rulings. European Journal of Law and Economics, 14(1), 61-73.

Paxton, A., Maine, D., Freedman, L., \& Lobis, S. (2005). The evidence for emergency obstetric care. International Journal of Gynecology and Obstetrics, 88, 181-93.

Pearce, W., \& Raman, S. (2014). The new randomised controlled trials (RCT) movement in public policy: Challenges of epistemic governance. Policy Sciences, 47(4), 387-402. HTTPS://DOI.ORG/10.1007/s11077-014-9198-1

Permanand, G. (2007). EU pharmaceutical regulation: The politics of policy making. Routledge.

Perri, S. (2002). Can policy making be evidence-based? Journal of Integrated Care, 10(1), 3-8. Retrieved from https://doi.org/10.1108/14769018200200002

Peterson, J. (1995). Decision-making in the European Union: Towards a framework for analysis. Journal of European Public Policy, 2(1), 69-93. HTTPS://DOI.ORG/ 10.1080/13501769508406975

Petticrew, M., \& Roberts, H. (2003). Evidence, hierarchies, and typologies: Horses for courses. Journal of Epidemiology and Community Health, 57, 527-529.

Petticrew, M., Whitehead, M., Macintyre, S.J., Graham, H. \& Egan, M. (2004). Evidence for public health policy on inequalities: The reality according to policymakers. Journal of Epidemiology and Community Health, 8, 811-816. HTTPS://DOI.ORG/ 10.1136/jech.2003.015289

Pillow, W. (2003). Confession, catharsis, or cure? Rethinking the uses of reflexivity as methodological power in qualitative research. International Journal of Qualitative Studies in Education, 16(2), 175-196. HTTPS://DOI.ORG/10.1080/0951839032000060635

Potters, J., \& van Winden, F. (1992). Lobbying and asymmetric information. Public Choice, 74(3), 269-92.

Radaelli, C. M. (1995). The role of knowledge in the policy process. Journal of European Public Policy, 2(2), 159-83.

Radaelli, C. M. (1999). The public policy of the European Union: Whither politics of expertise? Journal of European Public Policy, 6(5), 757774. HTTPS://DOI.ORG/ 10.1080/135017699343360 
Radaelli, C. M. (2009). Measuring policy learning: Regulatory impact assessment in Europe. Journal of European Public Policy, 16(8), $1145-164$.

Raynor, D. K. (2007). The importance of medicines information for patients. Prescriber, $18(2), 60-62$.

Richardson, J. (1996). Policy-making in the EU: Interests, ideas and garbage cans of primeval soup. In Jeremy Richardson (Ed.), European Union: Power (pp. 3-23). London: Routledge.

Richardson, J. (2006). Policy-making in the EU: Interests, ideas and garbage cans of primeval soup. In J. Richardson (ed.), European Union: Power and PolicyMaking (p.3-30). New York: Rutledge.

Rimkute, D., \& Haverland, M. (2015). How does the European Commission use scientific expertise? results from a survey of scientific members of the commission's expert committees. Comparative European Politics, 13, 430-449. 10.1057/cep.2013.32.

Ritchie, J., \& Lewis, J. (2003). Qualitative research practice: A guide for social science students and researchers. London: Sage.

Ritchie, J., \& Spencer, L. (1994). Qualitative data analysis for applied policy research. In Bryman, A. \& Burgess, R. G. (Eds.), Analyzing qualitative data (pp.173-194). London: Routledge.

Ritter, A. (2009). How do drug policymakers access research evidence? The International Journal of Drug Policy, 20, 70-75

Rosenmöller, M., McKee, M., \& Baeten, R. (2006). Patient mobility in the European Union: Learning from experience. European Observatory on Health Systems and Policies.

Rumsfeld, D. (Speaker). (2002). The Donald Rumsfeld "Library of Quotations". Broadcasting House, BBC Radio 4.

Sabatier, P. (1988). An advocacy coalition framework of policy change and the role of policy-oriented learning therein. Policy Sciences, 21, 129-69.

Sabatier, P. (1999). Theories of the policy process. Boulder: West View Press.

Sabatier, P. A. (1998). The advocacy coalition framework: Revisions and relevance for Europe. Journal of European Public Policy, 5(1), 98130, HTTPS://DOI.ORG/ 10.1080/13501768880000051. 
Sabatier, P., \& Jenkins-Smith, H.C. (Eds.). (1993). Policy Change and Learning. An Advocacy Coalition Approach. Boulder: Westview Press

Sabatier, P., \& Weible, C. (2007). The advocacy coalition framework: Innovations and clarifications. In P. Sabatier (Ed.), Theories of the policy process (pp. 189-222). Boulder, CO: Westview Press.

Sabatier, P., \& Weible, C. (Eds.). (2014). Theories of the Policy Process (3rd edn.). Chicago: Westview Press

Sackett, D., Strauss, S., Richardson, W., Rosenberg, W., \& Haynes, R. (2000). Evidence-based medicine: How to practice and teach EBM (2nd ed.). Churchill Livingstone: Edinburgh.

Scharpf, F. W. (1997). Games real actors play. Actor-centered institutionalism in policy research. Boulder, CO: Westview.

Schuldt, J. P. (2013). Does green mean healthy? Nutrition label color affects. Health Communication, 28, 814-821, HTTPS://DOI.ORG/ $10.1080 / 10410236.2012 .725270$

Seale, C. (1999). Quality in qualitative research. Qualitative Inquiry, 5(4), 465-478.

Seale, C. (Ed.). (2004). Social research methods: A reader. London: Routledge.

Sedgley, M. (2001). Smits/peerbooms: A clarification of confusion?, Eurohealth, 7(4).

Segone, M., \& Pron, N. (2008). The role of statistics in evidence-based decision making. UNECE work session on statistical dissemination and communication. Retrieved from

http://www.unece.org/fileadmin/DAM/stats/documents/2008/05/diss emination/wp.10.e.pdf

Shroff Z., Aulakh B., Gilson L., Agyepong I. A., El-Jardali F., Ghaffar A. (2015).Incorporating research evidence into decision-making processes: Researcher and decision-maker perceptions from five low- and middle-income countries. Health Research Policy and Systems 13(70).

Silverman, D. (1998) The quality of qualitative health research: The openended interviews and its alternatives. Social Sciences in Health, 4, 104-18. 
Simon, H. (1991). Bounded rationality and organizational learning.

Organization Science, 2(1), 125-34.

HTTPS://DOI.ORG/10.1287/orsc.2.1.125.

Simon, H. A. (1983). Reason in human affairs. Stanford, CA: Stanford University Press.

Smismans, S. (2004). Law, legitimacy and European governance. Oxford: Oxford University Press.

Smith, J., \& Firth, J. (2011). Qualitative data analysis: The framework approach. Nurse Researcher, 18(2), 52-62.

HTTPS://DOI.ORG/10.7748/nr2011.01.18.2.52.c8284

Smith, K. (2013). Beyond evidence-based policy in public health: The interplay of ideas. Basingstoke: Palgrave Macmillan.

Smith, K.E., Fooks, G., Collin, J., Weishaar, H., Mandal, S., \& Gilmore, A. B. (2010). Working the system-British American tobacco's influence on the European Union treaty and its implications for policy: An analysis of internal tobacco industry documents. PLoS Med, 7(1), e1000202. https://doi.org/10.1371/journal.pmed.1000202.

Steffen, M. (2005). Health governance in Europe: Issues, challenges and theories. London, New York: Routledge.

Stenbacka, C. (2001). Qualitative research requires quality concepts of its own. Management Decision, 39(7), 551-555

Strehlenert, H., Richter-Sundberg, L., Nyström, M. E., \& Hasson, H. (2015). Evidence-informed policy formulation and implementation: a comparative case study of two national policies for improving health and social care in Sweden. Implementation science : IS, 10, 169. https://doi.org/10.1186/s13012-015-0359-1

Surel, Y. (2000). The role of cognitive and normative frames in policymaking. Journal of European Public Policy, 7(4), 495-512. HTTPS://DOI.ORG/ 10.1080/13501760050165334

Sutcliff, S., \& Court, J.. (2005). Evidence-based policymaking: What is it? How does it work? What relevance for developing countries? London: Overseas Development Institute

TABD. (1998). Transatlantic business dialogue charlotte conference: Statement of conclusions. Retrieved from http://static.tabd.com/manilaGems/1998CharlotteCEOReport.pdf. 
The Lancet Editorial. (2007). The direct-to-consumer advertising genie. Lancet, 369, 1. HTTPS://DOI.ORG/ 10.1016/S0140-6736(07)600014

The Guardian (2007, May 21). Drug firms and patient groups join in fight to overturn advertising ban. Retrived from https:// https://www.theguardian.com

Versluis, E., Keulen, M., \& Stephenson, P. (2011). Analyzing the European Union policy process (1 ed.): Hampshire: Palgrave Macmillan.

Wasserfallen, F. (2010). The judiciary as legislator? How the European Court of Justice shapes policy-making in the European Union. Journal of European Public Policy, 17(8).

Weingart. (1982). The scientific power elite - A chimera; the deinstitutionalization and politicization of science. In N. Elias, Martins, \& R. Whitley (Eds.), Scientific establishments and hierarchies. Sociology of the sciences yearbook Vol VI (pp. 71-87). Reidel: Dordrecht.

Weiss, C. (1977). Research for policy's sake: The enlightenment function of social science research. Policy Analysis, 3(4), 531-45.

Weiss, C. H. (1979). The many meanings of research utilization. Public Administration Review, 39(5), 426-431.

Weiss, C.H. (1978). Introduction. In C. H. Weiss (Ed.), Using social research in public policy making (pp. 1-22). Lexington, MA: Lexington Books.

Weiss, C.H. (1982). Policy research in the context of diffuse decision making. In R.C. Rist (Ed.), Policy Studies Review Annual Vol. 6, Beverly Hills and London: Sage.

Weiss, C.H. (1986). Research and policy-making: A limited partnership. In F. Heller (Ed.), The use and abuse of social science (pp. 214-35). Beverly Hills and London: Sage.

Weiss, C.H. (1987). When politics and evaluation meet (with a postscript). In D. Palumbo (ed.), The politics of program evaluation (pp. 45-70). Beverly Hills and London: Sage.

Weiss, C.H. (1991). Policy research: Data, ideas, or arguments. In P. Wagner, C.H. Weiss, B. Wittrock \& H. Wollman (Eds), Social 
sciences and modern states: National experiences and theoretical crossroads (pp. 307-32). Cambridge: Cambridge University Press.

Whitehead, M., Petticrew, M., Graham, H., Macintyre, S.J., Bambra, C. \&, Egan, M. (2004). Evidence for public health policy on inequalities: Assembling the evidence jigsaw. Journal of Epidemiology Community Health, 58, 817-21. HTTPS://DOI.ORG/10.1136/jech.2003.015297

Whittemore, R., Chase, S., \& Mandle, C. L. (2001). Validity in qualitative research. Qualitative Health Research, 11(4), 522-537.

World Health Organization. (2004). Global strategy on diet, physical activity and health. Retrieved from https://www.who.int/

World Health Organization (2014). The challenge of obesity. Data and Statistics.

Retrived from http:/www.euro.who.int/en/healthtopics/noncommunicable-diseases/obesity/data-and-statistics

Winslow, C. (1920). The untilled field of public health. Science.51(1306),23-33.

Wismar, M. (2001). ECJ in the driving seat on health policy, but what's the destination? Eurohealth, 7(4), 5-6.

Wismar, M., Palm, W., Figueras, J., Ernst, K., \& van Ginneken, E. (2011). Cross-border healthcare in the EU: Mapping and analysing practices and policies. European Observatory on Health Systems and Policies.

Worrall, J. (2010). Evidence: Philosophy of science meets medicine. Evaluation in Clinical Practice, 16, 356-62.

Yin, R. K. (1994). Case study research: Design and methods. Thousand Oaks: Sage

Yin, R. K. (2003). Applications of case study research (2nd ed.). Thousand Oaks: Sage.

Yin, R. K. (2009). Case study research: Design and methods (4th ed.). California: Sage. 



\section{Appendices}

\section{Appendix I: EU Public Health Policy Proposals Between 2006 and 2009}

\begin{tabular}{|c|c|c|}
\hline Year & Legislative initiatives & Non legislative initiatives \\
\hline 2006 & & $\begin{array}{l}\text { Communication from the Commission } \\
\text { on a new Community strategy on } \\
\text { health and safety at work 2007-2012 }\end{array}$ \\
\hline 2007 & & $\begin{array}{l}\text { White Paper on health strategy } \\
\text { White Paper on nutrition }\end{array}$ \\
\hline 2008 & $\begin{array}{l}\text { Directive on Food information } \\
\text { to consumers } \\
\text { Directive on Information to } \\
\text { patients } \\
\text { Directive on strengthening and } \\
\text { rationalising EU } \\
\text { Pharmacovigilance } \\
\text { Directive on falsified } \\
\text { medicines } \\
\text { Directive on the application of } \\
\text { patients' rights in cross border } \\
\text { health care }\end{array}$ & $\begin{array}{l}\text { Communication on the future of the } \\
\text { single market in pharmaceuticals for } \\
\text { human use } \\
\text { Communication and Council } \\
\text { Recommendation on Patient Safety } \\
\text { and Quality of Health Services } \\
\text { Council recommendation on health } \\
\text { care associated infections }\end{array}$ \\
\hline 2009 & & $\begin{array}{l}\text { Solidarity in health: Reducing Health } \\
\text { inequalities in the EU } \\
\text { Action against cancer: European } \\
\text { platform } \\
\text { Proposal for a Commission initiative } \\
\text { on Alzheimer }\end{array}$ \\
\hline
\end{tabular}


Council recommendation on crossborder aspects of childhood immunization

Communication on combating HIV/AIDS in the EU and the neighbourhood - strategy and second action plan (2010 - 2014)

Communication on Social protection in health and Reform of the Financing of Health Systems in Developing Countries 


\section{Appendix II: List of Interviews}

\begin{tabular}{|c|c|c|c|}
\hline \#1 & Senior Policy Officer & Public Health NGO & $07 / 09 / 2011$ \\
\hline \#2 & Secretary General & Public Health NGO & $18 / 09 / 2011$ \\
\hline$\# 3$ & Head of Unit & European Commission & $15 / 12 / 2011$ \\
\hline \#4 & Senior Policy Officer & Public Health NGO & $19 / 12 / 2011$ \\
\hline \#5 & Researcher & Research & $19 / 12 / 2011$ \\
\hline \#6 & Researcher & Research & $19 / 12 / 2011$ \\
\hline \#7 & Health Attaché & Council of the EU & $13 / 01 / 2012$ \\
\hline \#8 & Secretary General & Public Health NGO & $13 / 01 / 2012$ \\
\hline$\# 9$ & Director General & Public Health NGO & $19 / 01 / 2012$ \\
\hline$\# 10$ & Political Advisor & European Parliament & $20 / 01 / 2012$ \\
\hline \#11 & Secretary General & Public Health NGO & $20 / 01 / 2012$ \\
\hline \#12 & Head of Department & Public Health NGO & $20 / 01 / 2012$ \\
\hline$\# 13$ & Dissemination Officer & Research & $27 / 01 / 2012$ \\
\hline$\# 14$ & Political Advisor & European Parliament & $01 / 02 / 2012$ \\
\hline$\# 15$ & EU Affairs Manager & Industry & $03 / 02 / 2012$ \\
\hline$\# 16$ & Director & Public Health NGO & $08 / 02 / 2012$ \\
\hline$\# 17$ & Journalist & External Perspective & $21 / 02 / 2012$ \\
\hline \#18 & Director & Industry & $21 / 02 / 2012$ \\
\hline \#19 & $\begin{array}{l}\text { Director Global and } \\
\text { Public Affairs }\end{array}$ & Industry & $24 / 02 / 2012$ \\
\hline$\# 20$ & MEP & European Parliament & $29 / 02 / 2012$ \\
\hline \#21 & EU Coordinator & Public Health NGO & $05 / 03 / 2012$ \\
\hline$\# 22$ & Health Attaché & Council of the EU & $07 / 03 / 2012$ \\
\hline$\# 23$ & MEP & European Parliament & $07 / 03 / 2012$ \\
\hline$\# 24$ & Administrator & European Commission & $11 / 03 / 2012$ \\
\hline$\# 25$ & Director & Industry & $12 / 03 / 2012$ \\
\hline$\# 26$ & Director & Public Health NGO & $12 / 03 / 2012$ \\
\hline \#27 & Health Attaché & Council of the EU & $16 / 03 / 2012$ \\
\hline \#28 & Deputy Head of Unit & European Commission & $30 / 03 / 2012$ \\
\hline$\# 29$ & Researcher & Research & $15 / 05 / 2012$ \\
\hline \#30 & Health Attaché & Council of the EU & $15 / 05 / 2012$ \\
\hline
\end{tabular}




\section{Appendix III: Semi-Structured Interview Guide}

1. How has your organisation been involved in the decision-making process for the proposal $1 / 2 / 3$ ?

2. What have been the main sources of information of EU decision makers in the formulation of the proposal?

3. What are, in your opinion, the main factors that influenced the formulation and the adoption of the proposal?

4. Do you consider that the proposal is "evidence based"? Why?

5. What has been the role played by stakeholders in the decision-making process?

6. Have the views expressed by stakeholders taken into account in the formulation of the proposal? How?

7. What do you think of the impact assessment accompanying the proposal?

- Development of scientific evidence

- Use of scientific evidence

- Assessment of the different policy options

- Public consultation

8. Do EU decision makers (commission officials, Member States representatives, MEPs) have adequate resources (evidence and procedures (time, training, protocols)) to inform their choices?

9. Do you want to add anything that we didn't address so far, and that you consider relevant for the purpose of this study? 
Appendix IV - Participant observation: List of meetings attended

\begin{tabular}{|c|c|c|c|}
\hline \multicolumn{4}{|c|}{ Cross-border health care 11} \\
\hline Date & Meeting title & Organized by & Place \\
\hline $10 / 01 / 2007$ & $\begin{array}{l}\text { Communication de la } \\
\text { Commission } \\
\text { Européenne sur les } \\
\text { services de santé }\end{array}$ & EP - PSE & Brussels \\
\hline $14 / 02 / 2007$ & $\begin{array}{l}\text { Intergroup on Health } \\
\text { Services and Patient } \\
\text { Mobility }\end{array}$ & $\begin{array}{l}\text { European } \\
\text { Parliament }\end{array}$ & Strasbourg \\
\hline 01/03/2007 & Health services & $\begin{array}{l}\text { European } \\
\text { Parliament }\end{array}$ & Brussels \\
\hline $30 / 03 / 2007$ & $\begin{array}{l}\text { Shaping the future for } \\
\text { Community action in } \\
\text { health services }\end{array}$ & $\begin{array}{l}\text { European } \\
\text { Health } \\
\text { Management } \\
\text { Association }\end{array}$ & Brussels \\
\hline $27 / 04 / 2007$ & $\begin{array}{l}\text { An expert panel } \\
\text { discussing Commission } \\
\text { draft proposals in the } \\
\text { field of health services }\end{array}$ & DG SANCO & Brussels \\
\hline $14 / 06 / 2007$ & $\begin{array}{l}\text { Citizens' mobility - } \\
\text { Accessibility of high- } \\
\text { quality health care as a } \\
\text { condition to the free } \\
\text { movement of people } \\
\text { within the European } \\
\text { Union }\end{array}$ & $\begin{array}{c}\text { European } \\
\text { Parliament }\end{array}$ & Brussels \\
\hline $\begin{array}{l}02- \\
04 / 10 / 2007\end{array}$ & $\begin{array}{l}\text { European Health Forum } \\
\text { Gastein }\end{array}$ & $\begin{array}{l}\text { European } \\
\text { Health Forum } \\
\text { Gastein }\end{array}$ & $\begin{array}{c}\text { Bad } \\
\text { Hofgastein }\end{array}$ \\
\hline
\end{tabular}




\begin{tabular}{|l|l|l|c|}
\hline $07 / 10 / 2008$ & $\begin{array}{l}\text { Regions facing a cross } \\
\text { border health mobility }\end{array}$ & $\begin{array}{l}\text { European } \\
\text { Parliament }\end{array}$ & Brussels \\
\hline $11 / 12 / 2008$ & $\begin{array}{l}\text { Health Systems } \\
\text { Governance in Europe: } \\
\text { the Role of EU Law and } \\
\text { Policy }\end{array}$ & $\begin{array}{l}\text { European } \\
\text { Observatory on } \\
\text { Health Systems } \\
\text { and Policies }\end{array}$ & Brussels \\
\hline $17 / 02 / 2009$ & $\begin{array}{l}\text { EV Health-Check } \\
\text { Debate: «Access to } \\
\text { treatments: which rights } \\
\text { for patients?» }\end{array}$ & $\begin{array}{c}\text { European } \\
\text { Voice }\end{array}$ & Brussels \\
\hline $\begin{array}{l}\text { 24- } \\
25 / 11 / 2011\end{array}$ & $\begin{array}{l}\text { The future EU } \\
\text { framework for health } \\
\text { systems governance: } \\
\text { from coordinating cross- } \\
\text { border care to improving } \\
\text { performance }\end{array}$ & $\begin{array}{l}\text { European } \\
\text { Social }\end{array}$ & Bruservatory \\
\hline
\end{tabular}




\begin{tabular}{|c|c|c|c|}
\hline \multicolumn{4}{|c|}{ Information to patients 14} \\
\hline Date & Meeting title & Organized by & Place \\
\hline $01 / 02 / 2007$ & $\begin{array}{l}\text { Strategic meeting on } \\
\text { information to patients } \\
\text { - Recent EU } \\
\text { developments }\end{array}$ & $\begin{array}{l}\text { Health Action } \\
\text { International }\end{array}$ & Brussels \\
\hline $31 / 05 / 2007$ & $\begin{array}{l}\text { Drafting Group- EC's } \\
\text { Draft Report on } \\
\text { Provision of } \\
\text { Information to Patients }\end{array}$ & EMEA & London \\
\hline 25/06/2007 & $\begin{array}{l}\text { How to ensure high } \\
\text { quality information to } \\
\text { patients }\end{array}$ & $\begin{array}{l}\text { European Life } \\
\text { Science Circle }\end{array}$ & Brussels \\
\hline $12 / 10 / 2007$ & $\begin{array}{l}\text { HAI Europe Open } \\
\text { Seminar "Ensuring } \\
\text { Independent Medicine } \\
\text { Information in } \\
\text { Europe" }\end{array}$ & $\begin{array}{l}\text { Health Action } \\
\text { International } \\
\text { Europe }\end{array}$ & Brussels \\
\hline 06/12/2007 & $\begin{array}{l}\text { "The Informed Patient } \\
\text { - What the European } \\
\text { Union has to do" }\end{array}$ & $\begin{array}{l}\text { European Life } \\
\text { Science Circle }\end{array}$ & Brussels \\
\hline $21 / 12 / 2007$ & $\begin{array}{l}\text { Independent drug } \\
\text { information for } \\
\text { patients, whose } \\
\text { concern? }\end{array}$ & $\begin{array}{l}\text { Agence Fédérale } \\
\text { des Médicaments } \\
\text { et des Produits de } \\
\text { Santé }\end{array}$ & Brussels \\
\hline $17 / 03 / 08$ & $\begin{array}{l}\text { EC Legal Proposal on } \\
\text { Information to Patients }\end{array}$ & $\begin{array}{l}\text { European } \\
\text { Medicines } \\
\text { Agency }\end{array}$ & London \\
\hline $19 / 03 / 2009$ & $\begin{array}{l}\text { Exchange of views on } \\
\text { Information to Patients }\end{array}$ & $\begin{array}{c}\text { European } \\
\text { Federation of } \\
\text { Pharmaceutical } \\
\text { Industries }\end{array}$ & Brussels \\
\hline
\end{tabular}




\begin{tabular}{|l|l|c|c|}
\hline 29/09/2009 & The Pharma-package & $\begin{array}{c}\text { European } \\
\text { Medicines } \\
\text { Agency }\end{array}$ & London \\
\hline $05 / 10 / 2009$ & $\begin{array}{l}\text { Exchange of views on } \\
\text { Pharmaceutical } \\
\text { Package }\end{array}$ & $\begin{array}{c}\text { European } \\
\text { Federation of } \\
\text { Pharmaceutical } \\
\text { Industries \& } \\
\text { associations }\end{array}$ & Brussels \\
\hline $09 / 12 / 2009$ & $\begin{array}{l}\text { The Pharmaceutical } \\
\text { Package - Putting } \\
\text { Patients at Risk? }\end{array}$ & $\begin{array}{c}\text { Association of } \\
\text { Local Authorities } \\
\text { and Regions }\end{array}$ & Brussels \\
\hline $24 / 02 / 2010$ & $\begin{array}{l}\text { EV health check } \\
\text { debate: "Should } \\
\text { information to patients } \\
\text { be restricted?" }\end{array}$ & $\begin{array}{c}\text { European Voice } \\
\text { Debate: Better }\end{array}$ & Brussels \\
\hline $09 / 06 / 2010$ & $\begin{array}{l}\text { Information for } \\
\text { Patients - Can Europe } \\
\text { Deliver? }\end{array}$ & $\begin{array}{c}\text { European } \\
\text { Parliament }\end{array}$ & Brussels \\
\hline
\end{tabular}




\section{Appendix V - ECJ Rulings on cross-border health care}

[Adapted and partly based on Paulus (2002), Wismar, Palm et al. (2001, 2011) and Obermaier (2009)].

\begin{tabular}{|c|c|c|c|c|c|}
\hline \multicolumn{6}{|c|}{ ECJ Rulings on cross-border health care } \\
\hline Case & Parties & $\begin{array}{l}\text { Country of } \\
\text { services / country } \\
\text { of insurance }\end{array}$ & $\begin{array}{l}\text { Good or } \\
\text { service }\end{array}$ & $\begin{array}{l}\text { Main } \\
\text { issue }\end{array}$ & $\begin{array}{l}\text { ECJ } \\
\text { decision - } \\
\text { Core } \\
\text { principle }\end{array}$ \\
\hline $\begin{array}{l}\text { c- } \\
117- \\
77 \\
\text { and } \\
\text { C- } \\
182 / \\
78\end{array}$ & $\begin{array}{l}\text { Pierik I } \\
\text { Pierik II }\end{array}$ & $\begin{array}{l}\text { Germany/Netherla } \\
\text { nds }\end{array}$ & Hydrotherapy & $\begin{array}{l}\text { The Dutch } \\
\text { insurer } \\
\text { refused the } \\
\text { authorisati } \\
\text { on because } \\
\text { the } \\
\text { treatment } \\
\text { was not } \\
\text { covered }\end{array}$ & $\begin{array}{l}\text { The } \\
\text { authorisati } \\
\text { on should } \\
\text { be granted } \\
\text { as it } \\
\text { improved } \\
\text { the } \\
\text { medical } \\
\text { condition } \\
\text { of the } \\
\text { patient. } \\
\text { Authorisat } \\
\text { ions } \\
\text { procedures } \\
\text { should } \\
\text { focus on } \\
\text { the health } \\
\text { state } \\
\text { instead of } \\
\text { the } \\
\text { material } \\
\text { scope of } \\
\text { the } \\
\text { protection. }\end{array}$ \\
\hline $\begin{array}{l}\text { C- } \\
120 / \\
95\end{array}$ & Decker & $\begin{array}{l}\text { Belgium/Luxembo } \\
\text { urg }\end{array}$ & Glasses & $\begin{array}{l}\text { Asking for } \\
\text { care } \\
\text { without } \\
\text { prior } \\
\text { authorisati } \\
\text { on }\end{array}$ & $\begin{array}{l}\text { Requiring } \\
\text { prior } \\
\text { authorisati } \\
\text { on for } \\
\text { reimburse } \\
\text { ment of }\end{array}$ \\
\hline $\begin{array}{l}\text { C- } \\
158 / \\
96\end{array}$ & Kohl & $\begin{array}{l}\text { Germany/Luxembo } \\
\text { urg }\end{array}$ & $\begin{array}{l}\text { Orthodontic } \\
\text { treatment }\end{array}$ & $\begin{array}{l}\text { Using } \\
\text { health care } \\
\text { services } \\
\text { without } \\
\text { prior } \\
\text { authorisati } \\
\text { on }\end{array}$ & $\begin{array}{l}\text { ambulator } \\
\text { y } \\
\text { treatments } \\
\text { breaches } \\
\text { EU laws } \\
\text { on free } \\
\text { provision }\end{array}$ \\
\hline
\end{tabular}




\begin{tabular}{|c|c|c|c|c|c|}
\hline & & & & & $\begin{array}{l}\text { of goods } \\
\text { and } \\
\text { services }\end{array}$ \\
\hline $\begin{array}{l}\mathrm{C}- \\
160 / \\
96\end{array}$ & Molenar & France/Germany & $\begin{array}{l}\text { Long term } \\
\text { care }\end{array}$ & $\begin{array}{l}\text { France } \\
\text { country of } \\
\text { residence } \\
\text { but social } \\
\text { security } \\
\text { payments } \\
\text { in } \\
\text { Germany }\end{array}$ & $\begin{array}{l}\text { Social } \\
\text { security } \\
\text { premium } \\
\text { payments } \\
\text { can be } \\
\text { asked also } \\
\text { to people } \\
\text { living in } \\
\text { another } \\
\text { Member } \\
\text { State. } \\
\text { Some } \\
\text { entitlemen } \\
\text { ts can be } \\
\text { refused if } \\
\text { they } \\
\text { require the } \\
\text { same } \\
\text { country of } \\
\text { residence } \\
\text { and } \\
\text { insurance. }\end{array}$ \\
\hline $\begin{array}{l}\text { C- } \\
368 / \\
98\end{array}$ & Vanbraekel & France/Belgium & $\begin{array}{l}\text { Orthopaedic } \\
\text { hospital } \\
\text { treatment }\end{array}$ & $\begin{array}{l}\text { Denied } \\
\text { authorisati } \\
\text { on and } \\
\text { tariffs }\end{array}$ & $\begin{array}{l}\text { If the } \\
\text { authorisati } \\
\text { on is } \\
\text { wrongfull } \\
\text { y denied, } \\
\text { the } \\
\text { patients } \\
\text { should be } \\
\text { reimburse } \\
\text { d by an } \\
\text { equivalent } \\
\text { amount } \\
\text { would the } \\
\text { authorisati } \\
\text { on be } \\
\text { given in } \\
\text { the first } \\
\text { place. The } \\
\text { reimburse } \\
\text { ment } \\
\text { should be }\end{array}$ \\
\hline
\end{tabular}




\begin{tabular}{|c|c|c|c|c|c|}
\hline & & & & & $\begin{array}{l}\text { settled } \\
\text { according } \\
\text { to the } \\
\text { Country of } \\
\text { affiliation. }\end{array}$ \\
\hline $\begin{array}{l}\text { C- } \\
411 / \\
98\end{array}$ & Ferlini & $\begin{array}{l}\text { Luxembourg/Europ } \\
\text { ean Commission } \\
\text { arrangements for } \\
\text { civil servants }\end{array}$ & $\begin{array}{l}\text { Delivery and } \\
\text { stay in } \\
\text { maternity } \\
\text { clinic } \\
\end{array}$ & $\begin{array}{l}\text { Discrimina } \\
\text { ting billing }\end{array}$ & $\begin{array}{l}\text { Discrimin } \\
\text { ating } \\
\text { billing is } \\
\text { unjustified }\end{array}$ \\
\hline $\begin{array}{l}\mathrm{C}- \\
157 / \\
99\end{array}$ & $\begin{array}{l}\text { Geraets- } \\
\text { Smith }\end{array}$ & $\begin{array}{l}\text { Germany/Netherla } \\
\text { nds }\end{array}$ & $\begin{array}{l}\text { Impatient } \\
\text { Parkinson } \\
\text { treatment }\end{array}$ & \multirow{2}{*}{$\begin{array}{l}\text { Denied } \\
\text { reimburse } \\
\text { ment } \\
\text { because of } \\
\text { lack of } \\
\text { prior } \\
\text { authorisati } \\
\text { on }\end{array}$} & \multirow[b]{2}{*}{$\begin{array}{l}\text { Hospital } \\
\text { treatment } \\
\text { is an } \\
\text { economic } \\
\text { service } \\
\text { and } \\
\text { requiring } \\
\text { prior } \\
\text { authorisati } \\
\text { on is an } \\
\text { obstacle to } \\
\text { the } \\
\text { principle } \\
\text { of free } \\
\text { movement } \\
\text {. However, } \\
\text { for } \\
\text { hospital } \\
\text { services, } \\
\text { the prior } \\
\text { authorisati } \\
\text { on is } \\
\text { justified if } \\
\text { objective, } \\
\text { based on } \\
\text { non- } \\
\text { discrimina } \\
\text { tory } \\
\text { criteria } \\
\text { defined in } \\
\text { advance, } \\
\text { proportion } \\
\text { ate and } \\
\text { necessary } \\
\text { for the } \\
\text { planning } \\
\text { of hospital } \\
\text { services is }\end{array}$} \\
\hline $\begin{array}{l}\mathrm{C} \\
157 / \\
99\end{array}$ & Peerbooms & $\begin{array}{l}\text { Austria/Netherland } \\
\mathrm{s}\end{array}$ & Coma therapy & & \\
\hline
\end{tabular}




\begin{tabular}{|c|c|c|c|c|c|}
\hline & & & & & $\begin{array}{l}\text { in order to } \\
\text { guarantee } \\
\text { a } \\
\text { rationalize } \\
\text { d, stable, } \\
\text { balanced } \\
\text { and } \\
\text { accessible. } \\
\text { The } \\
\text { authorisati } \\
\text { on can } \\
\text { only be } \\
\text { refused if } \\
\text { the same } \\
\text { or equally } \\
\text { effective } \\
\text { treatment } \\
\text { can be } \\
\text { obtained } \\
\text { without } \\
\text { undue } \\
\text { delay from } \\
\text { an } \\
\text { establishm } \\
\text { ent with } \\
\text { which the } \\
\text { insured } \\
\text { person's } \\
\text { insurance } \\
\text { has an } \\
\text { agreement. }\end{array}$ \\
\hline $\begin{array}{l}\text { C- } \\
385 / \\
99-1\end{array}$ & Muller-Fauré & $\begin{array}{l}\text { Germany/Netherla } \\
\text { nds }\end{array}$ & $\begin{array}{l}\text { Denture/impl } \\
\text { antable }\end{array}$ & $\begin{array}{l}\text { Prior } \\
\text { authorisati } \\
\text { on }\end{array}$ & $\begin{array}{l}\text { Prior } \\
\text { authorisati } \\
\text { on } \\
\text { constitutes } \\
\text { a barrier to } \\
\text { free } \\
\text { movement } \\
\text {. The } \\
\text { principle } \\
\text { of free } \\
\text { movement } \\
\text { applies to } \\
\text { health care } \\
\text { system } \\
\text { relying on }\end{array}$ \\
\hline
\end{tabular}




\begin{tabular}{|c|c|c|c|c|c|}
\hline & & & & & $\begin{array}{l}\text { benefits in } \\
\text { kind in } \\
\text { ambulator } \\
\text { y care. }\end{array}$ \\
\hline $\begin{array}{l}\mathrm{C} \\
385- \\
99 / 1\end{array}$ & Van Riet & $\begin{array}{l}\text { Belgium/Netherlan } \\
\text { ds }\end{array}$ & $\begin{array}{l}\text { Athroscopic } \\
\text { treatment }\end{array}$ & $\begin{array}{l}\text { Waiting } \\
\text { time }\end{array}$ & $\begin{array}{l}\text { When } \\
\text { assessing } \\
\text { whether } \\
\text { waiting } \\
\text { time are } \\
\text { acceptable } \\
\text { the } \\
\text { national } \\
\text { authorities } \\
\text { should } \\
\text { take into } \\
\text { account all } \\
\text { the } \\
\text { circumstan } \\
\text { ces of } \\
\text { each } \\
\text { specific } \\
\text { case } \\
\text { including } \\
\text { the } \\
\text { degree of } \\
\text { pain, the } \\
\text { nature of } \\
\text { the } \\
\text { patient's } \\
\text { and his/her } \\
\text { medical } \\
\text { history }\end{array}$ \\
\hline $\begin{array}{l}\text { C- } \\
56 / 0 \\
1\end{array}$ & Inizan & Germany/France & $\begin{array}{l}\text { Hospital } \\
\text { Treatment }\end{array}$ & $\begin{array}{l}\text { Denied } \\
\text { reimburse } \\
\text { ment }\end{array}$ & $\begin{array}{l}\text { The prior } \\
\text { authorisati } \\
\text { on } \\
\text { condition } \\
\text { provided } \\
\text { for in } \\
\text { Article } 22 \\
\text { of } \\
\text { Regulation } \\
1408 / 71 \\
\text { are } \\
\text { consistent } \\
\text { with } \\
\text { articles } 49 \\
\text { and } 50 \mathrm{EC}\end{array}$ \\
\hline
\end{tabular}




\begin{tabular}{|c|c|c|c|c|c|}
\hline & & & & & $\begin{array}{l}\text { on the } \\
\text { freedom to } \\
\text { provide } \\
\text { services. }\end{array}$ \\
\hline $\begin{array}{l}\text { C- } \\
08 / 0 \\
2\end{array}$ & Leichtle & & Spa treatment & $\begin{array}{l}\text { Reimburse } \\
\text { ment }\end{array}$ & $\begin{array}{l}\text { Condition } \\
\text { for the } \\
\text { reimburse } \\
\text { ment } \\
\text { (report } \\
\text { drawn by } \\
\text { a medical } \\
\text { officer) } \\
\text { are } \\
\text { contrary to } \\
\text { the } \\
\text { freedom to } \\
\text { provide } \\
\text { services. } \\
\text { Articles } 49 \\
\text { and } 50 \text { of } \\
\text { the Treaty } \\
\text { apply also } \\
\text { to health } \\
\text { cure costs. }\end{array}$ \\
\hline $\begin{array}{l}\mathrm{C}- \\
145 / \\
03\end{array}$ & Keller & $\begin{array}{l}\text { Zwitzerland/Germa } \\
\text { ny/Spain }\end{array}$ & & $\begin{array}{l}\text { Referral to } \\
\text { another } \\
\text { country } \\
\text { without } \\
\text { authorisati } \\
\text { on. } \\
\text { Reimburse } \\
\text { ment. }\end{array}$ & $\begin{array}{l}\text { Spain is } \\
\text { required to } \\
\text { cover the } \\
\text { costs of } \\
\text { the } \\
\text { treatment. } \\
\text { Medical } \\
\text { examinati } \\
\text { on of the } \\
\text { need of } \\
\text { the referral } \\
\text { to a third } \\
\text { country } \\
\text { was not } \\
\text { needed. }\end{array}$ \\
\hline
\end{tabular}




\begin{tabular}{|c|c|c|c|c|c|}
\hline $\begin{array}{l}\mathrm{C}- \\
372 / \\
04\end{array}$ & Watts & France/UK & $\begin{array}{l}\text { Hip } \\
\text { replacement }\end{array}$ & $\begin{array}{l}\text { Waiting } \\
\text { time and } \\
\text { denied } \\
\text { reimburse } \\
\text { ment }\end{array}$ & $\begin{array}{l}\text { The } \\
\text { obligation } \\
\text { to } \\
\text { reimburse } \\
\text { the costs } \\
\text { of hospital } \\
\text { treatment } \\
\text { received in } \\
\text { another } \\
\text { Member } \\
\text { Stateapply } \\
\text { also to } \\
\text { countries } \\
\text { where the } \\
\text { same } \\
\text { service is } \\
\text { provided } \\
\text { free of } \\
\text { charge. } \\
\text { The } \\
\text { reimburse } \\
\text { ment can } \\
\text { be denied } \\
\text { only if the } \\
\text { treatment } \\
\text { would } \\
\text { have been } \\
\text { available } \\
\text { in the } \\
\text { home } \\
\text { country } \\
\text { within a } \\
\text { medically } \\
\text { acceptable } \\
\text { period } \\
\text { taking into } \\
\text { account } \\
\text { the } \\
\text { patients' } \\
\text { health } \\
\text { state and } \\
\text { clinical } \\
\text { needs. } \\
\text { Extend the } \\
\text { free } \\
\text { movement } \\
\text { of services }\end{array}$ \\
\hline
\end{tabular}




\begin{tabular}{|c|c|c|c|c|c|}
\hline & & & & & $\begin{array}{l}\text { to national } \\
\text { health } \\
\text { systems. }\end{array}$ \\
\hline $\begin{array}{l}\text { C- } \\
466 / \\
04\end{array}$ & $\begin{array}{l}\text { Acereda } \\
\text { Herrera }\end{array}$ & France/Spain & & $\begin{array}{l}\text { Reimburse } \\
\text { ment of } \\
\text { travel and } \\
\text { accommod } \\
\text { ation costs } \\
\text { denied }\end{array}$ & $\begin{array}{l}\text { The } \\
\text { reimburse } \\
\text { ment } \\
\text { depends } \\
\text { on the way } \\
\text { in which } \\
\text { the costs } \\
\text { are } \\
\text { covered in } \\
\text { the } \\
\text { Country of } \\
\text { insurance. } \\
\text { The right } \\
\text { to be } \\
\text { reimburse } \\
\text { d for } \\
\text { travel and } \\
\text { accommod } \\
\text { ation is } \\
\text { not } \\
\text { conferred } \\
\text { with the } \\
\text { authorisati } \\
\text { on through } \\
\text { a E112 } \\
\text { form. }\end{array}$ \\
\hline $\begin{array}{l}\text { C- } \\
444 / \\
05\end{array}$ & Stamatelaki & Uk/Greece & $\begin{array}{l}\text { Cancer } \\
\text { treatment }\end{array}$ & $\begin{array}{l}\text { Reimburse } \\
\text { ment of } \\
\text { treatment } \\
\text { in private } \\
\text { hospitals } \\
\text { abroad }\end{array}$ & $\begin{array}{l}\text { Reimburse } \\
\text { ment of } \\
\text { treatment } \\
\text { in a } \\
\text { private } \\
\text { hospital } \\
\text { abroad } \\
\text { cannot be } \\
\text { refused. }\end{array}$ \\
\hline
\end{tabular}




\begin{tabular}{|c|c|c|c|c|c|}
\hline & & & & & $\begin{array}{l}\text { No } \\
\text { differentia } \\
\text { tion } \\
\text { between } \\
\text { public and } \\
\text { private } \\
\text { hospitals. }\end{array}$ \\
\hline $\begin{array}{l}\text { C - } \\
211 / \\
08\end{array}$ & $\begin{array}{l}\text { Commission/ } \\
\text { Spain }\end{array}$ & France/Spain & $\begin{array}{l}\text { Hospital } \\
\text { services }\end{array}$ & $\begin{array}{l}\text { Denied } \\
\text { reimburse } \\
\text { ment }\end{array}$ & $\begin{array}{l}\text { The Court } \\
\text { makes a } \\
\text { clear } \\
\text { distinction } \\
\text { between } \\
\text { scheduled } \\
\text { and } \\
\text { unschedul } \\
\text { ed } \\
\text { treatment. }\end{array}$ \\
\hline $\begin{array}{l}\mathrm{C}- \\
512 / \\
08\end{array}$ & $\begin{array}{l}\text { Commission/ } \\
\text { France }\end{array}$ & & & $\begin{array}{l}\text { Reimburse } \\
\text { ment } \\
\text { procedures } \\
\text { of } \\
\text { treatment } \\
\text { outside } \\
\text { hospital } \\
\text { setting } \\
\text { requiring } \\
\text { use of } \\
\text { major } \\
\text { medical } \\
\text { equipment }\end{array}$ & $\begin{array}{l}\text { Member } \\
\text { States may } \\
\text { maintain } \\
\text { prior } \\
\text { authorizati } \\
\text { on for } \\
\text { treatment } \\
\text { outside } \\
\text { hospital } \\
\text { setting } \\
\text { requiring } \\
\text { use of } \\
\text { major } \\
\text { medical } \\
\text { equipment }\end{array}$ \\
\hline
\end{tabular}


Appendix VI: Types of Evidence and references listed in the Assessment Report Accompanying the Proposal on Cross Border Health Care - Detailed List

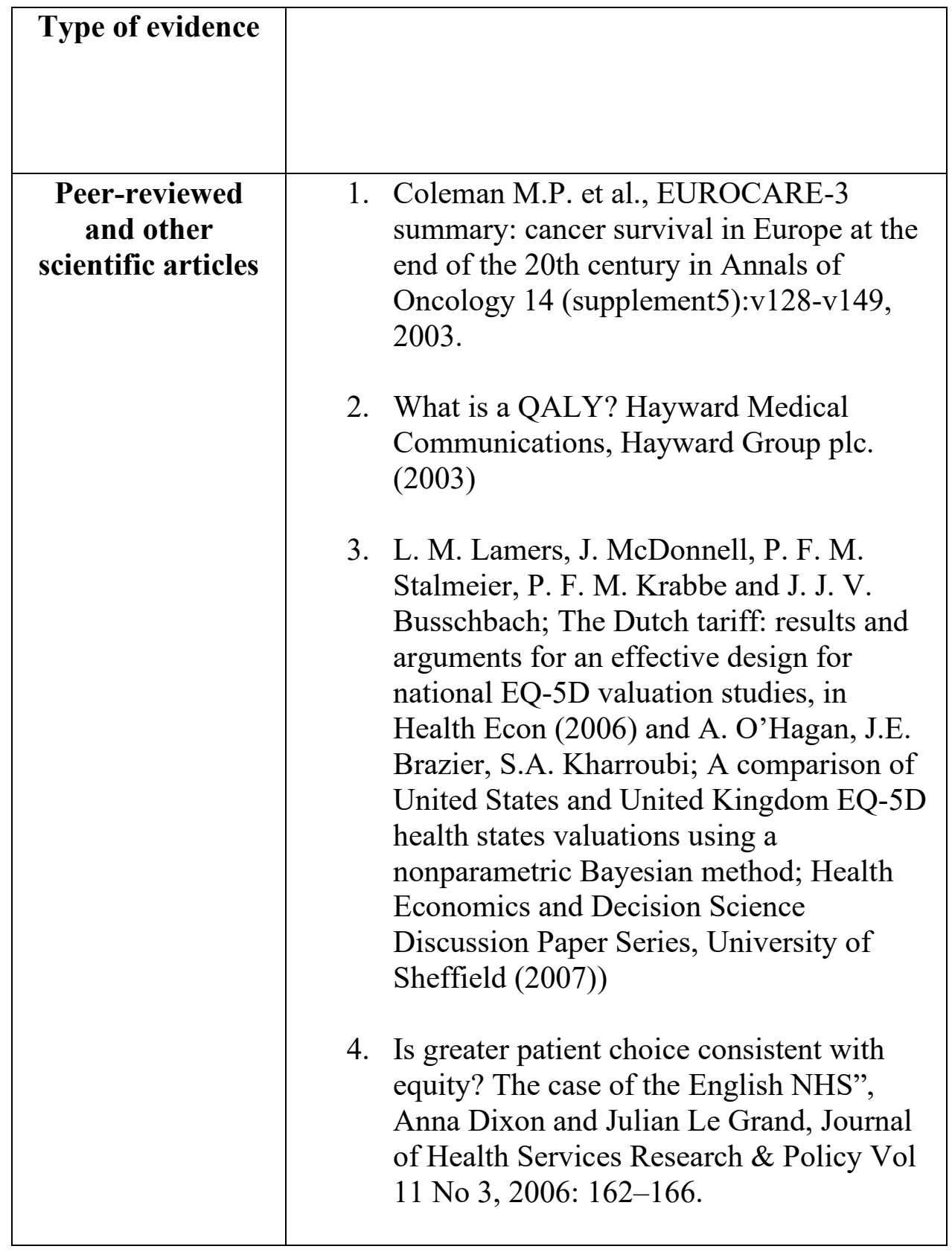




\begin{tabular}{|c|c|}
\hline & $\begin{array}{l}\text { 5. Dawson D, Jacobs R, Martin S, Smith P. Is } \\
\text { patient choice an effective mechanism to } \\
\text { reduce waiting times? Appl Health Econ } \\
\text { Health Policy, 2004;3: 195-203; cited by } \\
\text { Dixon and Le Grand, ibid }\end{array}$ \\
\hline $\begin{array}{l}\text { EU funded } \\
\text { projects }\end{array}$ & $\begin{array}{l}\text { 6. EUREGIO projects } \\
\text { 7. Europe for Patients project ( } x \text { 4) } \\
\text { a. Including Cross-border care in the } \\
\text { south: Slovenia, Austria and Italy } \\
\text { in Rosenmöller, M., McKee, M. } \\
\text { Baeten, R., Patient Mobility in the } \\
\text { European Union, Learning from } \\
\text { experience, World Health } \\
\text { Organisation (2006). This study is } \\
\text { part of the project, an EC FP6 } \\
\text { funded research project } \\
\text { HealthBASKET - Health Benefits and } \\
\text { Service Costs in Europe - is a project } \\
\text { funded by the European Commission } \\
\text { within the Sixth Framework Research } \\
\text { Programme. }\end{array}$ \\
\hline $\begin{array}{l}\text { European Court } \\
\text { of Justice Rulings }\end{array}$ & $\begin{array}{l}\text { 9. Case C-158/96 Kohll [1998] ECR I-1931 } \\
\text { 10. Case C-120/95 Decker [1998] ECR I- } \\
\text { 1831. } \\
\text { 11. Case C-368/98 Vanbraekel [2001] ECR I- } \\
\text { 5363; } \\
\text { 12. Case C-157/99 Smits and Peerbooms } \\
\text { [2001] ECR I-5473; } \\
\text { 13. Case C-56/01 Inizan [2003] ECR I-12403; } \\
\text { 14. Case C-8/02 Leichtle [2004] ECR I-2641; } \\
\text { 15. Case C-385/99 Müller-Fauré and Van Riet } \\
\text { [2003] ECR I-4503. }\end{array}$ \\
\hline $\begin{array}{l}\text { Eurostat, } \\
\text { Eurobarometer } \\
\text { surveys and other } \\
\text { polls }\end{array}$ & $\begin{array}{l}\text { 16. Flash Eurobarometer Series \#210, Cross- } \\
\text { border health services in the EU, } \\
\text { Analytical report, conducted by The } \\
\text { Gallup Organization, Hungary upon the }\end{array}$ \\
\hline
\end{tabular}




\begin{tabular}{|c|c|}
\hline & $\begin{array}{l}\text { request of the European Commission, the } \\
\text { Health and Consumer Protection } \\
\text { Directorate-General (DG SANCO), } 2007 . \\
\text { 17. EU economic data pocketbook 1-2007, } \\
\text { Eurostat (2007) } \\
\text { 18. Europe in figures - Eurostat yearbook } \\
\text { 2006-07, Eurostat (2007) } \\
\text { 19. European Statistics on Income and Living } \\
\text { Conditions (EU-SILC) survey }\end{array}$ \\
\hline $\begin{array}{l}\text { European } \\
\text { Commission } \\
\text { commissioned } \\
\text { studies and } \\
\text { analysis }\end{array}$ & $\begin{array}{l}\text { 20. Wismar M, Palm W, Figueras J, Ernst K } \\
\text { and Van Ginneken E, Cross-Border } \\
\text { Healthcare: Mapping and Analysing } \\
\text { Health Systems Diversity, European } \\
\text { Observatory on Health Systems and } \\
\text { Policies, } 2007 \text {. } \\
\text { 21. The impact of ageing on public } \\
\text { expenditure: projections for the EU25 } \\
\text { Member States on pensions, health care, } \\
\text { long-term care, education and } \\
\text { unemployment transfers (2004-2050), } \\
\text { European Economy Special Report } 1 / 2006 \text {, } \\
\text { produced by DG ECFIN }\end{array}$ \\
\hline $\begin{array}{l}\text { National } \\
\text { government } \\
\text { studies (including } \\
\text { regulatory } \\
\text { agencies) }\end{array}$ & $\begin{array}{l}\text { 22. Grunwald CA, Smit R. } \\
\text { Grensoverschrijdende zorg - Zorg op Maat } \\
\text { in de Euregio Maas-Rijn; evaluatie van een } \\
\text { experiment. Utrecht, NZI (research } \\
\text { institute), } 1999 .\end{array}$ \\
\hline $\begin{array}{c}\text { Stakeholders } \\
\text { surveys and } \\
\text { studies }\end{array}$ & $\begin{array}{l}\text { 23. Health Consumer Powerhouse survey on } \\
\text { cross-border health care (2006) }\end{array}$ \\
\hline $\begin{array}{c}\text { Public } \\
\text { consultations }\end{array}$ & $\begin{array}{l}\text { 24. Commission document, Summary report of } \\
\text { the responses to the consultation regarding } \\
\text { "Community action on health services" } \\
\text { (2007) }\end{array}$ \\
\hline
\end{tabular}




\begin{tabular}{|c|c|}
\hline $\begin{array}{c}\text { Internal } \\
\text { consultations with } \\
\text { other commission } \\
\text { services, Member } \\
\text { States and } \\
\text { stakeholders via } \\
\text { advisory groups } \\
\text { and ad hoc } \\
\text { working groups } \\
\text { and consultations }\end{array}$ & $\begin{array}{l}\text { 25. Interservice consultation } \\
\text { 26. High Level Reflection Process } \\
\text { 27. the Open Forum } \\
\text { 28. the High-Level Group on Health Services } \\
\text { and Medical care }\end{array}$ \\
\hline $\begin{array}{l}\text { Document from } \\
\text { other institutions } \\
\text { (e.g. WHO, } \\
\text { Council of the EU } \\
\text { and European } \\
\text { Parliament }\end{array}$ & $\begin{array}{l}\text { 29. Towards High-Performing Health } \\
\text { Systems", the final report of the OECD } \\
\text { Health Project, OECD 2004, ISBN 92-64- } \\
\text { 01555-8. } \\
\text { 30. "The contribution of health to the economy } \\
\text { in the European Union", OPOCE 2005, } \\
\text { ISBN 92-894-9829-3. } \\
\text { 31. 2733rd Employment, Social Policy, Health } \\
\text { and Consumer Affairs Council meeting, } \\
\text { Luxembourg, 1-2 June } 2006 \text {. } \\
\text { 32. European Parliament Report on a } \\
\text { community action on the provision of } \\
\text { cross-border healthcare (the 'Bowis- } \\
\text { report'): A6-0129/2005 final } \\
\text { 33. Resolution on Community action on the } \\
\text { provision of cross-border healthcare } \\
\text { (2007): B6-0098/2007 } \\
\text { 34. Report on the impact and consequences of } \\
\text { the exclusion of health services from the } \\
\text { Directive on services in the internal market } \\
\text { (the 'Vergnaud-report) (2007): A6- } \\
\text { 0173/2007 final }\end{array}$ \\
\hline
\end{tabular}




\begin{tabular}{|c|c|}
\hline Other & $\begin{array}{l}\text { 35. Techniker Krankenkasse (TK), Medizin in } \\
\text { Europa: Ergebnisse der TK-Mitglieder- } \\
\text { Befragung 2003 (2003) }\end{array}$ \\
\hline Total & $\mathbf{3 5}$ \\
\hline
\end{tabular}


Appendix VII: Types of Evidence and references listed in the Assessment Report Accompanying the Proposal on Information to patients - Detailed List

\begin{tabular}{|c|c|}
\hline Type of evidence & Number of references \\
\hline $\begin{array}{l}\text { Peer reviewed } \\
\text { and other } \\
\text { scientific articles }\end{array}$ & $\begin{array}{l}\text { 1. Bagwell, Kyle (2005) "The economic } \\
\text { analysis of advertising" } \\
\text { 2. Bowskill R, Clatworthy J, Parham R, Rank } \\
\text { T, Horne R (2007) "Patients' perceptions of } \\
\text { information received about medication } \\
\text { prescribed for bipolar disorder: } \\
\text { implications for informad choice", J Affect } \\
\text { Disord 100, pp 253-257 } \\
\text { 3. Cockburn J., Pit S. "Prescribing behaviour } \\
\text { in clinical practice: patients' expectations } \\
\text { and doctors' perceptions of patients' } \\
\text { expectations-a questionnaire study", BMJ } \\
\text { 1997;315:520-523 } \\
\text { 4. Donal P O'Mathuna, Adam McAuley, P } \\
\text { Anne Scott, "Informing Irish Patients: } \\
\text { Implications for direct-toconsumer } \\
\text { advertising of prescription medications", } \\
\text { Patients' Rights Research Team, School of } \\
\text { Nursing and School of Law \& } \\
\text { Government, Dublin City University, } \\
\text { Ireland } \\
\text { 5. Eysenbach G, Köhler, Christian (2004) } \\
\text { "Health-related searches on the Internet", } \\
\text { JAMA, 291, p 2946 } \\
\text { 6ysenbach, Gunther and Köhler, Christian } \\
\text { (2002) "How do consumers search for and } \\
\text { appraise health information on the world } \\
\text { wide web? Qualitative study using focus } \\
\text { groups, usability tests, and in-depth } \\
\text { interviews", BMJ, 2002;324; pp573-577 } \\
\text { 7. Gellad ZF, Lyles KW: Direct-to-consumer } \\
\text { advertising of pharmaceuticals. Am J Med } \\
\text { 2007; 120:475-480 }\end{array}$ \\
\hline
\end{tabular}




\begin{tabular}{|l|l|}
\hline 8. Goossens H, Ferech M, Vander Stichele R, \\
et al. Outpatient antibiotic use in Europe \\
and association with resistance: a cross- \\
national database study. Lancet. 2005; \\
365:579-587. \\
9. Haahtela T (1999) "Early treatment of \\
asthma", Allergy 54 Suppl 49, pp 74-81 \\
10. Harms F. "Innovative drugs, Direct to \\
consumer and Patient Empowerment", \\
http://www.mig.tuberlin.de/files/2005.teach \\
ing.ss/mbwl3 2005.06.23_ex.pdf \\
11. Hesse BW, Nelson DE, Kreps GL, Croyle \\
RT, Arora NK, Rimer BK, Viswanath K \\
(2005) "Trust and sources of health \\
information: the impact of the internet and \\
its implications for health care providers: \\
findings from the first Health Information \\
National Trends Survey", Arch intern Med \\
165(22), pp 2618-2624 \\
12. Hu G, Lakka TA, Lakka HM, Tuomilehto J \\
(2006) "Lifestyle management in the \\
metabolic syndrome", Metab Syndr Relat \\
Disord 4(4), pp 270-286 \\
13. Koo M, Krass I and Asani P, (2005) \\
"Patient characteristics influencing \\
evaluation of medicine information: lessons \\
for patient education" Annals of \\
Pharmacotherapy 39, 1434-1440 \\
14. Koo MM, Krass I, Aslani P (2003) "Factors \\
influencing consumer use of written drug \\
information", Ann Pharmacother 37(2), pp \\
259-267 \\
15. Lindström J, Ilanne-Parikka P, Peltonen M \\
et al. (2006) "Sustained reduction in the \\
incidence of type 2 diabetes by lifestyle \\
prevention: follow-up of the Finnish \\
Diabetes Prevention Study", Lancet \\
11;368(9548), pp 1673-1679
\end{tabular}




\begin{tabular}{|l|l|}
\hline 16. Macias W, Pashupati K, Lewis LS (2007) \\
"A wonderful life or diarrhea and dry \\
mouth? Policy issues of direct-to-consumer \\
drug advertising on television", Health \\
Commun 22, pp 241-252 \\
17. Mintzes et al (2002) "Influence of direct- \\
to-consumer pharmaceutical advertising \\
and patients' requests on prescribing \\
decisions: two site cross sectional survey", \\
BMJ Vol 324 (February) p2 \\
18. Moxey, A., O'Connell, D., McGettigan, P. \\
and Henry, D. (2003) "Describing \\
treatment effects to patients: how they are \\
expressed makes a difference", Journal of \\
General Internal Medicine, Vol 18, No 11 \\
(November), pp 948-959(12), Blackwell \\
Publishing \\
19. Närhi U, Airaksinen M, Enlund H (2001) \\
"Do asthma patients receive sufficient \\
information to monitor their disease- a \\
nationwide survey in Finland", Pharm \\
World Sci 23(6), pp 242-245 \\
20. Palzer, Carmen and Scheuer, Alexander \\
(2004) "Self-regulation, co-regulation, \\
public regulation" \\
21. Raynor, D.K., et al (2007) "A systematic \\
review of quantitative and qualitative \\
research on the role and effectiveness of \\
written information available to patients \\
about individual medicines," Health \\
Technology Assessment 2007, Vol 11, No \\
5 \\
22. Scott, Tim, Stanford, Neil and Thompson, \\
David (2004) "Killing me softly: myth in \\
pharmaceutical advertising", BMJ 329, \\
pp1484-1487 \\
23. Shaw, J. M., Mynors, G. and Kelham, C. \\
(2005) "Information for patients on \\
medicines", BMJ 331, pp1034-5
\end{tabular}




\begin{tabular}{|c|c|}
\hline & $\begin{array}{l}\text { 24. Vander Stichel RV, "Measurement of } \\
\text { patient compliance and the interpretation of } \\
\text { randomized clinical trials, Eur J Clin } \\
\text { Pharmacol. 1991;41(1):27-35. } \\
\text { 25. Ziad F, Gellad, MPH, and Kenneth W. } \\
\text { Lyles (June 2007) "Direct-to-consumer } \\
\text { advertising of pharmaceuticals", The } \\
\text { American Journal of Medicine, Vol 120, } \\
\text { Issue 6, pp 475-480 } \\
\text { 26. Ziad F., Gellad, MPH, and Kenneth W. } \\
\text { Lyles (June 2007) "Direct-to-consumer } \\
\text { advertising of pharmaceuticals", The } \\
\text { American Journal of Medicine, Vol 120, } \\
\text { Issue 6, pp 475-480 }\end{array}$ \\
\hline $\begin{array}{l}\text { EU funded } \\
\text { projects }\end{array}$ & $\begin{array}{l}\text { 27. The European Surveillance of } \\
\text { Antimicrobial Consumption (ESAC) } \\
\text { project, granted by the DG SANCO, } \\
\text { established for the first time a } \\
\text { comprehensive database of internationally } \\
\text { comparable data on antibacterial } \\
\text { consumption in Europe in out- and in- } \\
\text { patients }\end{array}$ \\
\hline $\begin{array}{l}\text { European Court } \\
\text { of Justice } \\
\text { Judgments } \\
\end{array}$ & $\begin{array}{l}\text { 28. ECJ ruling in case C-143/06 Juers-Pharma } \\
\text { 29. ECJ ruling in case C-374/05 Gintec }\end{array}$ \\
\hline $\begin{array}{l}\text { Eurostat, } \\
\text { Eurobarometer } \\
\text { surveys and } \\
\text { other polls }\end{array}$ & \\
\hline $\begin{array}{l}\text { European } \\
\text { Commission } \\
\text { commissioned } \\
\text { studies and } \\
\text { analysis } \\
\end{array}$ & $\begin{array}{l}\text { 30. Europe Economics independent impact } \\
\text { assessment study }\end{array}$ \\
\hline $\begin{array}{l}\text { National } \\
\text { government } \\
\text { studies (including }\end{array}$ & $\begin{array}{l}\text { 31. Närhi, U (2006) "Drug information for } \\
\text { consumers and patients - a review of } \\
\text { research", National Agency for Medicines, } \\
\text { Finland }\end{array}$ \\
\hline
\end{tabular}




\begin{tabular}{|l|l|}
\hline $\begin{array}{l}\text { regulatory } \\
\text { agencies) }\end{array}$ & $\begin{array}{l}\text { 32. Ministry of Consumer Affairs (July 2005) } \\
\text { "Industry-led regulation discussion paper" }\end{array}$ \\
33. National Institute for Healthcare \\
Management (September 2000) \\
"Prescription drugs and mass media \\
advertising" \\
34. National Audit Office (2007) "Prescribing \\
costs in primary care",HM Stationery \\
Office
\end{tabular}




\begin{tabular}{|l|c|}
\hline $\begin{array}{l}\text { States and } \\
\text { stakeholders via } \\
\text { advisory groups } \\
\text { and ad hoc } \\
\text { working groups } \\
\text { and consultation }\end{array}$ & $\begin{array}{l}\text { 41. EHPF EU Health Policy Forum (May } \\
\text { 2005) "Recommendations on health } \\
\text { information" }\end{array}$ \\
\hline $\begin{array}{l}\text { Document from } \\
\text { other institutions } \\
\text { (e.g. WHO, }\end{array}$ & $\begin{array}{l}\text { 42. Interservice consultation } \\
\text { Council of the } \\
\text { EU) and other } \\
\text { articles in non- } \\
\text { scientific }\end{array}$ \\
journals & $\begin{array}{l}\text { 2003) "A framework for economic analysis } \\
\text { of direct-to-consumer information about } \\
\text { prescription medicines", Europe }\end{array}$ \\
\multicolumn{1}{|c|}{ Economics staff working paper } \\
\multicolumn{1}{|c|}{ Total } & $\begin{array}{l}\text { 44. Bartle, Ian, and Vass, Peter (2005) "Self- } \\
\text { regulation and the regulatory state - a } \\
\text { survey of policy and practice", research } \\
\text { report 17, CRI Centre for study of } \\
\text { regulated industries }\end{array}$ \\
\hline \multicolumn{2}{|c|}{} \\
\hline
\end{tabular}




\section{Appendix VIII: Additional literature on DTCA and Provision of Information to Patients}

- 't Jong G.W., Strichker B.H.C., Sturkenboom M.C.J.M. (2004). Marketing in the lay media and prescriptions of terbinafine in primary care: Dutch cohort study. British Medical Journal 328:931.

- Abel G.A., Lee, S.J., Weeks, J.C. (2007). Direct-to-consumer advertising in oncology: A content analysis of print media. Journal of Clinical Oncology, 25: 1267-12 71.

- Abel G.A., Neufeld E.J., Sorel M., Weeks, J.C. (2008). Direct-toconsumer advertising for bleeding disorders: a content analysis and expert evaluation of advertising claims. Journal of Thrombosis and Haemostasis, 6: 1680-1684.

- Almasi, E.A., Stafford, R.S., Kravitz, R.L., Mansfield, P.R. (2006).What are the public health effects of direct-to-consumer drug advertising? PLoS Med 3(3): e145.

- Antonuccio D.O., Danton W.G., McClanahan T.M. (2003). Building a firewall between marketing and science. American Psychologist 58(12): 1028-1043.

- Basara L.R. (1996). The impact of a direct-to-consumer prescription medication advertising campaign on new prescription volume. Drug Information Journal 30:715-29.

- Bavelaar J. (2007). Direct-to-public information on prescription-only medicines (in Dutch). PhD thesis in Health Science, June 2007. Amsterdam: VU University Amsterdam.

- Boessen, S. (2008). The politics of European Union policymaking. An actor-centred institutionalist analysis. Maastricht: University Press Maastricht.

- Brown, H. (2007). Advertising prescription drugs. Sweetening the pill. British Medical Journal, 334(7594), 664-666.

- Conrad, P., Leiter, V. (2008). From Lydia Pinkham to queen Levitra: direct-to-consumer advertising and medicalisation. Sociology of Health and Illness 30(6): 825-838.

- Cooper R.J., Schriger, D.L., Wallace, R.C., Mikulich, V.J., Wilkes, M.S. (2003). The quantity and quality of scientific graphs in pharmaceutical advertisements. Journal of Gen Intern Med 2003, 18: 294-297. 
- Donohue, J.M., Cevasco, M., Rosenthal, M.B. (2007). A decade of Direct-to-consumer advertising of prescription drugs. New England Journal of Medicine, 357: 673-681/

- Frosch D.L., Krueger P.M., Hornik R.C., Cronholm P.F., Barg F.K. (2007). Creating demand for prescription drugs: a content analysis of television direct-to-consumer advertising. Annals of Family Medicine 5(1): 6-13.

- Gilbody S., Wilson P., Watt I. (2005). Benefits and harms of direct to consumer advertising: a systematic review. Qual Saf Health Care 14:246-50.

- Greving, J.P., Denig, P., Zeeuw, de D., Haaijer-Ruskamp. F.M. (2007). Claims in advertisements for antihypertensive drugs in a Dutch medical journal. Journal of Hypertension, 25: 713-725.

- Jeffries, M. (2000). The Mark of Zorro. Pharmaceutical Marketing, May 2000, 4-5.

- Kravitz R.L., Epstein R.M., Feldman M.D., Franz C.E., Azari R., Wilkes M.S., Hinton L., Franks P. (2005). Influence of patients' requests for direct-to-consumer advertised antidepressants: a randomized controlled trial. JAMA 293(16): 1995-2002.

- Lipsky MS, Taylor CA. The opinions and experiences of family physicians regarding direct-to-consumer advertising. J Fam Pract 1997; 45:495-499

- Medawar, C., \& Hardon, H. (2004). Medicines out of control? Antidepressants and the Conspiracy of Goodwill. Amsterdam: Aksant Academic Publishers.

- Mintzes B., Barer M., Lexchin J., Bassett K.L. Introduction of directto-consumer advertising of prescription drugs in Canada: an opinion survey on regulatory policy. (2005). Res Social Adm Pharm 1(2):31030 .

- Mintzes B., Barer M.L., Kravitz R.L., Bassett K., Lexchin J., Kazanjian A., Evans R.G., Pan R., Marion S.A. (2003). How does direct-to-consumer advertising (DTCA) affect prescribing? A survey in primary care environments with and without legal DTCA. CMAJ 169:405-12.

- Mitka M. (2003). Survey suggesting that prescription drugs is helping public is met with skepticism. JAMA 289(7):828-828. 
- Montgomery B.D., Mansfield P.R., Spurling G.K., Ward A.M. (2008). Do advertisements for antihypertensive drugs in Australia promote quality prescribing? A cross sectional study. BMC Public Health 8: 167.

- Moynihan R., Doran E., Henry D. (2008) Disease mongering is now part of the global health debate. PLoS Med 5(5): e106.

- Moynihan R., Heath I., Henry D. (2002) Selling sickness: the pharmaceutical industry and disease mongering. British Medical Journal 324:886-91.

- Murray E., Lo B., Pollack L., Donelan K., Lee K. (2003). Direct-toconsumer advertising: Physicians' view of its effects on quality of care and the doctor-patient relationship. Journal of the American Board of Family Practice 16(6): 513-524.

- Murray E., Lo B., Pollack L., Donelan K., Lee K. (2004). Direct-toconsumer advertising: public perceptions of its effects on health behaviors, health care, and doctor-patient relationship. Journal of the American Board of Family Practice 17(1):6-18.

- Pastore M. Healthcare and Web advertising: a prescription for success? Darien, Conn.: INT Media Group, Ad Resource, 2001.

- Payer L. (1988). Medicine and Culture. New York: Owl Books.

- Reast J., Palihawadana D., Shabbir H. (2008). The ethical aspects of direct to consumer advertising of prescription drugs in the United Kingdom: Physician versus consumer views. Journal of Advertising Research, Sept 2008: 450-464.

- Robinson A.R., Hohmann K.B., Rifkin J.I., Topp D., Gilroy C.M., Pickard J.A., Anderson R.J. (2004). Direct to consumer pharmaceutical advertising: physician and public opinion and potential effects on the physician-patient relationship. Arch Intern Med 164(4):427-32.

- Rosenthal et. al (2002) Promotion of Prescription Drugs to Consumers N Engl J Med 2002; 346:498-505 HTTPS://DOI.ORG/ 10.1056/NEJMsa012075

- Shapiro, M.F. (1997). Regulating pharmaceutical advertising: What will work? Canadian Medical Association Journal 156(3): 359-361.

- Toop L., Richards D. (2002). DTCA in New Zealand: the challenge of finding an acceptable balance. The British Journal of General Practice, April 2002: 341. 
- Toop L., Richards D., Dowell T., Tilyard M., Fraser T., Arroll B. For health or for profit? Report to the Minister of Health, New Zealand, 2003.

- Velo G., Moretti, U. (2008). Direct-to-consumer information in Europe: the blurred margin between promotion and information. British Journal of Clinical Pharmacology 66(5): 626-628.

- Weissman J., Blumenthal D., Silk A.J., Zapert K., Newman M., Letman R. (2003). Consumers reports on the health effects of directto-consumer-advertising. Health Affairs, W3: 82-95.

- Wilkes MS, Bell RA, Kravitz RL. Direct-to-consumer prescription drug advertising: trends, impact, and implications. Health Aff (Millwood) 2000; 19:110-128

- Zachry W.M., Ginsburg, D.B. (2001). Patient autonomy and the regulation of direct-to-consumer advertising. Clinical Therapeutics, 23 (12), pp.2024-2037.

- Zachry W.M., Shepherd M.D., Hinich M.J., Wilson J.P., Brown C.M., Lawson K.A. (2002). Relationship between direct-to-consumer advertising and physician diagnosing and prescribing. Am J Health Syst Pharm; 59:42-9. 
Appendix IX: Types of Evidence and references listed in the Assessment Report Accompanying the Proposal on Food information to consumers - Detailed List

\begin{tabular}{|c|c|c|}
\hline $\begin{array}{l}\text { Types of } \\
\text { evidence }\end{array}$ & Food labelling & Nutritional issues \\
\hline $\begin{array}{l}\text { Peer reviewed } \\
\text { scientific articles }\end{array}$ & $\begin{array}{l}\text { 1. Drichoutis, A.; } \\
\text { Lazaridis, P. and } \\
\text { Nagaya, R .M. (2006), } \\
\text { "Consumers' use of } \\
\text { nutritional labels: a } \\
\text { review of research } \\
\text { studies and issues", } \\
\text { Academy of Marketing } \\
\text { Science Review 2006 } \\
\text { (9). } \\
\text { 2. Golan, E. Kuchler, F } \\
\text { and Mitchell, L (2001), } \\
\text { "Economics of Food } \\
\text { Labelling", Journal of } \\
\text { Consumer Policy 24, p. } \\
\text { 117-184. } \\
\text { 3. Boden, M.; Dadswell, } \\
\text { R. and Hattersley, S. } \\
\text { (2005), "Review of } \\
\text { statutory and voluntary } \\
\text { labelling of food } \\
\text { allergens' in: } \\
\text { Proceedings of the } \\
\text { Nutrition Society, Vol. } \\
\text { 64, 475-480. and } \\
\text { Gowland, M.H. (2001), } \\
\text { "Food Allergen } \\
\text { Avoidance - the } \\
\text { patient's viewpoint", in: } \\
\text { Allergy, vol.56, } \\
\text { suppl.67, pp.117-120 } \\
\text { 4. Boden, M.; Dadswell, } \\
\text { R. and Hattersley, S. }\end{array}$ & $\begin{array}{l}\text { 1. Drichoutis, A, } \\
\text { Lazaridis, P, and Nagaya. } \\
\text { R, M. (2005) "Consumers' } \\
\text { use of nutritional labels: a } \\
\text { review of research studies } \\
\text { and issues", Academy of } \\
\text { Marketing Science } \\
\text { Review } 2006 \text { (9). } \\
\text { 2. Cowburn, G. and } \\
\text { Stockley, L., "Consumer } \\
\text { understanding and use of } \\
\text { nutrition labelling: A } \\
\text { systematic review," Public } \\
\text { Health Nutrition } 8(1) \text {, } \\
\text { (2004): } 26 . \\
\text { 3. Mathios, A. D. (2000) } \\
\text { The impact of Mandatory } \\
\text { Disclosure Law on } \\
\text { product choices: as } \\
\text { analysis of } \\
\text { the salad dressing market. } \\
\text { Journal of Law and } \\
\text { Economics 43:2. } \\
\text { 4. Mojduszka, E. M., } \\
\text { Caswell J. A. (2000) “A } \\
\text { Test of Nutritional Quality } \\
\text { Signaling In Ford Markets } \\
\text { Prior to Implementation of } \\
\text { Mandatowy Labelling" } \\
\text { American Journal of } \\
\text { Agricultural Economics } \\
\text { 82.2 p. 298-309. }\end{array}$ \\
\hline
\end{tabular}




\begin{tabular}{|l|l|l|}
\hline & (2005), 'Review of & 5. Golan, E. Kuchler, F \\
statutory and voluntary & and Mitchell, L (2001), \\
labelling of & "Economics of Food \\
food allergens, in: & Labelling", Journal of \\
Proceedings of the & Consumer Policy 24, p. \\
Nutrition Society, Vol. & 117-184. 24 \\
64, 475-480. & 6. Grunert, K and Wills, J \\
5. Krissoff, B.; Kuchler, & (2007) A review of \\
F.; Nelson K., Perry, J. & European research on \\
and Somwaru, A. & consumer response to \\
(2004), Country-of- & nutrition \\
Origin & information on food \\
Labelling: Theory and & labels, Journal of Public \\
Observation. Electronic & Health (in press) \\
Outlook Report of the & 7.A. Cumbers, R. Leigh \\
Economic Research & and D. Smallbone, "The \\
Service, & Single European market \\
WRS -04-02, United & and the new regulatory \\
States Department of & regime in the food sector: \\
Agriculture, & The impact on small and \\
Washington, D.C. and & medium-sized \\
the official proposal & manufacturing firms", \\
and impact assessment & British \\
and Federal Register / & Food Journal, 97(4) \\
Vol. 68, No. 210 / & (1995): 13-19. 40 8. \\
Thursday, October 30, & Christine Moorman, D. \\
2003 / & Rex and Carl F. Mela, \\
Proposed Rules. & "The effect of \\
6. VanSickle, J; R. & standardized information \\
McEowen; C.R. Taylor; & on firm \\
N. Harl and J.Connor & survival and marketing \\
(2003), Country of & strategies": (2005) 263-74. \\
Origin & 41 Moorman, C. (1998) \\
Labelling: A Legal and & Market-level effects of \\
Economic Analysis. & information: Competitive \\
Policy Brief Series & responses and consumer \\
PBTC03-5, & dynamics, Journal of \\
International & Marketing Research 35:1. \\
\hline
\end{tabular}




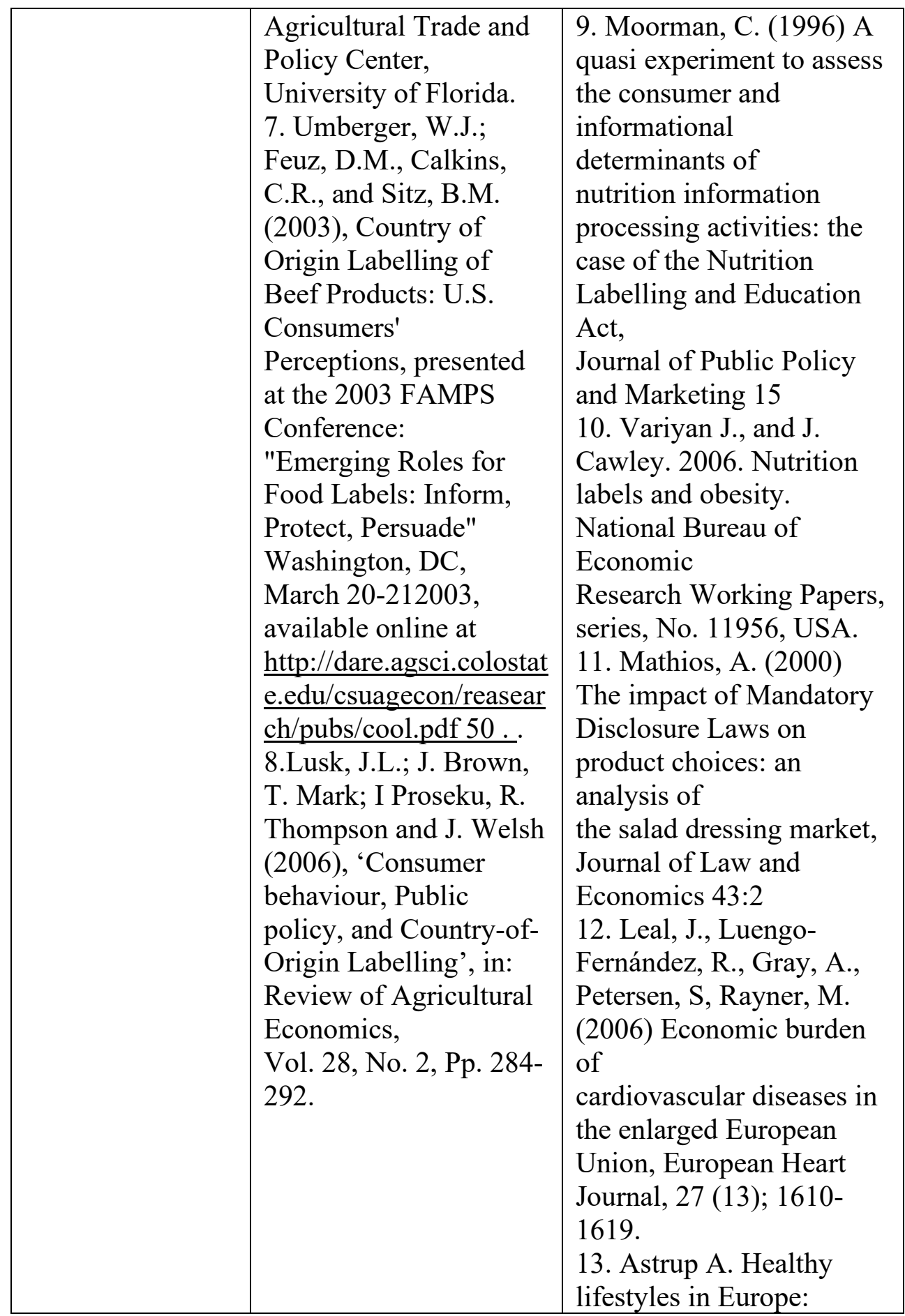




\begin{tabular}{|c|c|c|}
\hline & & $\begin{array}{l}\text { prevention of obesity and } \\
\text { type II diabetes by diet } \\
\text { and } \\
\text { physical activity. Public } \\
\text { Health Nutrition, 2001; } 4 \\
\text { (2B): } 499-515 \text {. } \\
\text { 14. Muth et al. (2003), } \\
\text { FDA Labelling Cost } \\
\text { Model. }\end{array}$ \\
\hline $\begin{array}{l}\text { Eurostat, } \\
\text { Eurobarometer } \\
\text { surveys and non- } \\
\text { commissioned } \\
\text { polls }\end{array}$ & $\begin{array}{l}\text { 1.AC Nielsen survey in } \\
2005 \text { compares } \\
\text { how consumers in } \\
\text { different countries have } \\
\text { different priorities in } \\
\text { how they use food } \\
\text { labelling } \\
\text { 2. Eurostat (2004), The } \\
\text { food industry in Europe, } \\
\text { Statistics in focus } \\
\text { 39/2004. } \\
\text { 3. Eurostat (2006) } \\
\text { 4. Eurostat database }\end{array}$ & $\begin{array}{l}\text { 1.**Eurostat (2004), The } \\
\text { food industry in Europe, } \\
\text { Statistics in focus } \\
39 / 2004 \text {. }\end{array}$ \\
\hline $\begin{array}{l}\text { European } \\
\text { Commission } \\
\text { commissioned } \\
\text { studies and } \\
\text { analysis }\end{array}$ & $\begin{array}{l}\text { 1.A qualitative study on } \\
\text { labelling was carried } \\
\text { out by an external } \\
\text { contractor } \\
\text { (OPTEM) in } 2005 \text { in } \\
\text { order to assess } \\
\text { consumers' attitudes } \\
\text { with respect to labels } \\
\text { and their information } \\
\text { content, and to analyse } \\
\text { consumers' } \\
\text { expectations. OPTEM } \\
\text { (2005), The European } \\
\text { consumers' attitudes }\end{array}$ & $\begin{array}{l}\text { 1. **European Advisory } \\
\text { Services (EAS). The } \\
\text { Introduction of Mandatory } \\
\text { Nutrition Labelling in the } \\
\text { European Union, Impact } \\
\text { Assessment Undertaken } \\
\text { for DG SANCO, } \\
\text { European Commission } \\
\text { (Service } \\
\text { contract nr } \\
\text { SANCO/2004/D4/EAS/SI } \\
2.378734 \text { ). } 30 \text { November } \\
2004\end{array}$ \\
\hline
\end{tabular}




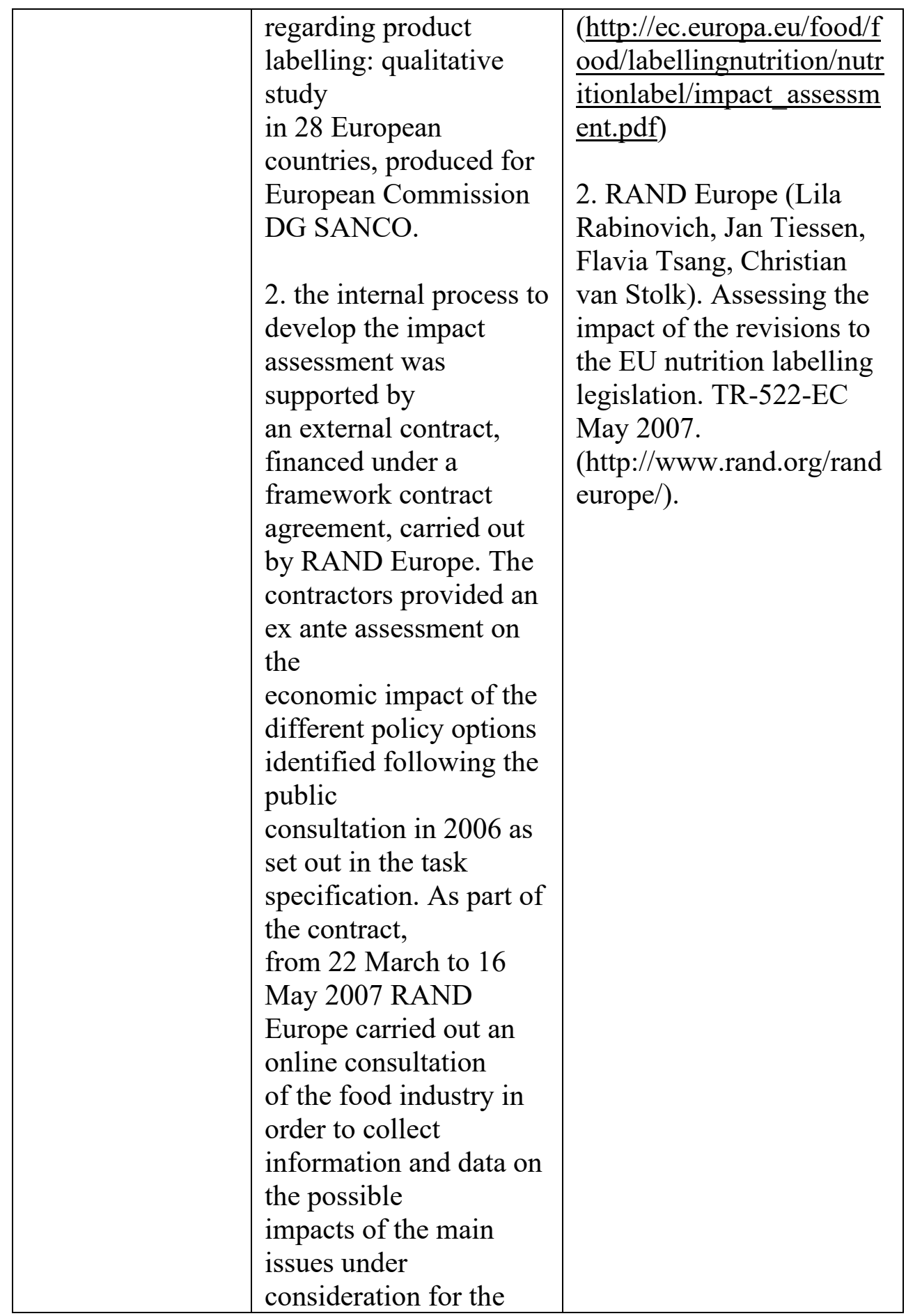




\begin{tabular}{|c|c|c|}
\hline & $\begin{array}{l}\text { revision of the } \\
\text { legislation. } \\
\text { More than two hundred } \\
\text { responses to the } \\
\text { questionnaire were } \\
\text { submitted. } \\
\text { 3. The European } \\
\text { Evaluation Consortium } \\
\text { (2003) Evaluation of the } \\
\text { food labelling } \\
\text { legislation, final } \\
\text { report, DG SANCO, } \\
\text { Belgium. } \\
\text { 4. European Advisory } \\
\text { Services (EAS). The } \\
\text { Introduction of } \\
\text { Mandatory Nutrition } \\
\text { Labelling in the } \\
\text { European Union, } \\
\text { Impact Assessment } \\
\text { Undertaken for DG } \\
\text { SANCO, European } \\
\text { Commission }\end{array}$ & \\
\hline $\begin{array}{l}\text { National } \\
\text { government } \\
\text { studies ( } \\
\text { including } \\
\text { regulatory } \\
\text { agencies) }\end{array}$ & $\begin{array}{l}\text { 1. Food Standards } \\
\text { Agency (2006), } \\
\text { Consumer research on } \\
\text { marketing terms used in } \\
\text { food labelling, } \\
\text { 2. Schuttelaar \& } \\
\text { Partners (2005) Desk } \\
\text { research report on } \\
\text { labelling prepared for } \\
\text { the Ministry of } \\
\text { Health, Welfare and } \\
\text { Sport, The Hague, The } \\
\text { Netherlands } \\
\text { 3. The Nordic Council } \\
\text { of Ministers (2007), }\end{array}$ & $\begin{array}{l}\text { 1. Food Standards Agency } \\
\text { (2007) Food Labelling } \\
\text { Consumer Research What } \\
\text { Consumers Want A } \\
\text { Literature Review. } \\
\text { 2. Schuttelaar \& Partners } \\
\text { (2005) Desk research } \\
\text { report on labelling } \\
\text { prepared for the Ministry } \\
\text { of } \\
\text { Health, Welfare and Sport, } \\
\text { The Hague, The } \\
\text { Netherlands. } \\
\text { 3. Schuttelaar \& Partners } \\
\text { (2005) Desk research }\end{array}$ \\
\hline
\end{tabular}




\begin{tabular}{|l|l|l|}
\hline Food Labelling. Nordic & report on labelling \\
Consumer' Attitudes to & prepared for the Ministry \\
Food & of \\
Labelling, TemaNord, & Health, Welfare and Sport, \\
2007:513. 13 & The Hague, The \\
4. The Nordic Council & Netherlands. \\
of Ministers (2007), & 4.** FSA (2006), "Food \\
Food Labelling. Nordic & Standards Agency: \\
Consumer' Proposals & Administrative Burdens \\
for & Measurement Exercise: \\
Improvements, & Final \\
TemaNord, 2001:573. & Report", June 2006. \\
5. Mori (2000), & 5.** Leatherhead Food \\
Importance and Impact & International (2006) \\
of Country of Origin of & Evaluating the impact on \\
Food, Research study & business of changes to \\
conducted for & nutrition \\
the Ministry of & labelling requirements in \\
Agriculture, Fisheries & the UK, prepared for the \\
and Food, United & Food Standards Agency, \\
Kingdom. & London, UK. \\
6. Donovan Research & 6. Ofcom (Office of \\
(2001), Food Labelling & Communication) (2007) \\
Issues - Consumer & Impact Assessment Food \\
Qualitative Research, & Advertising to Children. \\
Study & 7. CCFRA Technology \\
prepared for the & Limited (2005) An \\
Australia New Zealand & assessment of the Uptake \\
Food Authority & of the Food Standards \\
7. Food Standards & Agency \\
Agency (2007), Food & Guidance on Clear Food \\
labelling Consumer & Labelling. \\
Research: What & 8. **Campden \& \\
Consumers Want. A & Chorleywood Food \\
Literature Review. Food & Research Association \\
Standards Agency U.K., & Group (2005) An \\
London. & Assessment of the Uptake \\
8. FSA (2006), "Food & of Food Standards Agency \\
Standards Agency: & Guidance on Clear Food \\
\hline
\end{tabular}




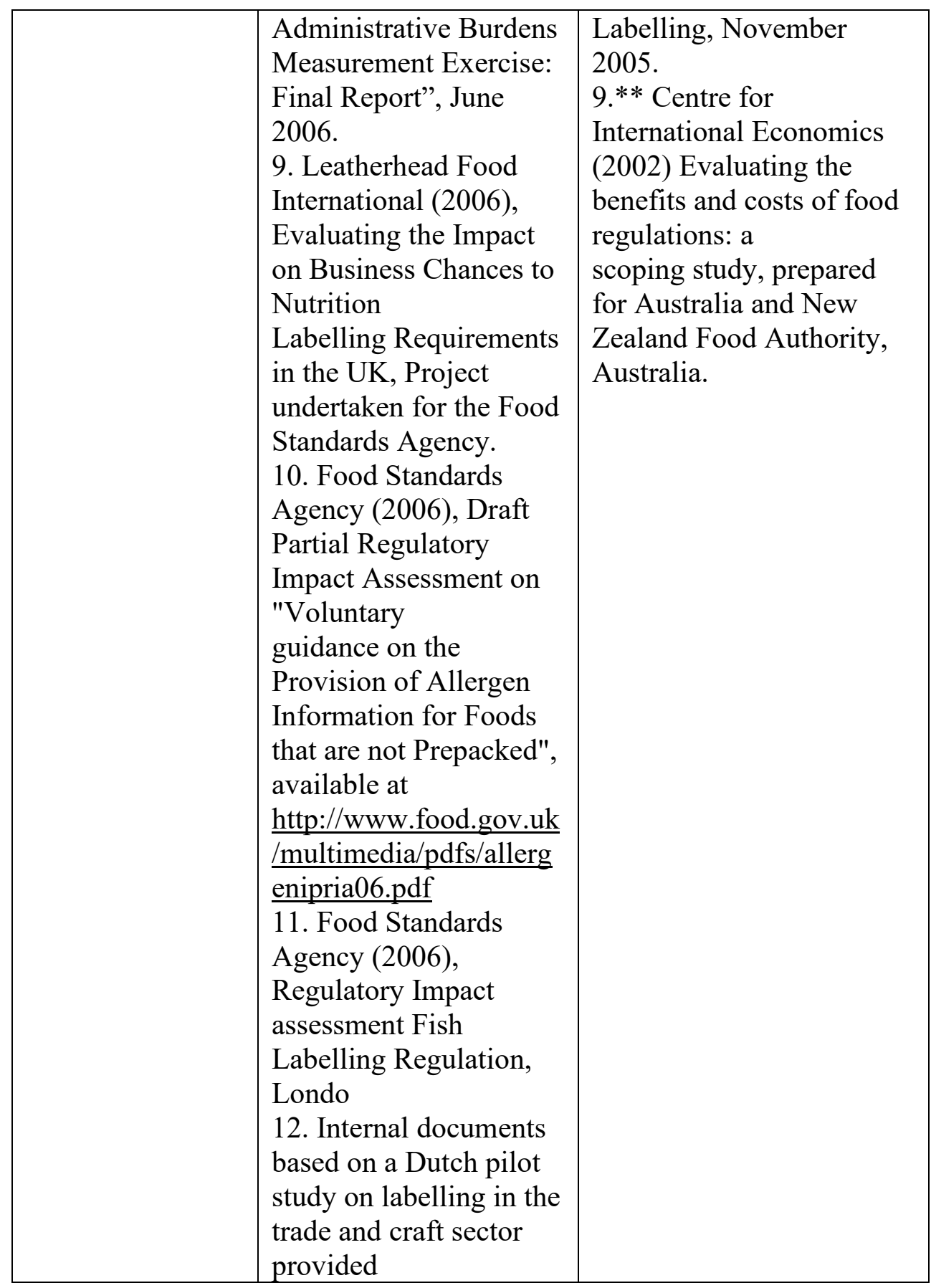




\begin{tabular}{|c|c|}
\hline . & $\begin{array}{l}\text { to RAND by the Dutch } \\
\text { Ministry of Health, } \\
\text { Welfare and Sport. } \\
\text { 13. Food Standards } \\
\text { Agency (2006), Draft } \\
\text { Partial Regulatory } \\
\text { Impact Assessment on } \\
\text { "Voluntary } \\
\text { Guidance on the } \\
\text { Provision of Allergen } \\
\text { Information for Foods } \\
\text { that are not Prepacked", } \\
\text { available at } \\
\text { http://www.food.gov.uk } \\
\text { multimedia/pdfs/allerg } \\
\text { enipria06.pdf } 39 \\
\text { 14. Food Standards } \\
\text { Agency (2006), Draft } \\
\text { Partial Regulatory } \\
\text { Impact Assessment on } \\
\text { "Voluntary } \\
\text { Guidance on the } \\
\text { Provision of Allergen } \\
\text { Information for Foods } \\
\text { that are not Prepacked", } \\
\text { available at } \\
\text { http://www.food.gov.uk } \\
\text { /multimedia/pdfs/allerg } \\
\text { enipria06.pdf } \\
\text { 15. CIE (2006) } \\
\text { Feasibility of extending } \\
\text { COOL. A benefit cost } \\
\text { analysis, prepared for } \\
\text { Food Standards } \\
\text { Australia and New } \\
\text { Zealand, Australia. } 16 . \\
\text { NZIER (2005) COOL } \\
\text { revisited. Benefit cost } \\
\text { analysis of country }\end{array}$ \\
\hline
\end{tabular}




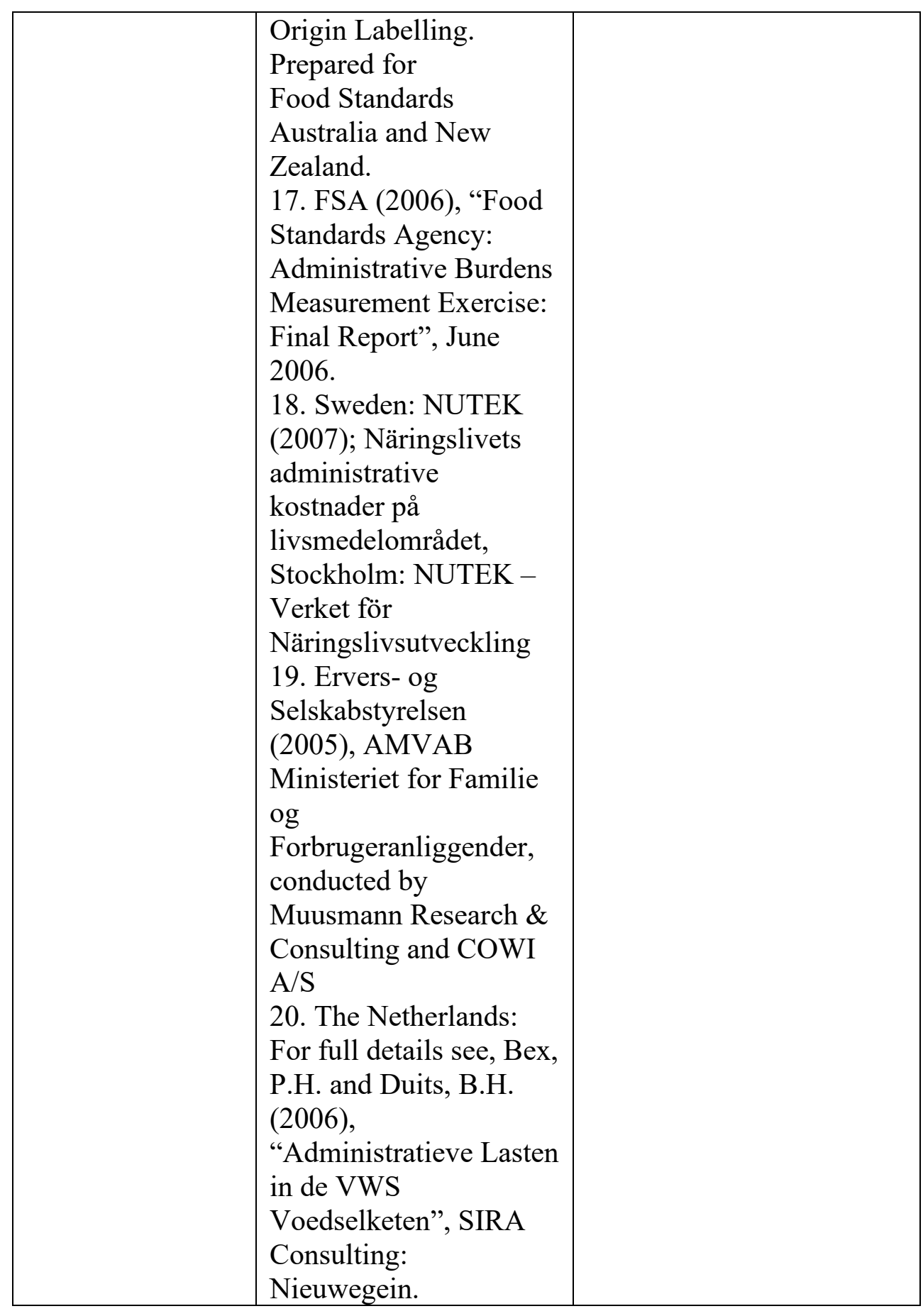




\begin{tabular}{|c|c|c|}
\hline & $\begin{array}{l}\text { Interdepartmentale } \\
\text { Projectdirectie } \\
\text { Administratieve Lasten } \\
(2003) \text { "Meten is } \\
\text { Weten: Handleiding } \\
\text { voor het Definieren en } \\
\text { Meten van } \\
\text { Administratieve Lasten } \\
\text { voor ket Bedrijfsleven", } \\
\text { Den Haag, December }\end{array}$ & \\
\hline $\begin{array}{l}\text { Stakeholders } \\
\text { surveys and } \\
\text { studies }\end{array}$ & $\begin{array}{l}\text { 1. CIAA (2006) } \\
\text { Structure of the } \\
\text { European food and } \\
\text { drink industry }\end{array}$ & $\begin{array}{l}\text { 1.European Consumers' } \\
\text { Organisation (BEUC) } \\
\text { (2005) Report on the } \\
\text { Consumers' Perception of } \\
\text { Foodstuffs Labelling. } \\
\text { Results of Consumer } \\
\text { Research conducted on } \\
\text { behalf of BEUC from } \\
\text { February } \\
\text { to April 2005 } \\
\text { (BEUC/X?032/2005 } \\
\text { August 2005). } \\
\text { 2. European Heart } \\
\text { Network (2003) A } \\
\text { systematic review of the } \\
\text { Research on Consumer } \\
\text { understanding } \\
\text { of nutrition labelling. } \\
\text { 3. Confederation of Food } \\
\text { and Drink Industries of the } \\
\text { EU (2006) Data and trends } \\
\text { of the European } \\
\text { Food and Drink Industry, } \\
\text { CIAA, Belgium }\end{array}$ \\
\hline $\begin{array}{l}\text { Public } \\
\text { consultations }\end{array}$ & $\begin{array}{l}\text { 1. DG SANCO } \\
\text { launched a public } \\
\text { consultation process on } \\
\text { labelling in March } \\
2006 \text {, }\end{array}$ & $\begin{array}{l}\text { 1.** Labelling: } \\
\text { competitiveness, } \\
\text { consumer information and } \\
\text { better regulation for the } \\
\text { EU. A DG SANCO }\end{array}$ \\
\hline
\end{tabular}




\begin{tabular}{|c|c|c|}
\hline & $\begin{array}{l}\text { by means of a } \\
\text { consultative document } \\
\text { dealing with different } \\
\text { areas of labelling,and } \\
\text { among others, } \\
\text { identifying on the basis } \\
\text { of the above evaluation } \\
\text { the major } \\
\text { questions that have to } \\
\text { be considered in the } \\
\text { review of the food } \\
\text { labelling } \\
\text { legislation." }\end{array}$ & $\begin{array}{l}\text { consultative document. } \\
\text { http://ec.europa.eu/food/fo } \\
\text { od/labellingnutrition/better } \\
\text { regulation/competitiveness } \\
\text { consumer_info.p } \\
\text { df). }\end{array}$ \\
\hline $\begin{array}{l}\text { Internal } \\
\text { consultations } \\
\text { with other } \\
\text { commission } \\
\text { services, } \\
\text { Member States } \\
\text { and stakeholders } \\
\text { via advisory } \\
\text { groups and ad } \\
\text { hoc working } \\
\text { groups and } \\
\text { consultations }\end{array}$ & $\begin{array}{l}\text { 1.In } 2003 \text { DG SANCO } \\
\text { in close co-operation } \\
\text { with the representatives } \\
\text { of the } \\
\text { Member States, of } \\
\text { consumers, of industry } \\
\text { and of trade, launched } \\
\text { an evaluation of } \\
\text { the legislation on food } \\
\text { labelling. The aim of } \\
\text { this review was to } \\
\text { enable the } \\
\text { Commission to reassess } \\
\text { the effectiveness of its } \\
\text { labelling policy and its } \\
\text { legal } \\
\text { basis, and to identify the } \\
\text { needs and expectations } \\
\text { of today's consumers for } \\
\text { information on food } \\
\text { labels, taking into } \\
\text { account the technical } \\
\text { and logistical }\end{array}$ & $\begin{array}{l}\text { The Commission has } \\
\text { conducted specific } \\
\text { consultations of } \\
\text { stakeholders on the } \\
\text { revision of the legislation } \\
\text { in } 2003 \text { and } 2006 \text { along } \\
\text { with input from various } \\
\text { discussions within } \\
\text { Commission Committees } \\
\text { and Advisory Groups. } \\
1 . \text { The Commission wrote } \\
\text { to the Member States on } \\
21 \text { January } 2003 \text { seeking } \\
\text { their } \\
\text { views and experience on } \\
\text { the implementation of } \\
\text { Directive } 90 / 496 / \text { EEC on } \\
\text { Nutrition Labelling of } \\
\text { Foodstuffs } 2 \\
\text {. Fifty responses were } \\
\text { received from } 14 \\
\text { governmental } \\
\text { organisations, } 2 \text { consumer } \\
\text { groups, } 4 \text { public health } \\
\text { NGOs and } 30\end{array}$ \\
\hline
\end{tabular}




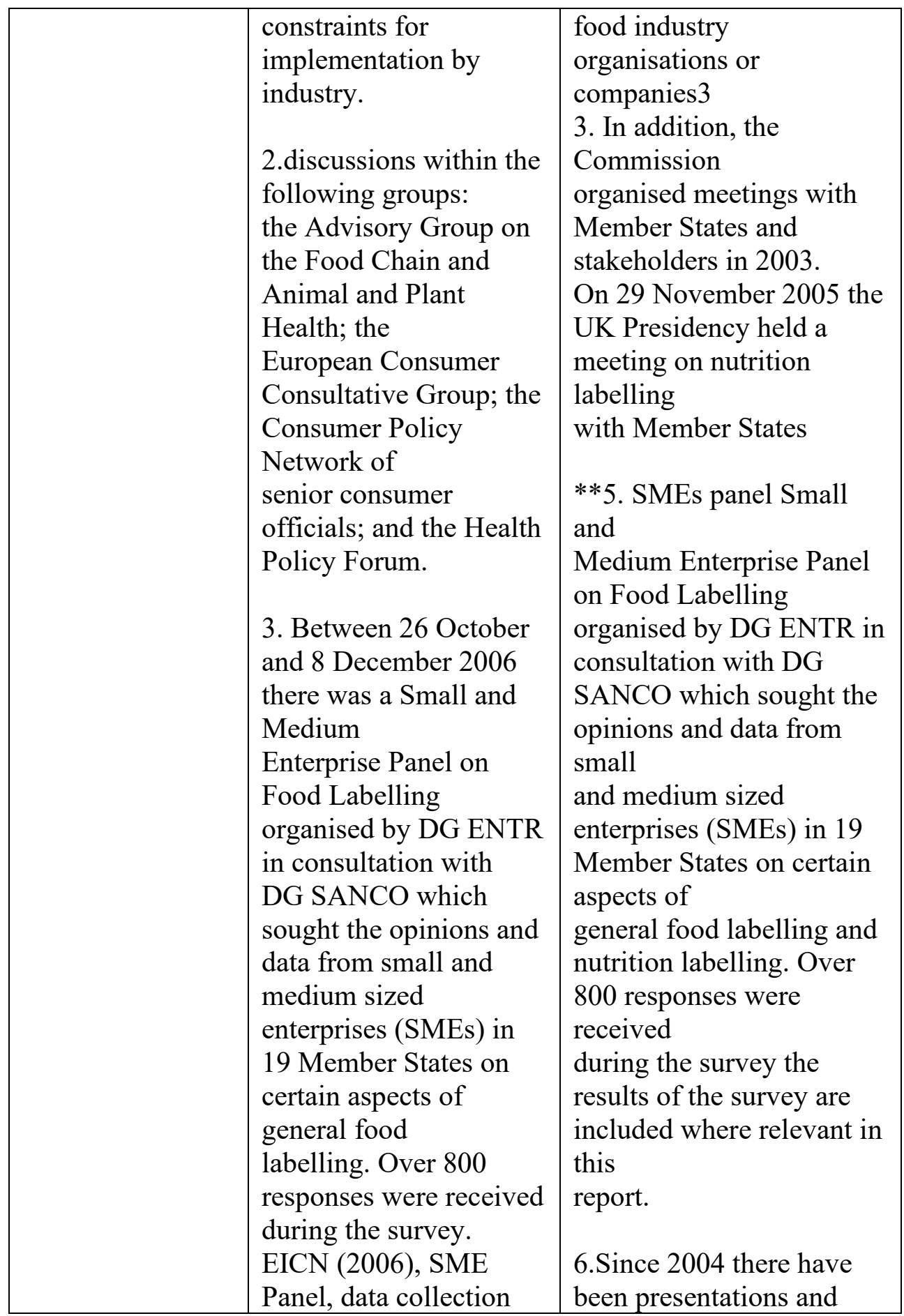




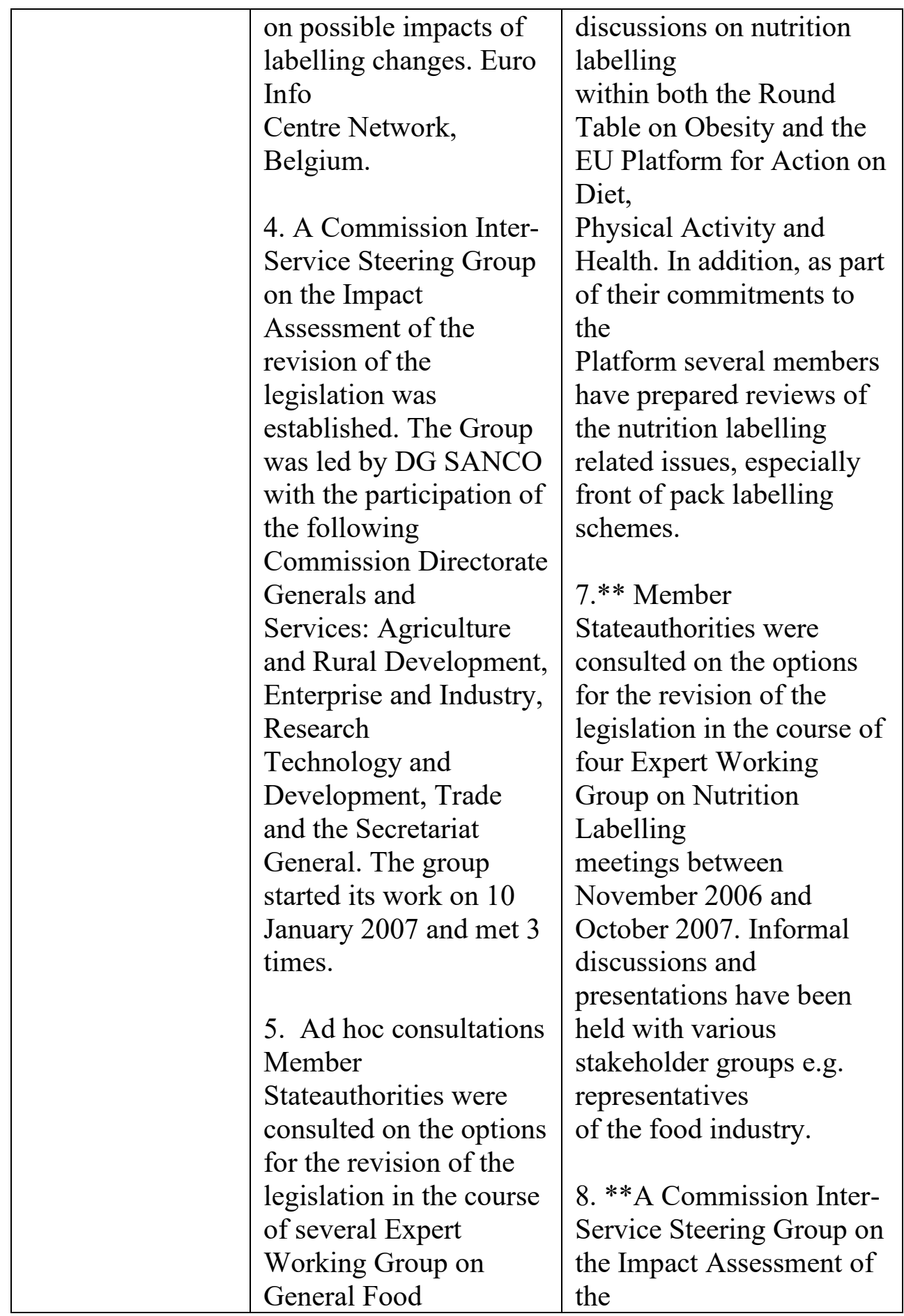




\begin{tabular}{|c|c|c|}
\hline & $\begin{array}{l}\text { Labelling meetings in } \\
2006-2007 . \text { Informal } \\
\text { discussions and } \\
\text { presentations have } \\
\text { been held with various } \\
\text { stakeholders' groups } \\
\text { e.g. representatives of } \\
\text { the food industry. }\end{array}$ & $\begin{array}{l}\text { revision of the legislation } \\
\text { was established. The } \\
\text { Group was led by DG } \\
\text { SANCO } \\
\text { with the participation of } \\
\text { the following Commission } \\
\text { Directorate Generals and } \\
\text { Services: Agriculture and } \\
\text { Rural Development, } \\
\text { Enterprise and Industry, } \\
\text { Research } \\
\text { and Technology } \\
\text { Development, Trade and } \\
\text { the Secretariat General. } \\
\text { The group met } \\
\text { on } 10 \text { January } 2007 \\
\text { (planned approach and the } \\
\text { identified options were } \\
\text { discussed), } 27 \text { March } 2007 \\
\text { (report from the contractor } \\
\text { on progress and collection } \\
\text { of data were discussed) } \\
\text { and } 18 \text { June } 2007 \\
\text { (exchange of views on } \\
\text { draft impact } \\
\text { assessment report). The } \\
\text { Group was consulted on } \\
\text { the development of the } \\
\text { online } \\
\text { questionnaire conducted } \\
\text { by the contractor and } \\
\text { relevant documentation } \\
\text { was } \\
\text { circulated between } \\
\text { meetings. }\end{array}$ \\
\hline Others & $\begin{array}{l}\text { 1. Council of the } \\
\text { European Union } \\
\text { (2007), Council } \\
\text { conclusions on }\end{array}$ & $\begin{array}{l}\text { 1.Note from the } \\
\text { Presidency on nutrition } \\
\text { labelling, } 16 \text { December } \\
2005 \text { (Doc ref: } 15897 / 05 \text { ) }\end{array}$ \\
\hline
\end{tabular}




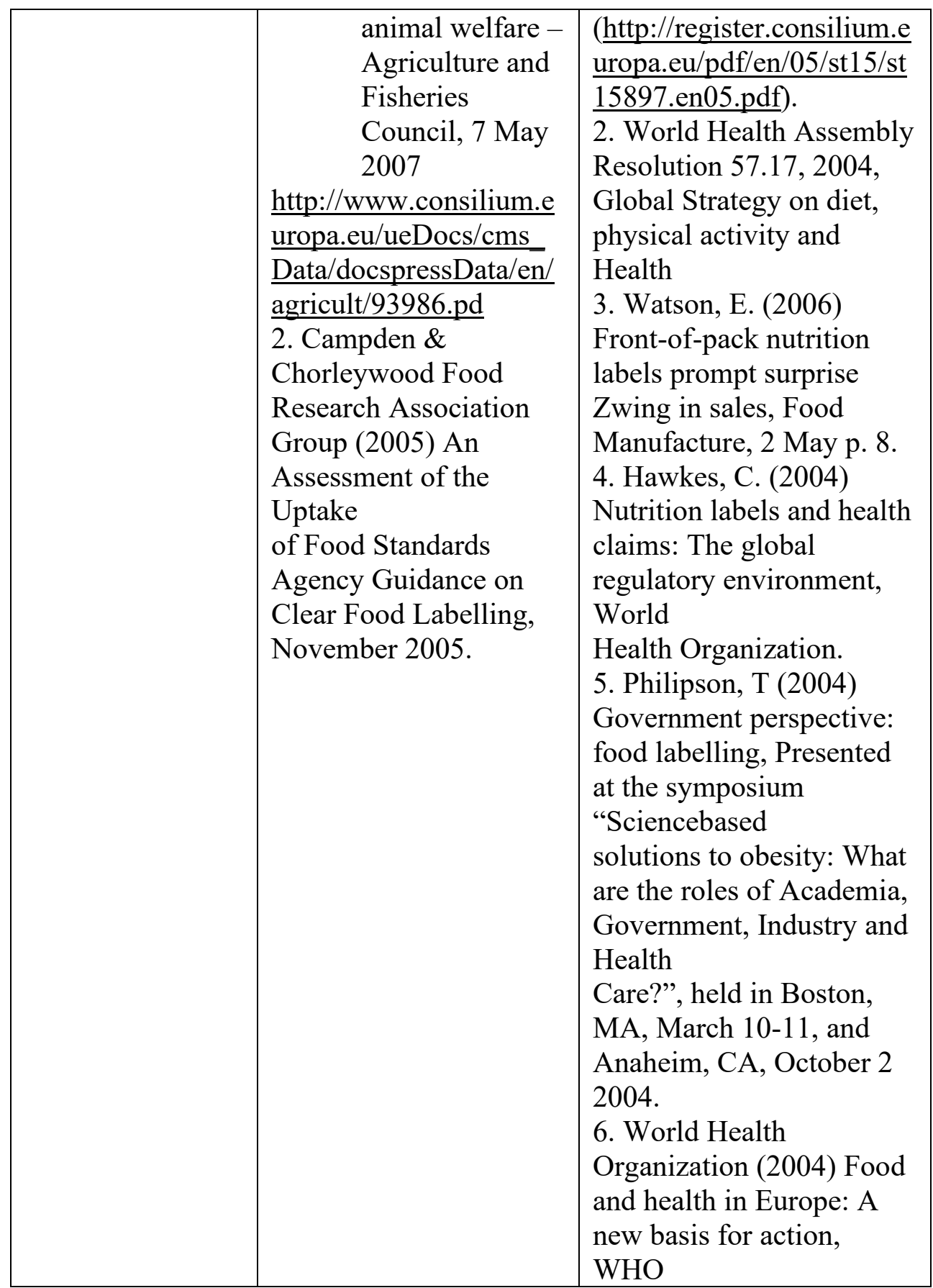




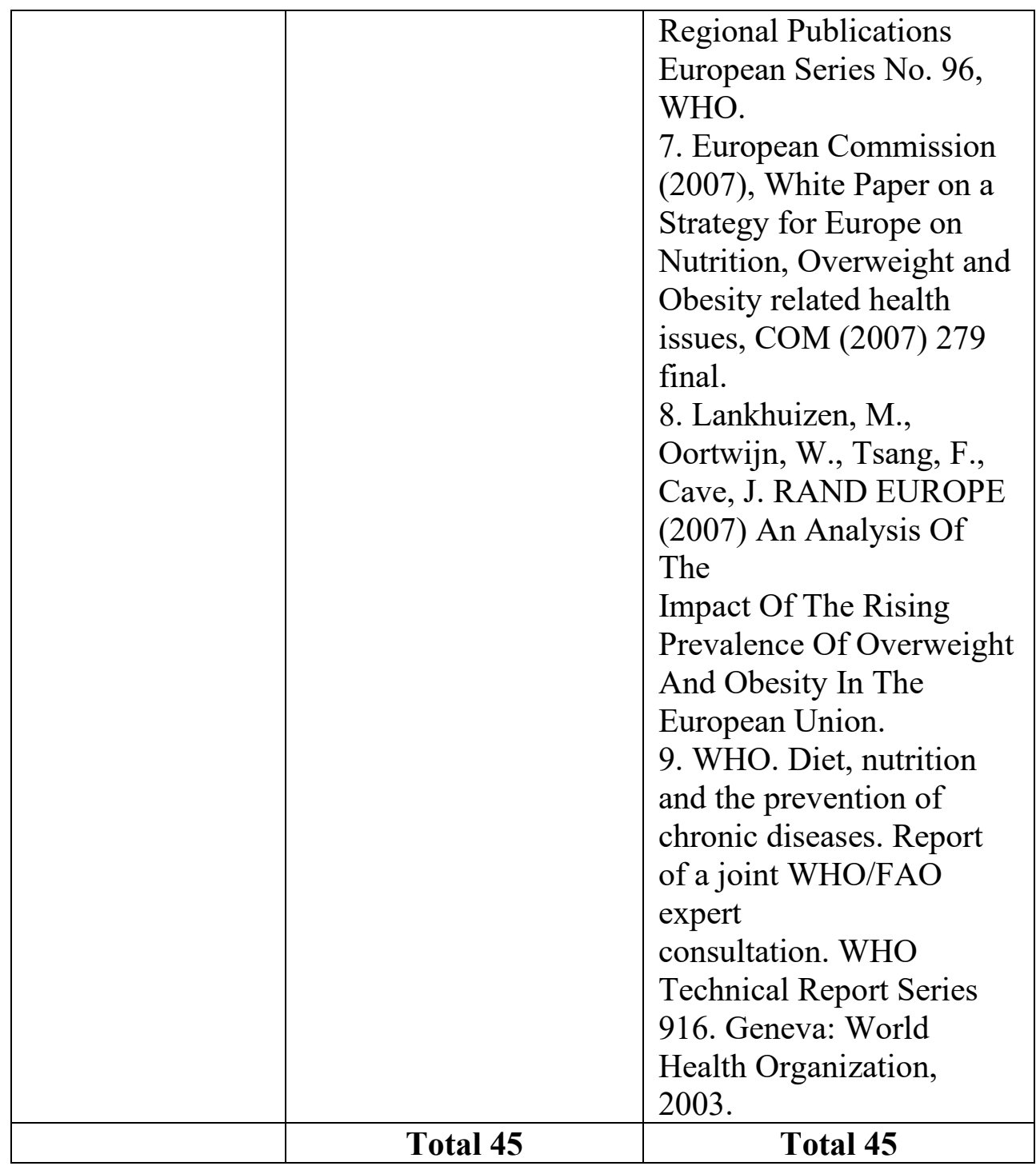

Information sources used for the impact assessment reports. Many sources are used in both reports and counted only once. 



\section{Summary}

This research aims to investigate the role of evidence in the formulation of European public health policies. Three case studies and a comparative analysis are undertaken to investigate (a) the kind of evidence sourced and used in the European Union's (EU) public health policymaking, (b) the perceptions of the use of evidence of key participants in the process and (c) the uptake of a specific type of evidence, namely research evidence. The aims of the research are further explained in Chapter 1. In particular, the study explores the similarities and differences in how the European Commission sourced and used the evidence in the formulation of legislation in the following areas: cross-border health care, information to patients on prescription medicines and food information to consumers.

The key concepts underpinning this research are presented in Chapter 2. They are mostly borrowed from knowledge-utilisation theories (Caplan1979; Weiss 1979; Lindblom 1990; Radaelli 1995; Boswell 2009). The complex dynamics of the evidence used in the EU policymaking are addressed looking at the demand-supply relationship between the policymakers seeking the evidence to inform their decision and gain legitimacy and consensus and policy networks of the affected stakeholders trying to shape the policy according to their beliefs. To better navigate the use of evidence in the formulation of policy, the Bowen and Zwi (2005) evidenceinformed pathways model is used as the main framework for the analysis.

Chapter 3 describes the research methodology. This study is a descriptive and exploratory qualitative research that applies a multiple comparative case-study design. The main sources of information and data have been a study of the literature on evidence-based policies, EU health policies, impact assessment, EU policy-making process and knowledge utilisation, official and unofficial written documents from the European institutions, media, stakeholders, interviews with key informants and direct observations, courtesy of the researcher's privileged position as insider in the Brussels lobbying scene.

Chapter 4 analyses the case study on cross-border health care. The Commission funded various ad-hoc research projects on cross-border health care under the Public Health Programme and the 6th Framework Research Programme according to its specific policy needs. In addition, the Commission funded an independent expert analysis from the European Observatory on Health Systems and policies to support the impact assessment 
accompanying the proposal. The Observatory acted as evidence broker. The views of the stakeholders and European citizens on the issue of cross-border health care were sought through a public consultation and a Eurobarometer survey respectively. There were no major opposing fronts among the stakeholders. Those who lobbied the European Commission the most were the Member States. Health care professionals, patients and the health care industry played a marginal role and focused their lobbying especially on the European Parliament. Some interviewees challenged the impact assessment because of the biased selection of the information gathered from the project results, the public consultation, and the questionability of the reliability of the figures on patient flows. Researchers, stakeholders and policymakers revealed that the evidence gathered only had a legitimizing role and was just a tool to justify a decision already taken at the political level. The impact assessment was considered a communication exercise, a lobbying tool with limited or no added value in providing a solid evidence base to the Commission's Proposal. According to the interviews and on the basis of participant observations, the research evidence sourced was not useful because it didn't produce reliable data on the main issue, namely patient flows, and didn't have the EU-wide coverage needed by the European Commission. This was also one of the main hindering factors for the uptake of evidence. While the main factors facilitating the use of evidence were policymakers' information needs, the available research provided in a policymakers' friendly format and the direct relationship between the European Observatory and the officials in charge of the dossier in the European Commission.

Chapter 5 investigates the case study on information to patients. As for the sourcing of evidence, the analysis shows a common pattern in the way the European Commission approached the evidence generation in the adoption of the pharmaceutical review in 2001 and 2008, namely with the creation of parallel stakeholder fora used to generate consensus and ideas about the issue but formally detached from the legislative policymaking process. The types of evidence used by the European Commission to formulate the Proposal also included a limited literature review conducted by a consultancy that prepared an independent study report to support the impact assessment. They also included ad-hoc working groups with the Member States and stakeholders, in addition to horizontal EU fora such as the EU Health Policy Forum, public consultations and the economic and political arguments gathered from the stakeholders and Member States. Over the years, the Commission demonstrated at least a commitment to improve the use of 
scientific evidence and involvement of the stakeholders in the formulation of policy, but the actual impact on the legislation proposed remains unclear. The selective choice of research evidence and the way the stakeholders were consulted (the number of public consultations, wording of the questions, presentation of the consultation results, imbalance in the composition of working groups such as the High-Level Pharmaceutical Forum) - as they emerged from the analysis of documents, from the interviews and from participant observation -, confirm that the use of evidence by the European Commission was a sort of cosmetic exercise to increase legitimacy and consensus around a Proposal already decided upon at the political level.

The lack of clear-cut research evidence on the possibility to make a clear distinction between information and advertising, the selective use of the available literature on Direct To Consumer Advertising used as upper-bound evidence and the lack of interest, training and skills to assess the research evidence on the public health of the policymakers who drafted the Proposal, emerged as the key hindering factors for the uptake of evidence. The decisive factor that influenced both the use of evidence and the overall Proposal was the personal will of Commissioner Verheugen. Overall, the perception of the interviewees is that in the EU policymaking process, evidence doesn't play a strong role. Despite several attempts to build consensus, the Commission Proposal was not accepted and never became an EU law.

Chapter 6 presents the case study on food information to consumers. Food labelling is a key public health policy tool in the fight against obesity and overweight, as it allows consumers to better understand the nutritional value of their food and make healthy choices. In preparation of the draft legislation, the European Commission actively sought different sources of evidence on the costs and benefits of bringing a change in the legislation. The two impact assessment reports that accompanied the Proposal were the results of the three studies commissioned to external consultancies and various forms of consultations with the stakeholders. While measuring the administrative costs of the industry was relatively easy - even if the Commission admitted that the industry figures were overestimated - deciding on what kind of information consumers were entitled to and in which format the information should be provided were considered to be the more "societal issues" that had to be discussed with the stakeholders. The research findings of studies by academics and reports from national authorities were among the main sources of information referred to in the impact assessment. However, from the analysis, it emerged that the Commission largely relied on the inputs from the 
stakeholders. The key stakeholders in relation to the draft legislation were, on the one side, the food and drinks industry and, on the other side, health NGOs and consumer associations. The stakeholders were consulted in different ways, including closed consultations addressed to some constituencies only, public consultations, surveys and interviews conducted as part of the external studies commissioned to consultancies, via consultation made by the Member States at the national level as well as via the various European Commission stakeholder fora (e.g., Diet platform on nutrition and health). "Good enough evidence" on food labelling was not fully available when the Commission was preparing the draft legislation, and information gaps existed that the Commission and the consultancies that worked on the topic tried to fill in consulting the stakeholders. The main facilitating factor for the uptake of evidence were policymakers' information need to make the impact assessment while the main hindering factors were the lack of relevant and timely research, the lack of policymakers' skills to assess the available evidence and policymakers' personal beliefs.

Chapter 7 made a comparative analysis of the three case studies. The legislative proposals are similar with regard to the policy instruments used and the policy goals that the European Commission wanted to achieve, and they followed very similar legislative pathways within the well-defined procedures set out in the Treaty. The European Commission's internal procedures influenced the way decision makers seek, analyse and uptake both the research evidence and the evidence provided by stakeholders via the European Commission expert groups and public consultations. More specifically, it is possible to conclude that the European Commission placed equal efforts in gathering research evidence for the three proposals. Interviewees perceived that often the available research evidence is inconclusive or biased or not relevant and that several factors (e.g. lack of time, lack of training and so on) hinder its proper uptake in the formulation of EU policies. For the three proposals, the European Commission gathered knowledge and information via polls but conducted further surveys for the proposal on food information. The stakeholders' views had more weight for the proposal on information to patients and food information as they were organised around two opposing advocacy coalitions while they were more dispersed and voiced less strongly for the proposal on cross-border health care. Evidence about costs played a more important role in the proposal on information to patients and food information than for the proposal on crossborder health care while politics was more relevant for the proposal on crossborder health care due to disputes over the limited EU competence on health 
care. Overall politics, including the political saleability of a legislative proposal as well as the need to adopt a balanced legislation with the consensus of all interested parties, is the element that seems to have influenced most the formulation of the three legislative proposals.

Chapter 8 provides the main conclusion of the research, its strengths and limitations and some recommendations for policy makers and researchers. From the three case studies and comparative analysis, it emerged that for the European Commission, evidence goes beyond what is commonly understood as evidence in relation to evidence-based policies and it includes research evidence usually gathered indirectly through the filter of stakeholders or consultancies conducting external studies to support the European Commission impact assessments. Policymakers consider research evidence not only the research produced by academic institutions and published in peer-reviewed journals but also the research by think tanks and governmental bodies. Other types of evidence used include Eurobarometer surveys, statistics stakeholders' views economic and political interests of the Member States. The way evidence is sourced largely depends on the organisational procedures put in place by the European Commission itself and that EU officials have a limited margin of manoeuvre.

The participants in the process believe that the European Commission selects evidence by choosing data and information in line with its political agenda and decisions already taken. They consider that the collection of evidence is just a cosmetic exercise to gain legitimacy and consensus.

Overall it is possible to conclude that the formulation of EU public health policies can be defined as evidence-based only if evidence is considered in a very broad sense as to include not only research evidence but also other types of evidence such as information, interests and ideas of stakeholders, politics and economics.

The most important methodological strength of the research regarding both data collection and analysis also represents the main limitation: the direct involvement of the researcher in the EU debates on public health policies offered a privileged observational perspective, valuable insider knowledge as well as easy access to official and confidential documents. It also allowed the researcher to undertake in-depth and open conversations with the interviewees. At the same time, this position increased the risk of bias. Such risk has been mitigated mostly by triangulating results with other information sources and with the existing literature. 
The most important recommendations for EU policy makers is to be clearer with themselves, with citizens and stakeholders about what they consider as evidence and to update the European Commission guidelines for the commissioning of external studies and for the drafting of the impact assessments. It is also important to ensure that EU officials have the necessary training, time and resources not only to collect the evidence but also to assess it critically and to use it appropriately. The most important recommendation for future researchers willing to investigate the role of evidence in policymaking is to clearly identify what they mean by the term "evidence" and use a consistent definition throughout their study. This research study also shows that it would be useful for researchers who wish their work to be used in the EU policymaking process to know more about how the process works and to tailor their research to policymakers needs, however without compromising their scientific integrity. 


\section{Valorisation}

This chapter presents the valorisation of this dissertation, which is "...the process of creating value from knowledge, by making knowledge suitable and available for societal and/or economic application and by transforming it into products, services, processes and new business".

The use of evidence in policymaking is the subject itself of this dissertation. Research should not remain within the circles of the scientific community. It can be used to improve policymaking and elaborate sound, effective and balanced policies. This is particularly important for the formulation of public health policies as the use of research findings can contribute to create a healthier society. In this spirit, this chapter explains how the main results of this research study can be applied in practice, what added value they bring to researchers, policy makers and society. It concludes with a description of the actions that will be undertaken to disseminate the knowledge acquired during the research study.

\section{Relevance for researchers}

The finding of this thesis can be useful for the scientific community, namely for researchers in the field of EU and public health studies and those investigating the concept of evidence-based policy. These findings are also relevant for researchers of all disciplines who want their work to be used for policymaking and for those who want to use participant observation as a source for data collection.

Researchers in the field of EU studies can adapt the theoretical framework developed in this thesis for analyzing policymaking in other areas. This research also adds new insights on how the European Commission deals with evidence and offers an empirical description of the policy process useful for future research on lobbying theories, network analysis, advocacy coalitions and EU governance.

This dissertation advances the study and understanding of public health policies by shedding lights on how they are formulated at European level, who are the main actors involved and which are the main drivers.

This research also contributes to the rich field of science concerned with studying the concept of evidence-based policy. More specifically, this research endorses a wider definition of evidence which includes not only research but also other types of evidence. In addition, this research takes into account a wider perspective, investigating the views of policymakers, 
stakeholders and researchers on the use of research evidence. It also offers a more nuanced approach than that of surveys using a comparative case studies analysis and provides experiences from the EU dimension.

This research study also offers a learning tool for all those researchers who wish their work to be used in the EU policymaking process. It does this by explaining the importance of learning the "rules of the game" to know more about how the process works and to tailor research to policymakers needs, both in terms of content and in terms of how their findings are presented (lengths, technical language). It also explains that policy makers' need for information might be unpredictable and within a very short time frame that doesn't allow proper scientific research rigor. This may help preventing researchers from feeling frustrated if their research is not used by policy makers. Moreover, it raises researcher's awareness on the fact that their research can be used selectively and used as ammunition by policy makers or stakeholders to serve their needs. Lastly, it offers them a basis for reflection to decide whether they want to play an active role and make sure, their work is used for policy purposes at the risk of being biased or if they prefer to maintain full academic independence, decide on the research agenda, find alternative funding and just publish their studies.

Finally, the research study adds new insights also about the strengths and the weaknesses of participant observation as a data collection tool and thus can be useful for all those researchers who intend to use this as a method for data collection.

\section{Relevance for policy makers and society}

This thesis brings an added value to policy makers by offering them a comprehensive external analysis on what constitutes evidence in the formulation of European public health policy, on how it is sourced and used and on how the most affected stakeholders perceive the policy process. Policy makers can use it as checklist to verify whether they have applied (or not) the principles of the EU Better Regulation Agenda. It can be used to identify what can and should be improved and can help preventing policy mistakes and improving policy outcomes. From the results of the research, policy makers can also draw suggestions to make the process more efficient and transparent.

The dissertation adds value also to European citizens by providing them a learning tool on how the European public health policies are developed, on the information policy makers use to define them and on who 
influences the policy process and how. It also shows how and to what extent citizens views expressed in Eurobarometer surveys are taken into account. EU legislative and non-legislative initiatives in the field of public health have a direct impact on the health of all 500 million European citizens and it is in the interest of citizens to know how these initiatives are developed and on which basis policy makers choose one provision over another.

The principle of evidence-based policy is a cornerstone of democracy and it is now being challenged by the proliferation of disinformation and fake news. This thesis offers policy makers and society a basis of information and reflection to defend this principle and implement it more effectively for better policies. The publication of an in-depth analysis on how European policies are formulated also contributes to making EU policy makers accountable towards European citizens.

\section{Dissemination of knowledge}

To inform the scientific community, copies of the dissertations will be sent to researchers working in the field of evidence-based policy whose findings have been referred to also in this dissertation.

To inform policy makers, copies of this dissertation will be sent to senior policy makers in the European Commission including the DG Secretariat General, DG SANTE, DG GROWTH, DG RESEARCH and to the members of the Impact Assessment Board. Copies will also be sent to the Joint Research Center, which is the European Commission's science and knowledge service.

Furthermore, copies of the dissertations will be sent to the European Parliament (ENVI committee members and secretariat), the Science and Technology Options Assessment (STOA) Panel, the health attaches of the Member States Permanent Representations to the EU as well as to the main stakeholders in the EU public health community (NGOs, patients and consumers organizations, health care professionals' organizations, food and health care industry associations).

Links to the dissertation and to the summary will also be shared on the researcher's Linkedin and Twitter account (total outreach 2.263 people) which include mostly EU and national policy makers and stakeholders working in the field of EU health policy. 
Furthermore, to inform policy makers and stakeholders outside the EU bubble, the dissertation, the abstract and the summary will be sent to the Alliance for Useful Evidence. This is a network, hosted by the UK's innovation charity Nesta. The Alliance champions the smarter use of evidence in social policy and practice and provides an open access network of more than 4,300 individuals from across government, universities, charities, businesses, and local authorities in the UK and internationally. They will also be shared with the campaigning charity Sense about Science, which works on the misrepresentation of science and evidence in public life.

Finally, to reach citizens and the wider public interested in EU politics, the dissertation will be shared with some selected journalists interested in EU politics (e.g. Politico) and health issues. 


\section{Acknowledgments}

My deepest gratitude goes to my supervisors, Professor Hans Maarse and Dr. Aggie Paulus, for their endless patience, for being always available, for their understanding in some difficult moments of this journey, for their encouragement, for their prompt and valuable feedback and for the time they invested in commenting my papers. Thanks also to the members of the assessment committee and to the Department of Health Services Research and the Care and Public Health Research Institute (CAPHRI) of the Maastricht University for having given me the opportunity to do this $\mathrm{PhD}$ as an external student.

I would like to give a heartfelt thanks to Monique Goyens, Director General of the European Consumer Organization (BEUC), to whom this thesis is dedicated. Monique has always been my source of inspiration. I genuinely admire her ability to motivate people, her visionary leadership, her strong passion and commitment to defend the rights of all of us. Thanks also to all my former colleagues at BEUC for their interest in my research project, for caring about the progress and for no longer asking at a certain point.

I'm also very grateful to all the interviewees for taking time from their busy schedule to provide me with their experience and insights on the EU policy making process.

Thanks to my friends Taryn Bern, Irene Glinos Landolina, Ylenia Maitino, Ewa Matys, Helena Legido-Quigley, Teresa Leonardo Alves, Francesco Ronfini and Laura Surano for their help and friendship.

Thanks to my grandfather, for teaching me the value of learning and reminding me that not everybody has the chance to study.

Thanks to my parents, my greatest strength, for always being there and for taking care of me. Thanks to my husband and to my daughter for their unconditioned love and for the many evenings, weekends and holidays we couldn't spend together. 



\begin{abstract}
About the author
Curriculum Vitae

Born in Rieti (Italy) in 1981, Ilaria graduated magna cum laude and Dean's honor in Economics and Management from Bocconi University in Milan (Italy) in 2004. After graduation she moved to Brussels for an Internship in the health department of the Italian Permanent Representation to the EU. She then worked 2 years as health policy adviser for the international health and social affairs department of the Veneto Regional Government.
\end{abstract}

In 2006 she started working as health policy officer at BEUC, the European Consumer Organization and in 2014 she became Head of the Food and Health Department. In this role she was member of the European Medicines Agency (EMA) patients and consumers working party (PCWP), of the EMA Scientific Advisory Group on vaccines, of e-Health stakeholder group, of the EU health policy forum, of the stakeholder group of the EU network on Health technology Assessment, of the EU Platform on Diet, Nutrition and health, of the European Food Safety Authority Stakeholder Bureau. Between 2016 and 2018 she also served as member of the European Medicines Agency Management Board.

Since March 2018 Ilaria Passarani, is Secretary General of PGEU, the organization representing European Community Pharmacists. She provides strategic direction and leadership to the organization while managing the day to day operations and the relationships with the member associations and other stakeholders. She is also member of the Board of Directors of the European Medicines Verification Organization (EMVO), member of the Board of Trustees of the European Pharmacy Students Association (EPSA) and she represents the pharmacy sector in various European, national and international fora.

Since 2010 she has been a part-time PhD student at the Care and Public Health Research Institute (CAPHRI) of the Faculty of Health, Medicine and Life Sciences at the Maastricht University, The Netherlands. She speaks fluently English and French in addition to Italian, her mother tongue. 



\section{Publications}

- Passarani I. (2017), Engaging with civil society: the successful example of the European Medicines Agency. In: Greer SL, Wismar M, Pastorino G, et al., editors. Civil society and health: Contributions and potential. Copenhagen (Denmark): European Observatory on Health Systems and Policies. https://www.ncbi.nlm.nih.gov/books/NBK459045/

- Legido-Quigley, H., Passarani, I., Knai, C., Busse, R., Palm, W., Wismar, M., \& McKee, M. (2011). Cross-border healthcare in the European Union: Clarifying patients' rights. British Medical Journal, 342:d296. https://doi.org/ 10.1136/bmj.d296.

- Passarani I. (2010) What do patients want of performance information. British Medical Jorunal 2010;341:c6955W https://doi.org/ https://doi.org/10.1136/bmj.c6955

- Passarani I. (2009), Patents and competition: an inquiry in the pharmaceutical sector, Consumatori, Diritti e mercato. Milan: Altroconsumo.

- Passarani I. (2008), Pharmaceuticals: challenges and opportunities, Consumatori, Diritti e mercato. Milan:Altroconsumo.

- Bertinato, L., Busse, R., Fahy, N. Legido-Quigley, H., Mckee, M., Passarani, I.,(...), Ronfini, F. (2005). Policy brief: Cross-border health care in Europe. World Health Organization on behalf of the European Observatory on Health Systems and Policies, 28. 


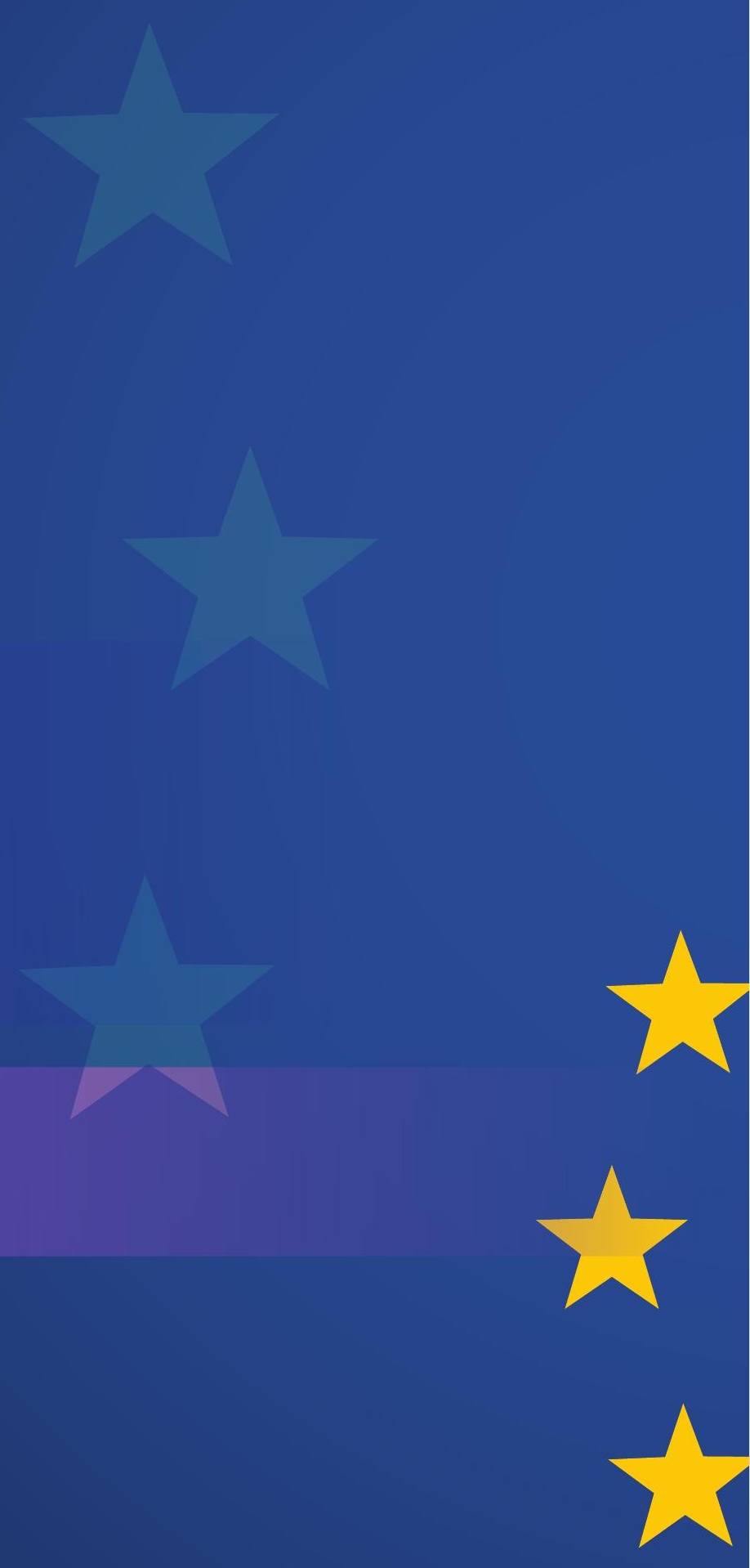